\title{
Ovids Verwandlungen verteutscht. Übersetzungen der Metamorphosen seit dem Mittelalter und der Frühen Neuzeit bis zum Ende des 20. Jahrhunderts ${ }^{1}$
}

\section{ULRICH SCHMITZER}

\section{Grundlagen}

Die Geschichte der deutschen Übersetzungen von Ovids Metamorphosen ist bisher noch nicht einmal ansatzweise geschrieben. Dieses Forschungsdefizit ist umso schmerzlicher, als die Metamorphosen nicht nur ein seit der Antike immer wieder bewundertes Werk der Dichtung sind, sondern auch zu den Grundlagentexten der europäischen Wissenskultur bis in die Moderne hinein gehören. Die Metamorphosen sind schon durch ihren von Ovid selbst gegebenen Titel die schlechthinnige Verkörperung von Transformation, sie stellen darüber hinaus ihrerseits die definitive Transformation des antiken Mythos in die Form dar, in der er die Antike überdauerte. Sie schufen also eine neue Realität des Mythos in der Synthese aus vielen unterschiedlichen Strömungen.

P. Ovidius Naso wurde 43 v. Chr. im mittelitalischen Sulmo geboren, 8 n. Chr. aus bis heute nicht geklärten Gründen von Augustus nach Tomi am Schwarzen Meer (im heutigen Rumänien) verbannt und starb dort ca. 17/18 n. Chr. Er verfasste Liebeselegien (Amores), liebesdidaktische Werke (Ars amatoria, Remedia amoris), die Tragödie Medea, die (Doppel-)Briefe von Frauen aus dem Mythos (Heroides), ein elegisches Lehrgedicht über den römischen Festkalender (Fasti) sowie die Metamorphosen. Aus der Exilzeit stammen Elegien (Tristia, Expistulae ex Ponto) und das Schmähgedicht Ibis. Die Metamorphosen umfassen ca. 12000 Verse, aufgeteilt auf 15 Bücher, und behandeln die Zeit von der Entstehung des Kosmos (prima ab origine mundi) bis in die eigene Zeit Ovids (ad mea tempora). Ihre zahllosen Sagen, denen das Verwandlungsmotiv zugrunde liegt, ohne stets dominant im Vordergrund zu stehen, sind auf bis zu fünf Erzählebenen aufgeteilt, so dass der chronologische Faden vor allem in den zentralen Teilen kaum mehr spürbar ist. Rezipiert sind sie meist nach isoliert betrachteten

1 Alle bibliographischen Hinweise auf online-Dokumente sind 2013/2014 geprüft worden und waren zu diesem Zeitpunkt verfügbar. Aus Gründen der leichteren Lesbarkeit ist auf eine detaillierte Datumsangabe verzichtet. Digitalisierte Quellen, insbesondere historische Übersetzungen, sind im Literaturverzeichnis um die URL bzw. URN ergänzt; wo immer möglich, wurde aus Gründen der bibliographischen Stabilität auf das Zentrale Verzeichnis Digitalisierter Drucke (www.zvdd.de) und die angeschlossenen Bibliotheken zurückgegriffen. 
Einzelsagen (z. B. Apollo und Daphne, Philemon und Baucis, Arachne, Niobe) - was etwa bis heute auch die schulische Beschäftigung prägt. Seit dem Mittealter ist Ovid selbstverständlich Schulautor, wobei die Metamorphosen fast immer im Zentrum stehen.

Dass Übersetzung eine Repräsentationsform der Transformation $\kappa \alpha \tau^{\prime} \dot{\xi} \xi \xi \chi \eta^{\prime} \nu$ ist, ist eine mittlerweile beinahe triviale Feststellung. ${ }^{2}$ Nicht trivial ist aber, wie Ovids Metamorphosen je nach angestrebtem Zielpublikum unterschiedliche übersetzerische Formen annehmen und damit allelopoietisch eine neue Realität des antiken Mythos entstehen lassen. ${ }^{3}$ Das macht die Untersuchung der deutschen Metamorphosen-Übersetzungen über die Aufarbeitung des Materials ${ }^{4}$ hinaus zu einem Testfall für die Tragfähigkeit des Transformationskonzepts. ${ }^{5}$ Denn die Metamorphosen sind ihrerseits eine transformierte Transformation, nämlich die Übertragung griechischer Mythologeme ins Lateinische und deren Einpassung in das Konzept des carmen perpetuum. ${ }^{6}$ Die so entstandene lateinische Metamorphosen-Dichtung wiederum ist in nachantiker Zeit in so gut wie alle europäischen Sprachen übersetzt worden. ${ }^{7}$ Und mehr noch: Das allelopoietische Potential der Metamorphosen bereits in der Antike zeigt sich paradigmatisch daran, dass sie zu den wenigen lateinischen Texten gehören, die ins Griechische (rück-)übersetzt wurden, als sich in byzantinischer Zeit Maximos Planudes ihrer annahm. ${ }^{8}$ So wird also die Übernahme aus dem Griechischen umgekehrt.

Es gilt also eine Forschungslücke ${ }^{9}$ zu schließen, die die Rezeption und Transformation Ovids auf allen Ebenen der kulturellen Milieus, nicht nur bei den lateinkundigen Eliten umfasst. Während für den Bereich der italienischen Renaissance die fundamentalen Studien von Bodo Guthmüller zu verzeichnen sind, ${ }^{10}$ während für die englischsprachige Renaissance und Frühe Neuzeit und neuerdings auch für den französischen und niederländischen Sprachraum ${ }^{11}$ eine Reihe von wichtigen Einzelarbeiten vorliegen, ${ }^{12}$ hat für den deutschsprachigen Raum eigentlich nur die mittelhochdeutsche Umsetzung des Albrecht von Halberstadt und deren Bearbeitung durch Jörg Wickram im 16. Jahrhundert größere Aufmerksamkeit auf sich gezogen. ${ }^{13}$

2 Vgl. Böhme/Rapp/Rösler (2007); Böhme et al. (2011), 53.

3 Dazu die Beiträge in Böhme et al. (2011).

4 Vgl. Landfester (2007).

5 Böhme et al. (2011).

6 Vgl. Schmitzer (2008).

7 Vgl. etwa die Zusammenstellung bei Hofmann (1981), 2171-2177.

8 Siehe Fisher (1990), außerdem Fodor (2004) (nicht zu den Metamorphosen [Bibl. 317], aber u. a. zu den Heroides).

9 Eine weitere, in näherer Zukunft aufzuarbeitende Forschungslücke betrifft die Übersetzungen der Werke Vergils, dazu aber immerhin Kleßmann (2009) und (speziell zu Schillers Vergilübersetzungen) und Jarislowski (1928).

10 Z. B. Guthmüller (1975) und (1997), siehe jetzt auch Bucchi (2011).

11 Faems/Minet-Mahy/Van Coolput-Storms (2011).

12 Fielitz (2000); Lyne (2002), 249-263; Oakley-Brown (2006).

13 Z. B. Rücker (1997), Klein (2008), außerdem Hexter (2007). 
Die Suche nach der Geschichte der Metamorphosen-Übersetzungen bedeutet nicht zuletzt den Schritt in eine terra incognita. Die Übersetzungen, die bis zum Ende des 18. Jahrhunderts entstanden sind, sind weitestgehend aus dem Gedächtnis selbst der Fachwelt verschwunden, sie sind am ehesten noch über die großen bibliographischen Zusammenstellungen des 19. Jahrhunderts zu eruieren. ${ }^{14}$ Damit sind auch die Instanzen der Wissensvermittlung - der Vermittlung vor allem über sprachliche Barrieren hinweg - vergessen, die für die bildende Kunst, die Musik und besonders die Oper oder die nationalsprachlichen Literaturen immense rezeptionsvermittelnde Bedeutung besaßen, wie die bisweilen in den Titeln explizit genannten Zweckbestimmungen ausweisen.

Vieles, was solcherart weitgehend in der Vergessenheit versunken war, kann durch die in den letzten Jahrzehnten entwickelten Hilfsmittel nun leichter gehoben werden: zuerst durch die OPACs und digitalisierten Zettelkataloge der einschlägigen Bibliotheken, die auch historische Bestände bequem und ortsunabhängig erschließen, und danach durch die großen Digitalisierungsprojekte, durch die bislang in abgelegenen Magazinen verborgene, gemeinfreie Bücher $\left(\right.$ beinahe $^{15}$ ) weltweit verfügbar wurden. Das stellt ein handhabbares, allerdings nur schwer systematisch nutzbares Gegenmittel gegen solche Amnesie dar, wenn man denn die Instrumente sachgerecht und gezielt einsetzt.

Ovids Metamorphosen sind mit ihrer langen Übersetzungsgeschichte besonders dafür prädestiniert, den üblicherweise (auch in diesem Band) gewählten, mit der Wende zum 19. Jahrhundert einsetzenden Untersuchungszeitraum erheblich auszuweiten. Mit dem erarbeiteten theoretischen und methodischen Rüstzeug kann man nämlich im Mittelalter auf die Urgeschichte der literarischen Übersetzung ${ }^{16}$ aus dem Lateinischen ins Deutsche stoßen. Aus diesem zeitlichen Ansatz der Analyse ergibt sich auch die inhaltliche Gliederung (nach 1. Einleitung):

(2.) Die Übersetzungen vom Mittelalter bis zum Beginn der Goethezeit, bis zu Rode und Voß, die in weiten Teilen (nach heutigen Kategorien) von disziplinären Außenseitern stammen und sich auch bisweilen explizit an ein nichtphilologisches Publikum wenden.

(3.) Die Übersetzungen der Goethezeit: Rode und Voß, die - anders als ihre Vorgänger - bis heute immer wieder (z. T. bearbeitet) nachgedruckt werden und damit den Beginn der modernen Übersetzungsgeschichte Ovids markieren.

14 Z. B. Schweiger (1834), Bd. 2,2, 667-670; Engelmann, Enslin (1847), 384-392. Eine Ausnahme stellt nur Elit (2002) (eventuell wegen des Titels bisher von der Forschung zur Ovid-Rezeption nicht berücksichtigt), bes. 142-150, dar, der auch kursorisch auf die Ovid-Übersetzungen des 18. Jahrhunderts eingeht.

15 Google Books etwa unterscheidet nach (über IP-Adresse abgefragter) Provenienz des jeweiligen Nutzers und sperrt manche digitalisierten Bücher außerhalb der USA, um wegen der unterschiedlichen Schutzfristen nicht in juristische Schwierigkeiten zu kommen.

16 Selbstverständlich gibt es frühere Übersetzung aus dem Lateinischen ins (Althoch-)Deutsche, etwa der Evangelienharmonie des Tatian (Katschorke, LexMA 8 [1997], 489-490), aber eben nicht paganer fiktionaler Texte. 
(4.) Die Übersetzungen des 19. und der ersten Jahrzehnte des 20. Jahrhunderts, die z. T. im Rahmen der großen Übersetzungsbibliotheken entstanden sind oder aus der Feder von Schulmännern stammen (und auch für den Schulgebrauch gedacht sind).

(5.) Die Wiederentdeckung der Metamorphosen durch eine breitere Öffentlichkeit am Ende des 20. Jahrhunderts, wofür als Epochenjahr das Erscheinen von Christoph Ransmayrs Die letzte Welt (1988) benennbar ist.

Selbstverständlich ist es unmöglich, alle diese Übersetzungen vollständig zu analysieren. Stattdessen soll anhand von besonders signifikanten Passagen (s.u.) beleuchtet werden, welche Schwerpunkte und Vorlieben die jeweiligen Übersetzungen in Prosa bzw. in metrische Formen (ab dem Ende des 18. Jahrhunderts meist im dem lateinischen Original entsprechenden Hexameter) aufzuweisen haben.

Das Konzept der Transformation warnt von vornherein generell davor, die Auseinandersetzung mit der Antike als Fortschrittsgeschichte zu lesen. Die Geschichte der Ovid-Übersetzungen unterstreicht das nachdrücklich: Wir haben es vielmehr mit rekurrenten Phänomenen zu tun, die oft von geringer Reflexion der Übersetzer über ihr eigenes Tun (von Ausnahmen wird noch die Rede sein) und von noch geringerer Kenntnis der jeweiligen Vorläufer zeugen. Das hängt ursächlich mit der tendenziellen Dekanonisierung Ovids seit dem späten 18. Jahrhundert zusammen, ${ }^{17}$ die verhinderte, dass es in der ganzen kulturellen Elite verbreitete Übersetzungen gab wie Voß' Homer im 19. und Schadewaldts Homer im 20. Jahrhundert oder Schleiermachers Platon seit gut zweihundert Jahren. Durch diese Entwicklungen kam es (wie überhaupt für die lateinische Literatur) auch nicht zu kanonischen, die außerphilologische Rezeption durch ihre spezifische Sprachform wesentlich bestimmenden Übersetzungen. Sogar die Übersetzer wissen wenig bis nichts von ihren Vorgängern: Im Jahr 1981 veröffentlichte Michael von Albrecht seine Prosaübersetzung der Metamorphosen in der festen Überzeugung, die erste deutsche Prosafassung überhaupt vorgelegt zu haben. ${ }^{18}$ Doch nur wenige Jahre später (1989) gab es von Gerhard Fink die Adaption der »ersten Prosaübersetzung durch August von Rode « $\left(1791,{ }^{2} 1817\right.$; Fink 1989). Aber auch dieser Anspruch ist falsch, wie der übersetzungshistorische Durchgang zeigen wird.

Übersetzungen stellen einen Spezialfall der Deutungsgeschichte dar. Sie sind deshalb mit anderen interpretatorischen Zugriffen zu kontextualisieren, den jeweils vorliegenden Editionen und Kommentierungen, ${ }^{19}$ aber auch mit dem wissenschaftlichen und außerwissenschaftlichen Ovid-Bild ihrer Zeit, um vor diesem Gesamthintergrund das in ihnen zu Tage tretende Ovid- und Mythenverständnis sichtbar werden zu lassen. Gerade bei den vormodernen Übersetzungen ist besonderes Augenmerk auf das Verhältnis von Übersetzer und (angestrebtem) Publikum zu legen. Denn es wird sich zei-

17 Einige (vornehmlich negative) Urteile aus der Frühen Neuzeit finden sich auch in der Vorrede zur anonymen Ausgabe Metamorphoseon libri XV Nürnberg 1759 (ohne Paginierung), siehe außerdem Stroh (1969).

18 von Albrecht (1981), 393: »Soweit mir bekannt, ist dies der erste Versuch einer vollständigen Wiedergabe der >Metamorphosen $<$ in deutscher Prosa. «

19 Die Basis bilden die Kommentare von Bömer (1969-2006) und Barchiesi/Rosati (2004-2007) 
gen, dass diese Übersetzungen oftmals in genau definierte regionale und soziale Kontexte eingebunden sind, etwa in das Meistersingermilieu der selbstbewussten süddeutschen Städte oder in das Selbstbild der Lehrer als Gelehrte im 19. Jahrhundert. Ferner ist nicht immer restlos klärbar, ob und in wieweit sie auf tatsächlicher Kenntnis der Originalsprache beruhen (s. u. bei Jörg Wickram und Hans Sachs) oder ob in ihnen lediglich vorhandene Versionen fortgeschrieben sind, ohne Abgleich mit dem lateinischen Text. Jedenfalls scheint dies bis ins 18. Jahrhundert hinein selbst bei Lateinkundigen ein keineswegs ehrenrühriger Usus gewesen zu sein. Auch hierin unterscheidet sich die vormoderne Übersetzungspraxis programmatisch und konzeptionell erheblich von späteren Ansprüchen.

Generell sind die hier behandelten Umsetzungen für an gegenwärtige Formen des Übersetzens gewöhnte Leser bisweilen gewiss befremdlich. In der Terminologie dieses Sammelbandes handelt es sich bis weit ins 18. Jahrhundert meist um » modernisierendassimilierende Übersetzungen $\ll,{ }^{20}$ natürlich ohne dass dieser Praxis ein explizites theoretisches Konzept zugrunde läge. Aber nicht nur die sprachliche Gestaltung unterscheidet die frühen Übersetzungen von den modernen, sondern auch der Umgang mit der äußeren Gestalt des zu übersetzenden Werks (dem nicht der neuzeitliche, von Quasi-Unantastbarkeit geprägte Werkbegriff zugrunde liegt), so dass Kürzungen, Umakzentuierungen und auch Zusätze gang und gäbe sind.

Die makrostrukturelle Frage nach Vollständigkeit, Kürzung oder Ergänzung des Gesamten hat ihr Gegenstück in der auf die Wortebene heruntergebrochenen, mikrostrukturellen Vollständigkeit. Die Einzelanalysen werden diesen Aspekt immer wieder zu berücksichtigen haben. ${ }^{21}$ Die Basis dafür bildet der Kriterienkatalog, wie er in Poiss et al. (in diesem Band), bes. $\$ 7$, expliziert ist und wo die Schadewaldt'schen Übersetzungsmaximen fortentwickelt werden (auch wenn die Benutzung dieses Katalogs nicht in jedem Einzelfall genannt ist). Die aus den Analysen abgeleiteten Folgerungen haben bisweilen wertenden Charakter, doch sind damit nicht absolute, gar objektive Urteile gemeint, sondern Aussagen über den Grad, in denen die Übersetzungen diesen Kriterien nahekommen oder eigene, etwa in Vorworten erhobene Ansprüche einlösen können.

Um die Verfahren der jeweiligen Übersetzungen zu konturieren, sind (sofern möglich: s. u.) drei Passagen der Metamorphosen als exemplarisch ausgewählt und werden mit den jeweiligen Umsetzungen verglichen:

a) Das Proömium (met. 1,1-4): Die Forschung der letzten Jahrzehnte hat übereinstimmend gezeigt, wie der Autor zu Beginn seines Werks durch die exakt kalkulierte Reihenfolge der Wörter über die prinzipielle Focus-Topik-Beziehung hinaus eine strategisch gezielte Gedankenführung herbeiführt: Durch die Sperrung von in nova und corpora wird der innovative Charakter von Ovids die ganze Weltgeschichte umfassenden Epos betont. Ins Spiel kommt weiter die Frage nach Inspiration für ein solches Universalepos, das Verhältnis von großem Zugriff und qualitätvoller Verarbeitung im Detail (carmen perpetuum vs. carmen deductum), die das zeitliche Konzept mit dessen

20 Poiss (in diesem Band), \$9; vgl. Böhme et al. (2011), 48, zum Transformationstyp der Assimilation.

21 Vgl. auch Mindt (2009), bes. 277-297. 
stilistischer Realisierung verknüpft. Zugleich zeigt sich hier ebenfalls exemplarisch, dass die Beurteilung der Übersetzungen nur unter Berücksichtigung des Forschungsstandes möglich ist - und zwar auf zwei Ebenen: auf der Ebene des zur jeweiligen Übersetzung zeitgenössischen Textverständnisses und als Kontrollinstanz auf der Ebene des aktuellen Wissens.

b) Die Episode von Pyramus und Thisbe (met. 4,51-166), die in betont schlichtem Ton beginnt und sich dann zu höchster Emotionalität steigert, also das stilistische Register des jeweiligen Übersetzers auf die Probe stellt.

c) Die Künstlergeschichte von Pygmalion (met. 10,243-297), die erzählerisch auf einen (gerade noch abgewendeten) Skandal hinsteuert und an der entscheidenden Stelle auch durch ein artistisches, für das Textverständnis punktuell signifikantes Wortspiel auffällt.

Noch nicht recht einzuschätzen ist beim aktuellen Stand der Übersetzungsforschung der Einfluss der Metamorphosen-Übersetzungen in moderne Fremdsprachen, v. a. ins Französische, die durch Lektüre oder gar als direkte Vorlagen auf die deutschen Übersetzungen eingewirkt haben. ${ }^{22}$

\subsection{Das Proömium}

Das Proömium ${ }^{23}$ ist von Ovid nicht als Teil des metamorphischen Prozesses gestaltet, sondern paratextuell abgesetzt. Das führt dazu, dass es in einer Reihe von Paraphrasen und Übersetzungen nicht als dem Werk zugehörig begriffen und folglich weggelassen wird, so bei Wickram 1545 und auch bei Voß $1798^{24}$ (met. 1,1-4): $:^{25}$

In nova fert animus mutatas dicere formas

corpora; di, coeptis (nam vos mutastis et illa) ${ }^{26}$

adspirate meis primaque ab origine mundi

ad mea perpetuum deducite tempora carmen.

Diese Passage hat in der jüngeren Metamorphosen-Forschung intensive Aufmerksamkeit gefunden. Die Trennung von in nova und corpora durch das über das Enjambement hinweg weitgestreckte Hyperbaton führt zu einer doppelten semantischen Akzentuie-

22 Safft (1766) etwa beruft sich auch auf seine Kenntnis der französischen Ovid-Forscher (vgl. generell Renger [2002]), auch die von ihm gewählte Lesart carebat in der Erzählung von vom Goldenen Zeitalter (met. 1,110; s. u.) könnte auf solchen französischen Einfluss hinweisen.

23 Siehe Barchiesi (2004), 133-145.

24 Die Übersetzungen sind im bibliographischen Anhang chronologisch zusammengestellt.

25 Textgrundlage ist, soweit nicht anders angegeben, Tarrant (2004), verglichen mit Anderson (1993) und Magnus (1914). Außerdem wird, wo es nötig erscheint, jeweils versucht, die in einer bestimmten Epoche gebräuchlichen Textfassungen und Editionen anzuführen. Das wird allerdings dadurch erschwert, dass die Übersetzer selbst ganz überwiegend keine einschlägigen Auskünfte geben.

26 Die heute am weitesten verbreitete Lesart illa (beziehbar auf corpora und coepta) ist eine Konjektur Lejays vom Ende des 19. Jahrhunderts (vgl. Magnus [1914] ad loc.); zuvor war illas die übliche Variante. 
rung, nämlich zum einen als initiale programmatische Ankündigung einer neuartigen Dichtung, zum anderen als Ankündigung einer Dichtung von körperlicher Verwandlung. Die Ambiguität wird von der artistischen Wortstellung getragen. ${ }^{27}$ Ein sprachlich so genau kalkulierter Anfang stellt damit auch eine besondere übersetzerische Herausforderung dar: Er kann nach der Sprachstruktur des Deutschen nicht unmittelbar nachgeahmt werden, sondern erfordert andere, kreative Lösungen, sofern man die spezifische Form nicht einfach ignorieren möchte. Am Ende, in den letzten eineinhalb Versen, betont Ovid nicht nur den chronologischen Rahmen der Metamorphosen, die die ganze Geschichte des Kosmos umfassen, sondern auch deren epischen Charakter (carmen perpetuum), der sich mit den kallimacheisch-hellenistischen Tugenden des feingesponnen Poems (carmen deductum) trifft und damit eine Synthese aus zwei eigentlich für unvereinbar gehaltenen poetischen Konzeptionen formt.

Dieses artistische Proömium hat schon früh die Leser aufmerksam werden lassen, etwa einen frühmittelalterlichen Grammatiker, der Ovids Wortfolge » richtig « stellt: $\gg$ Est enim ordo talis: $>$ fert animus in noua corpora mutatas dicere formas; di, coeptis adspirate meis, nam et uos mutatis illas $<\ll{ }^{28}$ Grundlegend für das Textverständnis der Metamorphosen seit der frühen Neuzeit ist der erstmals 1493 erschienene Kommentar des Raphael Regius, der vielfach nachgedruckt, noch öfter nachgeschrieben wurde. ${ }^{29}$ Dieser ersetzt damit sukzessive den Ovidius moralizatus des Petrus Berchorius, ${ }^{30}$ der mit seinen christlichen Allegorien die wichtigste mittelalterliche Leseanleitung gewesen war und auch noch im 16. Jahrhundert (bisweilen paraphrasiert) nachgedruckt wurde. ${ }^{31}$ Regius geht den Text Lemma für Lemma durch und erläutert ihn sprachlich wie inhaltlich: ${ }^{32}$

[...] IN NOVA: Est inquit mihi animus describendi mutationes corporum in novas figuras hac autem propositione, quae summam eorum continet quae in toto opere tractantur et dociles et attenti lectores efficiuntur. FERT ANIMUS: Cupit. Nam ferre inter alia significata est etiam cupere. [...] ASPIRATE: Spiritum ac favorem immittite. Est autem a ventis sumta translatio, qui dum navium vela implent, aspirare proprie dicuntur [...] DEDUCITE: pro-

27 Wheeler (1999), 8-33; Barchiesi (2004) ad loc.; allgemein zu Ovid: Lateiner (1990); generell zur Wort- und Satzreihenfolge im Lateinischen Devine/Stephens (2006) (naturgemäß mit Blick auf die Prosa, 524-610 zu Hyperbata und damit auch zu Sperrungen wie an unserer Stelle) sowie Spevak (2010); zum Unterschied zwischen Deutsch und Latein Kienpointner (2009), 359-385. - Prinzipiell ist zu bedenken, dass die einschlägigen Untersuchungen fast ausschließlich die lateinische Prosa (und allenfalls die Komödie) betreffen, die Dichtersprache in dieser Hinsicht so gut wie nicht untersucht ist. Eine Ausnahme ist Lateiner (1990), der sich aber im Rahmen seiner Untersuchung der »mimetic syntax « einen Sonderfall herausgreift.

Iulianus Toletanus, Ars grammatica, poetica rhetorica, pars 2, 19,51 (7. Jh. n. Chr.).

29 Siehe auch Benedetti (2008).

30 Bersuire (1979).

31 Zur partiellen Koexistenz von Berchorius und Regius im 16. Jahrhundert siehe auch Guthmüller (1997); vgl. Thimann (2002), 35-37, über den Einfluss der Deutungen Regius' auf die Kunst; zum Wandel des Ovid-Bildes zwischen Mittealter und Renaissance außerdem Gatti (2011).

Text nach Benedetti (2008). 
ducite, protrahite. Proprie autem, ut inquit Fabius (Quint. Inst. Orat. VIII 2,933) deduci carmina dicuntur, cum scribuntur. PERPETUUM: Continuum, sic ut nulla transmutatio pretermittatur alteraque alteri concinne apteque connectatur: id quod facile a diis impetravit poeta. Ita namque fabulam fabulae annectit, ut una ex alia nasci videatur. Sed quidam non minus insulsus quam temerarius, quorundam ineptirarum interpositione ea in multis exemplaribus separare conatus sit, quae deorum benignitate tam eleganter fuerant copulata. Id vero flagitium, quo totum opus inquinabatur, in primis curaui tollendum.

IN NOVA: Er sagt, ich habe im Sinn, die Verwandlungen der Körper in neue Gestalten zu beschreiben. Durch diese Voranstellung also, die die Zusammenfassung dessen enthält, was im ganzen Werk behandelt wird, werden die Leser belehrbar und aufmerksam gemacht. FERT ANIMUS: Er möchte. Denn ferre bedeutet unter anderen Bedeutungen auch mögen, wollen [...] ASPIRATE: Sendet euren Atem und eure Gunst hinein. Es ist dies aber eine von den Winden genommene Übertragung, die, während sie die Segel anfüllen, wörtlich mit »behauchen « bezeichnet werden [...] DEDUCrTE: Führt weiter, zieht weiter. Im eigentlichen Sinne spricht man aber, wie Fabius sagt [...] davon, dass Gedichte weitergeführt werden. PerpetuUM: so zusammenhängend, dass keine Verwandlung übergangen wird, sich die eine an die andere flüssig und passend anschließt. Das kann der Dichter leicht von den Göttern erhalten. Denn so reiht er eine Sage an die andere, dass die eine aus der anderen zu entstehen scheint. Aber jemand, der nicht weniger witzlos als verrückt war, hat versucht, sie durch die Einfügung von Unpassendem in viele Teile aufzuspalten, die sie doch durch die Gnade der Götter so geschmackvoll verbunden waren. Diese Schande freilich, durch die das ganze Werk entstellt wird, habe ich vor allem zu beseitigen mich bemüht.

Der Kommentar des Regius enthält eine Reihe von gerade auch für Übersetzungen wichtigen Beobachtungen, so die Gleichsetzung von fert animus mit cupere, den Hinweis auf die metaphorische Bedeutung von aspirare als »einen günstigen Verlauf geben «. Deducere dagegen ist offenbar noch nicht als eine aus der Textilverarbeitung übernommene Metapher des textlichen Webens erkannt (auch der Zusammenhang dieser Stelle mit Verg. ecl. 6,5 - deductum carmen - ist noch nicht hergestellt, so dass die poetologische Signifikanz für qualitätvolle Kleindichtung bis ins 20. Jahrhundert unentdeckt bleibt $\left.{ }^{34}\right)$. Man findet allerdings einen Hinweis auf die hinter deducere stehenden realen Vorstellungen schon in den deutschen Anmerkungen einer anonymen Ausgabe von der Mitte des 18. Jahrhunderts (Nürnberg 1759):

Deus coeptis adspiret meis. Gott gebe Glück zu meinem Vorhaben, befördere dasselbe. Die metaphora ist von dem Winde hergenommen, welcher das Schiff fort treibet, wenn er in die Segel blaset $[. .$.$] perpetuum carmen heißet ein aneinander hangendes Getichte [...] Dedu-$ cere: fortführen, wie ein Leineweber einen Faden an den andern webet, bis das Stück gantz und völlig wird.

33 Quint. inst. 8,2,9: »At illud iam non mediocriter probandum, quod hoc etiam laudari modo solet ut proprie dictum, id est, quo nihil inueniri possit significantius, ut Cato dixit C. Caesarem ad euertendam rem publicam sobrium accessisse, ut Vergilius $>$ deductum carmen $<$, et Horatius $>$ acrem tibiam $<$ $>$ Hannibalemque dirum<. In quo modo illud quoque est a quibusdam traditum proprii genus ex adpositis (epitheta dicuntur), ut >dulcis musti< et >cum dentibus albis <.«

34 Vgl. aber schon Scheller/Lünemann (1807) s. v. deduco: »spinnen: daher kommen die metaphorischen Redensarten bei Dichtern, deducere carmen, versum, Ovid [...] «. 
Dafür erkennt Regius die mit perpetuum verknüpfte Wichtigkeit der durchgängigen Erzählung, wobei nicht ganz klar ist, ob sich seine Polemik auf eine bestimmte Person (etwa Lactantius Placidus) oder allgemein auf die mittelalterliche Praxis der Unterteilung nach Einzelsagen bezieht.

\subsection{Pyramus und Thisbe}

Die Sage von Pyramus und Thisbe im 4. Buch der Metamorphosen ist eine der zahlreichen Digressionen Ovids aus der prinzipiell linearen Erzählung seines carmen perpetuum. Unbeeindruckt von dem sich ringsherum entwickelnden Bacchus-Kult tragen die Töchter des Minyas einander beim häuslichen Spinnen Geschichten vor, darunter die von Pyramus und Thisbe. Diese Episode gehört zu den rezeptionsgeschichtlich erfolgreichsten Sagen Ovids. ${ }^{35}$ Das liegt wohl nicht zuletzt an ihrer ohne gelehrte und intertextuelle Anspielungen auskommenden Vollständigkeit und der damit gegebenen Voraussetzungslosigkeit des Lektüreverständnisses, während mögliche Vorlagen völlig unbekannt sind, so dass man - zumindest in dieser Form - von einer Erfindung Ovids ausgehen kann. Seit dem christlichen Mittelalter ist sie bevorzugtes Objekt für ethischreligiöse Deutungen, auch in der bildenden Kunst (vgl. die drei Kapitelle im Basler Münster aus dem späten 12. Jahrhundert), worin Pyramus und Thisbe manchmal als positive exempla (z. B. für christliche Tugenden wie treue Ergebenheit), manchmal auch als Narren erscheinen. Eine solche moralische Lesart ist von Ovid gewissermaßen der ganzen Erzählung implementiert, ist dieses Mal doch weder von vorsätzlicher Täuschung noch erotischer Gewalt, auch nicht seitens der Götter (die aus der Erzählung ausgespart bleiben), die Rede.

Wie solche ethisch-religiöse Deutungen über das Mittelalter in den Humanismus und die Frühe Neuzeit fortgeschrieben wurden, zeigt die in der Mitte des 16. Jahrhunderts entstandene, 1606 gedruckte Auslegung des Georg Sabinus (1508$1560):{ }^{36}$

Exemplum Pyrami ac Thisbes docet, qualem vitae exitum sortiantur, nempe tristem et infelicem, qui illicitos suos amores charitati parentum anteferunt. idque exemplum quo sit illustrius, ac iuvenum animis inculcetur, Poeta fabulam exornat tanta affectuum et figurarum suavitate, vix ut possit quicquam excogitari suavius. Inseri miserabiles querelas infelicium amantium, \& crebras sermonis conversiones: nunc ad parietem, cum quo, perinde quasi intelligat, expostulant: nunc ad feras, a quibus alter optat afferri sibi interitum propter magnitudinem doloris ex alterius nece accepti: nunc ad parentes, a quibus officium sepeliendi flagitatur: nunc ad arborem, quam Thisbe alloquitur iam moritura, \& precantur, ut perpetuo servet gemini monimenta doloris. Eiusmodi siquidem conversiones, praesertim ad res inanimes, sunt haud mediocre condimentum suavitatis, ac mirifice afficiunt animum lectoris.

35 Vgl. Schmitt-von Mühlenfels (1972); Schmitzer (1992); Schmitzer (2001), 209-216; Barchiesi/Rosati (2007), 256-269; Klein (2008); Thimann (2005), 198. 
Das Beispiel von Pyramus und Thisbe lehrt, welches Ende ihres Lebens denen zugeteilt ist, nämlich ein trauriges und unglückliches, die ihre unerlaubten Liebschaften der Zuneigung ihrer Eltern vorziehen. Und damit dieses Beispiel umso plastischer sei und sich in die Sinne der jungen Leute tief einfurche, schmückt der Dichter die Erzählung mit einer solchen Süße an Affekten und Figuren aus, dass man sich kaum etwas Süßeres denken könnte. Es sind die traurigen Klagen der unglücklichen Liebenden eingefügt und häufiger Umgang im Gespräch: nun an die Wand gerichtet, von der sie etwas fordern, als ob sie es verstünde, nun an die wilden Tiere, von denen der eine für sich den Tod erhofft wegen der Größe seines Schmerzes, die er durch den Tod der anderen erfahren hat, nun an die Eltern, von denen der Dienst des Begräbnisses gefordert wird, nun an den Baum, den Thisbe schon todgeweiht anredet und ihn bittet, dass er auf Dauer als Andenken an den doppelten Schmerz diene. Hinwendungen solcher Art besonders an unbelebte Dinge sind keine geringe Würze der Süße und ergreifen wunderbar das Herz des Lesers.

Sabinus betont über die moralische Botschaft hinaus das hohe Potential an emotionalen Situationen, die in der Tat für das sprachliche Register und sein Spektrum in dieser Erzählung bestimmend scheinen - von der sachlichen Einleitung bis zu den Klagemonologen und zum Tod von Pyramus und Thisbe reichend. Sie stellen für Übersetzer eine besondere Herausforderung dar, da hier die Gefahr der inadäquaten, auch lächerlichen Wiedergabe besonders groß ist. Letzteres Potential hat bekanntlich Shakespeare im Sommernachtstraum realisiert. Andererseits legt gerade die Nähe zu bühnenhaften, ja opernmäßigen Formen eine besondere Berücksichtigung der Affekte nahe. Weiter ist für die nachantike Sagenbehandlung typisch, dass Ovids carmen perpetuum nicht nur in Einzelepisoden unterhalb der Bücher aufgeteilt wird (das gibt es bis heute in Übersetzungseditionen oder Schulausgaben ${ }^{37}$ ), sondern dass sich auch innerhalb der Einzelsagen Unterkapitel finden, die auch jeweils eigene Deutungen mit bisweilen unterschiedlichen Akzenten erhalten.

Ovid lässt seine (Binnen-)Erzählerin mit den folgenden Sätzen beginnen (zitiert nach der für das 18. Jahrhundert repräsentativen Ausgabe des Nikolaus Heinsius, ${ }^{38}$ hier im Druck von 1758):

Pyramus et Thisbe, iuvenum pulcherrimus alter,

altera, quas Oriens habuit, praelata puellis,

contiguas tenuere domos: ubi dicitur altam

coctilibus muris cixisse Semiramis urbem.

notitiam primosque gradus vicinia fecit.

tempore crevit amor. taedae quoque iure coissent;

sed vetuere patres, quod non potuere vetare. ${ }^{39}$

37 Erstmals finde ich diese Unterteilung in den Narrationes fabularum Ovidianarum des Ps.-Lactantius Placidus aus dem frühen Mittelalter (abgedruckt bei Magnus 1914).

38 Vgl. Reeve (1974), 133-166.

39 Die syntaktische Struktur wird heute anders abgeteilt (erstmals sehe ich das im lateinischen Text so in: Bach, Metamorphoseon libri XV (1831); aber auch schon in den Übersetzungen von Rode und Voß wird so interpungiert, vgl. Magnus (1914) ad loc.: »distinxerunt [...] JHV Voss et Gierig « [Leipzig 1804], wo es heißt: »Post patres posui interpunctionem maximam, quam vir doctus ap. Clark. ad Hom. Il. $\gamma 39$ et in alius Obersvatt. Miscel. Vol. II T. I p. 34 suasit. «): Der zweite Halbvers wird auf den folgenden Vers im Sinne einer vorweggenommenen Erläuterung bezogen, während bei Heinsius 
Ex aequo captis ardebant mentibus ambo.

conscius omnis abest; nutu signisque loquuntur,

quoque magis tegitur, tectus magis aestuat ignis.

Die Namen der beiden Protagonisten stehen überschriftartig am Anfang. Die genauere Vorstellung erfolgt trotz des dichotomischen, Parallelität suggerierenden alter - altera mit syntaktischer, inhaltlich chiastischer Variation. Nach der Parenthese entfaltet Ovid ekphrastisch den lokalen Handlungsrahmen weiter, wobei sich der Blick von den Häusern auf die Stadt Babylon und ihre sagenhafte (dicitur) Gründung durch Semiramis weitet. Dann kehrt die Erzählerin zu den beiden Hauptpersonen zurück und zur Entwicklung ihrer persönlichen Beziehung bzw. der Retardierung durch die Eltern (ob »patres « pars pro toto für jeweils beide Elternteile steht - vgl. 4,155 »parentes « oder für den bestimmenden männlichen Part, ist nicht klar zu entscheiden ${ }^{40}$ ), worin dann auch schon die Vorbedingung für die Katastrophe liegt, nämlich die Flucht vor dem Verbot der Eltern aus der Stadt, die Begegnung mit der Löwin und die wechselseitigen falschen Annahmen des Todes, aus denen sich der Selbstmord entwickelt.

Markiert der Anfang der Erzählung Ovids Fähigkeit zur knappen, sachlichen Exposition des narrativen Rahmens, so sind die Reden der emotionale Kontrapunkt, da in den Worten sowohl des Pyramus als auch der Thisbe Verzweiflung, Schuldgefühl und Todeswunsch eine Einheit formen. Am Ende ist die Metamorphose des Maulbeerbaums vorbereitet (met. 4,105-127):

Serius egressus vestigia vidit in alto pulvere certa ferae totoque expalluit ore Pyramus

ut vero vestem quoque sanguine tinctam

repperit, »una duos « inquit »nox perdet amantes,

e quibus illa fuit longa dignissima vita;

nostra nocens anima est. ego te, miseranda, peremi,

in loca plena metus qui iussi nocte venires

nec prior huc veni. nostrum divellite corpus

et scelerata fero consumite viscera morsu,

o quicumque sub hac habitatis rupe leones!

sed timidi est optare necem. « velamina Thisbes

tollit et ad pactae secum fert arboris umbram,

und anderen älteren Editionen eine Art Sentenz geformt ist: »Sie verboten, was sie nicht verbieten konnten. « Doch steht das nicht im Einklang mit dem weiteren Verlauf der Erzählung, denn die Heirat bleibt ja tatsächlich untersagt. - Vgl. den Kommentar des Regius ad loc.: »Sed vetuere patres: fatue quidem hoc esse dictum videtur. Si enim vetuere: quo modo vetare simul et lepide est dictum. Vetuerent enim ne nuptiarum iure coirent: prohibere autem non potuerunt ne animis: affectuque copularentur. « - $\gg$ Sed veture patres: Dies scheint freilich albern gesagt zu sein. Wenn sie nämlich verboten, dann ist zugleich witzig gesagt, wie sie verbieten wollten. Sie verboten nämlich, dass sie sich nach dem Recht der Ehe vereinten. Sie konnten aber nicht verbieten, dass sie das mit den Herzen taten und sich in Zuneigung verbanden.«

40 Vgl. Scheller/Lünnemann (1807), s.v. pater: »patres, Eltern Ovid«; so auch der Kommentar von Gierig (1804) ad loc.: »patres possent esse omnino parentes, ut alibi fratres pro fratribus et sororibus, reges pro rege et regina $[. ..] \ll-\gg$ Väter kann auch insgesamt >Eltern< heißen, wie anderwärts Brüder für Brüder und Schwestern, Könige für König und Königin [...] «. 
utque dedit notae lacrimas, dedit oscula vesti, »accipe nunc « inquit » nostri quoque sanguinis haustus! « quoque erat accinctus, demisit in ilia ferrum, nec mora, ferventi moriens e vulnere traxit. ut iacuit resupinus humo, cruor emicat alte, non aliter quam cum vitiato fistula plumbo scinditur et tenui stridente foramine longas eiaculatur aquas atque ictibus aera rumpit. arborei fetus adspergine caedis in atram vertuntur faciem, madefactaque sanguine radix purpureo tinguit pendentia mora colore.

Diese Passage ist geprägt von zahlreichen Kontrasten: zum betont sachlichen Anfang, zwischen der hochemotionalen Rede des Pyramus und dem illusionszerstörenden technischen Gleichnis, das wiederum die Charakterentwicklung des Pyramus spiegelt.

\subsection{Pygmalion ${ }^{41}$}

Auch die Erzählung von Pygmalion scheint zumindest in der uns vorliegenden Form eine Erfindung Ovids zu sein. Ovid baut nicht auf ein Vorwissen seiner Leser, sondern erzählt ohne Anspielung auf Vorlagen und ohne damit verbundene Kürzungen, sondern vollständig und ausführlich. ${ }^{42}$ Die Pygmalion-Sage entwickelte sich vor allem in der Neuzeit zu einem Schlüsseltext für die Künstlerpersönlichkeit, die sogar totes Material zum Leben erwecken kann. Bei Ovid ist sie zunächst eingebunden in den Gesang des Orpheus, der mit der Ankündigung puerosque canamus / dilectos superis inconcessisque puellas / ignibus attonitas (met. 10,152-154) beginnt, also von Knabenliebe und perversen sexuellen Gelüsten künden will. Und in der Tat ist Ovids PygmalionErzählung über weite Strecken eine Variation auf Erzählungen, in denen Menschen sich in Skulpturen verliebten und diese Leidenschaft bis zur sexuellen Perversion führte (am berühmtesten ist die Anekdote über die Aphrodite von Knidos, etwa bei Ps.-Lukian, Erotes 15$).{ }^{43}$ Ovid unterstützt die sinnliche Dimension durch eine streckenweise deut-

41 Vgl. Aurnhammer/Martin (2003); Feldherr (2010); James (2011); Stoichita (2011).

42 Die intertextuelle Pointe der Pygmalion-Sage liegt in ihrem kontrafaktischen Bezug auf bekannte Künstleranekdoten und - wie in einer eigenen Studie gezeigt werden wird - auf Vergils DidoErzählung, nicht auf stoffliche Vorlagen.

43 Für die christliche Kritik am antiken Heidentum ist dieser Aspekt natürlich besonders produktiv, vgl.

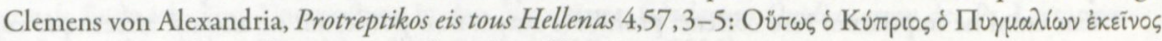

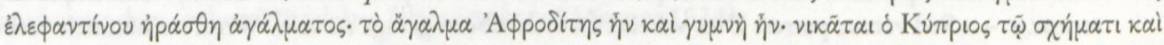

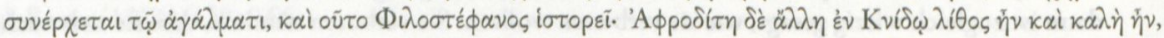

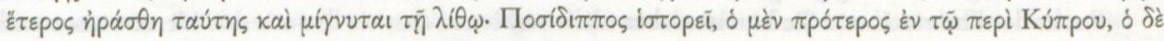

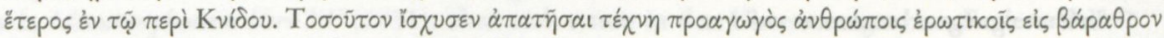

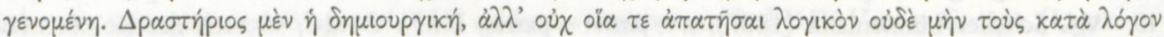

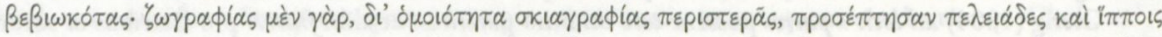

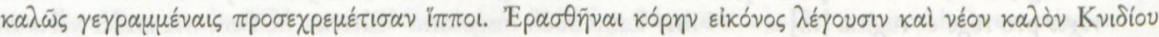

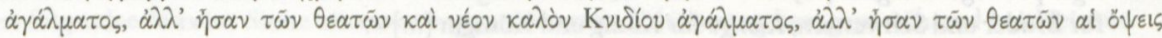


lich erotisch aufgeladene Sprache. Erst kurz bevor Pygmalion tatsächlich über sein eigenes Werk herfällt, wird Venus als eine Art von dea ex machina tätig, gibt der in der Antike namenlosen Statue (die seit dem 18. Jahrhundert, wohl seit Rousseau, den Namen Galat[h]ea trägt ${ }^{44}$ ) Leben und eröffnet damit den Weg zu einer glücklichen Mann-Frau-Beziehung auf Dauer.

Selbst daraus konnte die christliche Nachantike einen moralischen Sinn gewinnen, wie im Ovidius moralizatus des Petrus Berchorius: ${ }^{45}$

Per istum factorem imaginum intelligo praedicatores qui animam sciunt sculpere: et pingere correctionibus et virtutibus: per istam puellam eburneam intelligo quamlibet sanctimonialem: quae eburnea dicitur pro eo quod casta frigida ponderosa et honesta esse dici-

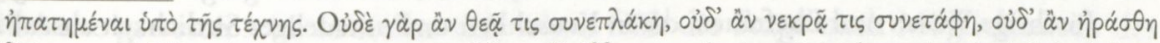

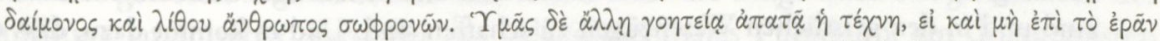

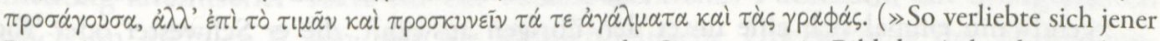
Pygmalion von Kypros in eine elfenbeinerne Statue; die Statue war ein Bild der Aphrodite und war nackt. Der Kyprier wird von der schönen Form überwältigt und umarmt die Statue, und das erzählt Philostephanos. Eine andere Aphrodite in Knidos war aus Marmor und war schön; ein anderer verliebte sich in sie und vermählt sich mit ihr; Poseidippos erzählt es, der erstere in dem Buch über Kypros, der andere in dem über Knidos. In solchem Maß vermochte Kunst zu täuschen, dass sie lüsternen Menschen Verführerin zum Abgrund wurde. Mächtige Wirkung hat die bildende Kunst, aber sie ist nicht imstande, ein vernünftiges Wesen oder gar solche zu täuschen, die vernunftgemäß gelebt haben. Zwar flogen wegen der Ähnlichkeit der Malerei zu gemalten Tauben andere Tauben hinzu, und schön gemalten Stuten wieherten Hengste zu. Ein Mädchen soll sich in ein Gemälde und ein schöner Jüngling in eine Knidische Statue verliebt haben, aber nur die Augen der Betrachtenden waren von dem Kunstwerk getäuscht. Denn kein vernünftiger Mensch hätte eine Göttin umarmt oder sich mit einer Toten zusammen begraben lassen oder hätte sich in eine Gottheit oder in einen Stein verliebt. Euch aber berückt mit einem anderen Zauber die Kunst, die euch, wenn sie euch auch nicht zum Verlieben verführt, doch dazu bringt, daß ihr die Statuen und die Gemälde verehrt und anbetet. « - Übers. O. Stählin). Arnobius, adversus nationes 6,22: $\gg$ Philostephanus in Cypriacis auctor est, Pygmalionem regem Cypri simulacrum Veneris, quod sanctitatis apud Cyprios et religionis habebatur antiquae, adamasse ut feminam mente anima lumine rationis iudicioque caecatis solitumque dementem, tamquam si uxoria res esset, sublevato in lectulum numine copularier amplexibus atque ore resque alias agere libidinis vacuae imaginatione frustrabiles. Consimili ratione Posidippus in eo libro, quem scriptum super Cnido indicat superque rebus eius, adulescentem haud ignobilem memorat - sed vocabulum eius obscurat - correptum amoribus Veneris, propter quam Cnidus in nomine est, amatorias et ipsum miscuisse lascivias cum eiusdem numinis signo genialibus usum toris et voluptatum consequentium finibus. « (»Philostephanus berichtet in den Kyprien, dass der König von Zypern, Pygmalion, sich in ein Bild der Venus, das bei den Kypriern im Ruf der heilig und von alters her ehrfürchtig behandelt wurde, wie in eine Frau verliebt habe, so dass sein Sinn, seine Seele, sein Scharfsinn und sein Urteilsvermögen erblindeten. Er war in seinem üblichen Verhalten so verblendet, dass er - gerade als wäre es seine Ehefrau - die Gottheit auf sein Bett legte und sich mit ihr unter Umarmungen vereinte und mit dem Mund andere Dinge nichtiger Leidenschaft beging, getäuscht von seiner Einbildung. Auf ähnliche Weise erwähnt Posidippus in dem Buch, das den Titel >Über Knidos< trägt, einen vornehmen jungen Mann - verschweigt aber dessen Namen -, der von der Liebesleidenschaft zu Venus ergriffen worden sei, wegen der Knidos im Ruhm steht, und dass er selbst erotische Ausgelassenheiten mit ihr ausgetauscht habe, wobei er das Bild der Gottheit auf das Ehebett legte und das Ende der folgenden Vergnügungen erreichte. «)

Bömer (1980), $96 \mathrm{f}$.

Bersuire (1979), fol. LXXV R. 
tur. Sed saepe contingit quod aliquis bonus pigmaleon id est aliquis bonus religiosus proponit perpetuo nec mulierem nec carnales amplexus appetere et talis convertit se ad imagines eburneas faciendas id est ad benignas sanctimoniales: et matronas in castitate et sanctitate informandas: et in moribus spiritualibus sculpendas: et accidit quod quandoque unam inter caeteras sibi eligit quam sororem vel filiam dicit et eam bono ac casto animo et amore associat et tangit.

In diesem Verfertiger von Bildern erkenne ich die Prediger, die die Seele zu formen wissen und durch Berichtigungen und Tugenden malen. In diesem elfenbeinernen Mädchen erkenne ich irgendeine Gottesfürchtige: Sie wird elfenbeinern deshalb genannt, weil man sagt, sie sei keusch, nicht heißblütig noch leichtlebig und vielmehr ehrbar. Aber oft kommt es vor, dass irgendein guter Pygmalion, d. h. irgendein guter und frommer Mann sich vornimmt, auf Dauer weder eine Frau noch fleischliche Umarmungen zu erstreben und sich so dazu wendet, elfenbeinerne Bildwerke zu schaffen, das heißt gutgesinnte und gottesfürchtige Wesen und Ehefrauen, die in Keuschheit und untadeliger Sittlichkeit auszubilden sind und in den geistlichen Wesenzügen zu schaffen sind. Und es kommt dazu, dass er irgendwann einmal sich eine unter den übrigen auswählt, die er Schwester oder Tochter nennt und sie mit gutem und reinem Geist und Liebe sich verbindet und berührt.

Diese positive Einschätzung von Pygmalions Handeln bleibt auch nach der Wende zum Humanismus und der Reduktion der Allegorisierung bestehen, wie sich in den folgenden Kapiteln anhand der Fassungen von Lorichius bei Wickram, verbunden mit dem Kommentar des Lorichius (1545) und Spreng (1564), zeigen wird.

Für die Analyse wird die Passage ausgewählt, in der der Erzähler ${ }^{46}$ in letzter Sekunde von der auf den Statuenfrevel hinzielenden Erzählrichtung abbiegt. Durch das Auftreten der dea ex machina Venus und ihr Wunder mündet das Geschen in ein happy end mit einer gegenüber der üblichen Verwandlungsrichtung umgekehrten Metamorphose: Aus dem Stein wird ein Mensch (met. 10, 280-297):

ut rediit, simulacra suae petit ille puellae incumbensque toro dedit oscula: visa tepere est; admovet os iterum, manibus quoque pectora temptat: temptatum mollescit ebur positoque rigore subsidit digitis ceditque, ut Hymettia sole cera remollescit tractataque pollice multas flectitur in facies ipsoque fit utilis usu. dum stupet et dubie gaudet fallique veretur, rursus amans rursusque manu sua vota retractat. corpus erat! saliunt temptatae pollice venae. tum vero Paphius plenissima concipit heros verba, quibus Veneri grates agat, oraque tandem ore suo non falsa premit, dataque oscula virgo

46 Der innerepische Erzähler ist Orpheus, der den gesamten zweiten Teil des 10. Buches dominiert, rezeptionsgeschichtlich blieb aber diese narrative Arbeitsteilung zwischen den verschiedenen Erzählinstanzen in den Metamorphosen folgenlos. 
sensit et erubuit timidumque ad lumina lumen attollens pariter cum caelo vidit amantem. coniugio, quod fecit, adest dea [...]

\section{Metamorphosen-Übersetzungen vom Mittelalter bis zum Ende des}

\section{Jahrhunderts}

2.1 Auf dem Weg zu einem deutschen Ovid. Übersetzerische Anverwandlungen der Metamorphosen vom Mittelalter bis zum Barock

Mag auch die Gelehrten- und Kirchensprache des Mittelalters selbstverständlich das Lateinische gewesen sein, so stellte sich schon früh die Frage nach Möglichkeiten der Vermittlung lateinischer Texte für ein volkssprachliches Publikum, am drängendsten natürlich im sakralen Raum, wie die althochdeutsche Übersetzung der Evangelienharmonie des Tatian (830) zeigt. Nicht selten spielte auch der romanische Sprach- und Kulturraum eine wichtige vermittelnde Rolle, so für die Aeneis. Die Metamorphosen nahmen dagegen einen besonderen Weg.

\subsubsection{Albrecht von Halberstadt (ca. 1180-nach 1251) ${ }^{47}$}

Die Geschichte der deutschsprachigen Ovid-Übersetzungen beginnt schon im Hohen Mittelalter, ${ }^{48}$ mit Albrecht von Halberstadt, der um 1200 die Metamorphosen in mittelhochdeutsche Verse brachte. Er tat das am Hofe des Hermann von Thüringen, an einem der führenden kulturellen Zentren dieser Zeit. ${ }^{49}$ Auch wenn über die näheren Umstände der Entstehung dieses höfischen Unternehmens nichts bekannt ist (weder sind Selbstaussagen noch zeitgenössische Testimonien erhalten), so ist doch festzuhalten, dass es sich um eine der frühesten Übersetzungen eines lateinischen Poesietextes ins Deutsche handelt, früher selbst als der Werke Vergils. Die Gründe für diese Bevorzugung liegen mangels externer Zeugnisse im Dunkeln, dürften aber zumindest zu einem erheblichen Teil der generellen Hochschätzung Ovids (vgl. etwa die Carmina Burana) und auch seiner Rolle als Schulautor ${ }^{50}$ geschuldet sein.

Während der ebenfalls in dieser Zeit am Thüringer Hof entstandene Eneasroman des Heinrich von Veldeke auf die französische Vorlage des Roman d'Énéas zurückgreift und kaum direkt auf Vergil, scheint sich Albrecht unmittelbar Ovid zugewandt zu haben. Albrecht adaptiert die Metamorphosen an die durch den Minnesang und die Ependichtung ausgebildete mittelhochdeutsche Dichtersprache. Dabei werden die

47 Vgl. Rosenfeld (1953), 178: »die erste ohne französ. Zwischenschritte gemachte Übersetzung aus der klassischen Antike $\ll$.

48 Vgl. Hexter (2007), bes. 1319-1320; Schmitzer (2010), 566 f.

49 Vgl. Peters (2004); Frölich (2007) (zu Albrecht nur sehr am Rande); Stackmann (1997), 34-36.

S0 Vgl. zuletzt Gatti (2014), 53-85. 
heidnischen Mythen für den Zeitgeschmack entschärft ${ }^{51}$ und in ein christliches Ambiente überführt. Von den ca. 2000 mittelhochdeutschen Versen sind allerdings nur noch ca. 780 Verse erhalten, ${ }^{52}$ so etwa aus der Sage von Tereus, Philomela und Procne. ${ }^{53}$ Der Beginn der Bitte, die Procne an ihren Ehemann, den König Tereus, richtet und mit der sie ihre Schwester aus Athen zum Besuch nach Thrakien kommen lassen will, lautet im lateinischen Original (met. 6,440 ff.):

»cum blandita viro Procne si gratia « dixit

$\gg$ ulla mea est, vel me visendae mitte sorori,

vel soror huc veniat. «

Albrecht formt daraus einen nach Vers- und Wortzahl deutlich längeren Text: ${ }^{54}$

Diu ]vrowe irem manne

ob] ich etteswanne

Ju v] Iiz in hulden icht getete,

vo]lgt herre, miner bete.

Lat ]mich varen über se,

vf] daz daz ich gese

Den] vater vnde die swester min.

$\mathrm{ma}$ ]ch des aber nicht sin,

Diu] swester kome zu mir here.

Natürlich handelt es sich nicht um eine Übersetzung im neuzeitlichen Sinne, sondern um eine zeitgemäße Paraphrase bzw. Umdichtung, die die Inhalte Ovids in die mittelhochdeutsche Dichtersprache einkleidet. ${ }^{55}$ Damit naturnotwendig verbunden ist die Aufgabe von wesentlichen Charakteristika von Ovids Erzählung, nicht nur des klassischen Hexameters, sondern der gesamten poetischen Diktion nebst auch der mythologischen Einkleidung (das wurde gewiss nicht als tatsächlicher Verlust empfunden, sondern als Zugewinn an Qualität). Die in den Metamorphosen vom epischen Erzähler gestaltete Erläuterung von Procnes schmeichelndem Ton ist bei Albrecht in die Rede integriert und Ovids gezielte brevitas zugunsten der Explizitheit aufgegeben. ${ }^{56}$ Damit

51 Vgl. Frölich (2007), 42: »Die Vorstellung von der Abgötterei der Heiden wirkte sich auf die Rezeption antiker Stoffe aus: Albrecht von Halberstadt in seiner Übersetzung von Ovids >Metamorphosen < und Herbort von Fritzlar in seinem $>$ Liet von Troye $<$ distanzieren sich ausdrücklich von den heidnischen Göttern.«

52 Vgl. Klein (2008); Rücker (1997), 29-91; auch Runge (1908).

53 Der thrakische König Tereus heiratet die athenische Königstochter Procne. Als diese Sehnsucht nach ihrer Schwester Philomela verspürt, bringt Tereus sie nach Thrakien, vergeht sich aber an ihr, schneidet ihr, um sein Verbrechen zu verschleiern, die Zunge heraus und hält sie gefangen. Philomela gelingt es, einen Bildteppich zu ihrer Schwester zu schmuggeln, die sie dann befreit. Gemeinsam planen sie Rache: Sie töten den Sohn des Tereus, Itys, und setzen ihn seinen Vater zum Mahl vor, der diese grausige Gabe zu spät bemerkt und seinen eigenen Sohn verschlingt. Tereus wird in einen Wiedehopf, Procne in eine Schwalbe, Philomela in eine Nachtigall verwandelt.

54 Vgl. dazu Behmenburg (2009), 141-186, mit Hinweis auf Bräuer (1990).

55 Vgl. Poiss et al. (in diesem Band), $\$ 9$ (modernisierend-assimilierende Übersetzung: der Ausgangstext wird in die Welt der Zielkultur übertragen); vgl. auch Botley (2007) und Müller (2007).

56 Ausführlich dazu Klein (2008). 
zeigt sich schon am Beginn der Übersetzungsgeschichte der Metamorphosen eine Tendenz, die einen Großteil der späteren Umsetzungen fundamental prägen wird.

Trotz ihrer Modernität ist Albrechts Übersetzung isoliert geblieben. ${ }^{57}$ Es gibt offenbar weder zeitgenössische Rezeptionszeugnisse noch weitere Versuche solcher Übersetzungen. Das steht im Gegensatz zu Entwicklungen in den romanischsprachigen Ländern, zu Frankreich und Italien (und partiell auch zu England ${ }^{58}$ ), wo am Ende des Mittelalters volkssprachliche Nachdichtungen und Kommentierungen ${ }^{59}$ in beträchtlicher Zahl entstehen.

\subsubsection{Jörg Wickram (ca. 1505-1562)}

Diese Situation änderte sich mit dem Beginn des 16. Jahrhunderts, mit der medialen Revolution des Buchdrucks. ${ }^{60}$ Dieser hatte nicht nur seit der editio princeps (Bologna $1471)^{61}$ die Verbreitung der originalen, kommentierten oder unkommentierten Metamorphosen in ungeahnter Weise befördert. Es existierte jetzt auch die kommunikative Basis für die Distribution der Übersetzungen (so etwa der italienischen Übersetzung Venedig 1497), die nun nicht mehr nur, wie die Albrechts, in wenigen, stets von Verlust gefährdeten Handschriften vorlagen.

Mit dem Kommentar des Raphael Regius (zuerst Venedig 1493), ${ }^{62}$ der schon zwei Jahrzehnte nach dem Erstdruck in einer Auflage von kaum glaublichen 50000 Exemplaren $^{63}$ verbreitet war, kehrte die humanistische Nüchternheit und Wortorientierung auch in die Ovid-Deutung ein, ohne dass die früheren allegorisierenden Formen (wie im Ovidius moralizatus) damit ganz eliminiert worden wären - diese existierten vielmehr komplementär weiter. Die nun selbstverständlich auf Latein geführten gelehrten Auseinandersetzungen ließen die europäische scholarly community ohne nationale Unterschiede diskriminierungsfrei teilhaben.

Auch auf der Ebene der nationalsprachlich geführten Diskurse, die bisweilen sogar regional definiert waren, wurde Ovid nun neue Aufmerksamkeit zuteil. Im deutschsprachigen Raum sieht das 16. Jahrhundert eine beträchtliche Zahl von volkssprach-

57 Vgl. Rosenfeld (1953), 177f. - Gescheitert ist der Versuch von Bartsch (1861), aus der Bearbeitung Wickrams die gesamte Fassung Albrechts zu re-konstruieren. Siehe prinzipiell Rücker (1997).

58 Schmitzer (2010), 565-567.

59 Schmitzer (2010), $565 \mathrm{f}$.

60 Zum weiteren übersetzungs- und geistesgeschichtlichen Rahmen siehe Giesecke (1991) sowie Müller (2007); außerdem Möckel (2007). - Die erste gedruckte Ovid-Übersetzung überhaupt - eher eine Paraphrase - galt den liebesdidaktischen Elegien: Capellanus/Hartlieb (1482); vgl. Rössig (1997), Nr. 19; der dem gedruckten Buch zugrundeliegende Text selbst war schon gut 50 Jahre älter.

62 Guthmüller (1975) und vor allem Benedetti (2008) mit ausführlichen Hinweisen zur Text- und Editionsgeschichte.

Guthmüller (1997), 59. 
lichen Umsetzungen, die vor allem aus dem Umfeld des Meistersanges stammen. ${ }^{64}$ Diese Meistersinger führten sich auf die Handwerkstradition zurück und verorteten sich dezidiert im städtischen Milieu. Das besagt aber a priori wenig über ihren tatsächlichen Bildungsgrad (so waren unter ihnen Juristen oder städtische Amtsträger), war doch in den großen Städten das Schulwesen auch unterhalb des akademischen Niveaus auf einer beachtlichen Höhe angesiedelt.

Der bekannteste und früheste Vertreter der so verorteten MetamorphosenÜbersetzer ist Jörg Wickram aus Colmar. Er brachte es trotz zwar patrizischer, aber unehelicher Herkunft (wodurch ihm ein höherer Bildungsgang verwehrt blieb) immerhin zum Stadtschreiber im elsässischen Burgheim und hinterließ ein umfangreiches schriftstellerisches Werk. ${ }^{65}$ Er hatte auf nicht näher bekannte Art von Albrechts Übersetzung Kenntnis erlangt ${ }^{66}$ und modernisierte sie 1545 nach Erfordernissen seiner Zeit, wie ausdrücklich in der Vorrede festgehalten ist. Auch nach gut 350 Jahren sieht er erstaunlicherweise keine Notwendigkeit zu einem völligen Neueinsatz, wie er unter den Rahmenbedingungen des städtischen Humanismus erwartbar gewesen wäre, vielmehr ist ihm der nicht nur deklaratorische Anschluss an die vorliegende Tradition wichtiger als Originalität - so wichtig, dass er sogar die Vorrede Albrechts mit ihrer Adresse an den Landgrafen Hermann bewahrt. Diese Betonung der Kontinuität, die den Autor weiterer legitimatorischer Zwänge enthebt, ist für das gewählte Verfahren wohl eher ausschlaggebend als der im Gestus der topischen Bescheidenheit vorgetragene Mangel an Lateinkenntnissen. ${ }^{67}$

Die oben für Albrecht zitierte Passage liest sich in der Diktion des 16. Jahrhunderts folgendermaßen: ${ }^{68}$

Progne irn man batt hertzlich sehr

Er sollt sie lossen uber Meer

Zù ihrer schwester Philomelam

Dann sie ihr entlich solchs furnam

Das sie wollt jren vatter sehen

Wo das jr man wolt lossen bschehen

So aber solchs je nit mag sein

64 Zum sozialen Status und Bildungsgrad der Meistersinger siehe (anhand von Nürnberg) Kugler (1977), 20-39; vgl. auch schon mit Blick auf Augsburg Pfeiffer (1919), 1-32.

65 Vgl. M. E. Müller/Mecklenburg (2007), darin generell vor allem den Beitrag von Jan-Dirk Müller, 2140.

66 In Straßburg ist im 16. und 17. Jahrhundert eine Handschrift bezeugt: vgl. Bartsch (1861), CXXXIII. Nach Lübben (1865) war wohl auch eine Abschrift im 16. Jahrhundert in der gräflich-oldenburgischen Bibliothek vorhanden, also außerhalb des süd- und mitteldeutschen Raumes.

$67 \mathrm{Ob}$ das tatsächlich auf mangelnde Kenntnis des Lateinischen zurückzuführen ist (so z. B. scharf urteilend Erich Schmidt [1897]) ist eine andere Frage; differenzierter dazu Rücker (1997), 116-121, die darauf hinweist, dass in einer Reihe von Fällen Wickrams Abweichungen von Albrecht näher an Ovids Text führen.

68 Vgl. zu den Unterschieden zwischen Albrecht und Wickram (der stärker moralische Kategorien einführt) Behmenburg (2007) und (2009), 141-186. 


\section{So bitt ich Koenig und Herre mein}

Bringt mir mein Schwester zù mir her $[\ldots]^{69}$

Neu gegenüber Albrecht ist, dass Wickram den Text Ovids nicht für sich allein stehen lässt, sondern - vielleicht nicht zuletzt aufgrund der konfessionell angespannten Atmosphäre in der Entstehungszeit - sich gegen mögliche Anstöße am heidnischen Kern des Textes absichert: Wie der »gelehrte« Ovid durch gelehrte lateinische Kommentare bereichert wurde, so fügt Wickram seinem Übersetzungstext die deutschsprachige Auslegung des scharf antireformatorisch ausgerichteten Theologen Gerhard Lorichius bei: $:^{70}$

Wie nun dieser Tereus seyn eygen schwägerin und haußfrauwe geschendt hat / muß er nun inn seinem eygenem quadt (sc. Kot) sitzen. Die Glosa uber den Leuiticum sagt: Upupa est lugubris avis, luctum amans. Das ist / der Widhopff ist eyn leyd vogel / ist gerne wo leydt und jamer ist. Schickt sich wol auff alle ketzer / so gemeyniglich nichts stifften dann jammer und leydt. Jsidorus sagt er neste gern inn todten grebern und mit menschen quadt. Er hat noch heut zu tag sein Königlich Kron auff seinem haupt.

Damit formt die christliche Ovid-Auslegung, die eine lange mittelalterliche Tradition hat, ${ }^{71}$ einen neuen Text, der die Namen und Sagen der antiken Mythologie in ein christlich-humanistisches Bedeutungsraster einfügt. Diese Inanspruchnahme ist zwar nicht mehr so willkürlich und geradezu gewaltsam wie im Mittelalter, im Ovidius moralizatus etwa, sie geht dennoch von der These einer intentionalen Vereinbarkeit der Metamorphosen mit dem (postreformatorischen) Christentum aus, von der sich der wissenschaftliche Humanismus, z. B. der Kommentar des Regius, gerade zu entfernen suchte. Der nach Episoden gegliederte Text erhält so einen dreistufigen Aufbau: die leserlenkende Überschrift, die deutsche Wiedergabe und schließlich die religiös-moralische Nutzanwendung, wobei keine direkte Wechselwirkung v. a. zwischen der zweiten und der dritten Stufe feststellbar ist, vielmehr eine additive Zusammenstellung vorliegt. ${ }^{72}$

Aber die Metamorphosen Wickrams machen Ovid nicht nur erbaulich, sie weisen ihm auch eine konkrete Nutzanwendung zu, die aus dem vollständigen Titel des Werks deutlich hervor geht:

P. Ovidii Nasonis, des aller sinnreichsten Poeten Metamorphosis. Das ist von der wunderbarlicher Verenderung der Gestalten der Menschen, Thier, und andere Creaturen etc. Jederman lüstlich, besonder aber allen Malern, Bildthauwern, und dergleichen allen künstnern nützlich, von wegen der ertigen Invention und Tichtung. Etwan durch den Wolgelerten M. Albrechten von Halberstat in Reime weiß verteutscht. Jetz erstlich gebessert und mit Figuren der Fabeln gezirt durch Georg Wickram zu Colmar etc. EPIMYTHIUM.

69 Hier und im Folgenden sind die Texte möglichst den Originaldrucken getreu wiedergegeben (mitsamt allen Eigenheiten der Graphie und Zeichensetzung und der nicht immer gegebenen Konsistenz der Rechtschreibung), lediglich bei der Darstellung der Umlaute sind dem mimetischen Prinzip Grenzen gesetzt, da die vorhandenen Zeichensätze kein kleines $e$ über dem $a, o$ oder $u$ erlauben, weshalb in diesen Fällen auf die modernen Umlaute ausgewichen wird.

70 Vgl. Stackmann (1967) und (1997), 36-41; Rücker (1997), 277-322; Schmitt (2008).

71 Schmitzer (2010), $564 \mathrm{f}$.

72 Bisweilen, so bei Spreng (s. u. S. 137), steht vor der deutschen Fassung noch eine kurze versifizierte Zusammenfassung des Inhalts. 
Das ist, Der lüstigen Fabeln des obgemelts buchs Auslegung, jederman kurzweilig, vornemlich aber allen liebhabern der Edeln Poesie stadtlich zu lesen Gerhardi Lorichii Hadamarii (Mainz 1545).

Natürlich war Ovid schon lange vorher zu einer Inspirationsquelle für Künstler geworden - man denke nur an Sandro Botticellis Primavera (um 1480; Florenz, Uffizien), deren Ovid-Bezug durch Aby Warburgs Deutung ${ }^{73}$ Wissenschaftsgeschichte geschrieben hat. Aber auch die italienische Renaissance griff beileibe nicht immer auf den Originaltext, sondern auf deutende, teils paraphrasierende volkssprachliche Ausgaben zurück. ${ }^{74}$ Speziell in Italien hatten sich die volkssprachlichen Ausgaben der Metamorphosen in Form der metamorphoseos vulgare als umfassende mythologische Handbücher etabliert, in denen keineswegs auf philologische Genauigkeit geachtet wurde, sondern vom Autor gelassene scheinbare Lücken stillschweigend und selbstverständlich ergänzt wurden. ${ }^{75}$

Im Zeitalter des Humanismus erhalten auch die an einem handwerklichen Ideal orientierten Künstler, die Maler, Kupferstecher, Verfertiger von Holzstichen etc., $\mathrm{Zu}$ gang zum antiken Wissensreservoir, indem Übersetzer wie Wickram ${ }^{76}$ (und Spreng) das notwendige Material bereit stellen. ${ }^{77}$ In welche Richtung man das noch weiter treiben und die Anleitung mit der Praxis verschränken konnte, zeigt sich deutlich in der 1563 (und erneut 1569) erschienenen Metamorphosen-Adaption Schöne Figuren auß dem fürtrefflichen Poeten Ovido, allen Malern, Goldschmieden und Bildhauwern zu nutz und mit Teutschen Reimen kürzlich erkleret des Johann Post von Germersheim (Johannes Posthius): ${ }^{78}$ Zuerst gibt es dort eine jeweils gereimte Inhaltsangabe der wichtigsten Sagen der Metamorphosen, dann zu den so ausgewählten Sagen Illustrationen mit deutschen und lateinischen Versen. ${ }^{79}$ Ovids Text wird damit endgültig seiner spezifischen poetischen Form und Narrativität entkleidet und auf den plot reduziert, ist gerade dadurch aber als Basis für künstlerische Umsetzungen geeigneter. ${ }^{80}$

Wickrams Übersetzung ${ }^{81}$ geht nicht ganz so weit, sie lässt aber v. a. durch die Zwischenüberschriften und die Reimform transformatorisch einen neuen Ovid, ${ }^{82}$ einen Ovid des deutschen 16. Jahrhunderts entstehen: ${ }^{83}$

73 Warburg (1893).

74 Schmitzer (2008).

75 Guthmüller (1975).

$76 \mathrm{Zu}$ Wickrams eigenen Illustrationen siehe Schreurs (2007) und Rücker (1997), 248-267.

77 Zur Bedeutung der Metamorphosen-Editionen für die Emblemkunst siehe Cappelletti (1997).

78 Horn (1995); Thimann (2002); 154; Karrer (1993), 374.

79 Karrer (1993), 378: In die 1581 erschienene Neuauflage (nachgedruckt 1609 und 1631) der Wickram'schen Bearbeitung wurden ohne ausdrückliche Nennung auch Posts Verse sowie Sprengs Fassung als Korrektiv und zur Füllung der vermeintlichen Lücken herangezogen.

$80 \mathrm{Zu}$ Ausnahmen - etwa bei Pieter Brueghel -, in denen Bildern tatächlich der ovidische Wortlaut zugrunde liegt, vgl. Schmitzer (1989) und (1992), bes. 539-544, mit weiterer Literatur.

81 Siehe prinzipiell Rücker (1997), 123-175.

82 Dieser Befund steht in Einklang mit dem im SFB »Transformationen der Antike« entwickelten Konzept der »Allelopoiese «; vgl. Böhme et al. (2011), 11 u. ö.

83 Dazu kurz Sieber (2007), $153 \mathrm{f}$. 
Von der traurigen lieb Thisbe uñ Pyrami von jrer nechtlichç flucht und erbermlichen endt. Es hat gewohnt zu Babilon

Eyn Jüngling auß der mossen schon

Der hieß mit namen Pyramus

Auch was eyn Junckfraw überaus

An schön und junckfrelicher tuget

Der gleich man nit fand irer juget

Thisbe was der junckfrawen nam

Ir schön die junckfrawen alsam

Fürtraff in Babilon der statt

Dise Thisbe ir wonung hatt

Zu nechst an dem haus Pyrami

Nichts dann ein wandt thet scheiden sie

Cupido hat die zwey verwunt

Mit seinem geschoss inn herzens grunt

Die noch beywonung semlichs macht

Doch ward auf sie mit fleiß geacht

Von iren eltern beider seit

$\mathrm{Da}$ sie beide zu keiner zeit

zu red noch gesprech nit mochten kummen

Doch ward jr keim die lieb benummen

Dann sie mit wincken und mit deuten

Ir lieb übten zu allen zeiten

So mehr man huot auff sie thet han

Jhe mer in ihn die liebe bran.

Aus der präzisen lateinischen Erzählung wird eine Art von volkssprachlicher Ballade, ${ }^{84}$ eine Paraphrase in Versen, die die konventionellen Vorstellungen auch da ins Spiel bringt, wo sie von Ovid gar nicht gesucht sind, etwa in der Erklärung der wechselseitigen Liebe durch die Verwundung vom Pfeil des Amor/Cupido. ${ }^{85}$ Die in den Metamorphosen überschriftartig zusammengestellten Namen der beiden Liebenden werden von Wickram so separiert, dass Pyramus zunächst allein als Protagonist erscheint, während Thisbe demnach erst sekundär dazu träte. Thisbe ist entsprechend den Vorstellungen der Zeit nicht nur als schön, sondern auch als tugendhaft gerühmt, und damit von vornherein in einen spezifischen Wertekanon gerückt, während bei Ovid aus der äußerlichen Attraktivität und der zunächst erwartbar anmutenden Liebesgeschichte erst allmählich ein Lehrstück über Charakterstärke und deren Grenzen wird. Auch die sentenzartige Wendung quoque magis tegitur tectus magis aestuat ignis ist in ihrer Signifikanz entstellt, da die Aufsicht (wohl der Eltern), nicht das Verbergen seitens der Liebenden in den Focus gerückt ist.

84 Vgl. Stackmann (1997), 31, über volksliedhafte mittelalterliche Rezeptionen der Metamorphosen (z. B. im $\gg$ Abendgang $\ll)$.

85 Zur transformationstheoretischen Relevanz dieser Veränderungen vgl. Böhme et al. (2011), 48 (Transformationstyp der Assimilation). 
Während Pyramus und Thisbe notgedrungen nur eine keusche Beziehung haben, ${ }^{86}$ ist die Pygmalion-Sage von manifester, gerade noch in unanstößige Bahnen gelenkter Begierde ihres Protagonisten geprägt. Eine Grundentscheidung, vor der alle Übersetzer dieser Passage stehen, besteht darin, wie weit man es wagen kann, Ovids erotische Sprache ins Deutsche zu bringen, oder ob man sich auf den als moralisch eruierten Kern zurückzieht. Wickrams Position in dieser impliziten querelle ist deutlich:

Von dannen gieng Pygmalion

Und wie er vor dik was gewon

$\mathrm{Zu}$ knien vor das schloffbet sein

Und küßt sein geschnites schons bülin

Welchs do nacket an seim bett lag

Sein mundt vernemend als ich sag

Pygmalionem jetz bedeucht

Wie er ganz warm wer / dazu feucht

Aber und aber er sie kußt

Und legt sein handt uff ihre brust

Do daucht ihn wie das fleisch wer zart

Und wich den henden ganz verwart

Pygmalion forcht noch das wunder

Und frewet sich danoch darunder

Wiewol er trawet der geschicht

Noch genzlich an ir selber nicht

So lang biß er das mit den henden

Begreiffen thet an allen enden

Umb das herz und an den armen

Befand er das es fast thet warmen

Darzu hats eyn weichen leichnam

Die adern klopfften alle sam

Zustundt begundt er sunder wohn

Der Goettin Venus danken schon

Er kust freuntlich seins bulins mundt

An welchem kein bedzug mehr stundt

Die magt zu stundt auch do empfandt

Des küssens und blickt uff zuhandt

Sie sach jren Bulen freuntlich ahn

Der hernach wardt jr ehlich man

Venus ihn selb die Bretlauff hielt

Pygmalion sehr groß freid wielt

Wickram scheut sich nicht, Ovids Erotik in die eigenen Verse zu überführen. Pygmalions Fühlen und Tasten, das Küssen schließlich sind unverkürzt erhalten. Bemerkenswert ist, wie Wickram der puella gegen Ende selbst eine aktive Rolle zuschreibt, während sie bei Ovid - selbst lebendig geworden - stets nur Objekt bleibt.

86 Zum Ehediskurs bei Wickram siehe auch Sieber (2007), 149. 
Lorichius bestätigt in seinem Kommentar mit ausführlicher Erörterung die in der Metamorphosen-Handlung enthaltenen Maximen des Neuen Testaments: Es ist für den Menschen besser, die Ehe zu suchen, als in ständiger sexueller Not zu leben. Durch Gottes Gnade findet der Mensch also zu einem ihm zuträglichen Leben. ${ }^{87}$

\subsubsection{Ambrosius Metzger (1573-1632) ${ }^{88}$}

Auch der Nürnberger Ambrosius Metzger gehört in das Milieu der Meistersinger. Nach dem Besuch der Nürnberger Lateinschule zu St. Sebald (wo er sich auch am Griechischen versuchte) und der als Magister abgeschlossenen theologischen Ausbildung an der Altdorfer Akademie wirkte er bis zu seinem Tod als Lehrer an der Lateinschule zu St. Egidien in Nürnberg, allerdings als schlecht bezahlter infimus und in einem Umfeld, das das Niveau ihrer Gründung durch Philipp Melanchthon nicht hatte bewahren können. Dennoch besaß er dadurch die Fähigkeit, sich Ovid im lateinischen Original anzueignen. ${ }^{89}$

Wie in vormodernen Anverwandlungen gebräuchlich, fehlt auch bei Metzger eine Umsetzung des Proömiums. Die eigentlichen Sagen sind nun, anders als bei Wickram und auch Spreng, dezidiert in die Form des Meistergesangs gegossen, z. B..90

Folget das virtte Buch

Ovidij von verEndrung

Der Gestalten. Erstlich

von der traurigen Lieb Thißbe vnd

pyrami, von ihrer Nächtlichen

Flucht vnd erbärmlichen Ende

Jn Orphei sehnlichen Klagweiß M. Metzgeri 1

Als Pyramum

thißbe thet liben,

vnd er hin wiederum

von gleicher lieb getriebn

gegen thi $ß$ ben der Jungfraw ward,

(doch nicht konden zu sammen kommen,

weil ihr Eltren waren dar wider hart,

nach dem Sie beeder liebes Brunst vernommen,)

bei Ninj grab,

am wald gelegen,

87 Vgl. Rücker (1997), 312-315, über die rigiden Ehe- und Moralvorstellungen des Lorichius.

88 Grundlegend immer noch Kugler (1977) zusammen mit seiner Edition Metzgers (1981); vgl. Rupprich/de Boor/Newald (1973), 267: »Noch im Barock versifizierte und vertonte Ambrosius Metzger Ovids >Metamorphosen< nach Wickrams Bearbeitung des Albrecht von Halberstadt in $155>$ Liedern $<, \ll$

89 Zur Biographie Kugler (1977), 40-42.

90 Text nach Metzger (1981). 
beschloßen Sie vorab,

da hin sich zu bewegen

bey kommenter morgen tags zeit.

Metzgers Fassung entfernt sich deutlich weiter als diejenigen seiner Meistersingerkollegen Wickram und Spreng von Ovids originaler Gestaltung, die epischen Metamorphosen sind nun in ein genuines Meistersingerlied transformiert. Die Beziehung zur Vorlage ist auf das Stoffliche reduziert, sogar der Handlungsort Babylon fehlt, ebenso die Rahmenerzählung von den Minyaden. Damit schließt sich Metzger eng an seinen Nürnberger Vorgänger an, den Erzmeistersinger Hans Sachs, den »Schuh-/ Macher und Poet dazu «, der sich in sehr freier Weise antiker Stoffe, auch ovidischer, bediente. ${ }^{91}$ Sachs' Bibliothek, deren Katalog erhalten ist,${ }^{92}$ umfasst sowohl lateinische Texte als auch Übersetzungen. Nach dem Erscheinen von Wickrams Version wurde diese seine Hauptquelle, was zum einen zeigt, welche Bedürfnisse Wickram befriedigte, und zum anderen die kulturellen Querverbindungen zwischen den Zentren des Meistersanges belegt. Allerdings erhebt Hans Sachs nicht den Anspruch, die gesamten Metamorphosen zu umfassen, sondern bedient sich daraus selektiv, während Metzger das ganze Corpus im Blick hat. Dennoch ist deutlich zu sehen, wie Metzger in der durch Sachs gesetzten spezifisch Nürnberger Gattungstradition steht: Es wird hieran besonders deutlich, dass übersetzerische Kontinuitäten und Übersetzernetzwerke beinahe ebenso wichtig sind wie die Kenntnis der originalsprachlichen Vorlagen, die gerade in vormoderner Zeit des öfteren vernachlässigbar erschien. ${ }^{93}$

Hartmut Kugler hat in seiner Grundlagenstudie u. a. die Gestaltung des Pygmalion-Stoffes durch Metzger analysiert. ${ }^{94}$ Er weist darauf hin, dass genau in der Mitte der 48 Verse Metzgers Pygmalion von »liebs Brunst « zu seiner Statue ergriffen wird (und sich danach die erotische Sprache deutlich wandelt), dass der Autor also die Komposition genau kalkuliert habe. ${ }^{95}$ Gegenüber der ausgeschmückten Fassung Wickrams mit ihren 115 (längeren) Versen ist hier »Raffung, Konzentration und Konstruktion « zu verzeichnen.

Hinzu kommt ein bislang offenbar nicht gesehener Aspekt, der möglicherweise die Kompetenz Metzgers weiter unterstreicht. Sein Text beginnt folgendermaßen:

In tyro wohnt ein könig reich,

Pigmalion genennet.

weil er keim weib trug lieb vnd gunst,

wolt er Allein verbleiben.

Metzger rekurriert hier auf Vergils Aeneis, wo Pygmalion als Bruder der aus Tyrus stammenden Dido erscheint und selbst dort als König residiert. Metzger bringt also auch seine Kenntnis des Vergil in die Sagengestaltung ein (ein Vorbild dafür ist nicht zu

91 Heinzmann (2001), 169, mit weiterer Literatur; ausführlich Baro (2009); vgl. auch Holzberg (2013).

92 Carlsohn (1960); vgl. Huber (2008), 81.

93 Vgl. generell Poiss et al. (in diesem Band), $\$ 10$.

94 Kugler (1977), 90-92.

95 Vgl. auch Kugler (1977), 126, über die kompositionelle Nähe zum Holzschnitt des Virgil Solis mit der Pygmalion-Szene. 
erkennen) und beweist auf diese Weise, dass er mit den antiken Texten selbständig umgehen kann, nicht nur auf Vorlagen zur Weiterverarbeitung angewiesen ist. ${ }^{96}$ Ansonsten ist Metzgers Fassung parallel zur Verknappung auch von einer Reduktion der Perspektive geprägt. Denn die Statue, die im Prozess der Erkenntnis ihrer Menschwerdung und des Erwachens der Liebe bei Ovid ja selbst auch zu Aktivität kommt, ist perspektivisch bei Metzger völlig ausgeblendet, der Focus bleibt auf Pygmalion und Venus gerichtet.

\subsubsection{Johann Baptist Spreng (1524-1601)}

Wie breit Ovid im Meistersängermilieu des 16. Jahrhunderts verankert war, zeigt weiter der Blick auf den Augsburger Meistersinger und Notar Johann Baptist Spreng. ${ }^{97}$ Seine Beschäftigung mit den Metamorphosen führte 1563 zunächst zu einer lateinischen Umsetzung mit Prosaparaphrase und einer in elegischen Distichen gehaltenen, ebenfalls lateinischen moralischen Auslegung, illustriert mit farbigen Holzschnitten ${ }^{98}$ des Virgil Solis.9 ${ }^{99}$ Sprengs Verleger Siegmund Feyerabend, auf dessen Initiative schon der lateinische Ovid zurückging, öffnete im folgenden Jahr den Weg für eine weitere Verwertung der Holzschnitte des Virgil Solis, indem er Spreng dazu anhielt, eine ebenfalls illustrierte deutsche Übersetzung der Metamorphosen (oder genauer: eine deutsche Umsetzung des lateinischen Ovid) zu erstellen (1564), ${ }^{100}$ und dabei den Metamorphosen aus eigenem Vermögen einen moralischen Sinn beifügte:

Also hat auch der alt und hochberühmt Poet P. Ovidius Naso / seine fünfftzehen Buecher von den verenderungen der gestalten / on zweiffel zu keinem andern end und zil gerichtet / dann daß dardurch ehr/scham/ und tugend bey menigklich gepflanzet / hergegen aber schand / laster / und allerley mutwillen (wiewol dise seine Lehr vil anderst im Buchstaben scheinet) außgereut und abgestelltet werde.

Durch diese Parallelität zweier Editionen desselben Autors in unterschiedlichen Sprachen, die in der Übersetzungsgeschichte der Metamorphosen singulär ist und die die ursprüngliche lateinische Edition nun auch in der Volkssprache zugänglich macht, können auch weniger gebildete Kreise davon profitieren, wie der Schluss des Titels demonstriert:

[...] darneben auch vilen Handwercksleuten / insonders den Goldschmiden / Malern / Formschneidern / Etzern / und andern kuenstreichen Meistern / der Figuren halben / dienlich / und zu jrer Handtierung befürderlich sein möchte.

96 Zu den der Ovid-Tradition zugehörigen Quellen Metzgers siehe Kugler (1977), 148.

97 Roethe (1893), 288-291; Pfeiffer (1919), 34-41.

$98 \mathrm{Zu}$ solchen illustrierten Ausgaben und zum Verhältnis von Bild und Text siehe prinzipiell HuberRebenich (2001) und (2009).

99 Vgl. Pfeiffer (1919), 46-49, mit genauerer Würdigung und Hinweis auf eine zweite Ausgabe Paris 1583.

100 Pfeiffer (1919), 50. 
Die explizite moralische Belehrung wird durch die konkrete, beruflich spezifizierte Nutzanwendung ergänzt, die sich nicht zuletzt aus dem städtischen Meistersingermilieu ergibt, zu dem handwerklich orientierte Produzenten von bildlichen Darstellungen aller Art gehörten. Diese Anwendbarkeit betraf eben keineswegs nur die solitärhaften künstlerischen Eliten, sondern auch die alltägliche Lebenswelt. ${ }^{101}$

Dennoch ist Spreng durch seinen Bildungshintergrund ein übersetzungsgeschichtlicher Sonderfall im Rahmen der Meistersingertradition. Er absolvierte ein regelrechtes Studium (u. a. in Wittenberg bei Melanchthon). Auch später wirkte er hauptsächlich als Verfasser deutscher und lateinischer Dichtungen und als Übersetzer, sein Beruf als Notar in Augsburg schuf ihm dafür die nötige Basis. Er trat zuerst mit der genannten lateinischen Adaption der Metamorphosen hervor, die er auf Wunsch des Verlegers um die hier interessierende deutsche Fassung ergänzte. Aber auch u. a. Vergil und Homers Ilias ${ }^{102}$ transformierte er ins Deutsche. Trotz dieser Breite des Zugriffs fügt sich Spreng in die generellen Tendenzen und Erfordernisse der Frühen Neuzeit ein. Dazu gehört der doppelte Nützlichkeitsanspruch - als moralische Instanz und als künstlerisches Repertorium - sowie die Aufteilung der ovidischen Sagen in mehrere Episoden (hier: drei), die jeweils von einer Inhaltsbeschreibung in Prosa eingeleitet werden, worauf die Übertragung folgt, um dann von einer Auslegung abgeschlossen zu werden. Die Übertragung der hier zu behandelnden Stelle lautet folgendermaßen:

Ein Juengling Pyramus genannt /

Und Jungkfrauw Thysbe weit erkannt /

Zwo Personen gleicher gestalt /

Begabt mit schöne mannigfalt /

Gegen den Orient so klar /

Wirt nit funden ein solichs bar /

Die zwey wohnten gar nach beysammen /

Waren entzündt in liebes flammen /

Die Häuser an einander stiessen/

Zusammen sich die zwey offt liessen /

Cupido mit sein Pfeil und Bogen /

Hett dises bar an sich gezogen /

Und jre herzen starck verwundt /

Die liebe wuchs auch alle stund /

Und sie hetten zusammen sich /

Verpflicht in ehren gütiglich /

Wann nur die Elteren darneben /

Hetten dareyn den willen geben /

Aber sie haben jnen das /

Hefftig verboten aller maß /

Daher das Feuwer unergründt /

Bey jnen mehr wurd angezündt. 
Trotz mancher Abweichung im Detail - etwa der engeren, sich dem Original annähernden Zusammenrückung von Pyramus und Thisbe, der Konzentration auf die optische Attraktivität etc. -, ist doch der Wickram und Spreng gemeinsame Duktus unverkennbar, der nicht als Problem empfundene Verzicht auf Textnähe (einschließlich der auslösenden Rolle Cupidos) oder Wörtlichkeit zugunsten der Integration in ein dem aktuellen Stand der deutschsprachigen Poesie entsprechendes Reimschema, das insbesondere durch den Meistergesang und die gegenüber dem lateinischen Hexameter wesentlich kürzeren Verszeilen von vornherein eine andere Verteilung des Gedankenganges im Vers generiert. ${ }^{103}$

Die Sagenerzählung mündet in die moralische Auslegung, die anders als in der sich allmählich entwickelnden ovidischen Erzählung (tempore crevit amor ist auch eine narratologische Botschaft) das unglückliche Ende explizit vorausnimmt und in eine Schuldzuweisung ummünzt: ${ }^{104}$

Die ungebuerlich liebe schon /

Empfaht zu letzt ein boesen lohn /

Bringt mit sich schaden / spot und schand /

Zu loben ist der Ehelichstand /

Den jren Kinden zu den tagen /

Die Eltern nit sollen abschlagen /

Sonst mehr ubels darauß entstaht /

Und mercklicher grosser unraht /

Gott den Ehestand eyngesetzt /

Der Sathan die Ordnung verletzt.

Mit dieser exegetischen Ausweitung und den integralen Abbildungen wird die Episode zu einer Einheit geformt. Ovids Erzählung erhält eine charakteristische Veränderung in ihrer Ausrichtung, die sich auch in der Übertragung niederschlägt: Die Reaktion der Eltern, die bei Ovid mit größtmöglicher Sachlichkeit genannt ist (sed vetuere patres), ist von Spreng als übermäßig qualifiziert, so dass die Hoffnung auf eine »guetigliche « Verbindung umso schärfer kontrastiert ist (von der Ehe ist bei Spreng explizit nicht die Rede, nur in der Auslegung).

In der Pygmalion-Erzählung ist Spreng bei den erotischen Passagen außerordentlich knapp und umschifft alle Klippen durch Kürzung:

Venus war jn erhören bald /

Und thet eingiessen allermeist

Dem Bild ein lebendigen Geist /

Darauß ein schöne Jungkfrauw ward /

103 Vgl. auch die Unterschiede in den Bildunterschriften je nach verwendeter Sprache bei Bauer (1703), z. B.: »Dum votum expectat Thisbe ardens rege ferarum / Per tenebras viso territa nuda fugit.« $\gg$ Am Brunnen einen Löwen siht / die Thisbe, und deßwegen fliht. «

104 Vgl. die lateinische Fassung: »haec illegitimo merces debetur amori/vincula coniugii sunt retinenda pii: / Quae natis quoties cupiunt prohibere parentes, / in mala tum suboles deteriora ruit. / Principio thalamos Deus ipse sacravit honestos, / Hostis at est Sathanas ordinis huius atrox.« 
Am ganzen leib subtil und zart /

Sie wurd jm zu der ehe gegeben /

Das er mit jr solt fridlich leben.

Das ist schon beinahe die äußerste Reduktionsform des Geschehens: Spreng beschränkt sich auf das Handlungsgerüst und lässt alles - womöglich als anstößig empfundene - Beiwerk beiseite, so dass Ovid auch für ein christliches Publikum konsensfähig wird und der Verfasser alle Anstößigkeit vermeidet. ${ }^{105}$ Dieses Verfahren stimmt mit der moralischen Zielsetzung der Ausgabe überein und ist einer der möglichen Modi vormodernen Umgangs mit Ovid, denn die gefährliche erotische Aufladung von Ovids Szenerie ist nur schwer mit dem Lob des traditionellen Ehestandes zu vereinbaren, die Spreng in seiner »Außlegung « ansteuert: ${ }^{106}$

Ein Weyb geziert mit zucht und Ehr /

von Gott allein tut kommen her /

Der ist darumb zu rueffen an /

Dieweil der Mensch je schwerlich kan /

Dempffen sein fleisch / und leben rein /

Wie uns lehrt das Exempel fein.

Die volkssprachlichen Metamorphosen des 16. Jahrhunderts bleiben ein Text der vielfältigen Nutzanwendung, die trotz der in ihnen präsenten heidnischen Götterwelt auch für einen Christen leitende Maximen enthalten.

\subsubsection{Joachim von Sandrart / Carl von Mander (1679)}

Die Verwendung der Metamorphosen als multifunktionales Repertorium reicht bis weit ins 18. Jahrhundert. Die transmediale Anverwandlung, die sie in den Dienst künstlerischer inventio stellt, ist in der Barockzeit besonders in einem Text anzutreffen, in Joachim von Sandrarts $(1606-1688)^{107}$ zusammen mit Sigmund von Birken ${ }^{108}$ verfasstem universellen künstlerischen Kompendium, der Teutschen Akademie (16751680). Dieser ist die ursprünglich niederländische Paraphrase des Carl von Mander

$105 \mathrm{Zu}$ solchen Ausblendungen vgl. Poiss et al. (in diesem Band), \$ 10, sowie Böhme et al. (2011), 50.

106 In der lateinischen Fassung von 1563 heißt es in vergleichbarer Weise:

»Coniugio quicunq; cupit felice potiri,

Hoc sine divina non potietur ope:

Uxor amica placens \& moribus aucta pudicis,

Est à clementi saepe petenda Deo:

Quam grave sit motus etenim frenare uagantes,

Edocet ardescens Pygmalionis amor. «

(»Wer auch immer eine glückliche Ehe erlangen will, der erreicht das nicht ohne göttliche Hilfe: Eine freundliche und gewinnende Gattin, die durch sittsames Wesen erhoben ist, muss man häufig vom milden Gott erflehen. Wie schwer es nämlich ist, die umherschweifenden Bewegungen zu zügeln, das lehrt die brennende Liebe des Pygmalion. «)

107 A. Schreurs, in: Kuhlmann/Schneider (2012), $1107 \mathrm{f}$.

108 Laufhütte (1997). 
(Karel van Mander, 1548-1606) beigegeben, die ihrerseits zuerst Teil von dessen Schilder-Boeck gewesen war, der ersten nicht-italienischen Kunsttheorie. Lateinische Auslegungen waren für das in Auge gefasste Zielpublikum nicht geeignet, die vorhandenen deutschsprachigen wie die Sprengs offenbar zu knapp und auch nicht zielgerichtet genug:

Wie Ovidius in seinen Verwandlungs-Büchern thut: Allda/ mit genauer Aufmerkung/ alle Eigenschafften klüglich/ und die mancherley Erdichtungen/ mit grosser Kunst/ aneinander gehängt sind: Aus welchen Vermummungen die Griechen ein solches Behagen schöpfften/ daß sie dieses Buch aus dem Latein ins Griechische übersetzten. Und dieweil es bey uns gemein/ und/ wegen Abmahlung der vielen Historien/ der Mahler Bibel genennet ward: hätte ich schon vorlängst gewünscht/ eine Erklärung oder Auslegung drüber zu sehen/ oder/ daß die darinnen verborgene schöne Lehren/ aus dem tunkeln Chaos zu dem hellen Phoebus hätten aufgeführt werden mögen; erwartete demnach und sahe mich fast nach jemanden um/ der gelehrt/ unserer Sprach kundig/ und hierzu Beliebung tragen möchte; allein ich habe unsers Flämischen Castellani Sprichwort/ daß diese Busen (oder Geheimnüsse) zu fest geschlossen und vermacht wären/ nur allzuwahr befunden. Halte aber darfür/ daß sie ihre Gedancken/ zu höhern Vornehmen und Dingen/ anwendende/ sich nicht bekümmert/ mit ihren Achaischen und Lateinischen Schlüsseln/ uns/ oder den Hochteutschen/ der Minerva Tempel aufzuschliessen.

Nachdem ich solches vermerckt/ hab ich wiewol/ mit mehrerm Willen/als Vermögen/ auch aller Bereitschafft/ so ich nur finden mögen/ Fleiß angewandt/ diese verborgene/ herrlich und köstliche Schätze zu entdecken. Sintemal ich nicht geringe Begierde hatte/ unsern Teutschen Schülern und Kunst-liebenden edlen Geistern einen Dienst zu thun. Ich habe/ meiner Meinung nach/ in dieser Verwandlungsbücher Auslegung/ einiger massen/ eine gewissenhaffte Vorsichtigkeit gebraucht/ und dasjenige/ was mich ungeziemend zu seyn gedünckt/ und von andern/ in andern Sprachen/geschehen war/ nemlich die Heydnische Fabeln auf einen geistlichen Sinn zu ziehen/ und auf Christum zu deuten/ vermieten: in Erwegung/ daß diese Dinge keine Gemeinschafft oder Vergleichung miteinander haben. Der Poet kannte Christum nicht. Seine Gedichte dienen auch nicht Christum zu verkündigen; wie dann geschrieben ist: Wir haben nicht gefolgt denen klugen Fabeln/ da wir euch verkündigten die Krafft und Zukunfft unsers HERRN. Dann sie zwar/ als bereits erwähnt ist/ sehr nützlich/ die Sitten zu verbessern/ und den Menschen zu einem aufrichtig-tugendhafften/ ehrlichem/ Bürgerlichem Leben anzuspornen/ auch andere natürliche Dinge erkennen zu lernen; weiter aber gleichwol nicht zu ziehen sind. In Vielen hab ich mich bedient der Weise/ daß ich erstlich die Geschicht erzehlt/ worauf die Fabel gegründet ist: darnach was ihre natürliche Bedeutung sey; und dann endlich die Lehr und erbauliche Auslegung beygefügt. Und wo ich auf einen Namen der Götter/ oder andern dergleichen merckwürdigen/ kommen; erzehle ich das Geschlecht/ Leben/ und was dardurch verstanden/ oder gelehret werde: jedoch setze ich nicht viel vom Text des Poeten: den man darneben lesen mag/ und alsdann sehen/was darmit angedeutet seye.

Wann der Poet einige Fabel berührt/ die von denen Griechen/ oder andern/ weitläufftig beschrieben ist/ bricht er solche vorsetzlich kurtz ab: damit er nicht das/ was von andern beschrieben/ oder damals bey dem Volcke gemein war/ wiederholen dörffen. An solchen Oertern/ bin ich genöthigt worden/ den Dingen nachzusuchen/ und sie weitläufftiger zu erzehlen: auf daß man sie desto besser verstehen möchte. Endlich achte ich so viel Eröffnung oder Entdeckung allhier gethan zu haben/ daß nicht allein der Grund dieses Buchs/ sondern auch vieler anderer Poetereyen/ leichtlich begriffen und verstanden werden könne; 
und zwar nicht/ sonder Nutz/ sondern viele erbauliche und gute Unterweisungen damit zu fruchten.

Die Metamorphosen sind also ein allumfassender Wissensspeicher ${ }^{109}$ und zugleich als exemplarische Verkörperung der pictura poiesis-Synthese zu sehen. In späteren Auflagen blieb diese Metamorphosen-Beigabe allerdings weg, da (so die seinerzeitigen Herausgeber) der Text eine völlige Neubearbeitung erfordert hätte - auch das ein Indiz für die Schwierigkeiten, einen zeitgemäßen Ovid zu schaffen. Mit Sandrart ist ein Gipfelpunkt einer solch enzyklopädischen Anwendung der Metamorphosen erreicht. Doch blieb der Anspruch der Übersetzer auf eine solche Vermittlung das ganze 18. Jahrhundert bestehen. Dies wurde ergänzt durch den Hinweis auf junge Leute und Frauen ${ }^{110}$, womit das Spektrum der Lateinlosen, aber prinzipiell Interessierten etabliert ist.

\subsection{Metamorphosen-Übersetzungen des 18. Jahrhunderts unterschiedlicher Provenienz ${ }^{111}$}

Die lingua franca nicht nur der Altertumswissenschaft war im 18. Jahrhundert weiterhin das Lateinische. Insofern sahen auch die universitären Vertreter keine Notwendigkeit, sich um Übersetzungen in die Nationalsprachen zu bemühen. Die Übersetzungen waren die Angelegenheit von Schulmännern und Theologen, Privatgelehrten oder Gebildeten mit universalen Interessen oder in manchen Fällen (gegen Ende des 18. Jahrhunderts) auch von aufstrebenden oder etablierten Dichtern. Mit den editorischen Bemühungen des 17. und 18. Jahrhundert und dem dadurch erzielten philologischen Fortschritt ${ }^{112}$ gab es nur lose, selten wirklich gesuchte Berührungen (vgl. im einzelnen zu den jeweiligen Übersetzungen). Ein Verbindungsglied zwischen den gelehrten Editionen (etwa der Heinsii und von Onkel und Neffe Burmann, gegen Ende des 18. Jahrhunderts der editiones Bipontinae $\left.{ }^{113}\right)$ und den auf Vermittlung in die Volkssprache ausgerichteten Übersetzungen bilden kommentierte Ausgaben (so die anonyme, mit deutschen Erläuterungen angereicherte Ausgabe, ersch. Nürnberg 1759) ohne eigenen wissenschaftlichen Anspruch. ${ }^{114}$

109 Thimann (2007), zu Mander 59-61.

110 Vgl. Voß (1789), III: »Aus Gefälligkeit gegen einige Damen, die Virgils Landgedicht von mir übersetzt wünschten, versuchte ich $[\ldots] \ll$.

111 Vgl. Schmitzer (2010), 568. - Zum übersetzungstheoretischen Kontext vgl. Fantino (2013).

112 Hierzu generell Bursian (1883), 260-516, außerdem die jeweiligen Einträge bei Kuhlmann/Schneider (2012).

113 Butters (1877).

114 Vgl. zu Vergil, dessen ewiges Pendant Ovid ist, immer noch die Zusammenstellungen von Jarislowski (1928), bes. 27-89. 


\subsubsection{Johann Georg Schmid(t) (Straßburg 1712) $)^{115}$}

Der erste belegte Versuch eine Verdeutschung im 18. Jahrhundert stammt vom Straßburger Juristen Johann Georg Schmid(t) (Straßburg 1712): ${ }^{116}$

P. Ovidii Nasonis / XV. Bücher der Verwandlungen/In das Teutsche übersetzt / Dergestalt / Daß die in denselben vorkommende / Gemüths=Reden der Götter / Göttinnen / Helden ec / Meistens in Reimen / Die übrigen Erzehlungen aber in ungebundener Rede vorgetragen werden [...] von Johann Georg Schmidt

Schmidt bezeichnet sein Unternehmen in der Einleitung als ein Jugendwerk aus der Studentenzeit ${ }^{117}$ (die Betonung der Entstehung im Jugendalter ist für literarische Werke der Frühen Neuzeit topisch, vgl. etwa Jakob Balde über seine Batrachomyomachie ${ }^{118}$ ), doch habe es sich nicht um eine reine Freizeitbeschäftigung und Fingerübung gehandelt, sondern er habe damit einen auch auf Ovid und dessen Vermittlung an weitere Kreise abzielenden Aspekt bedacht:

Noch eine andere Ursach / so mich antrieb / war / daß mir noch keine Ubersetzung dieser Ovidischen Verwandlungen / nach ihrem buchstaeblichen Verstand unter die Augen gekommen [...].

Es ist nicht zu entscheiden, ob Schmidt hier eine bestimmte Fassung - etwa die Jörg Wickrams ebenfalls aus dem südwestdeutschen Raum - im Auge hat oder ob er sich ganz generell in einer salvatorischen Klausel äußert. Auf jeden Fall kommt mit dem Postulat des » buchstäblichen Verstandes « eine gegenüber den bisherigen Paradigmen neuartige Kategorie ins Spiel, die der Treue und auch der Angemessenheit, der antiken

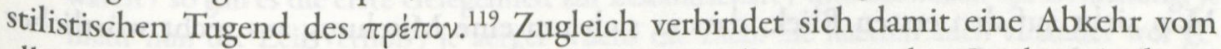
allegorischen Verständnis auch noch in dessen spät-humanistischer Spielart. Andererseits ist schon durch einen Blick auf die Form klar, dass hier keine Wörtlichkeit im Sinne von Humboldt oder Schleiermacher ins Auge gefasst ist, denn die Wahl einer aus Vers und Prosa gemischten Fassung steht in evidentem Widerspruch zu morphologischer Äquivalenz. Die Wahl des Prosimetrums ${ }^{120}$ begründet Schmidt sogar aus

115 Vgl. Elit (2002), 146-149.

116 In der Unterschrift des Vorworts: »Schmid«. Vgl. das Morgenblatt für gebildete Stände 3 (1809), 202 (anläßlich der Besprechung einer Aeneis-Travestie): »Der ungenannte Verfasser ist nach aller Untersuchung ein gewisser Johann Georg Schmidt, Licentiat der Rechte, geboren zu Straßburg im Jahre 1673, gestorben im Jahre 1730. Poesie war seine Lieblingsbeschäftigung. - Er versuchte sich unter anderem mit Glück im epigrammatischen Fache. Er hatte eine metrische Übersetzung Lucan's angefangen, aber nicht fortgesetzt. Von Ovid's Metamorphosen ist eine deutsche Übersetzung von ihm zu Strasburg 1712 im Drucke erschienen, gemischte Prosa und Verse. « Weitere Angaben zur Biographie sind mir nicht bekannt (auch nicht bei Elit [2002]).

117 Gemäß dem möglichen Geburtsdatum 1673 (siehe vorige Anm.) käme man also etwa in das letzte Jahrzehnt des 17. Jahrhunderts.

118 Schmitzer (2011).

119 Vgl. Kitzbichler (2009), 70-72 u. ö.

120 Zum Metrum der Verspassagen, der »Schäferliedstrophe«, vgl. Elit (2002), 148, Anm. 476. 
antiken Vorbildern, nämlich mit der Consolatio Philosophiae des Boethius, ${ }^{121}$ aber auch mit den unterschiedlichen emotionalen Qualitäten des Textes:

[...] theils weil die Abwechslung an sich selbst in andern natürlichen Sachen etwas Anmuthiges in sich enthaelt / theils weil die Gemüths=Reden / worauff ich vornhemlich gesehen / gleichsam aus einer Poetischen Wut / da die Lebens=Geister hin und wieder getrieben werden / heraußgeschüttet worden / wo die feurige Imaginatio mehr Theil gehabt / als die gelaßne Ordnung der schlechten Erzehlung.

Bisher kann ich in der Geschichte der Übersetzungen antiker Literatur kein Gegenstück finden, in dem ein formal einheitlicher Prosa- oder Poesietext übersetzerisch so unterschiedlich behandelt wurde. ${ }^{122}$ Es kann dies auf eine implizite Prototheorie der Emotionalität zurückzuführen sein, die in ästhetischem Zusammenhang mit den sich herausbildenden musikdramatischen Formen steht, so dass die Erzählung von der Rede als einer quasi-dramatischen Form geschieden ist. Das Vorbild könnte in zeitgenössischen Entwicklungen etwa in der Oper zu finden sein, namentlich der aus Frankreich stammenden opéra comique (die in Straßburg eventuell wegen der geographischen Nähe besonders bekannt war), ${ }^{123}$ oder dem sich um 1700 verbreitenden Singspiel, möglicherweise auch in der genuin literarischen Form des heroischen Romans.

Konkret liest sich bei Schmidt (1712) das Metamorphosen-Proömium folgendermaßen: ${ }^{124}$

Ich hab mir vorgenommen zu beschreiben / wie die Cörper in andere Gestalten sich verkehret. Ihr Götter, die ihr diese Wunderwerck verrichtet / seyd meinem Vorhaben geneigt und führet mein Gedicht glücklich von dem Anfang der Welt biß auff meine Zeit.

Man sieht auf den ersten Blick, dass es sich um eine Mischung aus recht wörtlicher Wiedergabe und interpretierender Paraphrase handelt. Nicht berücksichtigt ist die

121 Möglicherweise sind tatsächlich die vorliegenden Boethius-Übersetzungen für das gewählte Verfahren auslösend gewesen, z. B. die Schmidt zeitlich nächst stehende: Des Fürtrefflichen Hochweisen Severini Boetii, Weil. Bürgermeisters zu Rom, Consolatio Philosophiae, Oder Christlich-vernunfft-gemesser Trost und Unterricht in Widerwertigkeit und Bestürtzung über dem vermeinten Wohl- oder Ubel-Stand der Bösen und Frommen: Verteutschet, und Mit beygefügten kurtzen Anmerckungen über etliche dunckele Ort desselben, Lüneburg 1697.

122 Auch nichts Vergleichbares bei Kitzbichler (2012b) zu Homer. Dass nicht in das Versmaß des Originals, sondern entweder in Prosa oder zeitgenössische metrische Formen übersetzt wird, ist prinzipiell für das frühe 18. Jahrhundert der Normalfall: Kitzbichler (2009), 16f.; vgl. auch Schmidt (1998) zu metrischen und prosaischen Übersetzungen von Horaz' Oden im 18. Jahrhundert.

123 Vgl. Harper (1992), 192, über die barocke Operntheorie z. B. bei Barthold Feind: »Die drei theoretischen Schriften zeugen von der zentralen Bedeutung der Arie als Vehikel der Affektäußerung. «

124 Die weit verbreitete Ausgabe des Nikolaus Heinsius (Amsterdam 1664) hat folgenden Text: In nova fert animus mutatas dicere formas Corpora. Di, coeptis (nam vos mutastis \& illas)

Adspirate meis; primaque ab origine mundi

Ad mea perpetuum deducite tempora carmen.

Da die Bestände der Straßburger Stadtbibliothek im deutsch-französischen Krieg 1870 ein Opfer des Beschusses der Stadt wurden, lässt sich der mögliche intellektuelle Hintergrund Schmidts auch nicht aus den ihm damals prinzipiell zur Verfügung stehenden Ressourcen rekonstruieren. 
programmatische Anfangsstellung von in nova, dafür wird die Autor-Person an die Spitze gerückt (das entspricht auch den Vorgaben der Kommentare). Das syntaktische Verhältnis von formae und corpora ist umgedreht: Schon Regius, aber auch seine Nachfolger diskutieren nämlich teils heftig darüber, ob bei in nova ... mutatas ... formas corpora eine Hypallage vorliege - eine Auffassung, der auch Schmidt gefolgt zu sein scheint. Bei der Parenthese am Ende von Vers 2 ist die schlichte Aussage Ovids, die Götter hätten für die Verwandlung gesorgt (und seien deshalb auch für sein Verwandlungsgedicht zuständig) in die Wertung »Wunderwerck« interpretierend erhöht. Und am Ende fällt perpetuum gänzlich aus, eventuell weil es der nachantiken Tradition einer faktischen Kapiteleinteilung unverständlich ist; ${ }^{125}$ dafür ergänzt Schmidt mit glücklich (eine Wiederaufnahme von »seyd [...] geneigt«, was eine gedeutete Umsetzung von aspirate erklärlich macht) gewissermaßen ein konventionelles incipit feliciter. Die Abweichungen vom lateinischen Text sind also unspektakulär, aber spürbar, ohne dass es dafür eine wirkliche zielsprachliche Notwendigkeit gäbe. Vielmehr wird Ovids spezifischer Zugriff in die Bahnen der Konventionalität gelenkt.

Wie sehr die Wahl der äußeren Form die übersetzerischen Resultate präfiguriert, zeigt Schmidts Prosafassung von Pyramus und Thisbe (der die gesamte Sage wie in der Tradition üblich aufteilt, allerdings nur in zwei Abschnitte: die vergebliche Liebe in Babylon und die Flucht mitsamt der Katastrophe):

Der Pyramus und die Thisbe, jener der schönste von allen Jünglingen / diese von den Jungfern / so im Morgen-Land waren / hatten in Babylon / welche Stadt die Königin Semiramis mit gebackenen Steinen ummauert / ihre Haeuser neben einander. Weil sie nun Nachbarn waren / so gab es die erste Gelegenheit zur Bekandschaft / und bißweilen zur Besuchung. Je mehr nun die Zeit verfloß / je aerger wuchs die Lieb. Sie haetten auch einander wol geheurathet / aber die Eltern verboten es / welches sie doch nicht verbieten konnten. Auff solche Weiß liebten sie sich inniglichst / eines so herzlich als das andre. Niemand erfuhr was darvon. Dann sie sich auch mit Wincken und Zeichen unter einander zu verstehen gaben. Je mehr aber ein Feur verborgen ist / je mehr sucht es hervor zu dringen.

Sofort zu sehen ist die Verwendung der vormodernen Interpunktion nach sed vetuere patres. ${ }^{126}$ Schmidt löst auch Ovids Periphrase des Orts des Geschehens in das eindeutige »Babylon« auf. Ebenso neigt er generell zu mehr Explizitheit als die Vorlage, indem er etwa die Nachbarschaft noch einmal erwähnt. gradus wird im eigentlichen Sinn der Bewegung verstanden ( $\gg$ Besuchung $\ll$ ), nicht als $\gg$ erste Stufen $\ll$ der Liebesbeziehung. Auch im folgenden ist Ovids präzise Beschreibung zu eher allgemeinen Darstellungen aufgelöst: taedae iure bezeichnet den juristisch korrekten Akt der Eheschließung; ardebant nicht nur »innigliche «, sondern leidenschaftlich brennende

125 Dass die Signifikanz von perpetuum in der vormodernen Ovid-Gelehrsamkeit bekannt war, zeigt der Kommentar des Raphael Regius ad loc.: »perpetuum: continuum, sic ut nulla transmutatio pretermittatur alterque alteri concinne, apteque connectat.« (»perpetuum: zusammenhängend, so dass keine Verwandlung übergangen wird und sich die eine an die nächste eng und passend verbindet «). Siehe Moisan (1992) über andere renaissancezeitliche Anmerkungen zu dieser Stelle. - Vgl. auch Schlüter (1763), XXXII, über Safft: »Gleich im Anfang fehlt der Ausdruck: perpetuum, fortdauernd ununterbrochen, welches doch höchst nöthig war, indem Ovid dadurch sein Gedicht ein Ganzes nennt. «

126 Vgl. Anm. 39. 
Liebe, captis mentibus hat im Lateinischen auch schon die Konnotation des Wahnsinns ${ }^{127}$ und weist damit auf das Ende, den überstürzten Selbstmord des Pyramus voraus. Und schließlich ist mit Ovids Sentenz quoque magis tegitur ... eben nicht das Sichtbarwerden des Liebesfeuers, sondern die Intensität im Verborgenen gemeint. Trotz dieser ohne sprachlichen Zwang vorgenommenen Abweichungen vom lateinischen Original, die auch nicht auf leitenden ästhetischen Konzepten basieren, ist unverkennbar, wie sehr sich diese Prosafassung im Vergleich mit denen Wickrams und Sprengs an die lateinische Vorlage annähert. Die Transformation besteht nun nicht mehr in der Überführung in eine neue poetische Form, sondern in der Prosaisierung, der Reduzierung von Ovids Erzählung auf das Inhaltliche unter Verzicht auf den Großteil der poetischen Mittel. ${ }^{128}$

Wie schon im Titel angekündigt, greift Schmidt zur Wiedergabe emotionaler Reden zur metrischen Form: ${ }^{129}$

So bald er aber das blutige Gewand selbst gefunden / hat er erbaermlich angefangen aufzuschreyen:

Weh / eine Nacht wird zwey in ihren Schatten reißen

Von welches eines noch was laenger leben solt.

Mich kan man / allein die grausam Ursach heissen /

Dieweil ich es so haben wolt.

Ich habe dich umgebracht / du hasts von mir vernommen.

Ich / Ich bestimmte dieses Ort

Mit Schrecken angefuellt / mit Finsternuß umschwommen

Und bin doch nicht vor dir gekommen

Ich hab die Schuld an diesem Mord.

Ihr Loewen die ihr hie um diese Felsen wohnet

Zerfleischt mein Eingeweid / verschlingt mich und belohnet

Die grausamkeit an mir / daß ich bey solcher Noth

Der Thisben Jugend nicht schohnet.

Doch nur ein Feiger wuenscht den Todt.

Damit hub er der Thisben Haupt-Zierd auff und begab sich an den unter sich verglichnen Baum. Daselbst netzte er das Gewand mit den zahrtesten Thraenen / kueßte es wol tausend mal und sagte:

Du traegst der Thisben Blut / ich und sie waren einig

Du hast ihr Blut / nehm auch das meinig.

Zugleich zog er sein Schwerdt auß und stieß es sich in den Leib. Drauff eh er noch starb / riß er es wieder auß der warmen Wunden und warff sich ruecklings auff die Erden. Das Blut schoß heraus nicht anders als wie das Wasser auß einem langen Rohr / wann das bleyerne Gelenck etwan verderbt wird und das Rohr ein Loch bekommen. Die Fruechten an dem

127 Vgl. Thes. III, p. 340, 31-48, s. v. capio.

128 Vgl. generell Poiss et al. (in diesem Band), bes. $\$ 10, \mathrm{Nr} .12$ (»Reduktion «).

129 Die theoretische Basis für die Versifizierung (bei Schmidt und den späteren Übersetzern des 18. Jahrhunderts) sind deutsche Poetiken wie die von Opitz (1624/1690), 44-67 (»Von den Reimen / ihren Wörtern / und Arten der Gedichte «), oder Birken (1679), z. B. 40-51 (»Das V. Redstuck von der Reimung «) und 51-73 (»Das VI. Redstuck von den Gebändzeil-Fehlern «). 
dabeystehenden Maulbeer-Baum wurden besprizt / die Wurzel mit dem Blut angefeuchtet und die Beeren ganz schwarz.

Die Schilderung des Geschehens gewinnt in dieser Weise eine vom Ausgangstext unerwartete Dynamik und nähert sich in der Tat dem Wechsel von Rezitativ und Arie und damit dem Opernhaften an. Wenn es um den Handlungsfortschritt geht, ist die Prosaform gewählt; wenn sie durch die wörtlichen Reden vordergründig zum Stillstand kommt (in Wahrheit versteht es Ovid auch, die Reden als Vehikel des Handlungsfortschritts zu nutzen), setzen die Verspassagen mit ihren Paar- und Kreuzreimen begleitend die emotionalen Akzente. Diese literarische Aufgabenteilung transformiert Ovids carmen perpetuum in ein gewissermaßen dialogisches, sich wechselseitig kommentierendes Gebilde.

Die Pygmalion-Sage ist weniger von emotionalen Höhen und Tiefen geprägt denn von einer sich steigernden erotischen Spannung, die - wie bereits erwähnt - narrativ in den sicheren Hafen der Ehe umgeleitet wird. Für die Kernpassage findet Schmidt folgende übersetzerische Lösung:

Wie er wieder nach Hauß kehrete / verfügte er sich zu seinem angenehmen Bildnuß. Er fiel auff das Bett / und küßte es inbrünstig. Es schien ihm etwas lau zu seyn. Er küßte es noch ein mal und befühlete mit den Händen die Brust. Das befühlete Helffenbein ward weich / verließ die Härtigkeit und nahm die Finger an / nicht anders als wie das Wachs vom Berg Hymettus, wann es die Sonn erweicht / so kan man allerhand Figuren darauß bilden und es wird durch den Gebrauch selbst gebräuchlich. Indem er erstaunete / zweiffelte/sich gleichwol freute und doch förchtete / er möchte betrogen werden / so begriff er zwey / dreymal sein Verlangen. Kurz es war ein Leib / die Adern schlugen unter dem Daumen. Da hat Pygmalion auff das allerersinnlichste der Göttin Venus gedancket, darauff mit seinem Mund seines Bildnußes natürlichen Mund gedrucket. Die Jungfer empfand die Küß und entfärbte sich / also sah sie forchtsam in die Höh und zugleich den Himmel / zugleich ihren Buhlen. Die Göttin wohnete der Hochzeit-Feyer / welches sie angestiftet hatte / bey.

Es ist eine kleine, aber bedeutsame Änderung, die Schmidt an seiner Vorlage vornimmt. Bei Ovid steht erubuit, was auf jeden Fall die Möglichkeit eines erotischen Vergnügens einschließt, ${ }^{130}$ Schmidt macht daraus »entfärbte sich «, das eher ein Erschrecken denn ein Vergnügen markiert. Weder die zeitgenössischen noch die rezenten Wörterbücher (z. B. Stephanus, Schuller, Thes. ling. Lat.) kennen eine solche Bedeutung, vielmehr scheint Schmidt einer irrigen Etymologie aufgesessen zu sein: In erubescere in Analogie etwa zu emendare hat für ihn das e einen privativen Aspekt. Doch hat dieser Irrtum den Vorteil, dass er sich damit auch vor seinen Lesern salviert.

Die übersetzerische Crux dieser Passage ist nicht nur die Sinnlichkeit des lateinischen Textes, die in einem christlich geprägten Umfeld zum Problem werden kann, wenn der Übersetzer nicht davon ausgeht, durch den klassisch-antiken Text salviert zu Sein. ${ }^{131}$ Die Unterschiede zwischen Wickram und Spreng sind in dieser Hinsicht durchaus paradigmatisch. Denn darüber hinaus hat Ovid ein raffiniertes Wortspiel eingebaut: ad lumina lumen attollens bezeichnet das Aufschlagen der Augen der

130 Vgl. Verg. Aen. 12,64-71: das Erröten der Lavinia.

131 Zur Erotisierung des Pygmalion-Stoffes im 18. Jahrhundert siehe Aurnhammer/Martin (2003), $254 \mathrm{f}$. 
eburnea virgo, die natürlich das Tageslicht, aber auch die Augen des über sie gebeugten Pygmalion sieht, ${ }^{132}$ was im abschließenden Hauptsatz weiter ausgeführt wird (entsprechend ist der Bezug von ad àmò koเvoũ gestaltet). Bei Schmidt ist die Erotik der Szene (wie gezeigt) recht gedämpft, das Wortspiel ist auf die Dimension des Aufblickens reduziert, während der lumina-Aspekt beiseite bleibt.

Wie viele, wenn nicht die meisten Übersetzungen des 18. Jahrhunderts ist Schmidt nur wenig rezipiert worden. Sein Werk versank schon bald in Vergessenheit, vielleicht nicht zuletzt deshalb, weil seine prosimetrische Lösung keine Nachfolge fand und so ästhetisch obsolet wurde, vielleicht aber auch, weil seine Auseinandersetzung mit Ovid als Lokalereignis nicht weit über Straßburg hinauskam (allerdings zeigen die Bibliothekskataloge auch heute noch einen recht weit gestreuten Bestand).

\subsubsection{Johann Balthasar Sedlezki (1727-1772) $)^{133}$}

Johann Balthasar Sedlezki (auch: Sedletzki) war eine nicht zu gering zu achtende GröBe im kulturellen Leben Augsburgs im 18. Jahrhundert, wo etwa zwei Jahrhunderte früher auch der Meistersinger Spreng gewirkt hatte. Auch er setzte die Metamorphosen (1763) in eine der zeitgenössischen Ästhetik gemäße Form um, nämlich in gereimte Verse (so auch noch in seiner Odyssee-Übersetzung von 1784). ${ }^{134}$ Mit seiner Metamorphosen-Übersetzung möchte Sedlezki nützlich sein, allerdings nicht in dem vordergründigen Sinn einer religiös-ethischen Allegorese oder eines Künstlerhandbuchs, sondern zur Bereicherung der deutschsprachigen Literatur, wobei der $\gg$ zärtliche Ovid « (also der tenerorum lusor amorum aus trist. 4,10,1) in den Kontext der Empfindsamkeit gerückt ist (Vorrede, S. 5):

Das weitlaufigste und größte Werk des zärtlichen Ovid wird hier der Welt in einer deutschen Übersezung vor Augen gelegt. Man muß sich wundern, daß unsere Zeiten, die sich sonderlich der deutschen Poesie geneigt erzeigen, eines Dichters von so feinem Geschmacke entbehren koennen.

Sedlezki ist es um die Integration des Autors in den deutschen Sprach- und Gedankenraum zu tun, er will den Autor zum Leser holen, während der Übersetzer zum Autor kam (Vorrede o. p.):

So wie ich durch seinen Umgang, so zu reden, lateinischer geworden, so wurde er durch den meinigen ganz deutsch, und in dieser Tracht, die er mir doch gleichwohl zu danken hat, mag er nun hingehen und sein Glück suchen, wo er will. [...]

132 Bömer (1980), 109 ad loc.; Thes. ling. Lat. VII,2 s. v. lumen (1817): »veterum doctrinae: Avg. nat. bon. 41 p. 875,17 oculi sine aliquo -e -n videre non poterant, unde [...] -a nominantur. Isid. orig. $11,1,36$ oculi vocati, [...] quia occultum $-n$ habeant [...]; oculi autem idem et -a; et dicta -a, quod ex eis -n manat vel quod [...] clausam teneant lucem eqs. cf. Wilpert, RAC I 957 sqq.«; Maltby (1991), 351 s. v. lumen.

133 Meusel (1813), 5; Veith (1795), $162 \mathrm{f}$.

134 Vgl. Kitzbichler (2012b). 
Ich hätte meinen Dichter mit leichter Mühe in eben so viele oder auch wohl weniger deutsche Verse, als seine lateinischen sind, übersezen können. Aber er war mir allzulieb, als daß ich ihn hätte radbrechen und hier und da verstümmeln sollen [...] Seinen Sinn zu treffen, und einen leichten Wohlklang in den Versen zu beobachten, war meine erste Sorge. Meine zweite Sorge aber richtete ich darauf, um die Deutlichkeit, so viel in meinen Kräften stund, zu erreichen: welches insonderheit bey einigen kleinen Fabeln etwas schwer war, indem sich der Dichter daselbst oft gar zu kurz ausdrücket [...] und darüber dunckel wird.

Übersetzerisches Ziel ist in diesem Konzept, die Treue gegenüber dem Sinn über formale Äquivalenz zu stellen. Darin besteht auch die hier wie selten explizit gemachte Legitimation, sich in der deutschen Fassung vom Umfang des Originals zu emanzipieren. Ja die ursprüngliche Verszahl ist überhaupt nicht von Belang, so dass man problemlos in mehr, weniger oder auch gleich vielen Verse übersetzen kann. Damit nimmt er implizit, aber dezidiert Partei in einer alten querelle, die bis auf Hieronymus zurück reicht und die z. B. im 18. Jahrhundert in Frankreich mit den belles infidèles einen ähnlichen Ausdruck gefunden hatte. ${ }^{135}$ Das führt gleichzeitig zur prominenten Umsetzung

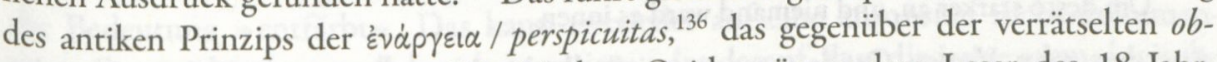
scuritas Vorrang haben muss: Die Mythen Ovids müssen dem Leser des 18. Jahrhunderts ohne weitere Studien verständlich sein. ${ }^{137}$

Wie dieses Konzept in der Praxis aussieht, zeigt schon seine Fassung des Proömiums:

Ich fühle einen Trieb von körperlichen Dingen,

Die sich in andere veränderten, zu singen.

Ihr, große Götter wißts, wie dieß geschehen sey.

Denn Ihr habt sie verkehrt. Drum steht mir jetzo bey,

Und laßt mich mein Gesang auf diese meine Zeiten

Vom Anbeginn der Welt ununterbrochen leiten!

Auffälligstes Resultat ist die Ausweitung der Verszahl: Aus den vier Hexametern des Originals werden sechs paarweise gereimte Verse im für das 18. Jahrhundert charakteristischen Metrum des sechshebigen Jambus, des Alexandriners. ${ }^{138}$ Er steht damit in der bis auf Albrecht von Halberstadt zurückreichenden Tradition einer unproblematischen Ausweitung des Textes bis in den Wortbestand hinein (»große Götter «, »jetzo «). Daraus resultiert offenbar auch die Füllformel $»[\ldots]$ wißts, wie dieß geschehen sey«, die keinerlei Gegenstück im lateinischen Text besitzt. Die temporale Abfolge prima $a b$ origine mundi - ad mea tempora ist invertiert und zum Hysteron proteron geworden. Allerdings war eine solche Vorstellung schon zu Sedlezkis Zeit beinahe obsolet - nicht

135 Kitzbichler (2007), 31 f.; Poiss et al. (in diesem Band), $\$ 8$.

136 Zur visuellen Dimension der Metamorphosen selbst siehe Fondermann (2008).

137 Vgl. Poiss et al. (in diesem Band), $\$ 10$., Nr. 13, über explikative Übersetzungen.

138 Vgl. auch Jaruslowski (1928), 42 f., über den Umgang der Aeneis-Übersetzer des 18. Jahrhunderts mit dem Umfang des Originals. 
nur im Allgemeinen, sondern konkret auch für Ovid, wie die Debattenbeiträge in den gelehrten Zeitschriften zeigen. ${ }^{139}$

Der aus dem Proömium gewonnene Befund hat auch für die narrativen Passagen Gültigkeit:

In einer stolzen Stadt, um die Semiramis

Den hohen Mauerbau von Ziegeln führen lies,

War Pyramus, dem sich ein Jüngling nie verglichen,

Und Thisbe, deren Reiz die schönsten Mädchen wichen,

Womit der Morgen prahlt. Dieß angenehme Paar

Ward bald genug bekannt, weil es benachbart war.

Durch Zeit und Umgang wuchs die Größe ihrer Flammen:

Der Eltern Eigensinn schien diese zu verdammen;

Dadurch die Hofnung denn, sich durch eine Eheband

Fest zu vereinigen, den Liebenden verschwand.

Allein, was half der Zwang. Er flammte ihre Sinnen

Um desto starker an, und niemand ward es innen.

Aus den zehn Versen Ovids werden bei Sedlezki abermals aus metrischen Gründen zwölf. Der systematische Zwang zum Reim bringt inhaltliche Umstellungen mit sich, teils auch syntaktische Verunklärungen. So ist der Anschluss von »womit der Morgen prahlt « unklar, auch die Bedeutung von oriens als geographische Bezeichnung (also eher »Morgenland « als »Morgen «) ist getrübt. Auch die Kausalverbindung, dass der Zwang die Liebe umso stärker entflammt habe, findet sich so nicht bei Ovid.

Daraus ergibt sich die dem Übersetzungskonzept inhärente Neigung zur paraphrasierenden Neudichtung, deren Resultat allerdings keineswegs ästhetisch zukunftsweisend ist, wenn man etwa an die Wirkung von Klopstocks Dichtungen in dieser Zeit denkt. Es scheint, dass Sedlezki gewollt Anschluss an einen als volkstümlich oder balladenartig empfundenen Sprachduktus sucht. In der Pygmalion-Passage zeigt Sedlezki keine Scheu, Ovid erotisch noch zu überbieten:

Kaum kame er nach haus, als er begierig ist,

Sein liebes Bild zu sehn. Indeme er es küßt,

Schien es ihr zimlich lau. Er lies es sich gelüsten

Und streckte gar die Hand nach den erhabnen Brüsten.

Das Helfenbein ward weich. Die starre Härte wich

Und gab den Fingern nach, wie bey der Sonne sich

Das Wachs erweichen läßt und allerley Gestalten,

In die man es gedrückt, sehr gern pflegt zu behalten.

Indem er stuzt, und sich darein nicht finden kann,

Rührt er es zwischen Furcht und Hofnung nochmals an.

139 Vgl. die anonmye Besprechung in der Allgemeinen deutschen Bibliothek 24 (1775) $83 \mathrm{f}$., zu Haymanns Versübersetzung des ersten Buches (1772): »Armer Ovid! Wie sind deine Verwandlungen von Händen des H. Haymann verwandelt worden, wie siehst du hier aus! [...] Gehe also wieder heim, woher du gekommen bist, zu deinem H. Haymann, giebt ihm das ganze Gottschedische mit allen den hie und da ausgesuchten Flitterchen und kritischen Blümchen verbraemte Kleid, das er in der Rüstkammer einer deutschen Gesellschaft zu einem andern Gebrauch aufhängen mag, samt den Schellen des Reims wieder zurück, und bitte ihn, dich künftig lieber in deiner Toga laufen zu lassen $[\ldots] \ll$. 


\begin{abstract}
Da wars ein rechter Leib. Er konnte schon das Spielen
Der Puls, die er berührt, mit seinem Daumen fühlen.

Da sagt Pygmalion von seines Herzensgrund

Der Göttinn Dank davor und heftet seinen Mund

Erst auf den ihren fest, der nunmehr klar empfunde

Und den gegebnen Kuß jungfräulich klug verstunde.

Sie schlägt die Augen auf, entfärbt sich und erblickt

Den Himmel und zugleich den Mann, der sie beglückt.

Die Göttinn segnete dieß Band, das sie gebunden.
\end{abstract}

Bezeichnend ist der Anfang des Textausschnitts. Sedlezki reimt »gelüsten « auf »Brüsten $\ll^{140}$ und übertrifft nicht nur damit Ovid noch, sondern auch durch die Hinzufügung des Epithetons »erhaben «. Überhaupt ist Sedlezki - vielleicht auch aus dem Zwang heraus, das Versmaß füllen zu müssen - durchaus freigiebig im Umgang mit Fortlassungen und Ergänzungen: Hymettia bleibt ganz weg, auf der anderen Seite wird das Wachs mit »sehr gern« angereichert. Wie Schmidt hat auch Sedlezki für erubescit die Bedeutung »entfärbt«. Das kann entweder auf eine ansonsten nicht dokumentierte Querverbindung zu Schmidt verweisen oder darauf, dass die irrige etymologische Ableitung im 18. Jahrhundert implizit weiter verbreitet war.

Sedlezki lässt das Wortspiel lumina lumen ganz unberücksichtigt. Sein Geheimnis wird es darüber hinaus bleiben, wie man einen $\mathrm{Kuß} \gg$ jungfräulich klug « verstehen kann. Bei Ovid ist das Gegenteil gemeint, nämlich dass die Geliebte erst allmählich gewahr wird, was geschieht und erst ganz am Ende, wenn sie Himmel und Mann sieht, das Geschehene begreift.

\title{
2.2.3 Johann Samuel Safft (gest. 1772) $)^{141}$
}

Johann Samuel Saffts Ausgabe stammt aus dem Jahr 1766 (Safft war seit 1763 Prediger in Marienfelde und Mariendorf bei Berlin, zuvor seit 1755 Subrektor am Köllnischen Gymnasium in Berlin, ${ }^{142}$ so dass es sich womöglich um ein spätes Parergon seiner schulischen Tätigkeit handelt). Erschienen ist sie bei August Mylius, einem für das Berliner literarische Leben im 18. Jahrhundert nicht unbedeutenden Verleger (der u. a. auch Goethes Skandalstück Stella mit großem kommerziellem Erfolg herausbrachte - er wird uns später bei August Rode noch einmal begegnen). So wenig Safft über seine Metamorphosen-Übersetzung hinaus publizistisch tätig geworden ist, eignet sich sein Verdeutschungsversuch dennoch zu einem - knapp zu haltenden - Einblick in die im 18. Jahrhundert gegebenen Rahmenbedingungen.

140 Reime wie »erblickt « / »beglückt « sind nicht anstößig, vgl. Opitz (1690), 51 .

141 Meusel (1812), $12 \mathrm{f}$.

142 Vgl. die Angaben in: Die Kirchenbücher der vor 1874 aufgenommenen und konzessionierten Kirchengemeinschaften im Bezirke der General-Superintendentur Berlin, Berlin 1905, 174 (online: http://wikide.genealogy.net/w/index.php?title=Datei:Berlin_Kirchenbuecher_1905.djvu\&page=181); Klöden/ Schmidt 1825,22 u. 26-28. 
In seiner Vorrede gibt Safft zunächst eine allgemeine Einführung in das Wesen der antiken Mythologie. Das zeigt die schulische Provenienz seiner Bemühungen an, wurden doch die Metamorphosen (und werden es bis heute noch) als mythologische Propädeutik genutzt. Ovid habe die bei älteren Dichtern vorhandenen Sagen gesammelt und in ein einheitliches Gewand gekleidet (22f.). Dann kommt er auf das Zielpublikum zu sprechen, nämlich die Künstler (s. o.), ${ }^{143}$ die Stoffe für ihre Werke bisher nur aus den vorliegenden französischen Übersetzungen gewinnen konnten: $\gg[\ldots]$ dem deutschen Künstler, den Ovid dergestalt in die Hände zu geben, daß er seinen Geschmack darnach bilden oder verbessern oder beurtheilen könne, ist der Hauptzweck bey gegenwärtiger Uebersetzung gewesen « (25). Aber auch ein allgemeineres Publikum hat Safft im Blick, nämlich die Frauen und die Dilettanten:

Sollte nicht der Ovid (ich verstehe die Verwandlungen) die Hände einer Schöne eben so gut zieren, und ihren Geschmack bilden können, als ein anderer heutiger Dichter? Sollte ein Liebhaber der eigenthümlichen Sprache des Römers, sich nicht die Erlernung derselben, und sonderlich das Lesen der Urschrift dadurch erleichtern können?

Damit soll Ovid Teil der deutschen Literatur werden, wodurch ein ähnliches Ziel deutlich wird wie zuvor bei Sedlezki. Wie viele seiner Zeitgenossen und Vorgänger gibt Safft nicht zu erkennen, ob er die früheren Ovid-Übersetzungen kennt. Doch im Unterschied zu diesem wählt Safft die Umsetzung in Prosa, offenbar die erste durchgängige Prosaversion der Metamorphosen überhaupt.

Safft versteht - was traditionsgeschichtlich keineswegs selbstverständlich ist - das Proömium als Teil der zu übersetzenden Metamorphosen:

Ich habe mir vorgesetzet, die in so viele neue Gestalten verwandelten Körper zu besingen. Beglücket, o ihr Götter! mein Vorhaben, (denn eben ihr seyd es, welche dieselben verwandelt habet) und führet mein Lied, vom Anfange der Welt, bis auf jetzige Zeiten.

Die Prosa zwingt zu deutlich weniger sprachlichen Anstrengungen als die metrische Form. Das konventionelle Verständnis der Verse ist gewahrt und liegt auf dem bereits skizzierten Niveau des zeitgenössischen Wissens. Erneut ist perpetuum nicht berücksichtigt, Ovids ad mea tempora ist gewissermaßen entindividualisiert und durch den allgemeinen Verweis auf die Gegenwart ersetzt. Wie bis heute üblich, wird das DichterIch an den Anfang gesetzt und damit animus substituiert, wobei in nova aus der betonten Anfangsstellung verdrängt wird.

Die Sage von Pyramus und Thisbe beginnt Safft mit großer Ausführlichkeit:

Pyramus, der schönste Jüngling im ganzen Orient und Thisbe, welche allen ihres gleichen, den Vorzug streitig machte, wohneten in jener prächtigen Stadt, welche Semiramis, wie man sagt, in hohe Mauren einschloß und ihre Häuser gränzten aneinander. Diese Nachbarschaft legte den ersten Grund zu einer Bekanntschaft; welche sich mit der Zeit in Liebe verwandelte, und sie würden sich auch durch das Recht der Hochzeitfackel, mit einander verbunden haben: wofern der Väter Eigensinn nicht verbothen haette, was sie doch nicht verbiethen konnten. Ihre beyderseitigen Gemüther brannten indes von einer Flamme; kein Mensch aber wußte um ihre Liebe.

143 Vgl. generell Kitzbichler (2008). 
An dieser Passage zeigt sich, wie Safft noch mit dem Medium der Prosa nicht wirklich über die Experimentierphase hinaus gelangt ist. Misstrauisch gegenüber der prosaischen Nüchternheit greift er zu aufgefüllten Formen wie » wohneten $\ll,{ }_{1}^{144}$ die später Voß als sogar für den deutschen Hexameter ungeeignet geißeln wird (vgl. unten S. 176). Überhaupt wirkt sein Zugriff deutlich bemüht. Er zieht die Namen weit auseinander, ersetzt puella durch »ihres gleichen « und kehrt vor allem Ovids Reihenfolge » aneinander grenzende Häuser « - »Babylon « um. Das tut er, um den anaphorischen Bezug in »diese Nachbarschaft « zu ermöglichen, während bei Ovid nach dem geographischen setting die Beziehung der beiden Protagonisten mit syntaktischem und inhaltlichem Neueinsatz erörtert wird. Dass »von einer Flamme « tatsächlich »von einer einzigen « meint, wird mangels prosodischer Unterstüzung nicht deutlich.

Wie schwer sich die Prosa des 18. Jahrhunderts (und nicht nur sie) mit dem Register emotionaler Exaltation tut, zeigt exemplarisch die von Safft gefundene Lösung, die ein grundlegendes Misstrauen gegen emotionales Aufwallen verrät, das aber verbunden ist mit explikativer Auxesis:

[...] wie er aber auch die mit Blut gefärbte Kleidung antrift, so spricht er: »Eine einzige Nacht wird zwey Verliebte unglücklich machen; doch mit dem Unterschiede, daß die eine ewig zu leben, der andere aber den Tod verdienet hat. Ach! unglückliche Thisbe! ich bin derjenige, so dich erwürget hat; weil ich dich bey der Nacht, an einen so fürchterlichen Ort habe kommen lassen, und nicht zuerst hieher gekommen bin. O! zerreisset doch diesen Körper, und verzehret die boshaften Eingeweide desselben, mit langsamen ${ }^{145}$ Bissen, ihr Löwen, die ihr in diesen Hölen und Steinklüften wohnet! Allein, Zaghaften gebühret es nur den Tod zu wünschen, den sie selbst in Händen haben. « Zugleich hebt er den Schleyer der Thisbe auf, nimmt ihn mit sich unter den Schatten des besagten Baumes; und nachdem er ihn vielmals geküsset, spricht er: »So empfange denn nun auch die Tropfen von unserem Blute.« Indem er solches spricht, durchbohret er zugleich seine Brust, mit dem an der Seite befindlichen Eisen; und als er dasselbe bald darauf sterbend aus der heißen Wunde, heraus ziehet: so sprützet das Blut, da er rücklings auf der Erde liegt, dergestalt in die Höhe, als wenn eine bleyerne Röhre zerreisset, und ein zarter Wasserstrahl, indem er aus den Ritzen mit zischen heraus sprützet, die Lüfte zertheilet. Die Früchte des Baumes nehmen sogleich, von dem Ansprützen des Blutes, eine schwarze Gestalt an, und die mit Blut befeuchtete Wurzel färbt die herabhängenden Maulbeeren, mit einer Farbe von Purpur.

Die deutsche Umsetzung ist von tiefem Misstrauen gegen Ovids Prägnanz geprägt. Das timidi est optare necem wird durch einen ganzen Relativsatz pedantisch erläutert, »doch mit dem Unterschiede« hat keine wirkliche Entsprechung im Lateinischen. Pyramus nocens anima (mit dem Doppelsinn von »schädlich « und »schuldig «) wird in »den Tod verdienet « aufgelöst etc. Dafür fällt notae lacrimas [...] vesti ersatzlos weg, ohne dass damit eine sachliche Notwendigkeit verbunden wäre. Die auf artifizielle Fülle angelegten Verbformen wie » verdienet « oder » wohnet « sind eher Manier denn aus dem Sprachstand begründet. ${ }^{146}$ Damit wird Saffts Übersetzung unabhängig von

144 Vgl. Poiss et al. (in diesem Band), $\$ 10$, Nr. 11.

145 sero [...] morsu findet sich (statt fero morsu) in einigen vormodernen Ausgaben, so in der anonymen Edition Nürnberg 1759, mit dem Kommentar ad loc., und in der Bipontina von 1783.

146 Im 17. Jahrhundert ist das noch problemlos möglich: z. B. Buchner (1663), 104. 
den bereits thematisierten sprachlichen Problemen auch zu einem Musterfall für die Grenzen einer Übersetzung in Schulmanns- und Predigerprosa.

Die bereits konstatierte Neigung Saffts zur Abundanz, zur Auffüllung von durch die ovidische Prägnanz offen gebliebenen Leerstellen ist auch in der Pygmalion-Sage zu verspüren, wie allein schon der Blick auf den Umfang der Passage bei Safft zeigt. So wird aus Ovids visa tepere est bei Safft »so däuchte es ihm, daß er einige Wärme an ihm bemerke « - aus drei Wörtern macht er elf, ohne dass ein inhaltlicher oder stilistischer Zugewinn damit verbunden wäre:

$\mathrm{Da}$ er nun nach seiner Wohnung zurückkehret: so eilet er gleich nach dem Bilde seines Mädchens. Und indem er sich über das Ruhbette neiget, und es küsset: so däuchte es ihm, daß er einige Wärme an ihm bemerke. Er küsset es also wiederum, und legt, um seiner Sache gewiß zu seyn, die Hand auf seine Brust, und siehe! er fühlet es, daß das Elfenbein weich zu werden anfängt. Es verlieret seine Härte allmählich, und lässet sich eindrücken, und weichet den Fingern aus, nicht anders, als ein hymettisches Wachs, das die Strahlen der Sonne biegsam machen, und wenn es durch ziehen und unter dem Druck der Finger, mancherley Gestalten annimmt, alsdenn erst anfängt nützlich und brauchbar zu werden. Pygmalion erstaunet anfänglich darüber, und freuet sich mit zittern; indem er sich vielleicht selbst $\mathrm{zu}$ betrügen besorgt ist. Er untersucht also den Gegenstand seiner Wünsche von neuem, und will von ihrer Erfüllung durchs Gefühl gewiß werden; allein seine Empfindung betrügt ihn keinesweges. Er fühlet wirklich einen natürlichen Körper, und die Adern schlagen unter seinen Fingern. Da fällt der Held von Paphos, für Freuden nieder, auf seine Kniee. Sein Mund bricht in lauter Danksagungen aus, gegen die Göttin und seine Dankbarkeit kann nicht Ausdrücke genug finden. Endlich versiegelt er ihre nunmehr wahrhaftige Lippen, mit einem zärtlichen Kuß. Die Jungfrau empfindet es und erröthet; und indem sie mit einiger Furchtsamkeit das Licht ihrer Augen, zu jenem himmlischen Lichte erhebt: so siehet sie zum erstenmal den Himmel und ihren Geliebten. Die Göttin, welche diese Ehe gestiftet hatte, begnadigte sie auch in der Folge, mit ihrer Gegenwart [...].

Um die Mitte des 18. Jahrhunderts hatte sich im Zeichen der Aufklärung das literarische Leben so sehr intensiviert, dass auch die Übersetzungen nun explizit in den literarischen Diskurs eingebunden waren, was zugleich zu einem verschärften Wettbewerb unter den Übersetzern führte. Das zeigt sich an der ausführlichen, anonymen Besprechung von Saffts Übersetzung in der Neuen Bibliothek der schönen Wissenschaften und freyen Künste. ${ }^{147}$ Der Rezensent scheint sich - so ist aus seiner Übersetzungprobe aus met. 13 (S. 267 f.) zu schließen - auch selbst an einer Ovid-Übersetzung versucht $\mathrm{zu}$ haben. Allerdings lässt sich eine tatsächliche Publikation nicht verifizieren. Er spricht damit jedenfalls als potentieller Mitbewerber. Ausgangspunkt der Rezension ist die Zweckbestimmung der Metamorphosen als künstlerisches Inventar. Dieses Lob der Nützlichkeit wird erweitert durch den Ovid attestierten Witz, eine Eigenschaft, die sich ex eventu unter den sich zum Ende des Jahrhunderts hin ändernden ästhetischen Paradigmen - siehe Lessings Verdikt über den » witzigen Hofmann « Vergil - rasch als zweischneidiges Lob erweiset. Ebensowenig uneingeschränkt poisitv ist die Aussage, 
dass durch Ovid Einblicke in die griechischen Originale gewährt werde. Bald las man zumindest deklaratorisch lieber gleich die Griechen:

Für den Künstler, dem zur Erfindung und zum Ausdruck in seinen Gemälden und Statuen die Mythologie bekannt sein muß, ist der fleißige Ovid das nächste und leichteste Handbuch. Seine Erzählungen sind nicht nur Materialien zur historischen Wissenschaft der Fabel; sein Witz, seine Erfindung, sein Ausdruck leiten selbst den Witz, die Erfindung, den Ausdruck des Künstlers, so sehr als es ein Dichter tun kann. Man setze zum Werthe der ovidischen Erzählung noch dieses hinzu, daß sie, nebst der glücklichsten Nachahmung, auch zugleich der vollständigste Auszug der griechischen Poesie ist.

Doch schon der Anfang der Auseinandersetzung mit dem vorliegenden Text verheißt nichts Gutes:

Wie sehr würden wir uns über die Erfüllung so sehnlicher, aber oft betrogener Wünsche erfreuen, wenn wir viele Übersetzungen griechischer und lateinischer Autoren ankündigen könnten, die wahrhafte und getreue Vorstellungen ihrer Originale wären, die den unphilologischen, aber doch nicht geschmack- und verstandlosen Liebhaber oder Beflissenen der schönen Künste, für seine Unwissenheit in der alten Literatur, schadlos halten, und es ihm begreiflich machen könnten, wie würdig diese Werke des Genies des Althertums der Lobsprüche sind, welche so viele Jahrhunderte hindurch, immer einer dem andern nachgesprochen hat, und welche jetzt von jedermann, als ausgemachte und eigene Erfahrungen (leider mit wie wenig Wahrheit!) nachgesprochen werden müssen. Wie stolz würden wir auf solche Übersetzungen sein!

\section{Und so kommt es bald ziemlich dick:}

Die Übersetzung haben wir mit dem lateinischen Text ${ }^{148}$ verglichen; aber auch ohne Vergleichung wird der Leser bey manchen Stellen anstoßen, die ihn auf die Richtigkeit der Übersetzung [...] mißtrauisch machen müssen.

Auch wenn der Rezensent nicht mit einem »Fehlerverzeichnis ermüden « will, so füllt er doch die nächsten 15 Seiten mit einer keineswegs vollständigen Auflistung - dafür nur ein Beispiel:

S. 10. Und keinem unerneuertem Acker mangelte es an schwangeren Ähren «

Nec renovatus ager gravidis canebat aristis.

Warum mußte der Üb. carebat für canebat lesen? - fast sollte man vermuthen, daß er die Construktion nicht verstand. Etiam ager non renovatus etc. das hieße wohl: Auch das Feld, welches niemand im Frühlinge bearbeitet hatte, war von vollen Ähren weiß.

Doch diese Kritik träfe nur ins Schwarze, wenn Safft nicht in der Tat einen anderen lateinischen Text als Vorlage gehabt hätte. ${ }^{149}$ Die Lesart carebat findet sich im 18. Jahrhundert in der Ausgabe von Walchius (1714) und auch in Werken allgemeineren Inhalts, so schon bei Gonet (1669), 523, und bei de Boyer (1743), 278. Demnach gibt es offenbar einen Zweig der Drucktradition der Metamorphosen, in dem Saffts Übersetzung (da ja kein lateinischer Text, der die Kontrolle ermöglichen würde, beigegeben

148 Welche Ausgabe der Rezensent verwendet (zu Safft siehe Anm. 149), darüber gibt er keine Auskunft.

149 Die Lesart carebat ist nicht in der editio maior von Magnus (1914) verzeichnet: ad 1,110: »canebat $t$ candebat $f . \ll$ 
ist) eine denkbare Lösung darstellt. Trotz solch teilweiser Rehabilitierung erweist sich Saffts verbose und umständliche Übersetzung als wenig zukunftstauglich. Das attestiert ihm auch sein Nachfolger, der allerdings ebenfalls stark angefeindete Johann Georg Karl Schlüter (1786), der in einem kurzen Überblick über die vorhandenen Ovid-Übersetzungen (s. u. S. 160) zu Sedlezki lakonisch »erbärmlich« anmerkt und sich zu Safft ausführlicher, aber keineswegs positiver äußert:

Saft hat den Ovid fast immer verstanden, und in so fern kann seine Übersezzung helfen, und hat mir auch in manchen Stellen geholfen. Das wäre denn auch ihr einziger Nuzzen: den guten Geschmack verdirbt sie ganz gewiss bei dem, der nun zuerst die Höhe ersteigen, und von den Alten das Edle Gute und Schöne lernen will. Weh ihm, wehe dem Künstler, wenn sie die Ursprache nicht verstehen, keinen Freund, keinen Lehrer haben, der sie auf bessere Wege leitet, und zu der lauteren Quelle führen kann. Ich habe sie genutzt, aber ich lege sie weg, und dicker Staub mag sie begraben. Die Noten sind so elend, als die Übersetzzung.

Unabhängig von diesen harten Urteilen ${ }^{150}$ gehört Saffts Übersetzung in einen Kontext, der Ovids Metamorphosen möglichst denjenigen Kreisen erschließen möchte, die von einer Lektüre besonders profitieren können, indem sie daraus entweder künstlerischen oder moralischen Nutzen ziehen können. Aus dieser im weiteren Sinne pädagogischen Absicht erklärt sich auch die Wahl der Prosa, da es eben nicht um Mimesis (das ist auch gar nicht Gegenstand des Übersetzungsdiskurses), sondern um die Vermittlung von Inhalten geht. Der verlegerische Erfolg (s. u. S. 163) gab diesem Projekt auch recht und belegt, welches Bedürfnis in dieser Zeit nach deutschen Fassungen der antiken Texte bestand. Während sich diese Übersetzungen aufs Ganze gesehen der Texttreue und Wörtlichkeit näherten, machten sie dadurch auch Platz für explizite Paraphrasen und Nacherzählungen, wie diejenige von Johann Gottlieb Lindner ${ }^{151}$ (zu dieser Zeit Lehrer in Langensalza) aus dem Jahr 1764, die ihre pädagogische Absicht im Titel trägt: Lehrreicher Zeitvertreib in Ovidianischen Verwandlungen. In einem ausführlichen Vorwort streift er zunächst kurz die künstlerische Verwendbarkeit, um dann detailreich die Eignung der ovidischen Mythenerzählung für die moralische Erbauung zu entwickeln und sie beinahe auf eine Ebene mit den Darstellungen der Bibel zu setzen. Das ist aber nicht unbedingt ein Rückfall in voraufgeklärte Allegorese, sondern eher eine Nivellierung der diversen literarischen Genres, die alle in den Metamorphosen zusammenkommen. Am Ende vergleicht er die Metamorphosen mit der sich in dieser Zeit entwickelnden Romanliteratur v. a. englischer Provenienz:

150 Vgl. auch Bremer (1781), 3: »Mit gegenwärtigen Verwandlungen aus dem Ovid fängt der Übersezer an, eine Idee auszuführen, die man hie und da angegeben hat: dieses Dichters Metamorphosen, denen Sedlezky und Safft übel mitgespielt haben, nicht ganz, sondern nach einer gewissen Auswahl zu verteutschen; und er hat dabei die Nebenabsicht, die groben Mißhandlungen, die dem Ovid von den erstgenannten Übersetzern wiederfahren sind, durch seine Verteutschung [...] einigermaßen wieder gut zu machen. «

151 Anemüller (1883); Horn (2001); siehe ausführlicher unten S. 185 f. 
Andere hingegen, mögen diese Verwandlungen ebenso lesen, wie etwan der Grandison, oder die Pamela ${ }^{152}$ gelesen wird, ohne daß man sich bekümmert, wer diese oder jene Person gewesen sey oder, wo dieses oder jenes Dorf lieget.

\subsection{4 $\gg$ Ferdinand ${ }^{* * *} \ll(1786)$}

Gegen Ende des 18. Jahrhunderts war die Zeit offenbar reif auch für MetamorphosenÜbersetzungen im Versmaß des Originals. Im Jahr 1786 erschienen gleich zwei solche Umsetzungen. Die erste hier behandelte ist augenscheinlich das Werk eines jungen Dilettanten, die mit $\gg$ Ferdinand ${ }^{* * *} \ll$ anonymisiert wurde. ${ }^{153}$ Sie zeigt noch deutliche Spuren des Tastenden und Experimentellen, auch fehlen sämtliche Beigaben wie ein Vorwort oder Erläuterungen, so dass die explizite Einbettung in den übersetzerischen Metadiskurs der Zeit ausbleibt. ${ }^{154}$

Ferdinand wählt einen eigenen Weg im Umgang mit dem Proömium. Wie für viele ältere Übersetzungen sind die vier Einleitungsverse auch für ihn kein integraler Teil des Textes, sie werden aber nicht ganz unterschlagen, sondern zum vorangestellten Motto umfunktionalisiert und damit als Paratext ausgeklammert.

Euren Beystand, ihr Götter, erfleh ich, wenn ich es wage,

ferner und naher Zeiten Verwandlungen würdig zu singen.

Trafen sie nicht auf euer Geheiß der Erden Bewohner?

Aus Ovids vier Hexametern sind drei deutsche geworden. Anders als im lateinischen Original stellt Ferdinand die Inspirationsbitte an den Anfang - eine Rekonventionalisierung von Ovids Verfahren -, dafür entfällt die Nennung des zeitlichen Rahmens mitsamt der göttlichen Verantwortlichkeit völlig, woraus sich auch die Kürzung ergibt. ${ }^{155}$

Wenn die Übersetzung tatsächlich ein Jugendwerk ist, dann müsste auch ein jugendliches Personal dem Verfasser besonders gelegen kommen.

Pyramus, unter den Jünglingen so der Schönste, als Thisbe, unter den blühenden Töchtern des Morgenlandes, bewohnten

152 Sir Charles Grandison und Pamela oder die belohnte Tugend (Pamela, or Virtue Rewarded): zwei auch in Deutschland überaus erfolgreiche Briefromane von Samuel Richardson (1740/1753).

153 Als »Schulz « aufgelöst schon bei Schweiger (1834), 669 (und seither in den Bibliothekskatalogen). Siehe auch Schmidt/Voight (1834), Nr. 138, 362 f. über Joh. Ernst Ferdinand Schulze (1765-1834): »Schon in seinem 20. Jahre übersetzte er >Ovids Verwandlungen<, was zu einem Briefwechsel mit dem Dichter Wieland führte, der ihm unter anderen schrieb: >Ich finde Ihre Übersetzung sehr gut und schön; Ihre Versification fast immer leicht, fließend, angenehm, dem Ohre schmeichelnd und den Gegenständen angemessen.«« - Solche anonymen Originalpublikationen (und auch Rezensionen, s. o. S. 154) sind im 18. Jahrhundert nicht selten, vgl. auch die kommentierte Ausgabe Nürnberg 1759. Schlüter (s. u. S. 163) bemüht sich offenbar erfolglos um die Identifizierung eines anonymen Rezensenten.

154 Zur moralisierenden Tendenz dieser Übersetzung, die deshalb auch anzügliche Passagen unmarkiert auslässt, vgl. Elit (2002), 150, Anm. 482.

155 Vgl. generell Poiss et al. (in diesem Band), $\$ 10$, Nr. 6. 
Einst Semiramis Stadt, und lernten als Nachbarn sich kennen.

Mit den Jahren erwuchs die Liebe: und eheliche Bande

sollten sie ewig verbinden. Doch trennten die grausamen Eltern

beide Liebende: aber umsonst! sie liebten noch immer,

schwuren sich ewige Treue, und doppelt glimmte die Flamme,

da sie verdekt war.

Die überschriftsartige Anfangsstellung von »Pyramus « ist beibehalten, dagegen ist die syntaktische Gleichstellung von »Thisbe « zugunsten eines Vergleiches aufgegeben verbunden mit dem Verzicht auf die Positionierung an zweiter Stelle. Auffällig sind vor allem zwei Phänomene, die beide auf metrischen Zwang, also die ungenügende Beherrschung des literarischen Handwerkszeugs zurückzuführen sind. Dadurch kommt es zur Einfügung von tatsächlich funktionslosen Füllwörtern ohne Gegenstück im Lateinischen wie »blühenden Töchtern « (bei Ovid nur sachlich puellis) oder »ewig«. Darüber hinaus ist es für den Übersetzer nicht möglich, den ovidischen Gedankengang mit seinen Sinneinschnitten in Einklang mit den metrischen Grenzen zu bringen, so dass es zu gehäuften Enjambements kommt, die auch die abschnittsweise Gliederung unklar machen. ${ }^{156}$ Das zeigt sich besonders deutlich im dritten Vers: Der Gedankengang über den Handlungsrahmen in Babylon ist deutlich kürzer als bei Ovid, so dass Ferdinand sogleich im selben Vers mit dem Kennenlernen fortfährt. Dadurch fällt aber die von Ovid durch die Versgrenze bewusst gesetzte gedankliche Zäsur zwischen Ort und Beginn der Handlung weg. In die bereits öfter beobachtete Kategorie der Rekonventionalisierung fallen Zusätze wie » ewig «, »grausam « oder » umsonst «: Ovids betont sachliche Einleitung wird auf diese Weise ihres die gesteigerte Emotionalität vorbereitenden Effektes beraubt.

Um nicht zu ermüden, kann hier die Behandlung der Dialogszene beiseite bleiben, da auch die Pygmalion-Passage hinreichenden Aufschluss gibt

Er kehrte zurük, und küßte sein Mädchen:

und o Wunder, schon schien sie zu athmen, schon wichen die zarten Glieder

dem Drucke, wie Wachs. In süssem Entzücken verlohren

staunte der liebende Jüngling der Göttin holdes Geschenk an;

bis ihm ihr pochender Busen sein Glük bezeugte: da küßt' er

wonnetrunken die Lippen der Schönen. Erröthend erwacht sie,

schlägt das Auge empor, und Venus knüpfet das frohe

Band der glüklichsten Ehe in ihrer ersten Umarmung.

Ferdinand normalisiert den Ovid weiterhin: Das Kunstwerk ist bei ihm gleich das Mädchen, das Resultat des Verwandlungsvorgangs ist vorweggenommen. Damit werden die nachfolgenden Schilderungen nur noch Erläuterungen des Geschehens, nicht Teil eines dramaturgischen Spannungsaufbaus. Dafür finden sich wieder Ergänzungen, die Ovids Text an die Lesererwartungen anpassen: »süssem Entzücken«, »liebende

156 Solche Enjambements prangert schon Birken (1697), 60 an: »Die Rede sol/mit dem Verse sich etlichermaßen schließen / und ja nicht ein oder zwei hinterstellige Wörter in die nächstfolgende bringen / noch sich mit einem oder zweyen im vorhergehenden anfangen [...].« Vgl. Jaruslowski (1928), $47 \mathrm{f}$. zu den Aeneis-Übersetzungen des 18. Jahrhunderts. 
Jüngling $\ll, ~ \gg$ wonnetrunken « etc. Wo Ovid den Leser zur steten Überprüfung und Anpassung des Entwurfes zwingt, der im Lektüreprozess vom Text entsteht, ist die Sache bei Ferdinand viel schneller entschieden und wird nur noch im Nachhinein redundant illustriert.

Die bisher behandelten Paraphrasen und Übersetzungen unterscheiden sich an dieser spezifischen Stelle vor allem spürbar im Umgang mit den sinnlichen Passagen, die von einigen Verfassern auffällig knapp und oberflächlich, gleichsam nur pflichtgemäß und der Vollständigkeit halber behandelt werden. Andererseits scheut sich etwa der Prediger Safft nicht, die Handlungen und Gefühle des Pygmalion, aber auch die Reaktion der zur Frau werdenden Statue ausführlich und auch mit deutlichem Vergnügen zu beschreiben. Diese Spannweite ist durchaus repräsentativ für den zeitgenössischen Umgang mit Ovid, wie die Verteidigungen und Verdammungsurteile über die Ars amatoria flankierend belegen. Allerdings wird man wohl nicht so weit gehen können, offensiven Umgang mit der Erotik der Metamorphosen mit den die Moralschranken angreifenden Bemühungen des Sturm und Drang in eins zu setzen. Denn die lateinischen Schulautoren gehörten zum Establishment, gegen das man anlief, das man sich nicht dienstbar machte. Wenn etwa im Werther antike Prätexte eine Rolle spielen, dann sind das Homer und allenfalls der ebenfalls unkanonische Catull. ${ }^{157}$ So nützen offenbar geistliche Schulmänner wie Safft vielmehr das erotische Potential der PygmalionErzählung, um geschützt durch den klassischen Ausgangstext literarisch-papierene Sinnlichkeit ausleben zu können.

\subsubsection{Johann Georg Karl Schlüter (1774-1798)}

Mit Schlüter treffen wir erstmals auf einen Übersetzer, der eine sukzessive Gesamtübersetzung Ovids anstrebte und damit offenbar einen systematischen Ansatz verfolgte. Entsprechend stellte er auch eine auf Vollständigkeit abzielende, nach Art einer bibliographie raisonée gestaltete Übersetzungsbibliographie zusammen. ${ }^{158}$ Offenbar

157 Schwindt (1996) und (1997).

158 Volständige Samlung aller Uebersezzungen der Griechen und Römer vom 16. Jahrbundert bis 1784, Frankfurt/Leipzig 1785. Vgl. Vorrede p. V: »[D]er Nutzen der Uebersetzungen ist groß. Man sage nicht, daß sie den Lernenden, den Jünglige [sic], der kaum mit den Grazien der Alten, oder dem Anfänger, der kaum mit griechischen und lateinischen Wörtern bekannt gworden ist, verführen, und unthätig machen, daß er nicht zur Quelle gehe und daselbst schöpfe. Der Jüngling nehme das Original und die Uebersetzug und lese, aber man lasse ihn nicht ohne Führer. Der Lehrer sage ihn $[s i c]$ wie er die Uebersetzung gebrauchen sollte, es versteht sich, daß der Lehrer ein heller Mann ist, und das Ding wird gut gehn.« Die Metamorphosen-Übersetzungen sind p. 192 aufgeführt und bewertet: Albrecht von Halberstadt, Wickram, Spreng, Schmidt, Lau (scil. Theodor Ludwig Lau, »de[r] monströse Uebersezer des Virgils « [1743], ohne Orts- und Jahresangabe: die Übersetzung ist nicht eruierbar), Peter Schenk, J. C. Schwarz (jeweils nur angekündigt), Sedlezky (»im höchsten Grade schlecht «), Lindner (ausführlich negativ besprochen), Saft (höchst negativ besprochen, vgl. oben), Schlüter 
konnte er neben den gelehrten Zeitschriften und Verlagsanzeigen die Bibliotheken ${ }^{159}$ an den verschienden Orten, an denen er als Lehrer wirkte, ${ }^{160}$ produktiv nützen. Schlüter neigt, wie sich schon an seiner Auseinandersetzung mit Safft zeigte, ${ }^{161} \mathrm{zu}$ harschen Urteilen, z. B.: $\gg$ Die beiläufigen Proben, die Herr Sella von seiner Kunst im Uebersetzen gegeben hat, sind uns hinlänglich Bürge, daß er den Ovid in den Grund verderben wird. $\ll^{162}$ Schlüter ist auch der erste mir bekannte Übersetzer, der versucht, aus Ovids lateinischen Hexametern äquivalente deutsche zu machen. ${ }^{163}$ Zwar fehlt noch die theoretische Untermauerung und Reflexion (stattdessen ist der Vorbericht teils polemisch gegenüber den Vorgängern, meist mit beinahe identischen Urteilen wie in der Vollständigen Sammlung, teils apologetisch über den Wert von Übersetzungen überhaupt), doch ist damit der Weg gewiesen für eine Modernisierung der OvidÜbersetzungen auf der Höhe der Zeit.

Schlüters hexametrische Fassung des Proömiums lautet folgendermaßen:

Von der Dinge Verwandlung in fremde Gestalten zu singen

Streb ich! ihr Götter! denn ihr, ihr habt sie verwandelt, begeistert

Mein Beginnen, und leitet vom ersten Werden der Welt an,

Mein fortdauerndes Lied bis auf meine Zeit herüber.

Schlüter geht mit der lateinischen Vorlage zunächst eher unbekümmert um. Aus den corpora werden $\gg$ Dinge «, nova wird enallagetisch zu forma gezogen und mit $\gg$ fremd « statt »neu « wiedergegeben (nichts in diesem Sinne bei Scheller/Lünnemann [1807]). Adspirate ist geradezu etymologisch wörtlich verwendet, wobei spiritus als »Geist « transparent zugrunde liegt. Dafür gestaltet er das syntaktische Enjambement zwischen Vers 2 und 3 nach und bemüht sich auch sonst im zweiten Teil um möglichste Textnähe und Angleichung an die Wortabfolge. Ein wenig störend wirkt dabei allenfalls das doppelte » mein « im vierten Vers.

Noch schwieriger ist die Bewältigung narrativer Strecken mit im Lateinischen wie im Deutschen gleicher Versfußzahl, wie bei Pyramus und Thisbe:

Pyramus war der Iünglinge Schönster, Thisbe die Fürstin

Unter den Mädchen, die der Orient zählte: sie hatten

Beide benachbarte Hütten, in jener Stadt, die mit hohen

Mauren von Bakstein Semiramis rings umzog. Die Bekanntschaft

Und die erste Liebe machte die Nachbarschaft. Täglich

(»komt Michaelis [1784] erst heraus «, tatsächlich erst 1786), außerdem verschiedene Teilübersetzungen.

159 Vgl. Schlüter (1786), XXXV.

160 Vgl. Meusel (1798), 179; Daten nach http://zs.thulb.uni-jena.de/receive/jportal_jparticle_00011641.

161 Siehe oben S. 156.

162 Schlüter (1785), 190.

163 Prinzipiell ist die Diskussion über die Möglichkeit, deutsche daktylische Verse zu schreiben, schon wesentlich älter und reicht bis in das 17. Jahrhundert zurück, auf Buchner (1663), 143-148; der Hexameter wurde durch Klopstocks Messias (s. u. S. 181) tatsächlich in der deutschen Literatur verbreitet. Etwa parallel zu Ovid finden sich auch Versuche hexametrischer Übersetzungen der Aeneis: Jarislowski (1928), $38 \mathrm{f}$. 
Aber wuchs die Lieb' und sie hätten sich feierlich verbunden,

Wenn nicht die Aeltern, was sie nicht konnten, hätten verboten.

Beide brannten gleich stark von gegenseitiger Liebe:

Keiner wußte darum, sie sprachen durch Zeichen und Winke,

Je mehr sie das Feuer verdekten, je heftiger brannt es.

Schlüter kämpft neben prosodischen deutschen Schwierigkeiten vor allem mit der Verteilung des Gedankenganges auf die Verse, die nicht kongruent zu der bei Ovid ist, wodurch die Zahl der Enjambements deutlich ansteigt, ohne dass die damit verbundenen Einschnitte inhaltliche Relevanz hätten. Auch punktuell sind einige Abweichungen vom Original ohne Funktionalität zu verzeichnen. Altam wird von Schlüter mit den Mauern, nicht mit der hoch aufragenden Stadt verbunden. Captis mentibus ist ausgelassen, das die Sentenz bezeichnende Passiv tegitur ist persönlich aufgelöst.

Dieser Befund gilt tendenziell auch für die Auffindungsszene:

$\mathrm{Da}$ er nun auch den Schleier fand mit Blute gefärbet,

Sprach er: so soll denn eine Nacht zwei Liebende tödten:

Sie war des längeren Lebens würdig, und ich bin an ihrem

Tode schuldig: ich habe dich Thränenwerthe getödtet;

Denn ich ließ dich an grauenvolle Oerter zur Nachtzeit

Kommen, und kam nicht zuerst! Ihr Löwen, die ihr bewohnet

Diese Hölen, zerreisset meinen Leib, und verzehret

Mein verruchtes Herz mit wüthenden Zähnen. Der Feige

Wünscht sich den Tod nur. Er erhob den Schleier der Thisbe, trug ihn unter den Schatten des Baumes, Küst' und benezte

Das ihm bekannte Gewand mit Thränen, und sprach: so empfange

Nun auch mein Blut, und da rant er das Schwert in die Brust sich,

Zog es dann sterbend aus der zischenden Wunde, zur Erde

Rükwärts stürzend. Hoch ergoss sich das Blut, wie aus einer

Aufgerissenen schadhaften Röhre von Blei, aus der kleinen

Zischenden Oefnung das Wasser heraussprizt, und hoch in die Luft steigt.

Von dem Besprizzen des Blutes wurden die Früchte des Baumes

Schwarz, und die Blut befeuchtete Wurzel färbte mit Purpur

Die am Baume hangenden Beeren.

Es kommt hier v. a. auch in der Wortstellung zu unidiomatischen Verwendungen (Ausklammerung des »sich « bei »rant das Schwert in die Brust sich «, noch dazu mit einem Monosyllabon am Versende), sinnstörenden Enjambements (»zur Erde/rükwärts «) etc.

Mit der Hinwendung zum Hexameter verbindet sich von vornherein eine stärkere Angleichung des Umfangs von Original und Übersetzung, was gerade gegenüber paraphrasierenden Umsetzungen deutlich spürbare Folgen hat. Dafür ergeben sich neue prosodische Probleme $e^{164}$ und auch die Notwendigkeit, das Verhältnis von Form und Inhalt in der Verteilung auf die Verse neu auszuhandeln. Eine typische Folge der Inkongruenz zwischen dem Deutschen und dem Lateinischen ist das gesteigerte Auftreten von Enjambements ohne Rücksicht auf syntaktische oder sinnhafte Einheiten.

164 Dazu mehr bei Voß, s. u. S. $175 \mathrm{f}$. 
Dies ist etwa bei den Versen $112 \mathrm{f}$. und 114f. gegeben, wobei in letzterem Fall die gnomische Aussage des Pyramus, die seine Entscheidung zum Selbstmord begleitet, in ihrer Signifikanz gestört ist. Eine weitere Konsequenz des noch wenig erprobten Umgangs mit solchen Versifikationen sind inhaltliche Diskrepanzen: So füllt das Wasserrohrgleichnis gut einen Vers weniger als im Lateinischen und beginnt noch dazu mitten im Vers.

Bei Ovids Pygmalion-Sage ließe sich vermuten, das Schlüters übersetzerisches Interesse auch an Ovids erotischen Elegien produktiv werden könnte. Allerdings gibt Schlüter in seiner Wiedergabe der Ars amatoria auch recht offen zu, dass ihm die Sprache des »verrufenen « Ovid manche Schwierigkeit bereitet hat: »Es ist wahr, sie (scil. die Bücher der Ars amatoria) enthalten hin und wieder Schlüpfrigkeiten, die das Ohr beleidigen und ein keusches Herz empören.« Daraus ergibt sich als Notwendigkeit: »[...] ich mußte Treue mit Sittsamkeit verbinden, und durfte weder der einen noch der anderen Tugend das geringste vergeben $\ll{ }^{165}$. Dieses Prinzip der Unanstößigkeit scheint auch für den Umgang mit der Pygmalion-Sage leitend gewesen zu sein:

Da er zurück kam, verlangt er das Bildnis seiner Geliebte,

Sezte sich auf das Bett', und küsst' es. Da schien es, als würd' es

Warm. Er küsst es von neuem, berührte die Brust mit den Händen,

Und vom Berühren wurde das Elfenbein weich, und die Härte

Schwand, und es wich und gab nach dem Eindruk der Finger, wie von der

Sonne hymettisches Wachs schmilzt, und von den Fingern gedrükket,

Viele Gestalten annimmt, und durch die Arbeit erst gut wird.

$\mathrm{Da}$ er noch staunt, und schüchtern sich freuet, getäuschet zu werden

Fürchtet, bald es kosst', und wieder durch Abziehn der Hände

Seine Wünsche verzögert, da ward es zu Fleisch, und die Adern

Schlugen vom Finger berührt. Da dachte Pygmalion wie er

Würdigen Dank der Venus darbrächt, er küsste mit seinem

Munde den würklichen Mund: das Mädchen empfand schon die Küsse

Und erröthete, hob empor die schüchternen Augen,

Und erblikte zugleich mit dem Lichte den Liebling. Die Göttin

War bei dem Bündnis, das sie gestiftet, zugegen [...].

Auch in dieser Passage wird deutlich, wie schwierig es tatsächlich ist, die lateinische Gedankenfolge mitsamt ihrer syntaktischen Gestalt in eine parallele deutsche Sprachgestalt zu überführen. Wieder fallen die zahlreichen Enjambements auf, die durch die Versgrenzen interne Sinngrenzen erhalten und die zur Besetzung der eigentlich betonten Versendposition durch blasse Wörter führt, etwa »wie von der « oder »mit seinem « (in beiden Fallen sind sehr enge syntaktische Verbindungen getrennt). Sodann: Ovids admovit os iterum wird simplifizierend zu »er küsst es von neuem «, wodurch die vorsichtige Annäherung Pygmalions verschleiert wird. In der isolierten Stellung von »es wich « bleibt unklar, dass das Wachs dem Druck der Finger nachgibt und nicht einfach verschwindet. Retractat bedeutet gewiss nicht »verzögert « und ist offenbar - unabhängig vom nicht gegebenen Sinn - mit retardat verwechselt (diese

165 Schlüter (1793), VI. Zum in der Übersetzungsgeschichte immer wieder auftauchenden Treue-Postulat vgl. Kitzbichler/Lubitz/Mindt (2009): Register. 
potentielle Lesart findet sich zumindest nicht bei Magnus [1914] im Apparat). Plenissima [...] concipit verba wird zum blassen »dachte «, dafür ist »würdig« als Attribut der Venus ohne lateinisches Gegenstück beigefügt. Diese Beispiele können verdeutlichen, dass der Übersetzer es nicht versteht, die Differenziertheit und durch exakte Kalkulation geprägte Dichtersprache Ovids ins Deutsche zu überführen, sondern dass er mit der Wahl des Hexameters einen notwendigerweise unbefriedigenden Kompromiss eingehen muss.

Schlüters Fassung fand auch schon bei seinen Zeitgenossen wenig Beifall, so in der mit $D z$. unterzeichneten Rezension der Allgemeinen Deutschen Bibliothek:

Dieß wäre in kurzer Zeit die zwote elende Übersetzung der Ovidischen Verwandlungen. Der arme Naso hat also für die Sünden seines üppigen und schwelgerischen Witzes noch nicht im Exil gelitten, er muss sie auch nach dem Tode unter den Händen seiner Übersetzer büßen.

Dieses Verdikt betrifft sowohl die »elend geschriebene « Vorrede als auch die eigentliche Übersetzung, in der der Rezensent wenig Lobenswertes findet, »desto mehr elende und holprige Versifikation, desto mehr matte und durchwässerte Stellen, desto mehr Fälle, wo der anspielende Witz oder das Bild untergegangen ist, desto mehr Worte ohne poetische Auswahl, desto mehr, entweder gar nicht, oder ganz falsch verstandene Stellen $\ll .{ }^{166}$

Da nützt es auch wenig, dass sich Schlüter in der Vorrede zur ebenfalls metrischen Übersetzung der Ars amatoria (Leipzig 1793) ${ }^{167}$ heftig wehrt:

[...] ob ich das geleistet habe, das wird der rechtschaffene Mann nur beurtheilen wollen und können, nicht aber ein, oder der ehrlose Recensent, in der Allg. Deutsch. Bibl. welcher sich als Recensent meiner metrischen Übersetzung der Verwandlung im 73. Bande mit D. Z. unterschrieben hat. Ein solcher ehrloser Mensch hat keine Stimme im Publiko, oder sie ist, wenn er sie erhebt, so widerlich als die Stimme eines gewissen Thiers im Thierreiche, welches sich durch diese Stimme eben so kenntlich macht, als durch sein paar lange Ohren.

$\mathrm{D}_{\mathrm{a}}$ Schlüters Metamorphosen-Übersetzung offenbar schnell in Vergessenheit geriet, lässt der Verfasser darüber seinem Unmut auch generell freien Lauf:

Vor einigen Jahren aber machte Herr Buchhändler Mylius mit großem Lärm und Getöse bekandt, daß ein wackerer Gelehrter in seinem Verlage ein Übersetung [sic] der Verwandlungen herausgeben würde, ${ }^{168}$ da man außer der ebenfalls in seinem Verlage vor ungefähr 20 Jahren erschienenen elenden? [sic] Saftschen Übersetzung, die nun vergriffen wäre, und wornach noch immer gefragt würde, keine neuere und brauchbare Uebersetzung der Verwandlungen hätte. So etwas vor dem ganzen Publiko zu behaupten, zeigt doch warlich von einer guten Dosi, Arroganz und Ignoranz.

166 Vgl. auch die anonyme Rezension in der Allgemeinen Literaturzeitung, 5. Bd. (1786), Leipzig 1788, 226-229: »Seine Arbeit ist nicht schlecht genug zu amüsieren, und nicht gut genug, zu gefallen.«

167 Außerdem: Mittel wider die Liebe (1796); Lieder der Liebe (1796), Ibis (1796), Fünf Trauerbücher (1798); sowie Petron (1796).

168 Gemeint ist die Prosaübersetzung von August Rode, s. u. S. $171 \mathrm{ff}$. 
Diese Äußerungen, gerade auch polemischer Art, zeigen, wie intensiv die Debatte im 18. Jahrhundert geführt wurde, wie schwer es aber auch war, tragfähige Kriterien zu benennen, die überhaupt für eine solche Übersetzung maßgeblich sein konnten.

\subsubsection{Parodien und Parodienhaftes}

Nicht aus der Tradition des deutschsprachigen Kulturraums, sondern aus französischhöfischem Milieu stammen die auch in Deutschland publizierten parodistischen Aneignungen der Metamorphosen. So wurden im späten 17. Jahrhundert die Metamorphosen von Isaac de Benserade, einem Mitglied der Académie française, in die modische französische poetische Form des Rundgedichts ( $\gg$ en rondeaux $\ll$ ) gegossen ${ }^{169}$ und damit möglichweise als Grundlage für ein Ballett verfügbar gemacht. Die hier genannte zweisprachige Ausgabe (Nürnberg $1689^{170}$ ), die Ovid in eine völlig andersartige Gedichtform überführt, macht diese Genealogie auch im Druck deutlich. ${ }^{171}$

Da diese Version auch in den Bibliotheken sehr selten ist (und erst jüngst digital zugänglich gemacht wurde), sei hier ein etwas ausführlicheres Zitat vorgestellt. Benserade nimmt in völliger Abkehr von der Tradition den Ausgang der Erzählung im Rahmen der Minyadenhandlung bei Semiramis (die bei Ovid nur als Gründerin von Babylon eine Funktion hat), betont ihre negativen, da von erotischen Trieben beherrschten Charakterseiten, rechtfertigt aber die Nennung durch den Hinweis auf die Autorität Ovids. Sodann setzt die Pyramus- und Thisbe-Erzählung (wie auch sonst bei Benserade) mit einem Holzstich ein (Thisbes Selbstmord mit Pyramus' Schwert unter dem Maulbeerbaum, flankiert von zwei Amoren), darauf folgt schon vorweg die $\mathrm{Zu}$ sammenfassung (zunächst auf französisch, was hier weggelassen ist, dann auf deutsch):

Pyramus und Thisbe hatten einander inniglich liebt / und ihre nah beysammen wohnende Eltern / so einander feind waren / wollten nicht zulassen / daß sie einander heurathen / ja gar nicht sehen solten. Als sie sich nun gleichwol auf einem gewissen Ort zusammen bestimmet; kam Thisbe zu erst / und ließ aus Furcht vor einem Lowen in der Flucht ihren Schleyr fallen / welchen der Löw blutig machte. Als Pyramus solchen ersahe / und sich drüber einbildete sie wäre vom Löwen gefressen worden / erstach er sich aus Verzweiflung: und that darauf desgleichen: und ihr Blut soll gemacht haben / daß der weise Maulbeerbaum / unter welchem sie zusammen kommen wollen / gefärbte Fruchte getragen.

Quid non sentit Amor?

169 Benserade (1689), beruhend auf Isaac de Benserade: Metamorphoses d'Ovide en rondeaux (Paris 1676); dazu Moog-Grünewald (1995).

170 Die an die Herzöge Rudolf August und Anton Ulrich von Braunschweig gerichtete Vorrede ist vom Verleger Johann Hoffmann unterzeichnet, der Urheber der deutschen Verse wird nicht genannt (auch der Name Benserade fällt nicht).

171 Vgl. auch Le Metamorfosi di Ovidio. Ridotte da Gio. Andrea dall' Anguillara in ottava rima, 2. Auflage, Venedig 1582. 
Damit ist der Leser genügend mit Wissen ausgestattet, um die gereimte Fassung genießen zu können: ${ }^{172}$

$$
\text { Pyramus und Thisbe. }
$$

Ein Liebes-Paar kam endlich überein

Sie wolten doch allein beysammen seyn:

Und war der Ort dazu auch schon benennt,

Die Thisbe lief / wie wenn ein feuer entbrennt /

Und kam zu erst voll Ungedult allein.

Der Pyramus erlidte gleiche Pein:

Da mengte sich der Unstern mitten drein.

Was thut nicht / und wird doch bald getrennet

Ein Liebes-Paar?

Es kommt ein Löw: die Thisbe flieht mit schreyn;

Ihr Schleyr fällt hin / das Thier bringt Bluth hinein.

Der Liebst erschrickt: ergreift sein Schwerdt und rennt

Selbst in den Tod. Als Thisbe ihn erkennet /

Folgt sie ihm nach. So irret insgemein

\section{Ein Liebes-Paar.}

Das Verhältnis von moralischer Deutung und ovidischem Inhalt ist hier anders als bei den Texten des 16. Jahrhunderts. Die Prosaparaphrase hat nur die Aufgabe der Inhaltsangabe, die Verse (die keine Übersetzung der französischen Fassung sind, sondern völlige Neudichtung - zwangsläufig angesichts des engen formalen Gewandes) mischen eine Variation des Inhalts (zugespitzt auf das erotische Verhältnis von Pyramus und Thisbe) und eine aufs Allgemeine zielende ethische Schlussfolgerung (»so irret insgemein $[\ldots] \ll)$ aus dem konkreten Geschehen. Dass der Verfasser offenbar den lateinischen Originaltext konsultiert hat, wird an der Aussage über die Eile der Thisbe deutlich, wo die Feuermetapher (quoque magis tegitur [...]) an einen etwas späteren Zeitpunkt der Handlung transponiert und von der Liebesleidenschaft auf das konkrete Verhalten der handelnden Personen übertragen ist.

172 Pyrame \& Tisbe.

A deux Amans parfaitement d'accord

L'Amour sembloit préparer un doux sort,

Du Rende-vous l'heure estoit déja prise,

Pour s'y trouver la jeune Fille éprise

S'impatiente, \& la premiere sort.

Le beau garçon suit le mesme transport,

Quand l'un pour l'autre ils se donnent la mort,

Quelle tragique, \& funeste surprise.

A deux Amans.

Un Lion vient, Tisbé s'ensuit d'abord,

Son voile tombe, \& soûtient tout l'effort,

Ce qui causa la saglante méprise.

Voilà comment l'erreur, \& la bestise

Entrent par tout, \& souvent sont grand tort.

A deux Amans. 
In der Pygmalion-Sage wird die Abkehr des Künstlers von den Frauen bereits in der Einleitung als Beleidigung der Venus dargestellt, die ihn mit der Liebe zu seinem eigenen Kunstwerk bestraft (das führt variiert zurück zur Vorstellung einer pervertierten Neigung, die Ovids Fassung zugrunde liegt). Doch seine Fähigkeit als Bildhauer hilft ihm, das steinerne Kunstwerk lebendig und so zu seiner Ehefrau werden zu lassen. Das betont (wie in späteren Deutungen der Pygmalion-Sage, ohne dass hier ein Kausalnexus bestünde) die Autonomie des Künstlers gegenüber der göttlichen Sphäre, während die Rundverse dann die Verzweiflung des Pygmalion sowie die erlösende Tat der Venus zum Thema haben. Sie enden:

Manch Weibes Bild läst sich so steinhafft finden.

Der ist verliebt / wer küßt was kalt und alt /

In einen Stein!

Mit diesem misogynischen Schluss fügt sich der deutsche Text dann doch wieder in die Auslegungstradition der Metamorphosen, die gegen die Tendenz des Textes bei Ovid genügend Anlass zum Frauentadel findet. ${ }^{173}$

Von den Rundgedichten führt der Weg weiter zu anderen Parodien, die sich vor allem im Umkreis des Wiener Hofdichters und Aufklärers Alois Blumauer finden. Dessen Aeneis-Travestie Bist du's, Aeneas? erreichte große Bekanntheit. Er wird in den 1790/91 publizierten anonymen Verwandelte[n] ovidische[n] Verwandlunge[n] ausdrücklich als Vorbild genannt (»ad modum Blumaueri«). ${ }^{174}$ Eventuell steht er sogar selbst hinter dem Pseudonym Amalgund Holzbirn ${ }^{175}$ einer weiteren MetamorphosenTravestie. Holzbirn verzichtet auf eine Adaption des Proömiums (oder was dafür stehen könnte) und setzt mit der Weltschöpfung ein: ${ }^{176}$

Als einst dem Zeus der Götter-Rath

Viel lange Weile machte,

173 Vgl. etwa Bersuire (1979) zu Pygmalion: »Sed procerto tandem accidit quod venus dea luxuriae id est carnis concupiscentia se interponit et ipsam imaginem mortuam convertit in vivam: et ipsam castam mulierem facit carnis stimulos sentire et eam mutat de bona in fatuam. (»Aber gewiss kommt es schließlich vor, dass Venus, die Göttin der Ausschweifung, das heißt der fleischlichen Begierde, sich einschaltet und selbst das tote Bild in ein lebendiges verwandelt. Und sie selbst lässt eine keusche Frau den Stachel des Fleisches spüren und verwandelt sie aus einer guten in eine Närrin.«)

174 Holzbirn (1790/1791). - Dazu die anonyme Rezension in der Neuen Bibliothek der schönen Wissenschaften und freyen Künste, Bd. 44 (1792), 105-108: »Leider nur zu sehr ad modum Blumaueri, und was noch schlimmer ist, ohne einen Funken von dem aechten Witz, um dessentwillen man jenem Dichter manche Unart verzeiht, die bei einem Versemacher, wie dieser Ungenannte, ganz unerträglich ist. « - Andere Beispiele sind: Verwandlungen, travestiert von Gottlieb Müller, 1-15. Buch in 12 Heften, Wien 1803-1807; Verwandlung, travestiert von Benedikt von Wagemann, 1. Bd. (1.-3. Buch), Frankfurt/Leipzig 1806.

175 Vgl. Weller (1856), s. v.: Aufgenommen in Blumauer (1840). - Weller (1864), 152: tatsächlich gedruckt bei Ferstl in Graz. - Zu den Vergil-Parodien Blumauers und deren Tradition siehe Kallendorf (2007), 196-200.

176 Holzbirn (1792), dazu die Oberdeutsche allgemeine Litteraturzeitung, 6. Jg. (Januar-Juni 1793): »Unter diesen Bedingungen sieht der Recens. dem zweyten und folgenden Bändchen mit Vergnügen entgegen, weil er sich davon wieder einige heilsame Erschütterungen seines Zwerchfelles, und ein paar recht heitere Stunden verspricht. « 
Und er an des Relati statt,

Ganz etwas anders dachte:

Da fiel ihm ein - aus nichts etwas

Zu machen - sey ein wahrer Spaß,

Und werth es zu probiren:

»Mich macht, sprach er, das einerley,

»In Wahrheit überdrüßig:

Auch zieh ich mir den Spleen herbei,

$\gg$ Geh ich so immer müssig;

»Parbleu: ich will nicht laenger ruh'n - -

$\gg$ Davor zum Zeitvertreib mir nun,

»Ein paar Schock Welten machen.«

Dem genre einer solchen Travestie entsprechend, bietet der Text nicht viel mehr als das äußere Handlungsgerüst (und nicht einmal das ist sakrosankt) und nimmt das zum Anlass (bzw. zum Vorwand), die Ernsthaftigkeit der Vorlage zu unterlaufen. In diesem Fall ist damit auch die Rückkehr zu klischeehaften Vorstellungen verbunden: Der Zeus Holzbirns ist offenbar das Gegenstück zum Schöpfergott der Genesis, nicht zum deus et melior natura (met. 1,21) Ovids, der die Entwicklung aus dem Chaos zum Kosmos ins Werk setzt. Von den mittelalterlichen und frühneuzeitlichen paraphrasierenden Umsetzungen unterscheiden sich Texte à la Holzbirn vor allem dadurch, dass sie nicht anstreben, Ovid in eine zeitgenössische Ästhetik umzusetzen, sondern ihn durch die Konfrontation mit zeitgenössischen ästhetischen und moralischen Maßstäben als veraltet erscheinen zu lassen. Die Herkunft dieser Bestrebungen aus dem französischen höfischen Ambiente ist ja auch noch in den deutschen Titeln und Untertiteln (» mit aecht französischer Freiheit «) erhalten, damit ist auch ihre produktive Phase mit dem Ende des Ancien Régime und dessen Spätformen beendet. ${ }^{177}$

Schon die Reaktion der Zeitgenossen auf diese Parodie war durchaus geteilt. ${ }^{178}$ Offenbar war mit dem zu Ende gehenden 18. Jahrhundert die Zeit für solche höfischen Scherze auch vorüber. Wegen der dezidiert nicht gegebenen Nähe zum Ovid-Text bleiben diese Formen im Folgenden außer Betracht. ${ }^{179}$

\subsubsection{Einstweilige Schlussfolgerungen}

Eine vorläufige Bilanz aus den Übersetzungen bis zum Ende des 18. Jahrhunderts zeigt: Sämtliche Übersetzer gehören nicht den wissenschaftlichen Eliten an. Sie sind zwar im Rahmen der jeweils zeitgeschichtlichen Möglichkeiten - gut gebildet, nehmen aber nicht an der wissenschaftlichen Debatte, an den Editionen und Kommentierungen, teil. Die Urheber dieser Übersetzungen sind (mit Ausnahme Schlüters) sonst nicht

177 Naiv ist Hannemann (2005), 198,95, über die Ovid-Adaptionen der romantischen Schriftstellerin Sophie Mereau, die Holzbirns Travestie für eine tatsächlich verwendbare Übersetzung hält.

178 Vgl. oben Anm. 174.

179 Vgl. Laird (2010), 1120 f., über Vergil-Parodien des 18. Jahrhunderts als Indiz für das sinkende Prestige dieses Dichters gegenüber Homer; außerdem auch Jarislowksi (1928), 9-14 und 19-25. 
weiter einschlägig hervorgetreten, trotz des Umfanges sind dies also dilettantische (verstanden im Sinne des 18. Jahrhunderts) Parerga. Bis ins 17. Jahrhundert hinein ist allerdings mit nur geringer sprachlicher Kompetenz der Verfasser zu rechnen, woraus sich notwendigerweise ergibt, dass man sich an vorhande Fassungen anschließt und diese fortschreibt. Dennoch überwiegt ihre Rolle als Vermittler der Textkenntnis an die Kreise, die die antiken Texte nicht oder nur schwer im Original lesen können.

Die formale Gestaltung entspricht jeweils den ästhetischen Prinzipien der Zeit. Noch die Übersetzungstheorie der Aufklärung forderte keineswegs die Angleichung an das fremdsprachliche Original, sondern sah entweder die Prosa oder eine zeitgenössische deutsche Metrik als die Mittel der Wahl an. Erst am Ende des 18. Jahrhunderts begann sich dies zu ändern; das Prinzip, nicht mehr den Autor zum Leser, sondern den Leser zum Autor zu bringen, die Form der deutschen Wiedergabe also klassisch zu gestalten, erschien am Horizont und sollte den übersetzerischen Diskurs der Folgezeit prägen. ${ }^{180}$

Die hohe Zahl von Metamorphosen-Übersetzungen bis zum Ende des 18. Jahrhunderts zeigt das Publikumsbedürfnis nach gemeinverständlichen Fassungen eines Basistextes für die Kenntnis der antiken Mythologie und deren künstlerische Umsetzungen. Mit dem Ende des 18. Jahrhunderts ändern sich nicht nur im Zeichen des Kults des Originalgenies die Rahmenbedingungen insgesamt, sondern durch veränderte ästhetische Paradigmen die Bedeutung der Metamorphosen-Kenntnis generell. Übrig bleibt die propädeutische Funktion als vermittelnde Anfangslektüre mit vermeintlich kindgemäßen, märchenhaften Inhalten. Dieser Paradigmenwechsel wird in nuce deutlich in Goethes Bericht über seine Begegnung mit Herder in Straßburg 1770:

[Herder] hatte mir den Spaß an so manchem, was ich früher geliebt, verdorben und mich besonders wegen der Freude, die ich an Ovids Metamorphosen gehabt, aufs strengste getadelt. Ich mochte meinen Liebling in Schutz nehmen wie ich wollte, ich mochte sagen, daß für eine jugendliche Phantasie nichts erfreulicher sein könne, als in jenen heitern und herrlichen Gegenden mit Göttern und Halbgöttern zu verweilen und ein Zeuge ihres Tuns und ihrer Leidenschaften zu sein [...]: das alles sollte nicht gelten, es sollte sich keine eigentliche unmittelbare Wahrheit in diesen Gedichten finden; hier sei weder Griechenland noch Italien, weder eine Urwelt noch eine gebildete, alles vielmehr sei Nachahmung des schon Dagewesenen und eine manierierte Darstellung, wie sie sich nur von einem Überkultivierten erwarten lasse. ${ }^{181}$

Die Schule sollte allerdings weiterhin ein Refugium, ja das Refugium für die Metamorphosen bleiben, die damit weiterhin Schüler der ersten lateinischen Lektürejahre in die antike Mythologie einführten.

Eine weitere wichtige Zielgruppe von Übersetzungen blieben auch über die Wende vom 18. zum 19. Jahrhundert hinaus die Frauen. Da ihnen üblicherweise eine altsprachliche Bildung verwehrt war, die aber zum intellektuellen Rüstzeug für alle die zählte, die im kulturellen Diskurs auf der Höhe der Zeit mithalten wollten, waren sie in besonderer Weise auf Übersetzungen angewiesen, sei es auf gedruckte, sei es auf ad hoc

$180 \mathrm{Zu}$ diesem Komplex ausführlich Kitzbichler (2009), 15-18.

181 Goethe, Dichtung und Wabrheit (MA Bd. 16, 1985), $444 \mathrm{f}$. 
erstellte. ${ }^{182}$ Gerade die Frauen aus gebildeten Ständen stellten auch ein zahlungskräftiges Publikum dar, ${ }^{183}$ was es nicht zuletzt für die Verleger reizvoll machte, diesen Markt zu bedienen.

\section{Die klassischen Metamorphosen-Übersetzungen der Goethezeit:} August Rode und Johann Heinrich Voß sowie Friedrich Gottlieb Klopstock

In die Goethezeit fällt eine tiefe Zäsur auch in der Geschichte der Übersetzungen. ${ }^{184}$ Mit den Unternehmungen von Voß für Homer, Humboldt für Aischylos und Schleiermacher für Platon wurde ein Niveau und Reflexionsgrad erricht, der Goethe zu einem höchst wohlwollenden Urteil veranlasste:

Was aber das Griechische, Lateinische, Italienische und Spanische betrifft, so können wir die vorzüglichsten Werke dieser Nationen in so guten deutschen Übersetzungen lesen, daß wir, ohne ganz besondere Zwecke nicht Ursache haben, auf die mühsame Erlernung dieser Sprachen viele Zeit zu verwenden. Es liegt in der deutschen Natur, alles Ausländische in seiner Art zu würdigen und sich fremder Eigenthümlichkeit zu bequemen. Dieses, und die große Fügsamkeit unserer Sprache macht denn die deutschen Übersetzungen durchaus treu und vollkommen. ( $\mathrm{Zu}$ Johann Peter Eckermann, 10. Januar 1835.)

Aus diesen Worten spricht die Vorstellung einer besonderen Eignung und Affinität des Deutschen für Übersetzungen. ${ }^{185}$ Während noch Humboldt ausdrücklich die deutsche Sprache durch die griechischen Texte übersetzend bereichern wollte, sieht Goethe nun die Sprachentwicklung zu einer solchen Reife gelangt, dass die Übersetzungen gegenüber den Originalen defizitlos sind. Das in der gesamten Übersetzungsdiskussion immer wiederkehrende Schlagwort von der »Treue « ist von Goethe mit der Hinwendung der Übersetzung zum Original (Schleiermachers »den Leser zum Autor bringen $\left.\ll^{186}\right)$ korreliert. Damit können die Übersetzungen jetzt tatsächlich die Rolle einnehmen, die sie außerhalb der Kreise der wirklich zur altsprachlichen Lektüre Befähigten immer schon hatten, nämlich für die Originale stehen. ${ }^{187}$

Die Wende zum 19. Jahrhundert ist aber auch charakterisiert durch den dramatischen Prestigeverlust der lateinischen Literatur gegenüber der griechischen im Zeichen von Klassizismus und Kult des Originalgenies. Das Lateinische erhielt selbst im Gymnasialunterricht programmatisch nur noch propädeutische und substitutive Funk-

182 Siehe Müller (2012), 44-73, bes. 55-57, wo über die Bitten Elisa von der Reckes an ihren Bruder berichtet wird, ihr doch »Uebersetzungen aus dem Vergil und Ovid [...] zu machen «.

183 Vgl. Müller (2012), 58,469, über die Subskribentinnen der Erstauflage von Voß' Odyssee-Übersetzung (1781).

184 Vgl. Kitzbichler (2009) bes. 15-28 (»Übersetzungstheoretischer Paradigmenwechsel um 1800«); zur Vorgeschichte vgl. Elit (2002), 113-160.

185 Kitzbichler (2009),

186 Kitzbichler (2009).

187 Vgl. zu dieser auch in der Bedeutung von Antikenrepliken und -kopien ablesbaren Tendenz in dieser Epoche prinzipell Bartsch et al. (2010). 
tion, mochten auch die tatsächlichen Unterrichtsstunden dauerhaft über denen des Griechischen liegen. ${ }^{188}$ Die intensive übersetzungstheoretische Debatte der Goethezeit fand damit fast zwangsläufig so gut wie vollkommen ohne Berücksichtigung des Lateinischen statt. Voß' Homer war ein öffentlich heiß diskutiertes Ereignis, ${ }^{189}$ sein Vergil und sein Ovid nicht. Schleiermacher und Humboldt arbeiteten sich am Verhältnis des Deutschen zum Griechischen ab, ${ }^{190}$ lateinische Texte zogen sie als Stoff ihrer Bemühungen nicht einmal in Betracht.

Und wenn lateinische Texte ins Blickfeld kamen und ein größeres Interesse beanspruchen konnten, dann waren das nicht die Dichtungen Ovids, sondern Vergils. ${ }^{191}$ Um dessen Aeneis lieferten sich Friedrich Schiller und Gottfried August Bürger einen übersetzerischen Wettstreit, ${ }^{192}$ der vor allem das 2 . und 4. Buch, das von je her beliebte Dido-Buch, betraf. ${ }^{193}$ Auch dabei ging es in erster Linie um die in diesen Jahrzehnten im Mittelpunkt der Übersetzungsdikussion stehende Metrik: Bürgers deutsche Hexameter ${ }^{194}$ gegen Schillers den aktuellen Vorlieben entsprechenden Stanzen. ${ }^{195}$ Vergils

188 Vgl. Fuhrmann (1999), bes. 55-68; Leonhardt (2009), 260-274; außerdem noch immer Paulsen (1885), hier v. a. 518-530; Baumbach (2002), 118, der für die preußischen Gymnasien eine Gesamtstundenzahl 76 (Latein) vs. 50 (Griechisch) nennt.

189 Vgl. August Wilhelm Schlegel, Rezension zu: Homers Werk, von Johann Heinrich Voss (1796), in: Kitzbichler/Lubitz/Mindt (2009a), 3-38; Kitzbichler (2012a) mit weiterer Literatur; Müller (2012), 57-61.

190 Vgl. auch Boeckh (1886) (in: Kitzbichler/Lubitz/Mindt [2009a], 201), der unter den »hervorragend $[e n]$ Leistungen « der Übersetzungskunst im 19. Jahrhundert nur solche aus dem Griechischen anführt.

191 Siehe auch Wilke/Suerbaum (2013) mit Streiflichtern zu Aeneis-Übersetzungen und -Illustrationen im 17. Jahrhundert.

192 Gottfried August Bürger und Friedrich Schiller hatten einander 1789 in Weimar kennengelernt und beschlossen, ihre poetischen Fähigkeiten an der Aeneis zu erproben. Dazu gibt es eine Vorgeschichte: Bürger hatte in seiner Abhandlung Bürger an einen Freund über eine teutsche Ilias vehement seinen Versuch einer jambischen Wiedergabe des Homer gegen den Hexameter verteidigt, da ihm dieser als ungeeignet erschien. Umso mehr musste es überraschen, dass er nun für die Aeneis just dieses inkriminierte Versmaß wählte. Deshalb sah er sich zu einer Rechtfertigung gezwungen (in der fiktiven dritten Person): »Ausser einer homerischen Übersetzung aber, meinte mein Mann, müßte man den deutschen Hexameter keineswegs verwerfen, wie er denn auch eine gänzliche Verwerfung in Bürgers Abhandlung nicht fand. So könnte, zum Beispiel, der deutsche Hexameter es ganz gut mit dem lateinischen aufnehmen, und wäre eine hexametrische Verdeutschung der Aeneis möglich, die sich allenfalls getrost neben ihr Original hinstellen könnte. « Bürger (1777), 243.

193 Vgl. prinzipiell Kleßmann (2009) (v. a. mit Blick auf die Übersetzungsgeschichte einzelner Passagen, aber ohne Forschungsliteratur). Hilfreich ist noch immer die Materialsammlung von Jarislowski (1928); außerdem Auhagen (2010); Binder (1950); Dettmer (1899); Müller (1970); Neuhöffer (1893); siehe weiter Laage (1961).

194 Aeneis 4,1-5: $\gg 1$. Aber die Königinn, längst zerrissen von innigem Aufruhr,

Blutet' an Wunden des Herzens und kocht' in heimlicher Flamme.

Immer rauschte der Ruhm des Helden, und immer der Adel

Seines Geschlechts ihr noch dem Seelenauge vorüber.

Tief im Busen und fest behafteten Wort und Geberde.« (Bürger, Dido [1777], 244).

195 Aeneis 4,1-5: »Längst aber krank vom Pfeil des Liebesgottes nährt

die Königin ein Feu'r, das heimlich sie verzehrt

mit immer wachsender Begier umranken 
Georgica erregten Aufmerksamkeit, als sich Johann Heinrich Voß (s. u.) ihrer annahm und das lateinische Gedicht vom Landbau zu einer Parallele zur eigenen durchaus erfolgreichen Idyllendichtung werden ließ.

Dennoch hatte auch die lateinische Literatur und darin die Metamorphosen impliziten Anteil an diesem Wandel und Fortschritt, dessen Resultate in Goethes zitierten Äußerungen festgehalten sind. Mit der Prosafassung durch August (von) Rode (1791) und der hexametrischen Umsetzung durch Johann Heinrich Voß (1798) ${ }^{196}$ erschienen zwei bis heute Maßstäbe setzende Übersetzungen, die gewissermaßen das Ende der Vorgeschichte der Ovid-Übersetzungen markieren.

\subsection{August von Rode ${ }^{197}$ (1751-1837) und Johann Heinrich Voß (1751-1826)}

August Rode gehört in das kulturelle und politische Umfeld des Dessauer Hofes. Die bedeutendeste dort vollbrachte kulturelle Leistung war die Schaffung des DessauWörlitzer Gartenreichs, an dessen programmatischer Konzeption Rode beteiligt war. ${ }^{198}$ Von besonderer übersetzungsgeschichtlicher Bedeutung ist seine in diesem Kontext entstandene, schon von den Zeitgenossen eifrig rezipierte Übersetzung der Metamorphosen des Apuleius, ${ }^{199}$ die mit dem mythologischen Programm des Parks korrespondierte. Er machte sich darüber hinaus durch seinen deutschen Vitruv und auch eine übersetzerische Anthologie verschiedener lateinischer Gedichte einen Namen. Diese Philosophische [n] und andere[n] Gedichte aus dem Lateinischen des Lukrez, Horaz, Catull, Virgil, Ovid, Lukan (Hamburg 1785) tragen den Untertitel »in der Versart der Originale verdeutscht « und enthalten aus den Metamorphosen die NiobeSage (met. 6,155-313). ${ }^{200}$ In der zugehörigen »Vorerinnerung « stellt Rode eine explizite Verbindung zur bildenden Kunst her:

Die Fabel der Niobe ist für die Liebhaber der Kunst höchst interessant wegen eines der schönsten Werke der Bildhauerei aus dem Alterthum, welches die Niobe mit ihren Kindern

des theuren Gastes Bild die trunknen Gedanken, des Volkes Glanz, des Führers Heldenmut.

Sein Anblick, seine Worte brannten tief in ihr Herz, noch nie gefühlte Kämpfe bannten den süßen Schlaf aus dem empörten Blut. « (Schiller, Dido [1791], 304).

196 Hierzu nunmehr die Beiträge in Baillot/Fantino/Kitzbichler (2014).

197 Vgl. Hosäus (1889); Niedermeier (2007), bes. 275-278; Pfeiffer (2002) sowie Stephan (in diesem Band). Rode wurde 1803 geadelt.

198 Vgl. Rode (1798).

199 Dazu Stephan (in diesem Band).

200 Siehe die Erläuterungen bei Rosati (2009), ad loc; ; außerdem Feldherr (2004/2005) (auch mit Blick auf die ekphrastische Struktur der Erzählung und damit auf das bildliche Potential). 
vorstellt und sich zu Rom in der Villa Medicis ${ }^{201}$ befindet. Winckelmann nennt diese Niobe mit ihren Töchter die höchsten Ideen der Schönheit [...]. ${ }^{202}$

Rode sucht also sehr deutlich den Anschluss an den Klassikdiskurs seiner Zeit, allerdings mit einem gerade dem klassizistischen Verdikt anheim fallenden Dichter. Der Rekurs auf Winckelmann bettet sich in den kulturellen main stream ein, bekommt aber dadurch eine besondere Bedeutung, dass der Fürst Franz von Dessau mit Winckelmann durch Italien gereist war. ${ }^{203}$ Rodes eigentlicher Text beginnt folgendermaßen (met. 6,155-161): $:^{204}$

\section{Die beglükteste Mutter}

Priese man izt Niobe, wofern sie nicht Dünkel bethöret.

Tiresias Erzeugte, die Zukunftskundige Manto

Hatte, durch göttlichen Antrieb erregt, in Mitte der Gassen

Thebens geweissagt: »Auf, Ismeniden, erhebt euch in Menge,

Bringt Latonen, bringt Latonens unsterblichen Kindern

Weihrauch, betet sie an, und umkränzet die Haare mit Lorbeer [...].«

Die Kursivierungen verweisen auf die Realienerläuterungen den Anmerkungen Rodes, so dass der Text grundlegend didaktisiert erscheint. ${ }^{205}$ Die Übersetzung selbst bemüht sich um die Beibehaltung des Verhältnisses von Sinn und Vers, des Satzduktus und auch des Wortmaterials, bisweilen um den Preis der Verständlichkeit, so in »Tiresias Erzeugte «, worin der dem lateinischen Ablativ entsprechende deutsche Genitiv nur mit

201 Seit 1780 in Florenz, in den Uffizien: Rode weiß von dieser Veränderung offenbar nichts. Vgl. generell Geominy (1984); zur Rezeptionsgeschichte in der Goethezeit siehe Dönike (2005),184-210.

$202 \gg$ Die Niobe und ihre Töchter sind als ungezweifelte Werke dieses hohen Stils anzusehen, aber eins von den Kennzeichen derselben ist nicht derjenige Schein von Härte, welche in der Pallas eine Muthmaßung zur Bestimmung derselben giebt, sondern es sind die vornehmsten Eigenschaften zu Andeutung dieses Stils, der gleichsam unerschaffene Begriff der Schönheit, vornemlich aber die hohe Einfalt, sowohl in der Bildung der Köpfe, als in der ganzen Zeichnung, in der Kleidung und in der Ausarbeitung. Dieses Schönheit ist wie eine nicht durch Hülfe der Sinne empfangene Idea, welche in einem hohen Verstand, und in einer glücklichen Einbildung, wenn sie sich anschauend nahe bis zur göttlichen Schönheit erheben könnte, erzeuget würde; in einer so großen Einheit der Form und des Umrisses, daß sie nicht mit Mühe gebildet, sonden wie ein Gedanke erwecket, und mit einem Hauche geblasen zu seyn scheinet.« Winckelmann (Bd. 3, 1812), 240 f. - Winckelmann konfrontiert seinerseits die Werke der bildenden Kunst mit der Darstellung in Ovids Metamorphosen: vgl. Johann Winkelmanns alte Denkmäler der Kunst, hg. von Friedrich Leopold Brunn, Bd. 2, Berlin 1792, $11 \mathrm{f}$.

203 Vgl. Ludwig Trauzettel, in: Paul (1994), 170-172.

204 In der Textfassung der Ausgabe London 1745, die Rodes späterer Gesamtübersetzung (s. u. S. 62) zugrunde liegt (met. 6,155-161):

$\gg$ et felicissima matrum

dicta foret Niobe, si non sibi visa fuisset. nam sata Tiresia, venturi praescia, Manto per medias fuerat, divino concita motu, vaticinata vias: Ismenides, ite frequentes: et date Latonae, Latonigenisque duobus, cum prece thura pia; lauroque innectite crinem. «

205 Zum Übersetzungsphänomen der Explikation vgl. Poiss et al. (in diesem Band), § 10, Nr. 13. 
Mühe zu erkennen ist. ${ }^{206}$ Prinzipiell neigt Rode allerdings auch über die Anmerkungen hinaus zur über das Original hinausgehenden Erläuterung. »Theben « ist bei Ovid aus Ismenides zu extrapolieren, die Unsterblichkeit von Latonas Kindern ergibt sich aus der vorauszusetzenden Göttlichkeit der Mutter. Ovids raffiniertes Gedankenspiel, dass Niobe gerade deshalb nicht glücklich war, weil sie sich selbst glücklich vorkam, wird von Rode moralisch transponiert und als Dünkelhaftigkeit gebrandmarkt, ist tatsächlich aber die Auseinandersetzung mit einem Erkenntnisproblem, analog dem des Narcissus, dem Tiresias ein langes und glückliches Leben geweissagt hatte si se non noverit ipse. ${ }^{207}$

Rode ging den mit seiner metrischen Übersetzung eingeschlagenen Weg nicht weiter. Vielmehr erschien wenige Jahre später (im Verlag von Rodes Schwager My$\mathrm{lius}^{208}$ ) die Gesamtübersetzung der Metamorphosen in Prosa (Berlin 1791, ${ }^{209} 2$. Auflage 1802, Neuausgabe 1816). Damit führt er die ovidischen Metamorphosen mit den Metamorphosen des Apuleius zusammen, die auf diese Weise zwei Versionen ein und desselben Textes werden. ${ }^{210}$ So bediente sich Rode $(1783)^{211}$ in seiner ApuleiusÜbersetzung für die unterschiedlichen Sprachebenen dieses Romans der Literatursprache seiner eigenen Zeit, des Rokoko, des Sturm und Drang sowie des hymnischen Stils Klopstocks und des jungen Goethe. Er kann also das vorhandene Register ausschöpfen und gewinnt damit übersetzerische Kompetenz für Ovid. Die beiden Verwandlungstexte werden auf diese Weise zu zwei Spielarten eines deutschen Verwandlungsromans.

In der Vorrede legt Rode zunächst Rechenschaft über die Textgrundlage ab:

[...] ich [habe] die Londoner Ausgabe von 1745 mit R. Brindley'scher Schrift zu Grunde gelegt; dabei aber die neueren Editionen verglichen und die Abweichungen von der Londoner Leseart, wozu ich durch die Anmerkungen der Commentatoren, oder auch durch meine eigenen Muthmaßungen veranlaßt worden bin, unterm Texte angemerkt [...].

$D_{a s}$ ist ein qualitativ neuartiges Verfahren, das die Tätigkeit des Übersetzers näher an die des Philologen rückt und demgemäß tendenziell entdilettantisiert. Sowohl in der

206 In der Prosafassung von 1791 ist das weitgehend übernommen: »Denn Tiresias Erzeugte, die Seherin der Zukunft, Manto, weissagte mitten in den Gassen, durch göttlichen Antrieb erregt [...] «. Die Formulierung findet sich auch in der Prosagesamtübersetzung von Heynemann (1797) (s. u.) und ist ein Indiz für dessen mangelnde Selbstständigkeit: »Denn Manto, Tiresias Erzeugte, der Zukunft Seherin, hatte von göttlicher Begeisterung getrieben, mitten auf den Straßen geweissagt [...].«

207 Vgl. Rosati (2009), ad loc.

208 Die genauen Lebensdaten des August Mylius sind nicht bekannt, eventuell leitete zu diesem Zeitpunkt schon dessen Witwe Sophie Christine, die Schwester Rodes, den Verlag.

209 Die Ausgabe Wien 1794 (Sammlung der römischen und griechischen Classiker in deutschen Übersetzungen, 12-14) in drei Bänden ist offenbar ein nicht autorisierter Raubdruck, It. dem Karlsruher Virtuellen Katalog (http://www.ubka.uni-karlsruhe.de/kvk.html) z. B. in der Bibliothek der Abtei Metten oder der Stadtbibliothek Worms sowie der Herzogin Anna Amalia Bibliothek Weimar vorhanden (non vidi); das bei Google Books digitalisierte Exemplar stammt ausweislich des Bibliotheks-

210 Vgl. Niedermeier (2007).

211 Laut Rüdiger (1960), $552 \mathrm{ff}$. 
Anthologie als auch in der Übersetzungsvorrede wendet sich Rode allerdings mit traditionellem Gestus an ein Publikum, das aus »angehenden Künstler[n] und ungelehrten Kunstliebhaber[n] « (unter Berufung auf Lessing, der im Laokoon die spezifischen Fähigkeiten der Literatur und der Kunst gegeneinander aufgewogen hatte) bestehen soll. Damit ist zugleich der Focus stärker auf das Stoffliche als auf die sprachliche Form gerichtet (auch in dieser Hinsicht ist der Verzicht auf metrische Wiedergabe konsequent), der sprachpflegerische Aspekt wie bei Humboldt und Schleiermacher ist Rode fremd.

Über die Motivation, warum er zur Prosafassung gegriffen hatte, hatte sich Rode schon in der vom Verlag verbreiteten »Ankündigung « seiner Übersetzung (s. o. S. 163) geäußert, die noch einmal der Ausgabe beigegeben ist. Auch hier findet sich der im intertranslatorischen Diskurs topische Anspruch der Treue:

Bei all dem haben wir von Ovids Verwandlungen in unsrer Sprache noch keine Uebersetzung, welche als ein getreues Conterfei des Originals anzusehen wäre; hat es gleich nicht an Versuchen dazu gefehlt.

Aufmerksam auf diesen Mangel unsrer Litteratur [...] hat gegenwärtiger Uebersetzer der Ovidischen Verwandlungen bey seiner Verdeutschung sich bestrebt: so nahe, als es immer Geschmack und Sprache verstatten, sich an das Römische Urbild anzuschließen; die wahren Farben desselben beizubehalten, und den Text eben so wenig durch Verkürzung zu verstümmeln, als durch Paraphrase wässerig zu machen. Diesem Zwecke desto näher zu treten, hat er sich dem Zwange eines Metrums nicht unterwerfen wollen, und um so lieber eine poetische Prosa zu seiner Uebersetzung gewählt; da viele mit dem, doch nur mangelhaft nachzubildenden, Silbenmaaße der Römer und Griechen nicht ganz sich aussöhnen zu können scheinen.

Dieses Programm weist geradezu auf die im 20. Jahrhundert entwickelten Schadewaldt'schen Maximen voraus, ${ }^{212}$ auch wenn er hilfsweise mit der (noch nicht) vorhandenen Möglichkeit argumentiert, die antike quantitierende Metrik ins Deutsche zu überführen.

Nur wenige Jahre nach der Erstauflage von Rodes Übersetzung folgte der erste Band, die Metamorphosen, einer geplanten Gesamtübersetzung Ovids durch Simon Heynemann (Frankfurt 1797), die allerdings durch den frühen Tod des Autors keine Fortsetzung fand. Wie Rode greift er zur Prosa, auch mit einer ähnlichen sprachlichen Begründung:

Mein Bestreben war, so treu und richtig zu übersetzen, als es möglich ist, dem Autor keine Schönheiten anzudichten, aber auch nicht ins Matte zu verfallen. Deswegen hielt ich mich so genau an den Periodenbau des Dichters, als es nur geschehen konnte, ohne der deutschen Sprache Gewalt anzuthun, und ich hoffe, dass man in der Uebersetzung noch fühlen wird, dass man einen Dichter liest.

Als Rektor des Gymnasiums von Speyer hat er aber kein so spezifisches künstlerisches Publikum im Auge wie Rode, überhaupt scheint er dessen Übersetzung nicht gekannt 
zu haben, ${ }^{213}$ was entweder an den schwierigen Zeitumständen liegt (Heynemann berichtet, er habe daran unter den Bedingungen der französischen Besatzung gearbeitet), oder daran, dass die Kenntnis von Rodes Fassung noch nicht bis in den Südwesten Deutschlands vorgedrungen war, da er eben doch vor allem in den Dessauer Raum gehört.

Ein weiteres Jahr später brachte dann Johann Heinrich Voß ${ }^{214}$ seine hexametrische Übersetzung (1798) heraus, nach Schlüter erst die zweite vollständige Hexameterfassung in der Geschichte der Ovid-Übersetzungen. Voß (1751-1826) ${ }^{215}$ studierte trotz widriger biographischer Umstände ab 1772 in Göttingen Philologie (zunächst auch Theologie) und kam dadurch sowohl in Kontakt mit der sich ausbildenden Universitätsdisziplin Klassische Philologie (1734 war hier das erste klassisch-philologische Seminar gegründet worden) unter Christian Gottlob Heyne als auch mit der literarischen Avantgarde wie dem Göttinger Hain. Aus dieser doppelten Ausrichtung speisen sich auch seine zahlreichen, intensiv diskutierten Übersetzungen, von denen der Homer am bekanntesten wurde.

Voß' Metamorphosen-Übersetzung kommt ohne jegliches Vorwort aus, so dass man davon ausgehen kann, dass für Voß die metrische Gestalt keiner weiteren Begründung mehr bedurfte. Als Ersatz kann dafür aber dienen, was Voß in der Vorrede zur Übersetzung von Vergils Georgica (Hamburg 1789) ${ }^{216}$ über den lateinischen und deutschen Hexameter geschrieben hatte und was er nun offenbar nicht noch einmal wiederholen wollte. Dort wehrt er sich gegen verbreitete Meinungen, die metrische Gestalt sei überflüssige Beigabe, beruft sich für die Bedeutung des numerus auf Cicero und kommt darüber zur Notwendigkeit eines präzise der antiken Gestalt entsprechenden Metrums:

Der deutsche Hexameter ist, wie jener der Alten, eine rhythmische deutlich begrenzte Periode von sechs vierzeitigen Takten, die mit einer gehobenene Länge anfangen, und entweder mit einer Länge, oder, den lezten ausgenommen, mit zwei Kürzen, aber auch (welches Neuerung ist) mit Einer Kürze, sich senken; d. i. die aus dem Spondäus oder Daktylus oder Trochäus bestehn. Füllt ein Trochäus den Takt, so wird seine Länge dreizeitig, oder, mit dem Musiker zu reden, ein punktirter Halbfuss: welche Ueberlänge, wenn nur der Begrif des Verweilens nicht unwerth ist, weit gefehlt zu beleidigen, auch ein griechisches Ohr durch angenehme und kraftvolle Abwechslung erfreun könnte. Man fordert, wie sich versteht, nicht grade die pünktliche Abzählung des Taktschlägers im Koncert; sondern wie etwa ein empfindender Tonkünstler ein gleichgemessenes Solo voll wechselnder Leidenschaft, bald etwas schneller, bald etwas langsamer, vorträgt. Der vorschallende Ausgang, welcher die rhythmische Periode begrenzt, ist gewöhnlich ein Daktylus mit folgendem Spondäus oder Trochäus: da gleichsam die mächtig gehobene Welle dem Ufer nahe mit

213 Fink (1989), 428, hält in seinen Literaturhinweisen diese Übersetzung der Rodes für »auffallend ähnlich «, suggeriert damit eventuell plagiatorische Ausschlachtung, wofür es allerdings keinen Beweis gibt.

214 Siehe zu Voß jetzt auch Fantino (2014); außerdem zuletzt V. Riedel, in: Kuhlmann/Schneider (2012), $1275 \mathrm{f}$.

215 Überblick bei Muncker (1896), 334-349; siehe auch die Beiträge in Baillot/Fantino/Kitzbichler (2014).

216 Vgl. Fantino (2014); Korten (2014); Couturier-Heinrich (2014). 
Heftigkeit singt, und noch einmal aufrauschend im Sande zerfliesst. Getheilt wird der sechstaktige Vers am häufigsten in zwei Hauptglieder, durch einen bald männlichen, bald weiblichen Einschnitt im dritten Takte, oder, wie die Griechen sagten, nach dem fünften Halbtakte (Penthemimeris):

Ueber das hohe Gewölk | sich der fliegende Reiter emporschwingt.

Oft auch siehest du Sterne, | sobald herdränget der Sturmwind.

[...] Aber nicht genug, dass die Bewegung des Verses wohlgemessen und gefällig sei; auch der Klang der bewegten Worte muss schmeicheln. Wer hört die selbige Melodie nicht lieber auf Kremonergeige, als auf der Stockfiedel? [...] Die Länge, besonders die in der Hebung steht, wechsle mit dunklen und hellen Vokalen, mit austönenden und vielfach abstossenden oder dämpfenden Konsonanten; nie hersche ein Gepiep, nie ein rauhes Hauchen oder Gezisch. Die Kürze des daktylischen Taktes sei leicht; selten mehr als Eine verkürzte Mittelzeit, zumal die zur Länge sich neigt, und diese durch kräftige Längen überschallt; nie ein Geschlepp von schweren oder widerlichen Mitlautern. Im trochäischen Takte dagegen darf die säumende Mittelzeit sowohl, als die vollere Kürze, oft dem schwebenden Spondäus nachahmen. Keine Gleichförmigkeit der Endungen, zumal in Schlussrhythmen, wo das leidige en sich so gerne einstellt. Niemals Zusammenziehungen, wie schmerzts, die schon der Redner vermeidet; oder wie heilger, die nur der härtere Iambus zulässt. Eben so wenig Ausdehnungen gegen den Sprachgebrauch, wie machete; obgleich goldene und höre te, die jener erlaubt, oft durch Bewegung und Klang willkommener sind. ${ }^{217}$

Mit Rode und Voß liegen also erstmals zwei theoretisch untermauerte, wenn auch fundamental divergente Übersetzungen vor. Dabei erwies sich der Voß'sche Ansatz zunächst als deutlich zukunftsträchtiger, wie die (anonyme) Rezension der Neubearbeitung von Rodes Übersetzung (1816) in den Heidelbergischen Jabrbüchern zeigt, in der sich der Rezensent empört:

Diese neue Übersetzung schmiegt sich dem Originale näher an, als die alte, aber sie ist, wie jene, in Prosa, und daß solche Uebersetzungen noch h. z. T. gesucht werden, ist ein trauriges Zeichen unserer Zeit. Schülern, und auch wohl mitunter Lehrern dienen sie als eine Brücke des Unfleißes, und angehende Künstler werden wenigstens durch sie nicht in ihrer Kunst gefördert. $^{218}$

Selbst die Nähe zum Ausgangstext, das sich Anschmiegen, kann den Verzicht auf Metrik in dieser Perspektive nicht aufwiegen. En passant kommt ein neuer, lange Zeit virulenter Aspekt der Übersetzungskritik ins Spiel: Unter den Bedingungen einer nunmehr gymnasial normierten altsprachlichen Ausbildung konnten Übersetzungen, die den Autor zum Leser zu bringen beabsichtigen, als allzu bequem, ja als $\gg$ Brücke des Unfleißes « und damit schon beinahe als Medium des Betrugs erscheinen.

Das Proömium gibt Rode folgendermaßen wieder (bei Voß fehlt es):

In neue Gestalten verwandelte Körper will ich singen. Ihr Götter, seid meinem Unternehmen hold, (denn auch ihre Verwandlung ist ja euer Werk) und leitet meinen Gesang vom Urbeginne der Welt ununterbrochen fort bis auf meine Zeit. 
Rode stellt gemäß Ovids in nova-Beginn den Neuigkeitsaspekt, die neuen Gestalten an den Anfang (die Sperrung mit corpora ist im Deutschen nicht nachbildbar). Dagegen weicht er mit der Wiedergabe von dicere als $\gg$ singen ${ }^{219}$ und von fert animus als $\gg$ will ich « unspektakulär, aber fühlbar vom Lateinischen ab. Deduco ist mit »fortleiten « etymologisch transparent umgesetzt, perpetuum im Gegensatz zu manch anderen Lösungen bewahrt. Der eigenen Forderung, die Gedankenfolge beizubehalten, widerspricht eigentlich nur die Vermeidung der Endstellung von carmen/» Gedicht «.

Diese schon am Proömium ablesbare Tendenz setzt sich bei den eigentlichen Sagenerzählungen fort:

Pyramus, der Jünglinge schönster, und Thisbe, die reizendste unter den Mädchen des Morgenlandes, bewohnten aneinander stoßende Häuser in der erhabenen Stadt ${ }^{220}$, welche der Sage nach - Semiramis mit Mauren von gebackenen Steinen umgeben hat. Die Nachbarschaft stiftet unter ihnen Bekanntschaft, und Freundschaft, die mit der Zeit Liebe wird. Gern hätten sie sich auch durch eheliche Bande verbunden; allein die Väter verbieten es. Doch können diese auch verbieten, daß nicht beider Herzen, von gleicher Liebe eingenommen, brennen? ${ }^{221}$ Sobald sie unbelauscht sind, sprechen sie durch Blicke und Zeichen mit einander; und je verborgener, desto heftiger lodert ihre Flamme [...].

Als er aber auch das blutige Gewand erblickt, ruft er aus: Ha! Eine Nacht vertilgt zwei Liebende! Ach! Sie war des längsten Lebens würdig; aber ich allein bin schuldig. Ich Unglückseliger, ich habe dich ermordet; da an einem so schreckenvollen Ort in der Nacht ich Dich kommen hieß, und nicht vor dir da war. Mich, mich zerreißt, ihr Löwen, die ihre diesen Felsen bewohnt! Meine ruchlosen Glieder verzehrt mit wilden Bissen! Doch, nur ein Feiger wünscht den Tod. Mit den Worten hebt er Thisbens Gewand auf, und mit ihm begiebt er sich in den Schatten des verabredeten Baums. Hier netzt er mit Thränen, hier küßt er das bekannte Kleid. Endlich spricht er: Itzt tränke auch mit meinem Blute Dich! und senkt das Eisen, womit er umgürtet war, sich tief in die Eingeweide, und sterbend reißt er es plötzlich wieder aus der dampfenden Wunde. Als er rückwärts da liegt am Boden, springt hoch das Blut empor; nicht anders, als wenn eine beschädigte Bleiröhre berstet, zischend aus der Oeffnung der dünne Wasserstrahl hervor spritzt, und spritzend die Lüfte zertheilt.

Die Früchte des Baumes, besprengt mit Blute, wandeln so fort ihre Farbe, und mit Blute benetzt färbt die Wurzel mit Purpurröthe die herniederhangenden Maulbeeren.

Rode macht aus Ovids Text eine gut lesbare, in den Inhalten unproblematisch verständliche Erzählung. Gemäß den Regeln der deutschen Prosa musste die überschriftsartige Stellung von Pyramus et Thisbe preisgegeben werden. Im Folgenden kommt es (wie auch früher) zu einer narrativen Normalisierung mit Einfügungen wie »Freundschaft « und der Paraphrase des signifikanten taedae iure durch die weniger spezifische Wendung »eheliche Bande «. Die vordergründige Korrektheit und Vollständigkeit geht allerdings auf Kosten der Emotionalität und der Plausibilität der Motivation. Eine

\footnotetext{
$219 \mathrm{Zu}$ canere/dicere als epische Chiffre siehe Bömer (1969), ad loc.

220 Anmerkung Rodes: »Babylon«.

221 Anmerkung Rodes: »Gegen die gewöhnlichen Lesarten mache ich bei patres im Texte einen Punkt, und nehme quod noin potuere vetare zum Folgenden, weil der Sinn dadurch gewinnt. « Das entspricht der heute üblichen Textgestaltung, s. o.
} 
sprachliche Unachtsamkeit ist die Wiedergabe des Gerundivs miseranda mit »ich Unglücklicher «.

Diese Tendenz setzt sich auch bei der Wiedergabe der Pygmalion-Sage fort:

Als er heimgekehrt, begiebt er sich wieder zum Bilde seiner Geliebten, drückt neben ihm das Lager und küßt es: Da schien es warm zu sein! Er küßt es noch einmal; fühlt mit der Hand auf die Brust, und unter seiner Hand erweichet das Elfenbein, verliert seine Härte, gibet nach und nimmt Eindrücke an; gleichwie Hymettisches ${ }^{222}$ Wachs an der Sonne weich wird, und dem Drucke des Daumens folgend, mancherlei Gestalten annimm und durch den Gebrauch nützlich wird. Indem er staunt, der Liebende, schüchtern sich freuet, noch sich zu täuschen fürchtet und wieder und wieder sich mit der Hand von der Erfüllung seiner Wünsche zu überzeugen sucht: Leibt und lebt das Bild, es pochen dem fühlenden Daumen die Adern entgegen! Nun bricht entzückt der Paphische ${ }^{223}$ Held in Dankgebete an Venus aus, drückt auf den nunmehr wirklichen Mund seine Lippen, und das Mädchen fühlt den

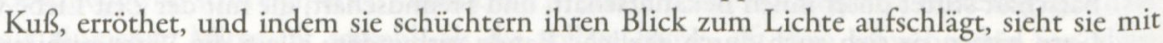
dem Himmel zugleich ihren Geliebten.

Diese Übersetzung kann ihre selbst gesteckten Ziele vollkommen erreichen. Sie liefert einen linear lesbaren Grundeindruck vom Text mit dem Akzent auf dem Stofflichen, wie es einem propädeutisch intendierten Unternehmen gemäß ist.

Dagegen geht es Voß um das Einfangen des Gesamteindrucks, der einen inhaltlichen wie einen ästhetischen, d. h. nicht zuletzt metrischen Aspekt hat. Auf die Wiedergabe des Proömiums verzichtet er (ebenso auf Anmerkungen und erklärende Paratexte) und konzentriert sich ganz auf den mythologischen Gedichtkern. Charakteristisch ist seine Version von Pyramus und Thisbe:

Pyramus war und Thisbe, der Jünglinge schönster der eine,

Hoch die andre gerühmt vor den morgenländischen Jungfraun.

Dicht angrenzende Häuser bewohnten sie, dort in der Hauptstadt,

Welche Semiramis einst mit thönernen Mauern befestigt.

Beide wurden bekannt, und wie Nachbarkinder vertraulich,

Dann allmählich verliebt; auch hätte sie Ehe vereinigt;

Doch dies wehrten die Väter: was nicht sie zu wehren vermochten,

Von gleichseitiger Glut entloderten beiden die Herzen.

Fern ist jeglicher Zeug'; Andeutungen sprechen und Winke;

Und je enger bedeckt, je heftiger brauset das Feuer.

Voß gelingt es hier in der Tat, Ovids zwei Anfangsverse fast nahtlos ins Deutsche zu bringen (er benötigt lediglich den Zusatz »war « und macht damit den Anfang zu einer syntaktischen Einheit): Er behält die überschriftartige Nennung der beiden Eigennamen bei, auch die nachgeschobene chiastische Erläuterung der Protagonisten. Rodes Syntax ist dagegen konventioneller und entspricht eher den deutschen Hörgewohnheiten, dafür muss er die Spitzenstellung von Pyramus et Thisbe aufgeben,

222 Anmerkung Rodes: »Der Berg Hymettus bei Athen war reich an wohlriechenden Kräutern, daher der auf demselben gewonnene Honig für den besten gehalten wurde. Ovid läßt hier dichterisch das Wachs am Ruhme des Honigs Theil nehmen.«

223 Anmerkung Rodes: »d. i. Pygmalion, hier vermöge einer Figur der Rede zum voraus also genannt, da der Name Paphos erst nachmals von dessen Sohne der Insel oder der Stadt gegeben wurde.« 
bewahrt aber ebenfalls Ovids Chiasmus und auch den Duktus des Satzbaues. Aber gerade die syntaktische Veränderung ermöglicht es Voß, auch im dritten Vers die Spitzenstellung von contiguas domos bei Ovid beizubehalten, allerdings ist diese syntaktische Mimesis im vierten Vers nicht mehr zu halten. Rode wirkt im Ganzen etwas genauer in der Wiedergabe der Einzelwörter (dicitur ist mit »der Sage nach « geradezu schulmäßig beibehalten; eine Ausnahme ist nur das paraphrasierende »Freundschaft « für primos gradus), bisweilen etwas pedantisch und nicht zuletzt durch die Fußnoten auch didaktischer. Selten greift er zu interpretativen Interventionen wie im diese Passage abschließenden Vers, wo er Ovids sprichwortartige und aufs Allgemeine zielende Aussage auf die handelnden Personen hin konkretisiert.

Voß hat bei Abweichungen im Wortmaterial eher den Blick auf die formale Angleichung, auf die Wiedergabe des gedanklichen und metrischen Flusses des Originals, was ihm phasenweise fast deckungsgleich gelingt. Damit wird schon aus dieser Passage exemplarisch deutlich, was unterschiedliche Übersetzungskonzepte an Auswirkungen auf die Apperzeption des durch sie vermittelten Originals haben.

Noch deutlicher wird dieser Unterschied beim zweiten Abschnitt aus dieser Sage:

Als sobald er den Schleier auch findet voll Blutes:

Eine Nacht denn soll zwei Liebende tödten! beginnt er.

War doch jene von beiden die würdigste längeres Lebens!

Schuldig ist meine Seel'; Ich bin, Elende, dein Mörder;

$\mathrm{Da}$ ich in grauliche Wüsten heraus dich lockte bei Nachtzeit,

Und nicht zuerst ankam! O zerreisst mit den Zähnen den Leib mir,

Und mein frevelndes Herz verschlingt in den wütenden Rachen,

Ihr, ihn jenem Geklipp herbergende Löwen der Wildnis!

Doch feig ists, nur wünschen den Tod! und die Hülle der Thisbe

Hebt er, und trägt sie zum Schatten des abgeredeten Baumes.

Als er mit Thränen genezt das bekannte Gewirk, und geküsset:

Jetzt denn, sagt er, empfang' auch meines Blutes Beströmung!

Und er senkt den umgürtenden Stahl in die Weiche des Bauches;

Schnell zieht er ihn sterbend hervor aus der kochenden Wunde;

Und wie er lag auf den Rücken gestreckt, springt röthliches Blut auf:

Anders nicht, als wenn mit beschädigtem Bleie die Röhre

Plazt, und gewaltig empor aus zischender Öfnung das Wasser

Sprüzt im verdünneten Stral, und hoch in die Lüfte sich auffschwingt.

Aber die Früchte des Baums, vom Todesblute gesprenget,

Nehmen die schwarze Gestalt; und die blutgefeuchtete Wurzel

Färbt mit purpurnem Dunkel die ringsher hangenden Maulbeern.

Bei Voß kommen die im lateinischen Text Ovids zu findenden Affekte, die wiederum mit der sachlichen Erzählung und dem harten technischen Gleichnis kontrastiert sind, erheblich stärker zum Ausdruck als bei Rode. Durch die Anpassung des syntaktischen Verlaufes an die Metrik des Hexameters kann Voß auch sprachliche Härten erträglich abfedern.

Das ist kein Zufall, sondern die durchgehende Methode, wie sich auch an Pygmalion erweist: 
Heim eilt jener zum Bilde zurück des trautesten Mägdleins,

Neigt sich über das Lager, und küsst; und sie scheint zu erwarmen.

Wieder naht er dem Mund', und wagt auch die Brust zu versuchen;

Weich wirds unter der Hand; des Elfenbeines Erstarrung

Senkt sich dem Druck der Finger, und weicht: wie das Wachs des Hymettus

Schmeidiger wird an der Sonn' und dem zwingenden Daum in Gestalten,

Immer verändert, sich biegt, und brauchbarer durch den Gebrauch wird.

Während der Liebende staunt, und bange sich freut, und Teuschung

Wieder besorgt, und wieder den Wunsch mit den Händen berühret;

War sie Leib; und es schlagen, versucht vom Daume, die Adern.

Jezo erhebt der pafische Held vollströmende Worte,

Worte des Danks zu Venus, der gütigen! Endlich vereint er

Zum nicht teuschenden Munde den Mund: die gegebenen Küsse

Fühlt die erröthende, hebt zu dem Lichte die leuchtenden Augen

Schüchtern empor, und schaut mit dem Himmel zugleich den Geliebten.

Rode ist auch hier wieder nahe am Ovid-Text, bisweilen mit geringfügigen explikativen Ausweitungen, z. B. dass sich Pygmalion neben das geliebte Bild legt. Ovids Variation dedit oscula und admovet os iterum ist nicht beibehalten, sondern in »küssen « vereinheitlicht, dafür ist umgekehrt temptat und temptatum (wodurch Ovid die Abfolge der Handlung sprachlich wiedergibt) mit unterschiedlichem Vokabular wiedergegeben, ebenso bei utilis usu und ora ore. Offenbar versucht Rode generell solche auch stilistisch gut motivierten Wortwiederholungen zu vermeiden. ${ }^{224}$

Voß beweist sein Gespür für Ovids Dichtersprache. Er greift das paronomastische utilis usu durch » brauchbarer durch den Gebrauch « auf, wohingegen Rode lexikalisch korrekt, aber uninspiriert »durch den Gebrauch nützlich« schreibt und so die im Deutschen (wie aber auch im Lateinischen) auffällige Doppelung vermeidet. Geradezu genial ist Voß' Lösung des lumina-Problems, indem er mit »die leuchtenden Augen « sowohl das Strahlen als auch die Körperlichkeit ausdrückt, wo Rode wieder eine Sicherheitslösung wählt.

Was aufs Ganze gesehen dennoch bei Voß vor allem gegenüber seinem Homer fehlt, ist die Möglichkeit, eine eigene deutsche epische Sprachform zu entwickeln, wie sie in seiner berühmt gewordenen Umsetzung der homerischen Formelsprache gelungen und stilbildend geworden ist. Auf der anderen Seite zeigt Voß, dass er auch mit höchst unterschiedlichen antiken Texten - der Formelsprache Homers und der punktgenauen Diktion Ovids - gleichermaßen umgehen kann.

Dennoch ist Voß' Übersetzung vielleicht die am häufigsten nachgedruckte Metamorphosen-Übersetzung, zumal sie Ende des 19. Jahrhunderts (um 1880) in Reclams Universalbibliothek übernommen wurde (lt. Katalog der Deutschen Nationalbibliothek bis 1928) und nach 1995 in 3. Auflage als Insel-Taschenbuch zusammen mit Picassos Graphikzyklus ${ }^{225}$ von 1931 publiziert wurde. ${ }^{226}$ Auch im online frei zugäng-

224 Vgl. Stephan 2015 (in diesem Band) über Rodes Apuleius-Übersetzung.

225 Ziolkowski (2005), 97. Zu Ovid als Inspirator der modernen Kunst siehe generell Reinhardt (2001), daneben gibt es zahllose, allerdings oftmals sehr flüchtige Internetseiten mit alten und neueren Illu- 
lichen Projekt Gutenberg ${ }^{227}$ ist sie eingestellt und damit einer nicht einschätzbaren Zahl von Zugriffen verfügbar. Damit erweist sich Voß’ Übersetzung als die Konstante in der neueren Geschichte des deutschen Ovid schlechthin.

\subsection{Friedrich Gottfried Klopstock (1724-1803)}

Klopstock hatte mit seinem epochemachenden Messias (veröffentlicht sukzessive seit 1748, erste Gesamtausgabe 1772) die deutsche Dichtersprache mitsamt ihrer Metrik in kaum zu überschätzender Weise fortentwickelt. Sein Versuch, als erster den deutschen Hexameter anzuwenden, und die theoretische Untermauerung in der Schrift Vom deutschen Hexameter (1767) beeinflusste auch Voß, der etwa die Auffassung vom »Wortfuß $\ll$ als kleinster metrischer Einheit übernahm. Wenn diese Bemühungen Klopstocks allerdings ausschließlich auf das Deutsche abhoben, so setzte er sich in seinem poetologischen Fragen gewidmeten Alterswerk, den Grammatischen Gesprächen (1794), ${ }^{228}$ neben allgemeinen Fragen des Übersetzens auch mit der Spezifik des Übersetzens aus den Alten Sprachen auseinander. Sein Anspruch war es, seine Übersetzungen als den Originalen überlegen zu erweisen, also im Sinne der aemulatio siegreich in den Wettstreit mit der Antike einzutreten. ${ }^{229}$ Dieser Aspekt sollte allerdings unter den von Humboldt und Schleiermacher gesetzten Prämissen bald über die Maßen unzeitgemäß erscheinen und führt dazu, dass sein Beitrag aus dem sich entwickelnden Übersetzungsdiskurs ausgeblendet blieb, wozu gewiss auch der idiosynkratische, schwer rezipierbare Charakter der » Gespräche « beitrug.

In den Gesprächen lässt Klopstock eine Vielzahl von allegorischen Personifikationen auftreten, die die unterschiedlichen Positionen und Stilideale verkörpern und dem Verfasser die Möglichkeit zur komplexen Darstellung des Gesamtphänomens geben. Die mit den Grammatischen Geprächen zusammenhängenden Fragen sind trotz Elit (2002) noch nicht einmal annähernd ausgelotet und sollen hier auch nicht interessieren. Es geht um die Rolle Ovids im Rahmen dieses Textes.

Im Gespräch mit »Einbildungskraft « und »Harmosis « übersetzt die »Vereinigung « ausgewählte Passagen des Orpheus-Abschnitts der Metamorphosen (met. 10 und 11), darunter die Pygmalion-Erzählung: ${ }^{230}$

Einb. Ich habe, Vereinung, die Kürze deiner Sprache durch dich genauer kennen gelernt, als ich sie kante. Jezt bin ich auf etwas ganz anderes neugierig. Hielte sie es auch wohl gegen die lateinische nach der Wendung aus, welche ihr Ovidius gab? Ver. In meinem Munde nicht.

strationen zu Ovid; vgl. etwa Peter Grau, Eichstätter Datenbank zur Antike-Rezption/Kunst (http:// www 1.ku-eichstaett.de/SLF/Klassphil/grau/kunst_intro.html).

226 Vorläufig letzte Ausgabe ist ein Reprint als Ebook im Jazzybee Verlag Altenmünster 2012 - die Belege finden sich im einzelnen bei der Deutschen Nationalbibliothek unter http://portal.d-nb.de.

227 http://gutenberg.spiegel.de/buch/4723/1.

228 Elit (2002).

229 Vgl. Kitzbichler (2009), 34.

230 Ausführlich analysiert von Elit (2002), 306-329. 
Warum rührest du mich mit dem Stabe an? Ich komme mir wie verwandelt vor! Ich merke, daß ich dir gehorchen muß! Du erlaubest mir doch, daß ich nur hier und da eine Blume breche? Einb. Thu, was du wilst. Harm. Du rächest mich an ihr, Einbildungskraft. Erst so karglaut; und jetzo muß sie Verschwenderin seyn!

Die Debatte dreht sich also um die Prägnanz des Ausdrucks und der Sprache und konfrontiert das Deutsche mit Ovids Diktion, wobei die Vergleichbarkeit auch durch selbstverständliche Verwendung des deutschen Hexameters unterstützt wird. Die Pygmalion-Sage wird abschnittsweise übersetzt, wobei die $\gg$ Vereinigung « $(» V e r . \ll)$ jeweils durch das Anzitieren des lateinischen Textes den aktuellen Rahmen bestimmt:

Ver. Interea niveum . . lacrimas.

Damals schuf sein Meissel aus Paros Marmor mit hoher

Glüklicher Kunst, und gab ihm Gestalt, wie gebohren kein Weib wird.

Und es ergrif ihn Neigung zu seinem Werke, zum wahren

Jüngferlichen Gesicht; sie schien zu leben und wehrte

Dieses ihr die Blöde nur nicht, sich bewegen zu wollen,

So verbarg er die Kunst durch seine Kunst. Der Bewundrung

Voll, von der Liebe Feuer entflamt zum geähnlichten Leibe,

Fasset er oft sein Werk mit prüfender Hand, ob es Leib sey?

Oder ob Marmor? gesteht den Marmor nicht zu; und er küsset;

Glaubt, er werde geküßt, und redet an, und umarmet;

Meint, daß er an der berührten die Spur des Fingers erblicke,

Fürchtet, es werd' ihr durch Bläue der Druck die Glieder entstellen.

Jezt liebkoset er; bringt Geschenke, wie Mädchen sie lieben,

Jezt ihr: Muscheln, geschliffenen Stein, dann Vögelchen, Blumen

Aller Farben, und Liljen, und bunte Bälle, der Thränen

Auch, wie vom Baume sie weint die Heliade.

Cum munere functus .. eburnea.

Er hatte geopfert, und stand jezt

Bebend an dem Altar: Wenn alles in eurer Gewalt ist,

Götter, so sey mein Weib, zu bitten, das marmorne Mädchen!

Wagte nicht Pigmalion, bat, dem marmornen ähnlich. ${ }^{231}$

Elit ${ }^{232}$ untersucht diesen Abschnitt im Detail und kann zeigen, wie nah (bei punktuellen Abweichungen) sich Klopstock an den Ausgangstext anlehnt. Der florilegienhafte Charakter der Übersetzung erlaubt es zugleich, »anzügliche « Passagen beiseite zu lassen, wie diejenigen, in denen Pygmalion das von ihm geschaffene, noch unbelebte Standbild wie eine reale Frau behandelt (met. 10,263-269). Instruktiv sind die Lösungen, die Klopstock für Passagen findet, die im Deutschen und Lateinischen auf diametral verschiedenen Sprachverwendungsmöglichkeiten fußen:

Die Lösung der »Vereinung « angesichts dieser etwas unübersichtlichen Formulierung besteht [...] nicht darin, den Ausdruck im Deutschen etwas zu vereinfachen, sondern eine noch schwerer verständliche Wortreihenfolge zu produzieren: 
Wenn alles in eurer Gewalt ist, / Götter, so sey mein Weib, zu bitten, das marmorne Mädchen! / Wagte nicht Pigmalion, bat dem marmornen ähnlich.

Als Erklärung für diese unnötig erscheinende, leicht »dunkle« Fügung kann nur ein Duktus vor allem von Klopstocks eigener Lyrik herangezogen werden. Die Möglichkeiten ungewöhnlicher Wortstellungen sind in vielen seiner Oden extrem ausgeschöpft. ${ }^{233}$

Doch es gibt auch inhaltliche Unterschiede: Ovids ars latet arte sua wird vom Sentenzhaften und Allgemeingültigen zur punktuellen Strategie Pygmalions umgedeutet. Ovids lapsas nimmt den aus Harz entstandenen Bernstein zunächst als Naturphänomen, der durch den Zusatz Heliadas mythisch erklärt wird, Klopstocks » wie [...] weint « wird unmittelbar zur Metapher. Auch die Verteilung des Gedankengangs auf die Verse unterscheidet sich von Ovid, z. B. legt Ovid mit qua femina nasci/nulla potest eine klare Pause zwischen die Entstehung der Frau und deren Unmöglichkeit, die bei Klopstock völlig verschwindet.

Ut rediit ... amantem.

Da er heimkomt, eilet er hin zu dem Bilde des Lieblings,

Wirft sich zu ihr auf den Teppich, und küßt sie; meinet, sie werde

Warm, naht wieder dem Munde, berührt die Brust mit den Händen:

Und der berührte Marmor wird weich, die Härte verliert sich,

Biegt sich dem Finger, giebt nach, wie hymettisches Wachs an der Sonne

Länger nicht start, gedrükt von dem Daumen, in alle Gestalten

Sich verwandelt, und brauchbarer immer durch den Gebrauch wird.

Als er erstaunet, und bang sich freut, noch Täuschungen fürchtet,

Wieder umarmt, mit der Hand die Wünsche wieder berühret;

Ist sie Leib, und es schlagen, gefühlt von dem Daumen, die Adern!

Jetzo strömet der paphische Held in Fülle der Wonn' aus,

Feyert durch jeden Preis die Göttin. Denn endlich vereint sich

Mit nicht täuschendem Munde sein Mund. Die gegebenen Küsse

Fühlt das Mädchen, wird roth. Sie schlägt nach der Pforte das Auge

Schüchtern auf, und erblikt mit dem Himmel den Liebenden. ${ }^{234}$

Klopstock versucht am Ende gar nicht, Ovids Wortspiel nachzumachen und geht mit der Einfügung der »Pforte « einen ganz anderen Weg. Diese Umgehung der ovidischen Bildersprache ist laut Elit ([2002], 328) bezeichnend für Klopstocks Verfahren, der die Fülle des ovidischen Ausdrucks auf Knappheit reduzieren und damit verbessern möchte, so dass seine Fassung als die überlegene erscheint, die den Sieg des deutschen Textes über Ovids Latein signalisiert. ${ }^{235}$

233 Elit (2002), $323 \mathrm{f}$.

234 Klopstock, Grammatische Gespräche (1794), $267 \mathrm{f}$.

235 Elit (2002), 312. 
4. Epigonales Abseits: Metamorphosen-Übersetzungen im Zeichen ästhetischer Geringschätzung im 19. und frühen 20. Jahrhundert

\section{Exkurs (von Amélie Schützsack): Nacherzählungen der Metamorphosen im 18., 19. und 20. Jahrhundert ${ }^{236}$}

\section{Einleitung}

»Eine Übersetzung des Ovid wird man hier vergebens suchen. Es ist dieses niemals meine Absicht gewesen $\ll,{ }^{237}$ so Johann Gottlieb Lindner in seiner Vorrede zu seinem 1764 veröffentlichten Werk Lehrreicher Zeitvertreib in ovidianischen Verwandlungen. Vielmehr sei seine Absicht »keine andere, als die ich auf dem Titelblatte ausgedrückt habe, nämlich meinen Lesern einen angenehmen und nützlichen Zeitvertreib, in ovidianischen Verwandlungen zu verschaffen $\ll$. Was aber findet der Leser anstelle einer Übersetzung vor? Lindners Bearbeitung der Metamorphosen Ovids lässt sich als »Nacherzählung « bezeichnen, die sich wiederum, folgt man dem Sachwörterbuch der Literatur, als »Umsetzung in eine andere (jüngere bzw. einfachere) Sprachform oder eine freie, nur sinngemäße Übersetzung ${ }^{238}$ definieren lässt. Der Begriff $\gg N$ acherzählung « ist demnach ein sehr weitreichender, nach welchem der Leser des Lehrreichen Zeitvertreibs in ovidianischen Verwandlungen - dessen Autor widersprechend - keine Nacherzählung anstelle einer Übersetzung vorfindet, sondern eine Nacherzählung als spezifische Untergruppe der Übersetzung. Als Übersetzungstyp zeichnet sich eine Nacherzählung durch ihren informativen Charakter aus: Dem Autor, der deswegen im Folgenden auch Übersetzer genannt wird, geht es in der Regel um die Vermittlung des Inhalts. ${ }^{239}$ Welche Übersetzungstechniken ${ }^{240}$ dafür im Speziellen angewendet werden, hängt von den Einzelentscheidungen des jeweiligen Übersetzers ab und kann dementsprechend nur mit Hilfe einer konkreten Textanalyse festgestellt werden. Aufgrund der in der Definition zu Tage tretenden Freiheit hinsichtlich der Anlehnung an das klassische Original beziehungsweise der gewählten Sprachform, können sich Nacherzählungen stark voneinander unterscheiden und sind nicht immer haarscharf von

236 Dieser Abschnitt (S. 184-196) geht auf eine latinistische Hausarbeit sowie eine fachdidaktische Masterarbeit zurück, die Amélie Schützsack 2012 im Rahmen ihres Master-Studiums an der HumboldtUniversität zu Berlin vorgelegt hat. Damit wird ein wichtiges Seitenstück der Übersetzungsgeschichte Ovids in diesem Kapitel konzentriert vorgestellt.

237 Lindner, Lehrreicher Zeitvertreib (1764), 28.

238 von Wilpert (1989), 659: Der Begriff »Nacherzählung « erhält hier allerdings keine »eigene « Definition, stattdessen wird man auf den Begriff »Paraphrase « verwiesen.

239 Poiss et al. (in diesem Band), \$9, v. a. Typ 2.

240 Poiss et al. (in diesem Band), $₫ 10$. 
anderen Übersetzungstypen ${ }^{241}$ abzugrenzen, so dass es zu fließenden Übergängen kommen kann.

Nacherzählungen antiker mythologischer Stoffe in deutscher Sprache stellen einen wichtigen Beitrag zur Antikerezeption in Deutschland dar $^{242}$ und geraten dennoch oft aus dem Blickfeld wissenschaftlicher Untersuchungen. ${ }^{243}$ Im Folgenden sollen nun Nacherzählungen von Ovids Metamorphosen näher betrachtet werden, von denen bisher keine Gegenstand einer wissenschaftlichen Fragestellung war. Neben der bereits erwähnten Nacherzählung von Lindner aus der Mitte des 18. Jahrhunderts werden zwei weitere Nacherzählungen behandelt: Zum einen Die Sagenwelt der Alten. Für die Jugend bearbeitet von K. A. Schönke aus dem Jahre 1856, die der Autor selbst »als eine freie, bloß den Sinn in vaterländischer Form wiedergebende Übersetzung ${ }^{244}$ bezeichnet. Zum anderen Märchen und Mythen Ovids übersetzt von Karl Kindt, erschienen 1949, in deren Einführung der Autor sogleich klar stellt, dass keine »Neufassungen der ovidischen Märchen, sondern Nacherzählungen aufgrund der Übersetzung « ${ }^{245}$ gegeben werden.

In einem ersten Teil soll nach der Zielsetzung des jeweiligen Autors gefragt werden: Warum verfasst er gerade eine Nacherzählung der Metamorphosen Ovids? Die Intention ist von der Person des Autors ebenso wie von dem von ihm intendierten Adressatenkreis abhängig. Es kann und soll daher nicht nur nach dem Warum gefragt werden, sondern auch: Wer schreibt und für wen? Wird der Adressatenkreis nicht bereits im Untertitel des Werkes genannt, so spätestens im Vorwort, in welchem der Autor auch seine Intention erläutert, weswegen besonders dieses als Quellentext genutzt werden wird. Sind diese Fragen beantwortet, so kann in einem zweiten Teil (»Blick in die Werkstatt $\ll{ }^{246}$ der Autoren) die Frage nach der Arbeitsweise des Autors als Übersetzer gestellt werden. Zur Beantwortung dieser Frage soll zunächst die vom Autor im Vorwort erläuterte Arbeitsweise vorgestellt werden, um daraufhin mit Hilfe einer kurzen Textanalyse deren praktische Umsetzung zu überprüfen. ${ }^{247}$ Innerhalb der genannten zwei Untersuchungsaspekte, deren letzter noch einmal in sich gegliedert ist, werden die Nacherzählungen jeweils in chronologischer Reihenfolge analysiert werden.

\section{Der Autor und sein Adressat}

Johann Gottlieb Lindner, geboren 1726, war zunächst als Lehrer an einem evangelischen Gymnasium in Dresden tätig, nahm danach ein Studium der Philologie in

241 Poiss et al. (in diesem Band), $\$ \$ 8$ und 9.

242 Evers (2001), 9.

243 Pleticha (1987), 33; Evers (2001), 9/64.

244 Schönke, Die Sagenwelt der Alten (1856), V.

245 Kindt, Märchen und Mythen (1949), 15.

246 So betitelt bei Fink (2001), 459-505.

247 Vgl. dazu Poiss et al. (in diesem Band), v. a. $\$ 7$. Hier werden Parameter, die für die Untersuchung einer Übersetzung wichtig sind, vorgestellt. 
Leipzig auf, und kehrte hierauf als Konrektor in den Schulbetrieb zurück, bis er schließlich Schulrektor wurde. ${ }^{248}$ Sein 1764 veröffentlichter Lebrreicher Zeitvertreib in ovidianischen Verwandlungen richtet sich an die $\gg$ studirende Jugend ${ }^{249}$, aber auch an diejenigen, »welche eben nicht vom Studieren Prozeßion machen, sonderlich dem schönen Geschlechte « (29). ${ }^{250}$ Lindners Hauptanliegen ist es, den jugendlichen Lesern einen »nützlichen Zeitvertreib in ovidianischen Verwandlungen « (28) zu verschaffen. Denn es sei zwar nichts Verwerfliches an der Meinung vieler Gelehrter, dass die Metamorphosen ein Buch seien, »welches man der Jugend, des Lateins und der Fabellehre wegen, in die Hände geben müsse « (1), aber in Form einer »neuen Übersetzung « (1), durch die sich das Werk besser kennen lernen ließe, könne es vor allem die »Einbildungskraft « der Jugendlichen bilden und ihnen »das Geheimnis so mancher Schildereyen, Gemählde und Statuen « (2) eröffnen. »Nützlich « sei die Lektüre außerdem deswegen, da Ovid ein »vortrefflicher Sittenlehrer « sei (4), von dem man »ohne Furcht eines etwa zu schöpfenden Aergernisses, sehr viel gutes lernen könne« (13). ${ }^{251}$ Damit argumentiert Lindner gegen diejenigen, »deren traurige Mischung des Blutes ihnen diejenigen lebhaften Empfindungen der Freude versagt, mit welchen witzige Einfälle, wohlangebrachte Wendungen, und abwechselnde Leidenschaften, auf ein fühlbares Herz wirken« (2), und die die Metamorphosen deswegen »als ein Buch, welches der Religion und den guten Sitten schnurstracks zuwider wäre, und die Einbildung mit nichts, als ärgerlichen und schädlichen Bildern, anfüllete « (2) meiden. Schließlich würde die Lektüre der Nacherzählung die Begierde der »studirende[n] Jugend « »zu dem Buche selbst « (29), gemeint ist die Originallektüre, wecken. ${ }^{252}$

Auch K. A. Schönke war im Schulbetrieb tätig, so wird er im Untertitel seines 1856 erschienen Buches Die Sagenwelt der Alten. Für die Jugend bearbeitet als $\gg$ Lehrer an der königl. Luisenschule [scil. einer Mädchenschule] und beim königl. Seminar für Erzieherinnen zu Posen « betitelt. Und auch er richtet - das wird bereits ebenfalls im Untertitel deutlich - seine Nacherzählung an »die Jugend «, die dieselbe wohl » mit Beifall « aufnehmen dürfte, da Mythen »von der phantasiereichen Jugend « generell gern gelesen werden und Ovid »die jugendliche[n] Gemüther ganz besonders « (III) anspreche. Schönke denkt hierbei vor allem an diejenigen, » welchen diese Dichtungen im Original unzugänglich oder in ihrer Gesamtheit zum Lesen nicht anzurathen sind « (III). Nachdrücklicher als Lindner verweist Schönke auf die Rezeption der in den Metamorphosen behandelten Mythen innerhalb der (plastischen) Kunst und der Lite-

248 Anemüller (1883); Horn (2001).

249 Lindner, Lehrreicher Zeitvertrieb (1764), 29. - Im Folgenden werden Seitenzahlen jeweils in Klammern hinter dem Zitat angegeben.

250 An den Höheren Mädchenschulen gab es zu dieser Zeit keinen Unterricht in den Alten Sprachen, vgl. dazu Evers, (2011), 34.

251 Um dies zu unterstreichen, zeigt Lindner Beispiele aus den Metamorphosen (4-11) sowie Parallelen zur Bibel auf (Loth und seine Töchter - Myrrha und ihr Vater [11], Philemon und Baucis - Geschichte Abrahams [13]).

252 Lindner verweist im Vorwort bereits darauf » wie vortrefflich und ausbündig schön« (13) Ovid sich ausdrücke. Dies komme besonders in seinen Vergleichen und Beschreibungen zum Ausdruck, was Lindner abermals mit Beispielen aus den Metamorphosen veranschaulicht (13-28). 
ratur, weshalb » eine Auswahl derselben, mit der der Jugend gebührenden Vorsicht und Schonung bearbeitet und mit hübschen Illustrationen versehen, für dieselbe eine recht passende Lectüre zu sein « (III) scheine. Stark betont Schönke den Gedanken, dass sein »Büchlein « auch zum besseren Verständnis der Originallektüre »nicht unwichtige Dienste leisten kann « (IVf.) und schließlich »durch gelegentliche Mittheilung mythologischer Kenntnisse manchem willkommen sei[n], da es die Jugend in den Mythenkreis der alten Welt einführt und gewissermaßen zur Grundlage des Studiums der Mythologie dienen kann « (VI). ${ }^{253}$ Dieser gewinnbringende Nutzen der Nacherzählung für Schüler im Hinblick auf den Schulunterricht wird in der dritten Ausgabe des Werkes $(1908)^{254}$ konkretisiert: Hier weist der Herausgeber im Vorwort darauf hin, dass die Nacherzählung nicht nur für »Schüler[] der lateinlosen Schulen und der Höheren Mädchenschulen « verfasst sei, sondern auch für »die Schüler der Lateinschulen « (IV). Denn da »in der heutigen Zeit des Materialismus und des Utilitarismus « die »allzu nüchterne Verstandesbildung « in den Schulen im Mittelpunkt stehe, würde die »Phantasie der Schüler « (III) sowie die antike Mythologie keine Berücksichtigung finden - und das obwohl ohne Kenntnis der letzteren die griechische und römische Literatur nicht zu verstehen sei (IIIf.). Selbst in den humanistischen Gymnasien habe man keine Zeit mehr für eine »gründliche Beschäftigung mit diesem anmutigen Dichter « (IV), würde doch die Lektüre der Metamorphosen in den Lehrplänen immer mehr beschränkt werden. Diese Lücke nun solle durch das vorliegende Lesebuch geschlossen werden.

Karl Kindt, Jahrgang 1901, war bis 1940 als Studienrat tätig und hatte nach dem Krieg Lehraufträge an der Ruprecht-Karl-Universität in Heidelberg inne, wo er 1954 Leiter des Pädagogischen Institutes wurde. Im Gegensatz zu Lindner und Schönke richtet er seine Nacherzählung nicht explizit an einen jugendlichen Adressatenkreis, sondern spricht allgemeiner - sich selbst mit einbeziehend - von » uns «, die wir wie $»$ Blinde « der Kunst begegnen würden, »hätten wir nicht an dem römischen Dichter einen sachgemäßen Interpreten « (6). Dieser sei besonders aufgrund der Metamorphosen » aus der Substanz des abendländischen Geisteslebens « (6) nicht fortzudenken. Doch Ovid könne nicht nur als der »bedeutendste[] Vermittler der antiken Tradition « fungieren, ferner treten in den Metamorphosen »so tiefsinnige Welt- und Lebensauffassungen zutage « (14), dass sie den Leser »mit ewigem Sinne, mit heiligen Warnungen, Mahnungen, Forderungen, Tröstungen « (13f.) beglücken können, wodurch sich Ovid »in die Schar der wenigen schöpferischen Geister der Weltliteratur, der großen Seher und Erzieher des Menschengeschlechts « einreihe.

Was lässt sich daraus nun über die jeweilige Intention des Autors, eine Nacherzählung zu verfassen, ableiten? Lindners Bezeichnung seiner Nacherzählung als »Zeitvertreib « für die Jugend macht deutlich, dass er diese als Freizeitlektüre verfasste. Diese wirke sich aber nicht nur förderlich auf die allgemeine Bildung der Jugendlichen aus,

253 Brüggemann (1987), 18, betont, dass die Forderung nach Kenntnissen der Mythologie nicht nur mit dem $\gg$ Streben nach Bildung des Individuums « zu begründen sei, sondern dass es damals vor allem eine »Frage des nationalen Ansehens « gewesen sei » in der Mythologie bewandert zu sein «.

254 Schönke, Die Sagenwelt der Alten (1908). 
sondern es ließe sich auch ein Nutzen für den Schulunterricht aus dieser ziehen, könne sich die Nacherzählung doch auf die Lektüre des Originals förderlich auswirken. Es würde sich somit zwar um eine außerschulische Lektüre handeln, jedoch begleitend zum Unterricht. Auch Schönke verfasste seine Nacherzählung zunächst losgelöst vom Schulkontext, zeigt aber deutlicher als Lindner die Möglichkeit auf, wie diese als Schullektüre im weiteren Sinn ${ }^{255}$ von Schülern genutzt werden kann. ${ }^{256}$ Diese Verwendung wird in den folgenden Auflagen stärker betont. Aufgrund ihres konkreten Adressatenbezugs lassen sich die Nacherzählungen Lindners und Schönkes zur Gattung der Kinder- und Jugendliteratur zählen, welche die Schullektüre einerseits sowie die Kinderund Jugendlektüre andererseits mit einschließt. ${ }^{257}$ Kindt hingegen verfasst sein Werk für einen allgemeinen Leserkreis - ein schulischer Kontext bleibt hier gänzlich unerwähnt. Vielmehr wird weitreichender von Ovid als einem »Erzieher des Menschengeschlechts « gesprochen, sowie - wie auch bei Lindner und Schönke - die Rezeption der Metamorphosen und deren daraus resultierende bedeutende Rolle innerhalb der abendländischen Kultur hervorgehoben. Kindt sieht sich selbst in der Rolle eines »gewissenhaften Konservators, der Schmuckstücke alter Kultur so pflegt und poliert, daß nichts sie mehr hindert, in ihrem eigenen Glanze zu leuchten « (15).

Lässt sich also hinsichtlich des Adressatenkreises ein eindeutiger Unterschied ausmachen, so ist der Kern der Zielsetzung aller drei Autoren dennoch derselbe: die Lektüre der Nacherzählung soll dazu dienen, Kenntnisse zu vermitteln. Diese Kenntnisse wiederum führen durch das »Verständlichmachen « von Kunst und Literatur zur Kultur des Abendlandes hin, bewahren dieselbe und fördern die Aneignung von allgemeinem beziehungsweise schulischem Wissen ebenso wie die Ausbildung von ethisch und moralisch wertvollen Verhaltensweisen (»Persönlichkeitserziehung ${ }^{258}{ }^{25}$ ). Hinzu tritt bei Lindner und Schönke der Aspekt der Anregung der Phantasie und der daraus resultierenden Freude am Lesen. Der Kern der Zielsetzung ist also ein pädagogisch motivierter, was sich zu einem großen Teil auf die Tätigkeiten aller drei Autoren im Schulbetrieb zurückführen lässt.

\section{$\gg$ Blick in die Werkstatt « der Autoren}

\section{Intendierte Arbeitsweise}

Um seine jugendlichen Leser nicht mit unwichtigen »Namen der Hunde [...], der Helden [...], und dergleichen Sachen mehr « (28f.) zu unterhalten, habe Lindner sich darum bemüht »alles in möglichster Kürze zusammen zu fassen« und »weder in das

255 Unter Schullektüre im weiteren Sinn werden alle Texte verstanden, die zusätzlich zu den schulischen Lehrbüchern im Unterricht oder auf lehrerseitige Veranlassung hin zu Hause begleitend zu diesem gelesen werden. Vgl. dazu Ewers (2000), 54.

256 Dieser Schulkontext wird auch am Ende des Vorwortes noch einmal unterstrichen, da Schönke sein »Büchlein der lieben Jugend und ihren Lehrern « übergibt; Schönke (1856), VI.

257 Ewers (2000), 16.

258 Brüggemann (1987), 14. 
trockene und seichte, noch in das schwülstige und gekünstelte, zu verfallen, sondern nach Beschaffenheit der Materien bald kürzer, bald weitläufiger zu sein « (29). Er habe jedoch darauf geachtet »die verschiedenen Gemüthsverfassungen der Personen im Reden « (29) mit auszudrücken. Lindner hat seine Auswahl an Erzählungen originalgetreu in 15 Bücher unterteilt, in denen die erzählerische Chronologie aus den Metamorphosen beibehalten wird. Illustrationen wurden keine beigefügt, auch ist auf einen Anhang »zur Erklärung der Mythologie und der alten Erdbeschreibung « verzichtet worden, um - so Lindner - das Buch nicht unnötig zu vergrößern, könne man doch, sofern einem daran gelegen ist, »Nachricht hiervon in den gemeinesten Wörterbüchern finden «. Ebenso sei es jedoch möglich, »diese Verwandlungen $[. .].[\mathrm{zu}]$ lesen, ohne daß man sich drum bekümmert, wer diese oder jene Person gewesen sei, oder, wo dieses oder jenes Dorf liegt « (29f.).

Schönke habe »aus den Ovidischen Mährchen die interessantesten auszuwählen und in einfacher Weise [...] und unter sorgsamer Vermeidung alles dessen, was dem jugendlichen Alter anstößig und verderblich sein könnte « (IV) darzustellen gesucht. Im Gegensatz zu Lindner beschreibt er seine Übersetzungsarbeit genauer: Seiner Nacherzählung zugrunde liegen die Übersetzungen ${ }^{259}$ von Pfitz und Voß sowie die Ausgaben und Hilfsmittel ${ }^{260}$ von Bach, Lindemann und Siebelis. Er habe sich - wenn möglich - immer an Ovid gehalten, an einigen Stellen jedoch habe er - » um ein leichteres Verständniß herbeizuführen « - auch andere Schriften benutzt; hier vor allem Apollodor, aber auch zeitgenössische mythologische Arbeiten ${ }^{261}$ wie zum Beispiel von Schwab oder Grimm (VI). ${ }^{262}$ Seine Auswahl an Erzählungen, die der Chronologie des Originals folgen, gliedert er in $36 \mathrm{Kapitel}$, die teilweise Unterkapitel enthalten. Anders als bei Lindner findet man bei Schönke nicht nur acht »colorirte Bilder $\ll,{ }^{263}$ sondern im Anschluss an die Nacherzählung auch ein ausführliches »Alphabetisches Register zur Sagenwelt der Alten « (244-288), das Erklärungen zu den in der Nacherzählung auftretenden Personen sowie zu Geographie, Speis und Trank und anderen Gegen-

259 Bei den Übersetzungen handelt es sich vermutlich um die von Heinrich Christian Pfitz (1833) und Johann Heinrich Voß (1798), siehe Literaturverzeichnis.

260 Bei den Ausgaben handelt es sich vermutlich um: P. Ovidii Nasonis Metamorphoseon libri XV, mit kritischen und erläuternden Anmerkungen von E. C. Chr. Bach. Dieses mehrbändige Werk erschien in seiner 1. Auflage in Hannover in den Jahren 1831-1833; Publii Ovidii Nasonis Opera, berichtigt, übersetzt und erklärt von Heinrich Lindemann, Leipzig 1853-1856; Johannes Siebelis, Wörterbuch zu Ovids Metamorphosen, wurde in der 1. Auflage erst 1867 veröffentlicht. Es ist daher anzunehmen, dass Schönke sich hier auf eine Auswahlausgabe beruft, die im Jahre 1856 bereits publiziert worden war.

261 Bei den zeitgenössischen mythologischen Arbeiten handelt es sich vermutlich um: Gustav Schwab, Die schönsten Sagen des Klassischen Alterthums. Nach seinen Dichtern und Erzählern, 3 Bde., Stuttgart 1838-1840; Jacob Grimm, Deutsche Mythologie, Göttingen 1835.

262 Im Vorwort zur dritten Auflage wird die Hinzuziehung anderer antiker und moderner Autoren gemindert. Es wird hier von »geringen Zusätzen und Erweiterungen aus andern Schriftstellern « gesprochen, weswegen der ab der 2. Auflage hinzugefügte Nebentitel Ein Lesebuch aus Ovid gerechtfertigt sei; Schönke (1856), III.

$263 \mathrm{Zu}$ folgenden Erzählungen: Narcissus und Echo, Innenseites des Einbandes; Phöbus und Phaethon (17), Europa und Cadmus (41); Pyramus und Thisbe (77); Niobe (115); Nisus und Scylla (143); Orpheus und Eurydice (185); Scylla und Charybdis (227). 
ständen beziehungsweise Naturerscheinungen enthält. Ein solches Verfahren sei nötig, das betont Schönke in seinem Vorwort, »damit das Buch auch solchen Lesern verständlich werde, die wenig oder gar keinen Unterricht in der Mythologie gehabt haben $\ll$ (VI).

Kindt geht in seiner Einführung zwar ausführlich auf Leben und Werk Ovids sowie explizit auf die Metamorphosen als Werk ein, fasst sich jedoch in Bezug auf seine Arbeitsweise äußerst kurz: Es handle sich, wie bereits zitiert, nicht um eine »Neufassung der ovidischen Märchen, sondern nur [um eine] Nacherzählungen auf Grund der Übersetzung « (15). Welche Übersetzungen zugrunde liegen, verrät er - im Gegensatz zu Schönke - nicht. Auch Kindts Auswahl der Erzählungen, die er auf 24 Kapitel aufteilt, folgt der originalen Chronologie. Ähnlich wie bei Lindner findet sich bei ihm im Anschluss an die Nacherzählung kein ausführlicher Anhang, sondern lediglich »Anmerkungen « (157-161) zu den einzelnen Erzählungen, die neben einem genauen Quellenverweis spärliche Worterklärungen, ${ }^{264}$ Vergleichsaspekte ${ }^{265}$ und Kommentare ${ }^{266}$ enthalten.

\section{Praktische Umsetzung der Arbeitsweise}

Um die praktische Umsetzung der Arbeitsweise miteinander vergleichen zu können, wurden für die Analyse Textstellen aus der Geschichte um Pyramus und Thisbe (met. 4,55-166) ausgewählt, anhand derer charakteristische Eigenarten der Übersetzungsweise deutlich werden. Bei den ausgewählten Textstellen handelt es sich um den Beginn der Erzählung (met. 4,55-58), die direkten Reden (met. 4,73-78: das Einreden auf die Wand; met. 4,108-115, 118: Monolog Pyramus'; met. 4,142-144, 148-161: Dialog Thisbes) sowie einen bildlichen Vergleich (met. 4,121-124). Freilich können die Textstellen aufgrund ihrer stichprobenartigen Auswahl nicht repräsentativ für die gesamte Nacherzählung stehen, sollen aber zumindest einen Einblick in die Übersetzungsweise der drei Autoren geben.

Ovid beginnt die Erzählung mit der Vorstellung der beiden Protagonisten (met. 4,55f.):

Pyramus et Thisbe, iuvenum pulcherrimus alter,

altera, quas Oriens habuit, praelata puellis [...]

Lindner fasst knapp zusammen: »Pyramus und Thisbe, das schönste Paar im ganzen Orient $[\ldots] \ll(38)$. Schönke und Kindt hingegen halten zwar nicht die chiastische Wortstellung ein, bemühen sich aber darum, die gegenüberstellende Satzkonstruktion in der Übersetzung nachzuahmen. So heißt es bei jenem: »Pyramus war der schönste aller Jünglinge, Thisbe die Krone der Mädchen des ganzen Orients.« (74), und bei diesem: » [...] Pyramus und Thisbe, er der Herrlichste aller Jünglinge, sie die Schönste

264 Zum Beispiel: »Zu >Die große Flut<: Met. I, v. 253 ff. - Der Styx: der das Totenreich neunmal umkreisende Höllenfluß« (157).

265 Zum Beispiel: »Zu >Athamas und Ino<: Met. IV, v. 416 ff. - Vgl. die Höllenschilderung bei Virgil, im 6. Buch der Äneis! « (157).

266 Zum Beispiel: $\gg \mathrm{Zu}>$ Das Schloß der Fama<: Met. XII, v. $39 \mathrm{ff}$. - Welch eine archetypische Schau: diese Vorwegnahme der $>$ Idee $<$ des - Rundfunks! (161). 
aller Mädchen « (54). Handelt es sich bei den beiden letztgenannten Autoren lediglich um eine Reduktion ${ }^{267}$ im Sinne einer Stilsenkung im Hinblick auf das Original, so lässt sich Lindners Zusammenziehung als ein weitaus massiverer Eingriff in den Text bezeichnen.

Nach der Einführung der Charaktere folgt bei Ovid die Lokalisierung der Erzählung, in einer Umschreibung, mit der - das war dem antiken Leser wohl bewusst - die Stadt Babylon gemeint ist (met. 4,57f.):

[...] ubi dicitur altam

coctilibus muris cixisse Semiramis urbem.

Wie gehen die Übersetzer mit dieser Textstelle um? Lindner lässt die Umschreibung gänzlich weg und nennt die Stadt konkret beim Namen: »Pyramus und Thisbe [...] wohneten zu Babel, neben einander « (38). Auch Schönke nennt die Stadt beim Namen, fügt jedoch eine Beschreibung hinzu: »In Babylon, der ältesten und berühmtesten Stadt des Morgenlandes [...] (74), während Kindt dem Stadtnamen lediglich ein Attribut beifügt: $\gg I m$ alten Babylon lebten einst $[\ldots] \ll(54)$. Die Nennung der Stadt in allen drei Nacherzählungen ist ein erläuternder Zusatz, der die Rezipierbarkeit des Textes erhöhen soll. Es handelt sich demnach um eine Explikation, ${ }^{268}$ welche bei allen drei Texten eine Elision nach sich zieht: Der Verweis auf die sagenhafte Stadtgründung durch Semiramis bleibt unerwähnt. Diese Elision wird bei Schönke und im Ansatz bei Kindt durch eine zusätzliche Beschreibung neu »gefüllt « .

Ein weiterer interessanter Vergleichsaspekt, an welchem charakteristische Vorgehensweisen der Übersetzer ablesbar sind, ist der Umgang mit der wörtlichen Rede. Lindner entfernt sich hier erheblich vom Original, indem er die wörtliche Rede gänzlich weglässt und lediglich deren Kerninhalte äußerst knapp in einer indirekten Formulierung wiedergibt. ${ }^{269}$ Auch Schönke wendet zunächst das Mittel der Elision an und gibt die erste Rede indirekt wieder, ${ }^{270}$ übersetzt jedoch die beiden darauf folgenden, weitaus bedeutungsstärkeren Monologe, die die Trauer und Auswegslosigkeit der Protagonisten über den jeweiligen - vermeintlichen - Tod des Anderen ausdrücken, äußerst textnah ins Deutsche. ${ }^{271}$ Auffällig ist hier der Ausdruck »Memme « für die

267 Poiss et al. (in diesem Band), $\$ 10, \mathrm{Nr} .12$.

268 Poiss et al. (in diesem Band), $\$ 10$, Nr. 13.

269 Zum Beispiel: met. 4,107-119 gibt Lindner wie folgt wieder: »[...] da er aber vollends das blutige Gewand seiner Geliebten zu Gesichte bekam, so verwies er sich seiner Zauderungen auf das empfindlichste, nahm den Mantel, und, nachdem er ihn auf das beweglichste geküsset, und mit Thränen benetzt hatte, erstach er sich unter dem Baume « Lindner (1764), 40. Vgl. auch ebenda, $39 \mathrm{f}$.

$270 \gg[\ldots]$ schalten auch wohl auf die neidische Wand, die sie verhindere näher zu kommen und dankten ihr zuletzt doch, daß sie wenigstens ihren Worten den Durchgang gestattete «; Schönke (1856), 74.

271 Zum Beispiel der Monolog des Pyramus: »>O,< sprach er, >eine einzige Nacht richtet zwei treue Herzen zu Grunde! Ach, und sie war doch des längsten Lebens würdig! Ich allein bin schuld an deinem Tod, ich habe dich, Ärmste, gemordet, da ich dir befahl, bei Nacht an einen so schaurigen Ort zu kommen, und nicht zuerst hieher kam. O, zerreißet meinen Leib in Stücke, ihr Löwen alle, die ihr hier unter diesen Felsen hauset, und verzehret mein schuldiges Herz mit grimmigen Bissen! Doch was wünsch' ich mir nur den Tod! Das tut jede Memme!< $[\ldots]>$ Auch mit meinem Blute sollst Du getränkt werden!<«; Schönke (1856), 76. 
Wiedergabe von sed timidi est (met. 4,115), wobei eine solche Modernisierung ${ }^{272}$ im Hinblick auf den restlichen Textverlauf der Erzählung eine Ausnahme bleibt. Kindt bleibt dem Original am stärksten treu: Er gibt jede der drei wörtlichen Reden mit einer äußerst emotional gehaltenen Übersetzung wieder. ${ }^{273}$

Weiteren Aufschluss über die Übersetzungsarbeit der drei Autoren kann ferner die Untersuchung der Wiedergabe des folgenden, recht ungewöhnlichen bildlichen Vergleichs bringen (met. 4,121-124):

[...] cruor emicat alte,

non aliter quam cum vitiato fistula plumbo

scinditur et tenui stridente foramine longas

eiaculatur aquas atque ictibus aera rumpit.

Abermals formuliert Lindner sehr knapp: »Das Blut spritzte, wie das Wasser aus einer geöffneten Röhre, in die Höhe [...] « (40). Bei Schönke lautet es: »Hoch spritzt das Blut in die Höhe, nicht anders, als wenn die schadhaft gewordene Röhre einer Wasserkunst berstet und aus der dünnen Öffnung zischend der Wasserstrahl in die Höhe fährt und die Lüfte durchschneidet. « Kindt schreibt: »Als er so dalag [...], schoß ein Blutstrom hervor, wie ein Bleirohr, wenn es platzt, aus enger zischender Öffnung einen langen Wasserstrahl hoch emporschnellt.« (56). Anders als Lindner bemühen sich Schönke und Kindt darum, den Vergleich anschaulich ins Deutsche zu übertragen, wobei sich Schönke durch den Ausdruck »Wasserkunst « für das schwer wiederzugebende (vitiato) fistula (plumbo), wahrscheinlich um der Rezipierbarkeit willen, stärker vom Original entfernt.

Diese, wenn auch kurze, Textanalyse macht bereits deutlich, dass Lindner seinem im Vorwort formulierten Anliegen »alles in möglichster Kürze zusammen zu fassen « ohne Bedenken nachgeht - freilich, das wird sogleich zu Beginn der Erzählung deutlich, auf Kosten des Inhalts und des sprachlichen Ausdrucks: Feinheiten werden zu Gunsten der Rezipierbarkeit für ein jugendliches Publikum ausgeblendet beziehungsweise verkürzt, soll doch die Nacherzählung als angenehme Freizeitlektüre dienen. Seinem weiteren Anliegen allerdings, »die verschiedenen Gemüthsverfassungen der Personen im Reden « auszudrücken, kommt er, zumindest in Bezug auf die Geschichte von Pyramus und Thisbe, in keiner Weise nach. Allerdings muss an dieser Stelle hinzugefügt werden, dass Lindner nicht nur »ausblendet « und »verkürzt «, sondern an Textstellen, wo es der christliche Glaube fordert, sowohl $\gg$ hinzufügt $\ll{ }^{274}$ als auch Ra-

272 Poiss et al. (in diesem Band), $\$ 10$, Nr. 4.

273 Zum Beispiel der Monolog des Pyramus: »O kann uns diese Nacht nicht vereinigt sehen, so seh sie uns beide tot! Du Liebe! Ich bin der Frevler, ich habe dich getötet! Ich habe dich hinausgelockt in die schreckliche Nacht und war nicht vor dir zur Stelle! Zerfleischt mich drum, zerreißt mein sündiges Herz, ihr Löwen, die ihr dort in den Felshöhlen haust! Aber den Tod nur wünschen, das ist Feigheit! [...] Trink nun auch mein Blut!«; Kindt (1946), 55. Für die Wiedergabe der beiden anderen Reden siehe ebd., 54 und $56 \mathrm{f}$.

274 Met. 4,96: audacem faciebat amor wird mit »Die Liebe macht sie, wider die Gewohnheiten ihres Geschlechtes, kühn « übersetzt; Lindner (1764), 39. 
tionalität für Leidenschaft eintauscht. ${ }^{275}$ Schönkes Absicht, die Erzählung auf »einfache[] Weise « darzustellen, schlägt sich in einer verständlichen, wenn auch - im Vergleich zu Lindner und Kindt - teilweise recht ausschmückenden Sprache ${ }^{276}$ sowie in der Auslassung ganzer Textpassagen ${ }^{277}$ nieder. Die bemerkenswerte didaktische Aufbereitung unterstreicht den Gedanken, dass bei dieser Nacherzählung von vornherein stark an eine unterrichtsbegleitende Verwendung gedacht wurde. Zur Beantwortung der Frage, ob Schönke seinem Anspruch »Verderbliches « zu vermeiden, gerecht wird, lässt die Textanalyse keine Rückschlüsse zu, fest steht nur, dass die von Lindner »zensierten « Textstellen hier unangetastet bleiben. Allerdings weist die Verwendung des Ausdrucks »Memme « darauf hin, dass Schönke darum bemüht ist, die Sprache der Übersetzung an seine jugendlichen Leser anzupassen. Dass Kindt in seinem Vorwort kaum auf seine Arbeitsweise eingeht, mag damit zu begründen sein, dass er sich von den drei Autoren am Wenigsten vom Original entfernt: Er muss sich weder für Hinzufügungen noch für Auslassungen rechtfertigen. Dies und die spärliche didaktische Aufbereitung wiederum lassen sich darauf zurückführen, dass Kindt die Nacherzählung nicht an die Eigenarten eines jugendlichen Adressatenkreis anpasst.

Dennoch passt auch Kindt seinen Text an »seine «, wenn auch nicht explizit definierte, Leserschaft an. Dieser Prozess der Anpassung eines Textes an eine intendierte Leserschaft wird als Akkommodation bezeichnet. Für Nacherzählungen generell gilt, das wird bereits an der Definition deutlich, ${ }^{278}$ dass deren Akkommodation zu einem großen Teil aus der Reduktion ${ }^{279}$ besteht. Dies ist bei den drei untersuchten Nacherzählungen allein schon daran erkennbar, dass in Prosa erzählt wird, die Eigentümlichkeiten der Dichtkunst also zu Gunsten der Rezipierbarkeit aufgehoben werden: Im Mittelpunkt steht die Vermittlung des Inhalts. Lindners und Schönkes Nacherzählungen zeichnen sich im Vergleich zu Kindt dadurch aus, dass sie den speziellen Grundsätzen der kinder- und jugendgemäßen Akkommodation ${ }^{280}$ folgen, was besonders gut durch die Straffungen und Auslassungen sowie die Anpassungen an die damaligen Moralvorstellungen zum Ausdruck kommt. Bei kinder- und jugendgemäßer Akkommodation gilt es, die Balance zu halten zwischen den Anforderungen von Erziehung und Bildung einerseits sowie den Bedürfnissen von Jugendlichen andererseits. Da bei Schönke der Nutzen für die Schule und somit der Pol »Erziehung und

275 Met. 4,60 ff.: taedae quoque iure coissent, | sed vetuere patres; quod non potuere vetare, | ex aequo captis ardebant mentibus ambo wird übersetzt mit: »Sie würden auch wohl Eheleute geworden sein, wenn sie der Aeltern Einwilligung hätten erhalten können. Die Unmöglichkeit, selbige iemals zu erhalten, nöthigte sie, einander ihre Liebe auf eine andere Weise zu offenbaren «; Lindner (1764), 38.

276 So zum Beispiel die Übersetzung von altera, quas Oriens habuit, praelata puellis (met. 4,56) mit »die Krone der Mädchen« (68) und die Beschreibung der Stadt Babylon mit den Superlativen »schönste $[\mathrm{n}] \ll$ und »berühmteste[n] Stadt des Morgenlandes «; Schönke (1856), 68.

277 Indirekte Wiedergabe der ersten wörtlichen Rede.

278 Siehe oben S. $184 \mathrm{f}$.

279 Poiss et al. (in diesem Band), \$10, Nr. 12.

280 Vgl. Ewers (2000), 178-189. 
Bildung « eine stärkere Rolle spielt als bei Lindner, ist diese Nacherzählung didaktisch besser aufbereitet.

\section{Fazit}

Es wurden Nacherzählungen der Metamorphosen Ovids aus drei Jahrhunderten untersucht: eine jede charakteristisch für sich - und dennoch konnten Gemeinsamkeiten untereinander ausgemacht werden. Freilich können die drei Nacherzählungen nicht als repräsentativ für die jeweiligen Jahrhunderte betrachtet werden, es kann aber die Frage gestellt werden, ob sich diese in den Kontext »ihrer « Zeit einordnen lassen. Im Folgenden wird daher in Kürze zusammenfassend der historische Rahmen abgesteckt werden, in welchem sich die drei Nacherzählungen bewegen.

Die ersten Nacherzählungen antiker Mythen und Sagen werden ab der Mitte des 18. Jahrhunderts veröffentlicht - früher als Märchen, Volks- und Heldensagen ${ }^{281}$ - und stehen somit am Beginn der sich am Ende des 18. Jahrhunderts endgültig herausbildenden Kinder- und Jugendliteratur. ${ }^{282}$ Das lässt sich damit begründen, dass antike Mythologie im 18. und 19. Jahrhundert als wichtiger Bildungsgegenstand galt und dementsprechend im altsprachlichen Unterricht einen großen Stellenwert einnahm, was zu einem Aufschwung der Darstellung antiker mythologischer Stoffe für Kinder und Jugendliche führte. ${ }^{283}$ Handelte es sich zunächst fast ausschließlich um didaktisch ausgerichtete systematische Darstellungen mit »Handbuchcharakter «, die explizit für den altsprachlichen Unterricht konzipiert wurden, ${ }^{284}$ so machte sich im Laufe des 19. Jahrhunderts eine Veränderung bemerkbar: Die systematischen Darstellungen antiker Mythologie wurden - unter romantischem Einfluss - allmählich zu Gunsten einer rein narrativen Darstellungsweise antiker mythologischer Stoffe verdrängt, ${ }^{285}$ weshalb man von einer »Tendenz zur Popularisierung mythologischen Wissens ${ }^{286}$ innerhalb der Kinder- und Jugenliteratur spricht. An dieser Stelle muss freilich Gustav Schwabs 1838 erstmals veröffentlichte Sammlung Die schönsten Sagen des Klassischen Alterthums genannt werden, deren bis heute (!) ungebrochene Popularität ${ }^{287}$ für die Blüte der Nacherzählungen der damaligen Zeit steht. Diese Veränderung zog einen immer stetiger zunehmenden Verlust der $\gg$ Schultauglichkeit « der Werke nach sich. Am Ende des 19. Jahrhunderts schließlich beginnt die germanisch-deutsche Sagenwelt die antike Mythologie zu verdrängen, bis diese mit dem Aufkommen des National-

281 Pleticha (1987), 33.

282 Hurrelmann (1995), 10; Evers (2001), 53.

283 Petzold (1983), 253; Brüggemann, 1987, $11 \mathrm{f}$.

284 Pleticha (1987), 36.

285 Evers (2001), 63.

286 Brüggemann (1987), 12.

287 Schwabs Sagensammlung wird nicht mehr in der originalen Form publiziert, bis heute erscheinen jedoch zahlreiche Kurzausgaben, überarbeitet und dem heutigen Sprachgebrauch angepasst. 
sozialismus endgültig der nationalen Sagenwelt weichen muss. ${ }^{288}$ Nach dem Zweiten Weltkrieg jedoch versuchen die Verlage an die alten Vorlagen anzuknüpfen. Die Nacherzählungen allerdings entfernen sich immer mehr vom Original - ein Bezug zum Schulunterricht ist nun nicht mehr auszumachen. ${ }^{289}$

Lindner reiht sich mit seiner Nacherzählung nicht nur in die Anfänge der narrativen Darstellungsweise antiker mythologischer Stoffe, sondern in die Anfänge der Kinder- und Jugendliteratur überhaupt ein. Die Tatsache, dass in dieser Zeit systematische Darstellungen, sogenannte Mythologien, für den Schulunterricht verwendet wurden ${ }^{290}$ und Lindner mit seiner narrativen Darstellungsweise Neuland betritt, mag vielleicht die Begründung dafür sein, dass er die Verwendung der Nacherzählung als Zeitvertreib derart stark betont und bei Unverständnis auf, zu dieser Zeit scheinbar gängige, Nachschlagewerke verweisen kann. Seine Rechtfertigung im Vorwort für eine Nacherzählung der Metamorphosen sowie das »Ausbügeln« moralisch verwerflicher Textstellen, entspricht seiner Zeit, in der die antike Mythologie zwar als unentbehrlich zum Verständnis einer allegorischen Sprache der Künste angesehen, aber dennoch von vielen aus religiösen und moralischen Gründen abgelehnt oder als Aberglaube dargelegt wurde. ${ }^{291}$

Schönke, rund 100 Jahre später, gliedert sich in die Hochphase der Nacherzählungen antiker mythologischer Stoffe für Jugendliche ein. Die Beschäftigung mit der Antike wird zum alläglichen Gegenstand gebildeter Bürger, was seinen Niederschlag zum einen in der privaten Lektüre, zum anderen aber auch in der Schullektüre findet sei es im Unterricht oder diesen unterstützend - wie zum Beispiel auf nichthumanistischen Gymnasien, wo das Lesen einfacher Übersetzungen auf dem Programm stand. ${ }^{292}$ Womöglich beginnen Nacherzählungen antiker mythologischer Stoffe für den Schulunterricht auch deswegen an Bedeutung zu gewinnen, weil die Anzahl systematischer Darstellungen deutlich abnimmt. Dadurch gewinnt die im Rahmen der kinderund jugendgemäßen Akkommodation zu haltende Balance zwischen Schultauglichkeit einerseits und Lesefreude andererseits an Brisanz, was bei Schönke unter anderem an der Nennung der Vorlagen für seine Nacherzählung auf der einen Seite sowie an der Hinzuziehung anderer Quellen zum besseren Verständnis auf der anderen Seite deutlich wird. Doch nicht nur mit dem Genre der Nacherzählung, sondern auch mit dem Stoff bewegt er sich mit dem Strom der Zeit, erscheint doch gerade im 19. Jahrhundert eine Vielzahl an Schulausgaben der Metamorphosen Ovids. ${ }^{293}$

Die mit dem Aufkommen des Nationalsozialismus verloren gegangen Tradition der Nacherzählungen antiker mythologischer Stoffe nimmt Kindt nach dem Ende des 2. Weltkrieges wieder auf. Er schreibt aber nicht mehr im Rahmen der Kinder- und Jugendliteratur, sondern für einen allgemein gefassten Leserkreis. Und auch trotz des in

288 Evers (2001), 10f.; Pleticha (1987), 40; Brüggemann (1987), 31.

289 Pleticha (1987), $40 \mathrm{f}$.

290 Evers (2001), 62.

291 Brüggemann (1987), 23, 30.

292 Evers (2001), $36 f$.

293 Ebd., 37. 
den 1960er Jahren einsetzenden und bis weit in die 1970er Jahre reichenden Aufschwungs der Verwendung von Kinder- und Jugendliteratur im Schulunterricht, ${ }^{294}$ lässt sich für die zweite Hälfte des 20. Jahrhunderts bis heute feststellen, dass Nacherzählungen antiker mythologischer Stoffe für Kinder und Jugendliche, besonders im Vergleich zum 19. Jahrhundert, von geringer Bedeutung sind ${ }^{295}$ und innerhalb des Angebotes zur Antike allgemein (Sachbücher, Romane, Comics, Hörbücher) einen geringen Teil ausmachen. ${ }^{296}$ Ein Blick auf den aktuellen Buchmarkt zeigt auf, dass es zwar eine Auswahl an Nacherzählungen der homerischen Stoffe, allen voran der Odys$s e e,{ }^{297}$ sowie allgemeiner antiker Sagensammlungen gibt, im Hinblick auf eine akzeptable, didaktisch gut aufbereitete Nacherzählung der Metamorphosen Ovids offenbart sich jedoch - leider - eine große Lücke. ${ }^{298}$ Und das, obwohl gerade eine solche sowohl die schon seit langem geforderten ${ }^{299}$ neuen Ansätze zur Behandlung antiker Mythen sowie die Verwendung von Kinder- und Jugendlektüre im Lateinunterricht ${ }^{300}$ endlich voranbringen könnte.

\subsection{Ovid-Übersetzungen im 19. Jahrhundert}

Die universitäre Klassische Philologie steht gerade im 19. Jahrhundert dem Übersetzen dezidiert ablehnend gegenüber. Die eindringliche Warnung August Boeckhs: »Wenn die Philologie anfängt zu übersetzen, hört sie daher auf, Philologie zu sein «, ${ }^{301}$ ebenso wie Moriz Haupts Weigerung, selbst im mündlichen Vortrag ins Deutsche (wohl aber vom Griechischen ins Lateinische $)^{302} \mathrm{zu}$ übersetzen, sind zwar pointierte (Berliner),

294 Der Durchbruch gelang Anna Krüger im Rahmen der Reformdiskussionen mit ihrer Publikation Kinder- und Jugendbücher als Klassenlektüre. Analysen und Schulversuche. Ein Beitrag zur Reform des Leseunterrichts, 3. Auflage, Weinheim u. a. 1973.

295 Brüggemann (1987), 31; Evers (2001), 12.

$296 \operatorname{Kipf}(2003), 78$.

297 Die Auswahl an Nacherzählungen der Aeneis ist im Vergleich dazu sehr begrenzt.

298 Aktuell, aber sehr schwer erhältlich und nicht empfehlenswert: Astrid von Schoenebeck, Das Mädchen im Lorbeerbaum, Mythen nach den Metamorphosen des Ovid neu erzäblt (nicht nur) für Kinder, München 2008.

299 Schönberger (1979), 193, schrieb bereits vor über 30 Jahren, dass ihm außer einer Darstellung, keine weiteren Ansätze zur Behandlung von antiken Mythen im gymnasialen Unterricht bekannt seien. Bis heute kann von einem befriedigenden Angebot nicht die Rede sein; es zeichnet sich lediglich ein verstärktes Interesse gegenüber der Behandlung antiker mythologischer Stoffe in der Grundschule ab. Hier stehen abermals die homerischen Stoffe im Mittelpunkt.

300 Kipf (2003), 79, konstatiert, dass der Einbeziehung der Kinder- und Jugendliteratur in den Lateinunterricht $\gg$ in der fachwissenschaftlichen und in der fachdidaktischen Forschung bisher zu wenig Aufmerksamkeit geschenkt « worden sei. Hurrelmann (2000), 915, meint demgegenüber, dass das Nicht-Verwenden von Kinder- und Jugendliteratur in der Sek. I weniger »fachlich begründeter Überzeugung « zu verschulden sei als vielmehr »pädagogischer Unbeweglichkeit oder schlichter Unkenntnis. $\ll-$ Siehe jetzt speziell zu Ovid in der Kinder- und Jugendliteratur Janka/Stierstorfer (2015).

301 Vgl. z. B. zuletzt Kitzbichler (2012), 63 f.

302 Wilamowitz (1925), 7. 
aber durchaus repräsentative Stimmen, ${ }^{303}$ die das übersetzerische Metier als subwissenschaftlich oder gar wissenschaftwidrig brandmarken. ${ }^{304}$ Demgemäß beteiligt sich die Universitätsphilologie bis weit ins 20. Jahrhundert hinein so gut wie nicht am Übersetzungsgeschäft. ${ }^{305}$

Dennoch professionalisierte sich im Verlauf des 19. Jahrhunderts die Abfassung und Distribution der Übersetzungen aus den Alten Sprachen. Sie fanden ihren Platz nicht zuletzt in Übersetzungsreihen, ${ }^{306}$ hinter denen mehr oder minder ausformulierte Verlagskonzepte ${ }^{307}$ standen (Metzler seit $1827^{308}$, Langenscheidt seit $1855^{309}$ ). Auch

303 Die wichtigste Ausnahme ist Wilamowitz mit seinen erfolgreichen Dramenübersetzungen (vgl. Lubitz [2009], 196-207), der auch in dieser Hinsicht eine eigenständige Stellung in der deutschen Klassischen Philologie einnahm. Sein Berliner Kollege Eduard Norden übersetzte z. B. nur im Rahmen des Kommentars zum 6. Aeneis-Buch sowie in einer Lieberhaberedition Apuleius' Märchen von Amor und Psyche. $\mathrm{Ob}$ das stärkere Engagement der Universitätsphilologie zum Ende des 20. Jahrhunderts hin mit den Konzepten der Reihen zusammenhängt, die etwas Besonderes verheißen - Texte zur Forschung (Wissenschaftliche Buchgesellschaft Darmstadt), SAPERE - Scripta Antiquitatis Posterioris ad Ethicam Religionemque pertinentia / Schriften der späteren Antike zu ethischen und religiösen Fragen (Akademie der Wissenschaften, Göttingen) - oder das Prestige des Herausgebergremiums - Edition Antike (hg. von Martin Hose/Thomas Baier/Kai Brodersen, Wissenschaftliche Buchgesellschaft Darmstadt) -, wäre zu untersuchen, würde aber wohl auch in hohem Maß psychologische Faktoren zu berücksichtigen haben.

304 Vgl. auch Wilamowitz (1928), 284: »Wir sahen uns bald genötigt, in unserem sog. Proseminar Neuerungen einzuführen [...]. Das erste war die Schaffung einer Oberstufe, in die eine Prüfung hineinführte. Sie bestand aus einer Übersetzung aus dem Lateinischen und Griechischen, was zuerst als zu leicht beanstandet ward, sich aber durchaus bewährte.« - Ebd. 287: »Vollends seit die Intuition als eine höhere und bequemere Methode aufgekommen ist, erlebt man die schauerlichsten Proben der anmaßlichen unwissentlichen, aber auch wissentlichen Verleugnung des sprachlichen Verständnisses, ganz zu schweigen von kaum verhüllter Abhängigkeit von Übersetzungen. Vorsokratiker versteht man nicht aus den Übersetzungen von Diels, philosophische Gedanken überhaupt nicht anders als indem man griechisch denkt, vom Rechte gilt dasselbe. Aber bei den Poeten, auch bei Thukydides, ist es kaum anders. «

305 Lubitz (2009), 182-185.

306 Siehe Bachleitner (2008) und Lubitz (2009), 117-130. - Die Collection Speemann (Lubitz [2009], 123) enthielt keine neue Ovid-Übersetzung, sondern druckte 1883 die Voß'sche Fassung nach, bereichert um eine Einführung von Friedrich Leo. Nicht enthalten war Ovid sowohl in der Cotta'schen Bibliothek der Weltliteratur als auch in den Klassikern des Altertums (zu diesen Reihen Lubitz [2009], 124-126).

307 Wenig profiliert ist noch die Münchener Sammlung der Griechischen und römischen Klassiker in neuen deutschen Uebersetzungen von einem deutschen Gelehrtenvereine unter Leitung des Herrn Professors Oertel in Ansbach (München: Fleischmann; auch unter anderen, leicht abgewandelten Titeln geführt) gemäß der Anzeige in der Allgemeinen Kirchenzeitung, Beilage 1830, Nr. 22 (o. p.) weist sie folgende Vorzüge auf: »Wohlfeilheit, gefälliges Format, treffliche mit schätzenswerthen Anmerkungen begleitete Uebersetzungen sind die Vorzüge dieser Sammlung, die sich in ganz Deutschland der ausgezeichnetsten Aufnahme erfreut, und jedem Gebildten mit Recht empfohlen werden kann. « Zum Zeitpunkt dieser Anzeige waren Cicero, Horaz, Justin, Ovid (Exildichtungen, s. u. S. 200), Plinius, Tacitus, Homer, Pausanias und Thukydides abgedeckt. - Die ausführliche Ankündigung im Anzeigeblatt zur Münchener allgemeinen Literatur-Zeitung 1821, Nr. 1, 2-4, durch den Herausgeber sprengt leider den zur Verfügung stehenden Rahmen.

308 Diese Übersetzungsbibliotheken konnten auch abonniert werden. So findet sich in der Beilage zur Allgemeinen Zeitung Nr. 8, 1827, 31, über die im Metzler-Verlag erscheinenden Prosaübersetzungen 
die Metamorphosen-Verdeutschungen sind kaum mehr individuelle, spontane Hervorbringungen, sondern in diese großen von den Verlagen veranstalteten Übersetzungsbibliotheken eingebunden und damit auch deren formalen Gestaltungsprinzipien (nicht zuletzt beim Umgang mit metrischen Texten spürbar) unterworfen. Es ist dies auch die große Zeit der übersetzenden Gymnasiallehrer, ${ }^{310}$ die mit der Normalisierung des Bildungsganges im Zuge der Humboldt-Süvern'schen Refomen und der Professionionalisierung ihrer Ausbildung sich zu Wissenschaftlern aufgewertet sahen ${ }^{311}$ und das in publizistischen Ehrgeiz umsetzten. Bekanntestes Medium sind die Schulprogramme, ${ }^{312}$ die häufig textkritische Einzelfragen behandelten, wie sie auch die Universitätsphilologie in jener Zeit umtrieben, oder »Proben einer Übersetzung « (o. ä.) antiker Autoren, darunter prominent vertreten der Schulautor Ovid, ${ }^{313}$ enthielten. Auf diese Weise wurde nicht zuletzt das unterrichtliche Alltagstgeschäft (wie es Thomas Mann anhand von Hanno Buddenbrooks Schultag mit bitterem Spott gezeichnet hat) sublimiert.

angemerkt: »Jeden Monat erscheinen vier Bändchen; mittelst einer Auslage, die jährlich nicht über 6 Rhtlr. sächs. oder $11 \mathrm{fl}$. rhein. steigen kann, kommt auf diese Weise Jeder, der auf das ganze Werk unterzeichnet, in wenigen Jahren in den Besitz einer vollständigen Sammlung von Uebersezungen der vorzüglichsten Klassiker des Alterthums, die Treue mit Verständlichkeit und gefälligem, reindeutschem Ausdruke vereinigen [...]«; die Allgemeine Bibliographie für Deutschland, Nr.34, 25. August 1837, p. 515, Nr. 1108, vermerkt für das »12te[] bis 20te[] Bändchen « (scil. Terenz) einen Subskriptionspreis von 2 Taler (?) 6 Groschen. Dass das bisweilen auch eine Art von Etikettenschwindel war, zeigt die Notiz über die Münchener Sammlung (s. o., Anm. 307) in der Außerordentlichen Beilage zur Allgemeinen Zeitung 1828, Nr. 51, 204: »Es wurde vorgezogen, diese Sammlung nicht in dünnen Heften erscheinen zu lassen, weil es weder für das Publikum noch für den Verleger von Nutzen ist, und weil nur der Unerfahrne durch den Schein der Wohlfeilheit getäuscht wird. Die Münchener Ausgabe erscheint wie bisher in ansehnlichen Bändchen, was von vielen gewünscht wird, die den ephemeren Zwergheftchen-Ausgaben keinen Geschmack abgewinnen können. « - Die institutionellen Rahmenbedingungen werden in einem eigenen Projekt genauer zu untersuchen sein.

309 Wikipedia s. v. »Langenscheidtsche Bibliothek sämtlicher griechischen und römischen Klassiker « (Stand 28. September 2012); der Bd. 74 (Propertius - Statius - Tibullus, Berlin, Stuttgart 18551890) enthält - wie generell in dieser Reihe üblich - eine unpaginierte Übersicht über die erschienenen und geplanten Bände sowie Einige Winke zur Benützung der Langenscheidtschen Bibliothek sämtlicher griechischer und lateinischer Klassiker. Die Properz-Übersetzung z. B. stammt vom (zuletzt Lübecker) Schuldirektor Friedrich Jacob, der auch schon eine lateinische Properz-Edition 1827 vorgelegt hatte (Eckstein [1871], 222; Bursian [1881]), nach dessen Tod überarbeitet von Wilhelm Binder (1810-1876, vgl. die Onlinefassung: http://www.idref.fr/066975956), einem der produktivsten Übersetzer seiner Zeit, über den Eckstein (1871), 40, vermerkt: »Binder, Wilhelm Christian, geb. am 16. April 1810 in Weinsberg, beschäftigt in der Staatskanzlei in Wien, lebte nachher zu Ludwigsburg, 1845 katholisch. « Vgl. außerdem Siemann (1985), 130-134, mit weiterer Literatur. Binder war als Pfarrerssohn und zunächst Gymnasiallehrer eine durchaus zeittypische Erscheinung.

310 Vgl. Kipf (2013); Baumbach (2002).

311 Vgl. Wilamowitz (1892), 14: »Und wenn wir nun keine Schulamtscandidaten mehr unter unseren Zuhörern haben sollten - ja, Schulamtscandidaten kennen wir auch jetzt nicht darunter: wir kennen nun Studierende der Philologie. « Siehe dazu Fritsch (1982).

312 Baumbach (2002), 116-125.

313 Vgl. die Zusammenstellung in der Bibliographie; grundsätzlich Kipf (2013). 
Diese Neuorientierung vollzog sich selbstverständlich nicht schlagartig. So zeugt etwa das Herausgebergremium der Metzler'schen Übersetzungsbibliothek noch von der traditionellen Nähe von Theologie und Philologie ${ }^{314}$ und von der Permeabilität zwischenden geistlichen und pädagogischen Laufbahnen. ${ }^{315}$ Demgemäß zeichnet für die Übersetzungen der Metamorphosen, Fasti und der Exildichtung Heinrich Christian Pfitz (1789-1869) verantwortlich, der zuerst im thüringischen Hildburghausen, dann im benachbarten Eishausen als Pfarrer wirkte. ${ }^{316}$ Auch das Vorwort zum ersten Teilband der Metamorphosen ist eine nach Gedanken und Bibliographie noch tief im 18. Jahrhundert verhaftete Einführung ins Ovids Leben und Werk, von Eberhard Friedrich Mezger (1780-1849), damals Pfarrer in Murrhardt. Letzterer ist ausweislich

314 Das trifft auch für den Herausgeber der bei Fleischmann in München (s. Anm. 307) erscheinenden Reihe zu; vgl. seinen autobiographischen Abriss: Professor Dr. [Eucharius Christian Ferdinand] Oertel in Ansbach, keiner Akademie Mitglied, keiner Behörde Rath, keines Ordens Ritter etc. als Theolog, Philolog und Hydrolog von ihm selbst dargestellt [...], Erlangen 1840.

315 Die Herausgeber waren Gottlieb Lukas Tafel, seit 1818 Professor für Klassische Philologie in Tübingen, Christian Nathanael Osiander (1781-1855), Pfarrer - zuletzt Superintendent in Ulm - und zwischenzeitlich Gymnasiallehrer in Stuttgart, und Gustav Schwab (1792-1850), im Brotberuf ebenfalls Gymnasiallehrer in Stuttgart und Pfarrer. Vgl. die Anzeige in der Allgemeinen Kirchenzeitung 12 (1833): »Uebersetzungen alter Klassischer Dichter. Von dem Werke: >Griechische und Römische Dichter in neuen metrischen Uebersetzungen <, herausgegeben von den Professoren Tafel, Osiander und Schwab « (Stuttgart, Metzler'sche Buchhandlung) ist so eben erschienen: Ovid's Verwandlungen, übersetzt von H. C. Pfitz, Pfarrer in Eishausen. Vollständig in 5 Bändchen. $2 \mathrm{fl}$ oder $1 \frac{1 / 4}{4}$ Thlr Preuß. Früher sind von dieser Sammlung erschienen: Homers Odyssee, übersetzt von E. Wiedasch, Director des Pädagogium zu Ilfeld. Vollständig in 5 Bdchn. 2 fl. oder 1 1/4 Thlr Preuß. Virgils Aeneis, übers. von Ludw. Neuffer, Stadtpfarrer zu Ulm. Zweite durchaus verbesserte Aufl. Vollständig in 4 Bdchn. $1 \mathrm{fl}$. $36 \mathrm{kr}$ oder 1 Thlr. Preuß. Zunächst werden nun die übrigen Werke Homer's, Ovid's und Virgil's, Kallimachus, Plautus und Terenz in durchaus gelungenen Uebertragungen folgen, von welchen bereits mehrere unter der Presse sind. Der Subscriptionspreis für jedes Bändchen von ungefähr 128 Seiten in Taschenformat ist nur 24 fr. oder $3 / 4$ Thlr. Preuß. Durch diese Sammlung von Uebertragungen der vorzüglichsten Dichter des Alterthums, in Verbindung mit den von denselben Herrn Herausgebern in gleichem Formate bei uns erscheinenden $>$ Griechischen und römischen Prosaikern in neuen Uebersetzungen $<$, von welchen bis jetzt 213 Bändchen ausgegeben sind und, bei dem nun vorhandenen Vorrathe an Manuscripten, in der nächsten Zeit die Fortsetzung rascher folgen kann, erhält Deutschland zum erstenmale eine vollständige Riehe von deutschen Uebertragungen aller vorzüglichsten Klassiker des Alterthums, ein Werk, wie keine andere Nation, selbst England und Frankreich nicht, ein ähnliches in ihrer Literatur aufzuweisen im Stande sind.«

316 Die biographischen Daten sind schwer zu eruieren; vgl. Mörike (Bd. 15, 2000), 442. Die Trauerpredigt vom 10. Januar 1869 ist im Landeskirchenarchiv Eisenach (http://lka.allegronet.de/grec.php? urN=17484) aufbewahrt. Der Hildburghauser Superintendent Dr. [Max] Wölfing kommt darin auch kurz auf Pfitz' gelehrte Bestrebungen zu sprechen (6): »Ich selbst habe zwei Jahre lang als Schüler zu seinen Füßen gesessen und er hat mich eingeführt in die Elemente der lateinischen und griechischen Sprache, er hat mir den Confirmandenunterricht ertheilt [...]. Auch als metrischer Uebersetzer lateinischer Dichter hat er sich einen Namen gemacht und es sind einige solcher Werke von ihm im Druck erschienen und haben reiches Lob geerndtet. « Trotz dieser Kürze zeigt sich daran noch einmal die enge Verbindung von geistlichem Amt, Schulunterricht und Publikationstätigkeit, wie sie in der ersten Hälfte des 19. Jahrhunderts wohl letztmals möglich war. - Ich danke dem Landeskirchenarchiv Eisenach für die freundliche und unkomplizierte Überlassung einer Kopie der Predigt. 
der verfügbaren Bibliothekskataloge publizistisch nicht weiter hervorgetreten, ${ }^{317}$ seine Rolle als Autor des Vorworts scheint also auf persönlicher Bekanntschaft mit einem oder mehreren Reihenherausgebern im Württembergischen Umfeld (eventuell von Tübingen als Studienort ausgehend) zu beruhen. Was Pfitz für seine Aufgabe qualifizierte und wie der Kontakt hergestellt wurde, ist nur zu vermuten. Womöglich war man auf ihn durch seine Prosafassung von Ovids Exilgedichten ${ }^{318}$ aufmerksam geworden. Dort hatte er sich knapp über seine übersetzerischen Prinzipien geäußert: ${ }^{319}$

Dabei ging mein vornehmstes Bestreben dahin, mit wörtlicher Treue die höchste Deutlichkeit des Sinns zu verbinden; und ich schmeichle mir in dieser Hinsicht nicht ganz umsonst gearbeitet zu haben. ${ }^{320}$

Auch von Pfitz gibt es neben seinen Übersetzungen keine weiteren einschlägigen Arbeiten, wir haben es also mit im Wortsinne Amateurarbeiten zu tun, wie sie für das 18. Jahrhundert noch weit typischer waren.

Aus den Paratexten der Übersetzung erfährt man wenig über die Anlage der Übersetzung. Mezger attestiert der Übertragung, dass sie » bei den Völkern deutscher Zunge dem alten Rom und einem seiner gefeiertsten Dichter den längst behaupteten Ruhm fernerhin zu sichern hofft « ${ }^{321}$ Die Übersetzung selbst ist fast völlig frei von kritischen und exegetischen Anmerkungen, sie ist gemäß dem Reihenkonzept im Hexameter gehalten. Das Proömium liest sich demzufolge in der metrischen Umsetzung folgendermaßen:

Körper, verwandelt dereinst in neue Gestalten, zu singen,

Treibt mich der Geist. Ihr Götter (denn ihr auch wandeltet jene)

Seyd dem Beginnen geneigt, und vom Uranfange der Schöpfung

Führt fortlaufend das Lied auf unsere Zeiten herunter.

Charakteristisch ist die Spitzenstellung von $\gg$ Körper «, vom zweiten Vers des Originals an den Anfang des gesamten Textes gerückt, so dass der sprachliche Duktus Ovids umgekehrt ist. Dafür ist »dereinst « ein Füllwort ohne Pendant im Lateinischen (dazu zählt auch die enallagetische Auffassung von »neue «). Ansonsten hält sich Pfitz weitgehend in schon traditionell gewordener Weise an Ovids Formulierungen. Erstmals wird in dieser Übersetzung prima ab origine mundi mit »vom Uranfange der Schöp-

317 Nur die Sammlung Drei Predigten an den vaterländischen Festen, die in den Kirchen Wirtembergs den 28. Mai. den 5. und 6. Nov. 1809 gefeiert wurden wurde Stuttgart 1810 publiziert (vorhanden in der Württembergischen Landesbibliothek Stuttgart).

318 München 1826; vgl. o. Anm. 307.

319 V.a. wegen des Verzichts auf eine metrische Umsetzung wird die Übersetzung scharf kritisiert von Fr. Liebeg. Becher, Jabrbücher für Philologie und Paedagogik, Bd. 5 (1827), 305-310; ähnlich in der Tendenz ist Gräfenhan, Neue Kritische Bibliothek für das Schul- und Unterrichtswesen, Bd. 17 (1827), 9395.

320 Pfitz, Klagelieder (1826), 3. - Das entspricht auch dem Programm der Übersetzungsreihe (siehe oben Anm. 307), die u. a. verheißt, »von allem fremdartigen und Gemeinen durchaus frey [zu] seyn, ohne jedoch in das Gezierte zu fallen « (p. 3).

321 Textgrundlage sei das Corpus poetarum latinorum, hg. von W. E. Weber, eine in Frankfurt 1832 erschienene umfangreiche (mehr als 1400 Seiten zählende) Sammelausgabe der wichtigsten lateinischen Dichter, verwendet jedoch »mit eigenem Urtheil und Auswahl der wesentlichen Varianten «. 
fung « wiedergegeben, was dann auch Lindemann (s. u. S. 205) und Suchier (s.u. S. 209) als metrisch bequem übernehmen. Die textile Metapher in deducere bleibt allerdings unberücksichtigt und wird nur auf die zeitliche Abfolge bezogen. Es zeigt sich also bereits hier eine dezidierte Hinwendung zum vordergründig Inhaltlichen ohne Umsetzung der stilistischen, sehr wohl aber auch das inhaltliche Verständnis tangierenden Feinheiten (wie den Anklang an die Inspirationsvorstellung in adspirate).

Während für den Beginn der Metamorphosen Voß nicht als Orientierung zur Verfügung gestanden hatte, lehnt sich Pfitz bei der Erzählung von Pyramus und Thisbe teils deutlich an seinen Vorgänger an:

Pyramus war und Thisbe, der schönst' aus den Jünglingen jener

Diese der Jungfau'n Kron' im Orient. Beide bewohnten

Nah' anstoßende Häuser der Stadt, der erhabenen, welche

Einst Semiramis, heißt's, mit Backsteinmauern umschlossen.

Nachbarschaft schuf erst Umgang und Vertraulichkeit, Liebe

Wuchs mit der Zeit; auch hätt' ein ehelich Band sie vereinigt,

Doch dieß wehrten die Väter. Was nicht sie zu wehren vermochten:

Von gleichmäßiger Gluth entbrannten die beiden im Herzen.

Jeder Vertraute gebricht; sie sprechen durch Zeichen und Winke,

Und um so mehr aufbraust das Feuer, je mehr es bedeckt. wird.

Der erste Vers ist fast wörtlich aus Voß übernommen (s. o. S. 178), wodurch die Spitzenstellung der Eigennamen bewahrt ist. Wenn Pfitz dann eigene Wege geht und Ovids verbales praelata in $\gg$ Kron « substantiviert, bekommt er durch den Verzicht auf den Relativsatz seinen deutschen Hexameter nicht mehr voll und wird zum Enjambement gezwungen (ebenso beim darauffolgenden Übergang »Liebe / Wuchs mit der Zeit «). Unglücklich gelöst ist »nah anstoßende «, da zwar das Partizip die Verbindung der beiden Häuser - die ja später wichtig wird -, bezeichnet, was aber durch $\gg$ nah « wieder konterkariert wird. Geradezu sinnwidrig lässt dann das Enjambement vom fünften auf den sechsten Vers den Gedankengang werden, denn der Leseduktus führt unwillkürlich dazu, »Umgang «, »Vertraulichkeit « und »Liebe « zusammenzunehmen, was erst nach der Versgrenze (und im Unterschied zu Ovids Versbau) korrigiert wird. Auch nach den Maßstäben des 19. Jahrhunderts ist »jeder Vertraute gebricht « hart am Rande des Idiomatischen. ${ }^{322}$ Am Schluss der Passage greift Pfitz mit »aufbrausen « noch einmal eine Voß'sche Lösung auf, die allerdings das aestuat Ovids uminterpretiert und letztlich unverständlich werden lässt. Man sieht schon aus diesem kurzen Ausschnitt, dass Pfitz erheblich mit dem deutschen Hexameter zu kämpfen hat, der ihn zu mancher aus inhaltlichen Gründen fragwürdigen übersetzerischen Entscheidung zwingt.

Dieser Befund lässt sich anhand der Fortsetzung verallgemeinern, ist also nicht punktuell und zufällig:

Aber sobald er mit Blut auch findet den Schleier besudelt,

Spricht er: Die nemliche Nacht wird nun zwei Liebende morden!

Ach von denen doch Sie des längeren Lebens so werth war!

322 Vgl. Grimm (Bd. 4, 1878), 1850-1856 (s. v. »gebrechen «). 
Schuldig allein bin ich. Ich habe dich, Arme, getödtet!

Der ich an Orte der Furcht des Nachts dich kommen geheißen, und nicht zuvor ankam! O meine Gebeine zerreißet

Und mein frevelndes Herz mir verzehret mit wüthigem Bisse,

All' ihr Löwen, die nur dieß Felsengeklüfte beherbergt!

Doch Feigherzige w ünschen ${ }^{323}$ den Tod! - Und den Schleier der Thisbe

Hebt er, und nimmt ihn mit zu des Baums, des bezeichneten, Schatten.

Als dem bekannten Gewand' er Thränen und Küsse gegeben,

Nunmehr, spricht er, empfang auch unseres Blutes Benetzung!

Und in die Weiche versenkt er den Stahl, womit er umgürtet.

Sonder Verzug entreißt er ihn sterbend der brennenden Wunde.

Und wie er rücklings lag am Erdreich, sprudelt das Blut auf,

Eben nicht anders, als wenn bei beschädigtem Bleie die Röhre

Borst, und der dünnere Strahle des Wassers aus zischender Oeffnung

Hoch mit Gewalt aufspritzt, und die Luft durchspaltet im Aufschuß.

Durch Ansprudeln des Bluts umwandeln die Früchte des Baumes

Sich in schwarze Gestalt, und die blutanschluckende Wurzel

Färbet mit purpurnem Schmelz die abwärtshängenden Maulbeer'n.

Der Kampf mit dem Metrum und der Verteilung der Wörter darin setzt sich auch in diesem Abschnitt fort. Dadurch wird zwar der Inhalt von Ovids Erzählung weitgehend nachvollziehbar ins Deutsche gebracht, aber syntaktische Härten und gewaltsam wirkende Wortverwendung (»den Schleier [...] hebt er «) und Wortbildungen (»blutanschluckende « - ohne Pendant im Lateinischen; »Aufschuß «) bleiben unvermeidlich, ebenso wie das Auffüllen des Verses (»dünnere «, dreisilbig statt des zweisilbigen »dünne«, was tenui eher entspräche), auch wenn das Bestreben zu einer möglichst wörtlichen Umsetzung Ovids im Rahmen des Möglichen unverkennbar ist. Dass die von Ovid mit subtilen Mitteln herbeigeführten Effekte (wie una duos) nicht im Ansatz umgesetzt werden können, versteht sich fast schon von selbst.

Der Eindruck redlichen, aber nicht wirklich inspirierten Bemühens wird auch durch die Pygmalion-Sage bekräftigt:

Gleich nach der Heimkunft naht er dem Bilde des trautesten Mädchens,

neigt sich über den Pfühl und küßt. Sie schien zu erwarmen.

Wiederum naht er dem Mund und versucht mit der Hand auch den Busen.

Weich wird unter der Hand ihm das Elfenbein, und geschmeidigt

Schmiegt es den Fingern sich an, nachgebend, wie Wachs des Hymettus,

Wieder erweicht an der Sonn' und vom Daume behandelt, in viele

Formen sich williglich fügt und brauchbarer durch den Gebrauch wird.

Während der Liebende staunt und bange sich freut, sich zu täuschen

Fürchtet und wieder und wieder sein Lieb mit Händen berühret:

Leibt und lebt sie. Geprüft vom Daum schon schlagen die Adern.

Aber der Paphische Held volltönende Worte begann er

Jetzo, der Venus den Dank zu bezahlen, und heftete nicht mehr

Endlich auf fälschliche Lippe die Lipp', und gegebene Küsse

323 Die Markierung der Betonung durch Druckauszeichnung findet sich auch in anderen Übersetzungen, z. B. bei Fink (s. u. S. 223). 
Fühlt die Erröthende, hebt das Augenlicht zu dem Lichte

Schüchtern empor und schaut mit mit Himmel zugleich den Geliebten.

Zur Ergänzung des oben Ausgeführten sei darauf hingewiesen, dass suae durch »trauteste « (metrisch bequemer) wiedergegeben ist, dass bei incumbens toro und admovet os die Bewegungsrichtung unscharf bleibt, utilis in den Komparativ gesetzt ist. Unglücklich, da sinnstörend, ist auf jeden Fall der Enjambement »bange sich freut, sich zu täuschen / fürchtet «. Dagegen ist etwa remollescit durch die Zufügung von » wieder « exakter ausgedrückt als in dem meisten sonstigen Umsetzungen. Insgesamt ist Pfitz' Übersetzung vor allem als Zeugnis für den Fortgang der metrischen Übersetzungen nach Voß interessant: Der Hexameter ist nun das selbstverständliche Medium geworden, das nicht nur die gesamte Übersetzungsreihe trägt (und deren Fortsetzung über lange Jahre hin zeigt, dass das Kalkül von Verlag und Herausgebern aufgegangen ist), sondern auch keiner Begründung oder gar Rechtfertigung mehr bedarf. ${ }^{324}$

Pfitz' Übersetzung bildet ausdrücklich die Folie, mit der sich als nächster Verfasser Heinrich Lindemann ${ }^{325}$ auseinandersetzt, der Ovids vorexilisches Gesamtwerk zwischen 1853 und 1867 zweisprachig herausbringt, als »vormaliger Gymnasiallehrer «, wie es kaschierend auf dem Titelblatt heißt. Er war nach der Märzrevolution 1848/49, bei der er sich in Sachsen mit konstitutioneller Zielsetzung betätigt hatte, 1849 aus seinem Amt als Lehrer in Plauen entfernt worden, gar zu einer sechsjährigen Zuchthausstrafe verurteilt, offenbar aber vorzeitig entlassen worden, ohne dass er jemals wieder in den Schuldienst hätte gelangen können (das unterscheidet ihn von Moriz Haupt, Otto Jahn und Theodor Mommsen, die gleichfalls - als Professoren - wegen ihrer Haltung in der Märzrevolution aus dem sächsischen Dienst entfernt, aber nicht zu Gefängnisstrafen veruteilt wurden und anderwärts Karriere machen konnten $\left.{ }^{326}\right)$. So verdiente er seinen Lebensunterhalt vornehmlich mit Nachhilfestunden, fand aber auch noch die Zeit und die Kraft zu einer Ovid-Übersetzung, die den Anspruch von Wissenschaftlichkeir und Zeitgemäßheit keineswegs aufgegeben hat. Die Begleitumstände der Entstehung sind allerdings in der Übersetzung nur mit äußerster Reduktion erwähnt. ${ }^{327}$ Wahrscheinlich wäre es in einer Zeit der Restauration dem verlege-

324 Noch nicht dokumentiert, geschweige denn aufgearbeitet sind die angesichts des Verwendungszwecks selbstverständlich in Prosa gehaltenen Übersetzungen und »Präparationen « zu lateinischen und griechischen Autoren, die den Schülern bei der Vorbereitung oder auch im Unterricht selbst das Leben erleichtern sollten. Sie erschienen teils in eigenen Reihen (Freund's Schülerbibliothek seit ca. 1859), teils auch anonym (»von einem Schulmann «), etwa die auf die 15 Bände aufgeteilten Präparationen $z u$ Ovid's Metamorphosen (Düsseldorf 1886-1887) oder die im Teubner-Verlag seit 1902 erscheinenden Schülerpräparationen zu lat. und griech. Schriftstellern; vgl. unten Anm. 333.

325 Siehe http://www.pantoia.de/Schiller/Lindemann1859/vita.html (Online-Ausgabe von Schillersche Dichtungen in Lateinischer Uebersetzung. Ein Beitrag zur hundertjährigen Geburtstagsfeier des Dichters, von Heinrich Lindemann, Leipzig 1859).

326 Siehe Rebenich (2005).

327 Lindemann, Ovids Werke (Bd. 1, 1853), XVIII (Schluss des Vorworts): »So mögen denn Ovids Verwandlungen in dem neuen Deutschen Kleide recht Vielen eine Quelle des Genusses werden, wie sie selbst dem Bearbeiter nicht nur seit seiner frühen Jugend eine Quelle hohen Genusses und vielfacher Belehrung, sondern auch in den letzten Jahren eine reiche Quelle des Trostes in Haft und Gefangenschaft waren. « Vgl. Einleitung, ebd., XXIII (über Ovids Verbannung): »[...] nicht durch 
rischen Erfolg abträglich gewesen, wenn der Verfasser im Geruch revolutionärer Umtriebe gestanden hätte, so dass nur das durch den früheren Beruf Lindemanns bewirkte Bildungsprestige und die Seriositätsgarantie erscheinen.

Die Übersetzung umfasst sechs Bände, davon drei für die Metamorphosen, sie wird um einen Index zu Ovids Verwandlungen. Mit besonderer Rücksicht auf die Ausgabe des $V f s$. (1859) ergänzt. Dieser doppelte Ansatz - einer nach aktuellem wissenschaftlichen Stand hergestellten Ausgabe und einer Übersetzung - ist schon am Beginn des Vorworts herausgestellt:

Der Zweck vorliegender Ausgabe der Verwandlungen Ovids ist, dieses altrömische Dichtwerk nach dem jetzigen Standpunkte der Kritik in der Ursprache berichtigt, sinn-, wortund maßgetreu übersetzt und in allen nicht schon durch die Übersetzung deutlich gewordenen Beziehungen erklärt, literarisch wie allgemein gebildeten Freunden des classischen Alterthums vorzulegen und zugleich Lernenden auf dem Gymnasium das Verständniß des Dichters zu erleichtern. ${ }^{328}$

Entsprechend diesem gelehrten Anspruch geht Lindemann die vorliegenden Editionen seit Burmann und Heinsius kritisch durch und verweist auf seine eigenen Studien, nämlich die Autopsie einer Ovid-Handschrift in der Dresdner Staatsbibliothek, ${ }^{329}$ wobei sein Plan, auch die übrigen Dresdner Ovid-Handschriften zu kollationieren, wohl unausgeführt blieb. ${ }^{330}$ Auf der anderen Seite beruht die gedruckte Übersetzung auf der früheren Unterrichtspraxis Lindemanns, der auch seine Schüler zu metrischen Übersetzungen anhielt. ${ }^{331}$ Es handelt sich also um eine geradezu idealtypische Demonstration, wie im 19. Jahrhundert die Gymnasiallehrer sich im Schnittfeld von Schule und Wissenschaft positionierten. ${ }^{332}$ Daran zeigt sich nicht zuletzt, dass die ästhetischen Verdikte über Ovid und die lateinischen Dichter insgesamt, die auch die Universitätsphilologie erreicht hatten, in der Schule von geringer oder gar keiner Be-

richterliches Erkenntniß oder Senatsbeschluß verhängt, sondern von dem Belieben des Herrschers dictirt wurde, mithin fürstliche Ungnade war, die schon damals zu grassiren anfieng $[\ldots] \ll .-$ Lindemann hat ausgerechnet die biographisch naheliegenden Exilgedichte Ovids nicht übersetzt, ohne dass sich dafür eine explizite Begründung finden ließe.

328 Lindemann, Ovids Werke (Bd. 1, 1853), V.

329 Mscr. Dresd. Dc. 143: It. dem aktuellen Katalog (Manuscripta Mediaevalia, http://www.manuscriptamediaevalia.de/dokumente/html/obj40173063) »schwer beschädigt «: »Ovidii metamorphoseon libri XV. Pergament *? 146 Bll. *? 13. Jahrh.; Äußeres: Cod. membr. 146 foliorum in 8. maj.; Geschichte: saec. 13. a pluribus librariis exaratus. In fronte inscripsit ignotus vir doctus: Hic, quem Lipsiae emi, codex forsitan fuit olim in Bibliotheca Fr. Ben. Carpzovii, is enim mentionem facit Metamorphoseos librorum membranae inscriptorum in Epistola ad Heinsium, quae extat in sylloge Burmanniana t. V nr. 279 p. 338. Regia bibl. eum emit a G. H. J. Stoeckhardto a. 1797 pretio 10 Thalerorum.«

330 Lindemann rekurriert besonders auf die Ausgabe von Vitus Loers (gest. 1862: Eckstein (1871), 284) 1843 (vorausgegangen war seine Schulausgabe 1837), der auf S. X auch den in Anm. 329 beschriebenen Codex erwähnt.

331 Lindemann, Ovids Werke (Bd. 1, 1853), VIII (Vorwort). - Vgl. zum Interesse an der Metrik schon Lindemann, Materialien (1830), wo die Verfertigung lateinischer Verse der metrischen Übersetzung ins Deutsche vorausgeht.

332 Vgl. Kipf (2013). 
deutung waren, da eben die Faktizität des Lehrplans die lateinischen Autoren zur Hauptlektüre machte. Den doppelten Anspruch, aber auch die apologetische Grundhaltung von Übersetzern in der damaligen Zeit demonstriert der weitere Fortgang des Vorworts: Einerseits hebt sich Lindemann dort gegen seine Vorgänger Voß und Pfitz durch detaillierte, v. a. auf das Metrische und die Wiedergabe einzelner Wörter zielende Übersetzungskritik sowie Aussagen über die korrekte deutsche Sprachverwendung und Metrik ab (ausführlich dann in der Einleitung, XXVIII-XXXIV), andererseits muss er sich auch gegen den Vorwurf verwahren, er leiste durch eine Übersetzung der Faulheit Vorschub:

Im Gegentheile werden Sachverständige, besonders erfahrene Lehrer, finden, daß in dieser Übersetzung dem Schüler keine Eselsbrücke erbaut ist, sondern im Gegentheile eine umso sorgfältigere Vorbereitung nöthig ist, als die wenn auch sinn- und möglichst wortgetreue, doch keineswegs wörtliche Übersetzung leicht verführen kann. ${ }^{333}$

Damit versucht der Übersetzer gewissermaßen eine Synthese der beiden dichotomischen Maximen » nach dem Sinn - nach dem Wort $\ll .{ }^{334}$ Wie das in der Praxis aussieht, zeigt die Umsetzung des Proömiums:

Wandlungen treibt zu verkünden der Form zu neuer Gestaltung

An mich der Geist. Zeigt, Götter - denn ihr auch habt sie verwandelt -

Meinem Beginnen euch hold, und vom Uranfange der Schöpfung

Führt bis auf unsere Zeit den Faden beständiger Dichtung.

Der Preis, der für den deutschen Hexameter zu zahlen ist, ist hoch und verhindert wohl in der Tat den bequemen Unterschleif: mutatas [...] formas wird substantiviert und zur Genitivkonstruktion, das daraus entstehende »Wandlungen « wird durch die Spitzenstellung zum Äquivalent eines antiken Buchtitels. Die Phrase selbst ist beinahe tmesishaft auseinander gerückt, die Stellung des eigentlich zu »Wandlungen « gehörigen »zu neuer Gestaltung « macht den deutschen Satz noch schwerer durchschaubar. »Geist «, bei Ovid bereits als viertes Wort erscheinend, wird durch Enjambement in den zweiten Vers der Übersetzung gerückt. Durch diese Umstellungen wird auch der deutsche BeZug von »sie « in der Parenthese verunklart.

Kurz, Lindemann bringt im Proömium weder den Autor zum Leser noch den Leser zum Autor, sondern erschafft gewissermaßen eine künstlich verrätselte Übersetzungssprache, die vom metrischen Diktat getragen den lateinischen Text wesentlich

333 Lindemann, Ovids Werke (Bd. 1, 1853), XVII. Zu einem solchen Vorwurf siehe pars pro toto z. B. die Besprechung eines Griechischlehrbuches in der Zeitschrift für Altertumswissenschaft (1835), Nr. 150, 1202, wo die Notwendigkeit der Neuerscheinung dadurch begründet wird, dass zum bisher verbreiteten Elementarbuch »Präparations- und Uebersetzungshefte von Geschlecht zu Geschlecht fortgepflanzt [werden] und oft selbst einen Handelsgegenstand ausmachen «. Aber noch schlimmer: »Wir meinen die schnödeste aller Sünden einer frechen Speculation auf die Faulheit der lernenden Jugend, jene gedruckte Uebersetzung des Jacobsischen Elementarbuches, mit welcher deren Verfasser nur die stinkenden Quellen, aus denen er die Elemente des Griechischen geschöpft, aufgedeckt und mit ewig denkwürdiger Unverschämtheit die ehrlose Art seiner eigenen Schülerbetriebsamkeit an den öffentlichen Schandpfahl gestellt haben kann.«

Kitzbichler (2007). 
komplizierter erscheinen lässt, als er tatsächlich ist, ohne die syntaktisch-verbalen Härten durch ein luzides Verständnis der Gedankenstruktur und -abfolge aufzuwiegen. Auch wenn nichts über Auflagenhöhe und Verkaufserolg der Ausgabe bekannt ist immerhin wurde das Gesamtprojekt über eineinhalb Jahrzehnte fortgesetzt (18531867) -, so zeigt doch die Tatsache, dass es offenbar weder Neuauflagen noch Nachdrucke gab, dass Lindemanns Übersetzung sowohl in ihrer eigenen Zeit als auch danach aus dem Übersetzungdiskurs herausgefallen war. Erschwerend kam hinzu, dass sie nicht in die übersetzerischen Großunternehmungen des 19. Jahrhunderts eingebunden war und damit auch nicht durch Reihensubskriptionen profitieren konnte.

Pyramus und Thisbe, der schönste der Jünglinge Jener,

Sie vorragend an Reiz vor den morgenländischen Mädchen,

Wohnten in Nachbarshäusern, allwo nach der Sage die hohe

Stadt Semíramis einst mit Backsteinmauern umschlossen.

Nachbarschaft machte bekannt und knüpfte die Bande der Neigung;

Liebe erwuchs mit der Zeit. Auch einte das Recht sie der Fackel,

war nicht der Väter Verbot. Was nicht verbieten sie konnten,

Von gleichmächtiger Gluth entzündet brannten die Herzen.

Jeder Vertraute gebricht, sie sprechen durch Zeichen und Winke;

Und je verdeckter sie brennt, je mehr nun lodert die Flamme.

Man tut Lindemann vielleicht nicht zu sehr Unrecht, wenn man an diesen Versen zeigt, wie der Übersetzer sich schwer tut, wenn er seinen eigenen Weg finden will. Das mag auch an der Schwierigkeit liegen, aus der mündlichen Präsentation des Unterrichts (darauf hatte er ja ausdrücklich für die Genese der Übersetzung verwiesen) den Übergang in eine rein schriftliche Kommunikationssituation zu finden, die keine individuelle Betonung erlaubt. Die Juxtaposition von $\gg$ Stadt $\ll$ und $\gg$ Semiramis $\ll$, die noch dazu durch das Enjambement enger gestaltet ist, lässt beim Lesen die Assoziation eines Städtenamens entstehen. Diese fehlende Disambiguierung zeigt sich auch gleich darauf in den nicht als Konjunktiv erkennbaren »einte «, was (anders als bei Ovid) zuerst in der Tat die Ehe suggeriert, bevor im folgenden Vers mit »war nicht « (evtl. Druckfehler für » wär nicht «; ansonsten wäre die Quasi-Indikativ-Form sehr irreführend) die Einschränkung vorgenommen wird.

Es fällt weiter auf, dass Lindemann nicht überall Distanz zu seinem gescholtenen Vorgänger Pfitz hält. Manche Verse sind beinahe wörtliche Übernahmen, z. B. »Jeder Vertraute gebricht «, »Und in die Weiche $[\ldots] \ll ;$; »im Aufschuß spaltet « (Pfitz: »durchspaltet im Aufschuß«). Will man dem Übersetzer nicht Plagiat unterstellen, so wird man von der Suggestion des Gelesenen, die sich über die sprachliche Schwierigkeit legt, auszugehen haben. »Beströmung « ist aus Voß übernommen, korrespondiert aber zugleich mit der ähnlichen Wortbildung »Bespritzung «:

Wie er jedoch den Schleier auch triefend von Blut fand,

Rufet er: Eine Nacht bricht zwei treu liebende Herzen;

Ach und des längsten Lebens doch werth war sie von uns Beiden!

Ich nur trage die Schuld, ich habe dich, Ärmste, gemordet,

Der ich zu kommen dir hieß bei Nacht an Orte voll Grausen

Und nicht zuerst ankam. O reißt mir den Körper in Stücke 
Und verzehrt mein schuldiges Herz mit grimmigem Bisse,

All' ihr Löwen zumal, die ihr haust hier unter dem Felsen!

Doch nur zu wünschen den Tod ist feig. Den Schleier der Thisbe

hebt er auf und nimmt ihn mit fort zu dem Schatten des Baumes.

Und wie Thränen, wie Küsse er giebt dem bekannten Gewebe,

Spricht er: Empfange denn jetzt auch meines Blutes Beströmung!

Und in die Weiche versenkt er den Stahl, mit dem er umgürtet.

Rasch drauf zieht er ihn sterbend heraus aus der brennenden Wunde.

Rücklings lag am Boden er da; hoch spritzt das Blut auf;

G'rade wie wann schadhaft die bleierne Röhre geworden,

Berstet und mächtig empor aus der dünnen zischenden Öffnung

Schleudert den langen Strahl und im Aufschuß spaltet die Lüfte.

Da nun wandeln die Früchte des Baumes von des Blutes Bespritzung

Um sich in schwarze Gestalt, und die Wurzel, vom Blute befeuchtet,

Tränkt mit Phönicischem Roth den Saft der hangenden Beeren.

Auffällig ist am Ende noch die Auffüllung »mit Phönicischem Roth «, die aus der weniger verbreiteten Lesart phoeniceo [...] colore ${ }^{335}$ übernommen ist, was auch die zugehörige Fußnote ausfürhlich belegt, ${ }^{336}$ doch scheint dies der Übersetzer selbst für erläuterungsbedürftig zu halten, da er colore durch die Angabe der konkreten Farbe vereindeutigt. Darin zeigt sich das Spezifikum von Lindemanns Arbeit, die sich um wissenschaftliche Anerkennung müht (die ihr allerdings versagt geblieben ist - sie ist nicht einmal bei Magnus [1914 $]^{337}$ erwähnt), auf die eigene Manuskriptautopsie abhebt (und dabei einen gewissen lokalpatriotischen Stolz auf die Dresdner Handschrift entwickelt) und der Übersetzung stützende Erläuterungen beigibt, jedoch es nicht wirklich schafft, auf diesem Fundament ein adäquates, überzeugendes Gebäude zu errichten. ${ }^{338}$

335 Die neueren Editionen ziehen diese Lesart nicht in Betracht, nur bei Magnus (1914) ist sie mit der Sigle $\varsigma$ (aliquot codices deperditi aut ab NHeinsio aut ab aliis collati) genannt; entsprechend auch in Heinsius (1758) und noch in Bach (1831), wo ad loc. purpureo als Glosse verdächtigt wird.

336 Lindemann erläutert: »Puniceo, das auch die Dresd. Hdschrift A hat, ist ohne Zweifel das Ursprüngliche und wird von zwei Pariser Hdschriften mit Poeniceo, der althertümlichen Form, dergleichen Ovid nicht liebte; purpureo ist (gewöhnliche) Glosse «; vgl. dazu die gleichartige Erläuterung von Bach (1831), vor. Anm.

337 Hugo Magnus war selbst Gymnasiallehrer für die Alten Sprachen (geb. 1851: siehe Kössler [2007], s. p.; verstorben 1914: Hermes 60 [1925], 113, Anm. der Redaktion zu Magnus' letztem Aufsatz); seine Editio maior der Metamorphosen (1914) hat bis heute einen wichtigen Platz in der Editionsgeschichte Ovids.

338 Die Übersetzung der Pygmalion-Passage ergibt keine wesentliche Modifizierung des bisher Gesagten. Lindemann gibt den Text philologisch richtig, aber sehr bemüht, unter Anwendung von aufgefüllten Formen (»nahet «), Doppelungen (»noch« »noch «) und altertümlicher Redeweise (»erwarmet «, belegt bei Schiller und Hölderlin), wieder:

Wieder zurück drauf kehrt er zum Bildniß seiner Geliebten.

Küsse ihr gab er, geneigt auf das Bett; sie schien zu erwarmen.

Wiederum nahet sein Mund, mit den Händen auch prüft er die Brüste:

Siehe, das Elfenbein wird weich, und frei von Erstarrung

Giebt den Fingern es nach und weicht, wie das Wachs des Hymettus

Weich an der Sonne wird und sich schmiegt zu vielerlei Formen 
Von erheblich größerer Langzeitwirkung war die Metamorphosen-Übersetzung Reinhart Suchiers, eines Gymnasiallehrers aus Hanau, ${ }^{339}$ die bis zum Ende des 20. Jahrhunderts immer wieder nachgedruckt und bearbeitet wurde (vgl. unten S. 225) und damit neben Voß am längsten auf dem Buchmarkt kontinuierlich präsent ist. Programmatisch stellt er in der Vorrede fest:

Das erste Erfordernis einer guten Übersetzung ist also Sprachrichtigkeit. Satzfügung, Wortstellung, Ausdruck müssen dem deutschen Sprachgebrauche entsprechen. Der römische Dichter muß, wenn er mit Ehren bestehen will, zu dem Deutschen nicht minder deutlich, edel und geziemend reden wie zu dem Römer; er darf sich nicht in lauter Latinismen bewegen, wie bei Voß, dessen Übersetzung [...] oft schwerer zu verstehen ist, als das Original selbst. ${ }^{340}$

Das ist eine klare Absage an das Humboldt/Schleiermacher'sche Übersetzungskonzept, das eben gerade die Bewahrung der Fremdartigkeit sich zum Ziel gesetzt hatte. ${ }^{341}$ Die metrische Form ist allerdings beibehalten (ebenfalls in der Vorrede erörtert), von gelehrtem Ehrgeiz zeugen (neben den erklärenden Anmerkungen) die beigegebenen Mythendeutungen ( $\gg$ aus dem uns Deutschen eigenen Bestreben hervorgegangen, einer Sache möglichst auf den Grund zu gehen «, VIII) und der kritische Anhang (u. a. mit Abweichungen von der Teubneriana Rudolf Merkels, zuerst 1852) zeugen vom gelehrten Ehrgeiz, wie er typisch ist für deutsche Gymnasiallehrer im 19. und auch noch im 20. Jahrhundert.

Unter des Daumens Druck, und brauchbar durch den Gebrauch wird.

Während er staunt und noch zweifelnd sich freut und Täuschung noch fürchtet,

Drückt er mit liebender Hand sein Sehnen wieder und wieder.

Körper denn war's; es klopfen, versucht mit dem Daumen, die Adern.

Jetzt in strömenden Worten ergießt sich der Paphische Heros,

Darzubringen der Göttin den Dank. Und fälschlichen Mund nicht

Drückt er mit seinem Mund nun mehr; es empfindet die Jungfrau

Schaamerröthend den Kuß; und das schüchterne Auge zum Lichte

Hebt sie empor und erblickt mit dem Himmel zugleich den Geliebten.

339 1823-1907, seit 1846 in Hanau; siehe Kössler (2007), s.p., außerdem Suchier (Schulprogramm 1853).

340 Suchier (1868), III.

341 Suchier (1868), IV, gibt sich ausdrücklich die Lizenz zu kreativem Umgang mit der Sprache: »Unsere moderne Sprache trägt sich mit so vielen schwerfälligen durch unnöthige Zusätze erweiterten Formen, daß man es der Poesie nur Dank wissen kann, wenn sie zur ursprünglichen Einfachheit zurückkehrt. Bux für Buxbaum, Bims für Bimsstein, Eben für Ebenholz, Wal für Walfisch haben dieselbe Berechtigung wie Tanne für Tannenbaum, Ur für Auerochs, Bambus für Bambusrohr; Beding, Gewähr, Eigner, gedenk, genehm, verlässig sind hinlänglich bezeichnet ohne den dehnenden Zuwachs. Die Form Eingeweide, die oft im Verse störend gewesen wäre, glaubte ich durch Geweide ersetzen zu können; sagt doch auch der Jäger ausweiden. Für das unbequeme elfenbeinern schien mir das alterthümliche helfen genügend, genüber für gegenüber hat die Analogie von gen für gegen für sich; zweiflig, unzweiflig läßt sich durch adlig, eklig, untadlig, runzlig, knorpelig, schwindlig rechtfertigen. Solche Freiheit der Dichtkunst [sic! die Rede ist ja eigentlich von der Übersetzung] zu benehmen hieße die Sprache in starre Bande zängen und dem Wege zum Fortschritte Thür und Thor zu verschließen.« Schon diese Ankündigung läuft keine geringe Gefahr, sich an das »traun fürwahr« von Heinrich Manns Professor Unrat anzunähern. 
Schon die Wiedergabe des Proömiums zeigt die Umsetzung dieser Prinzipien:

Lust wird rege zum Sang, wie sich Formen in andere Körper

Wandelten. Götter, o seid - ihr habt ja sie auch gewandelt -

Meinem Beginnen geneigt, und vom Uranfange der Schöpfung

Führt bis auf unsere Zeit des Gedichts fortlaufenden Faden.

Alle drei behandelten Übersetzungen des 19. Jahrhunderts schaffen es nicht, Ovids Text, den deutschen Hexameter und idiomatische deutsche Sprachverwendung zusammenzubringen. Die Absetzung von Voß führt zu künstlichen und gewaltsamen Lösungen.

Der erste Teil von Suchiers deutschem Hexameter ist eine Art von freier Variation über Ovids Text, wobei die sprachliche Idiosynkrasie »rege $\mathrm{zu}(\mathrm{m})$ « (wohl für das übliche »regt an «) in erheblichem Gegensatz zu Ovids geradezu prosahafter Wendung animus fert ${ }^{342}$ steht. Trotz dieser Abweichung kann Suchier die prinzipielle Struktur des Versbaus inklusive des Enjambements beibehalten. Daraus ergeben sich aber auch neue Probleme, denn die Parenthese nam vos mutastsis et illa(s) folgt bei Ovid auf coeptis (durch weite Sperrung von adspirate getrennt) und erläutert damit die an alle Götter (nicht nur wie üblicherweise in der epischen Tradition an einen bestimmten Gott oder eine Muse) gerichtete Inspirationsbitte, bei Suchier aber auf das blasse »seid «, das eigentlich keine Erklärung nötig hat. Die Änderung von mea in »unsere « ist eine gewisse Glättung und verschleiert die Beziehung zwischen coeptis meis und tempora mea, passt aber besser in den deutschen Hexameter (vgl. auch die in Anm. 341 zitierte Rechtfertigung, die ebenfalls metrische Aspekte enthält). Die textile Metapher von deducere ist prononciert herausgearbeitet. Insgesamt lässt sich in der deutschen Wiedergabe ein gewisser Hang zu verbaler Überpoetisierung feststellen, ein Misstrauen gegenüber der Ausdruckskraft von Ovids Dichtersprache.

Thisbe und Pyramus einst, der Jünglinge schönster der Eine,

Hoch die Andre berühmt vor allen Mädchen im Osten,

Wohnten als Nachbarn dort, wo die prächtige Stadt nach der Sage

Hatte Semiramis rings mit Backsteinmauern umgeben.

Umgang bracht zuweg' und vertrautes Gewöhnen die Nähe;

Liebe erwuchs mit der Zeit, und sie wären vereint von den Fackeln,

Ohne der Väter Verbot. Was die nicht konnten verbieten:

Beider Gemüth war gleich entzündet von heißem Verlangen.

Jeglicher Zeuge ist fern. Sie reden mit Winken und Zeichen,

Und je enger beschränkt, je mächtiger wallet die Flamme.

Suchier gelingt es, den Gedankengang so auf die Verse zu verteilen, dass Zusammengehöriges nicht durch Enjambements auseinander fällt. Das muss er durch die Auffüllung des Hexameters mit Wörtern wie »einst «, »allen « und »rings « - allerdings vergleichsweise wenig aufdringlich - erkaufen. Schwieriger wird es im folgenden Vers, wo im Deutschen die Kasus (Nominativ oder Akkusativ) unklar sind, so dass die Nachahmung der Endstellung von vicinia/»Nähe«, die im Lateinischen morphologisch kompensiert wird, zur Verunklärung führt, zumal die übliche Wortstellung im Deut-

342 Belege bei Barchiesi (2004), $134 \mathrm{f}$. 
schen eben die Reihenfolgen Subjekt - Prädikat - Objekt bildet (die unmittelbare Zusammenstellung von »Umgang « und »bracht « lässt das noch suggestiver werden). Unverständlich im Deutschen ist »vereint von den Fackeln « (auch nicht durch eine Anmerkung erklärt), da dieses Eheschließungsritual mit der Antike verschwunden ist. Am Ende schwingt sich Suchier noch einmal zu gewollter Poetizität auf, indem er aestuat in »wallet « umformt. Doch insgesamt ist ihm hier eine metrische Umsetzung gelungen, die mit Ovids Text deutlich weniger gewaltsam umgeht als oftmals sonst im 19. Jahrhundert üblich.

Später entschritten dem Haus nimmt wahr in dem lockeren Sande

Sichere Spuren des Thiers und erblaßt im ganzen Gesichte

Pyramus. Wie er das Kleid auch findet vom Blute geröthet,

Spricht er: $\gg$ Dieselbige Nacht wird Tod zwei Liebenden bringen;

Ach, und die würdigst war doch sie vieljährigen Lebens!

Ich nur trage die Schuld; ich habe dich, Ärmste, gemordet,

Der ich kommen dich hieß bei Nacht an grausige Stätte,

und als der Spätere kam. Reißt unseren Körper in Stücke,

Und mit dem grimmen Gebiß zehrt auf die verruchten Geweide,

All ihr Löwn zumal, die haus't hier unter dem Felsen!

Aber den Tod zu wünschen ist feig. « Und die Hülle der Thisbe

Hebt er vom Boden und nimmt sie mit in den Schatten des Baumes.

Wie dem bekannten Gewand er Thränen gegeben und Küsse,

Spricht er: »Empfange denn nun auch unseres Blutes Beströmung; «

Und er versenkt in die Weichen den Stahl, mit dem er gegürtet;

Rasch dann zieht er ihn sterbend heraus aus der brennenden Wunde.

Hochauf spritzte das Blut, wie er rücklings lag auf dem Boden;

Ähnlicher Art, wie wenn die beschädigte bleierne Röhre

Aufplatzt und mit Gewalt weithin feinstrahliges Wasser

Schleudert aus zischendem Loch und die Luft wegdrängt mit dem Schusse.

Von dem bespritzenden Blut gehn über die Früchte des Baumes

Plötzlich in schwarze Gestalt, und die Wurzel vom Blute befeuchtet

Tränkt sie mit punischem Saft und färbt die hangenden Beeren.

Suchier hat mit dieser emotionalen Passage (im Vergleich zum sachlichen Anfang) deutlich stärker zu kämpfen. Er mißtraut offenbar der Suggestivität der eigentlichen Erzählung und versucht, durch drastische Wörter dem abzuhelfen. So wird aus plena $m e t u »$ grausig «, aus fera $\gg$ grimm « und aus scelerata »verrucht «. Die Übernahme aus Voß, die auch schon Lindemann verwendet hatte, »Beströmung «, kehrt die Blickrichtung um und steht für das relativ sachliche haustus - wie überhaupt Ovids Diktion im Gleichnis selbst von geradezu betonter Nüchternheit ist, um den Gegensatz zum höchst aufgeregten Pyramus - bei aller sachlichen Gemeinsamkeit - deutlich werden zu lassen. Offenbar haben alle Übersetzer Scheu davor, an dieser Stelle Ovid zu folgen, und suchen einen die vordergründige Lesererwartung eher bedienenden Weg. Auch wenn »die Luft wegdrängt mit dem Schusse « ohne Blick auf das lateinische Original 
unverständlich ist, kann man Suchier auch in dieser Passage attestieren, dass er sich wacker schlägt.

Wie er daheim, ging jener sogleich zum Bilde des Mägdleins,

Neigte sich über das Bett und küßte sie. Wärme verspürt er.

Wiederum nahte sein Mund; mit der Hand auch prüft er den Busen.

Siehe das Elfenbein wird weich, und befreit von der Starrheit

Sinkt an den Fingern es ein, fügsam wie Wachs vom Hymettus,

Das von der Sonne erweicht sich unter dem knetenden Daumen

Schmiegt in manche Gestalt und brauchbar durch den Gebrauch wird.

Während er staunt und zagend sich freut und Täuschung befürchtet,

Naht er mit liebender Hand der Ersehnten wieder und wieder:

Ja, es ist Leib. Aufbeben, geprüft mit dem Daumen, die Adern.

Da nun richtet beglückt an Venus der paphische Heros

Worte des Danks im vollsten Erguß. Nun endlich vereint er

Wirklichem Munde den Mund, und die Jungfrau fühlt mit Erröthen

Wie er sie küßt und scheu aufschlagend zum Lichte die lichten

Augen, erblickt sie zugleich mit dem Himmel des Liebenden Antlitz.

Gegen Ende versucht Suchier - im Gegensatz zu fast allen Vorgängern und auch Nachfolgern - das auf der Doppelbedeutung von lumen basierende Wortspiel umzusetzen: die » zum Lichte lichten / Augen« (das Enjambement ist hier einmal sogar hilfreich, weil es die etymologische Zusammengehörigkeit unterstreicht).

Gegen Ende des 19. Jahrhunderts geriet die Übersetzung im »Versmaß des Originals« (o. ä), die lange Zeit die Übersetzungspraxis selbstverständlich geprägt hatte, generell wieder in die Diskussion ${ }^{343}$ - nicht ganz unverständlich angesichts der soeben vorgestellten Beispiele. Der Hexameter schien als metrisches Medium der deutschen Sprache und Literatur eher fremd und es erfolgte eine partielle Rückbesinnung auf die Traditionen der Dichtersprache im deutschen Sprach- und Literaturraum. Für die Metamorphosen lässt sich das anhand der Übersetzung von Constantin Bulle festhalten, der als Versform der Zielsprache die Stanzen wählte. ${ }^{344}$ Damit griff er ein mehr als hundert Jahre altes Verfahren auf, das Friedrich Schiller für seine deutsche Version von Teilen der Aeneis verwendet hatte ${ }^{345}$ und das im Zuge der Schillerbegeisterung im späten $19 .{ }^{346}$ und frühen 20. Jahrhundert neue Aktualität bekam. ${ }^{347}$ Diese Grundentscheidung impliziert automatisch eine spürbare Entfernung vom sprachlichen Duktus des Originals, die sich im konkreten Fall nicht zuletzt in einer durchlaufenden Stro-

343 Lubitz (2009), 148.

344 Bulle (1898). Constantin Bulle (1844-1905) war zunächst Gymnasiallehrer und -direktor in Bremen, dann auch Mitglied der Bremer Bürgerschaft und schließlich (1887-1890) kurze Zeit Reichstagsabgeordneter für die Deutsche Fortschrittspartei. Er publizierte eine Reihe von zeitgeschichtlichen und politischen Büchern. - Zur Biographie siehe die Biographien deutscher Parlamentarier 1848 bis heute (http://biosop.zhsf.uni-koeln.de/ParlamentarierPortal/biorabkr_db/biorabkr_db.php).

345 Zur Metrik Schillers vgl. Jarislowsky (1928), 162-171.

346 Vgl. auch die Schulprogrammarbeit von Thiele (1887).

347 Vgl. Norden (1927), VIII, der für seine polymetrische Übersetzung von Aen. 6 ebenfalls auf Schiller (als Vorbild für den Verzicht auf den Hexameter, aber metrisch nicht nachahmbar) verweist. 
phenzählung niederschlägt. Bulle wendet sich ausdrücklich an Leser mit einer altsprachlich-gymnasialen Vorbildung (»die sich aus ihrer Schulzeit eine freundliche Erinnerung an die antike Dichtung überhaupt und an so manche fesselnde Erzählung Ovids bewahrt haben«, V). Ihnen verheißt er durch die spezifische Form eine adäquate Umsetzung des Originals, die durch die vorliegenden bisherigen Versuche (ausdrücklich verweist er auf Voß - »hölzern « -, Zwirnmann $[1895]^{348}$ und Suchier, XIV) noch nicht geleistet sei. Ovid selbst hätte, »wenn er heute seine Metamorphosen einem deutschen Leser in dessen Muttersprache zugänglich machen sollte « (XV), gewiss nicht den Hexameter gewählt.

Das Ergebnis erinnert stark an die Übersetzungen vor dem 19. Jahrhundert, in denen das Verhältnis von Vers und Text oder die Abfolge der Vorstellungen eine untergeordnete Rolle spielte. Terminologisch lehnt sich Bulle an die homerischen Epen an, indem er die einzelnen Gedichtbücher als »Gesänge « apostrophiert; in den »ersten Gesang « integriert er auch das Proömium:

Mich treibt das Herz, die Wunder zu besingen,

Durch die Natur und Mensch Form und Gestalt

Gewechselt haben. Laßt es mir gelingen,

Ihr Götter, und wie eurer Allgewalt

Allein vergönnt war, jene zu vollbringen,

So helft auch mir jetzt, daß ich mannigfalt

Und lückenlos der Wandlungen Geschichte

Vom Weltbeginn bis diesen Tag berichte.

Es ist nicht ganz einfach, im Abstand von mehr als hundert Jahren zu beurteilen, ob die vor allem durch den Reim enstehende Komik - zumal wenn unterschiedliche Wortarten gereimt werden (»Geschichte « - »berichte «) - auch für die Zeitgenossen in dieser Form spürbar war. Mangels (mir bekannter) Rezensionen oder anderer Reaktionen ist das kaum zu rekonstruieren. Eventuell hat durch die Aufrufung des Schiller'schen Vorbilds und - obwohl nicht ausdrücklich genannt - die Analogie zur hochgeschätzen mittelhochdeutschen Epik (die Übersetzung des Nibelungenlieds in Stanzen durch Joseph von Hinsberg 1812 war zwar ein literarisches Fiasko, aber die Reimform war gleichwohl naturnotwendig gegeben) die Dignität dieses Versuches gegen solche Zweifel verteidigt.

Angesichts dieser Sachlage ist es nicht nötig, diesen Versuch genauer zu analysieren. Vielmehr soll ein einziges weiteres Beispiel (eine »Strophe«) zur Illustration des Umgangs mit narrativen Passagen genügen - aus der Pygmalion-Erzählung des 10. Buches die Nr. 48:

Und während er noch stutzt und nur mit Zagen Sein Glück genießt und vor Enttäuschung bangt,

Fühlt wieder er mit liebendem Behagen

Und immer wieder, was sein Herz verlangt.

348 Robert Zwirnmann hatte auch einige Gedichte Schillers ins Lateinische übersetzt (Carmina quaedam Schilleri Latine reddidit R. Z., 1871) - ein umgekehrter Beleg für die Bedeutung Schillers für die literarische Landschaft in dieser Zeit. 
Ja, das ist Fleisch! ja, diese Pulse schlagen!

Und überschwänglich preist und lobt und dankt er Venus' Huld aus tiefstem Herzensgrunde Und küßt lebend'gen Mund mit seinem Munde.

Die Stanze gibt nicht nur die Möglichkeit, sich vom Originaltext zu entfernen, sondern zwingt sogar dazu. Es ist dies ein an das Wilamowitz'sche Konzept der »Travestie « ( das Kleid muß neu werden, sein Inhalt bleiben «) $)^{349}$ angelehntes Verfahren, wobei gewissermaßen der plot als der Inhalt verstanden wird, die Form aber als ephemer. In gewisser Weise liefern, so verstanden, die antiken Texte sogar eine Art von Vorwand für eigenes Bemühen, das für sich alleine keinen Bestand gehabt hätte vor kritischer Betrachtung, aber von der Autorität des kanonisierten Autors und Werks seine eigene Dignität ableitet.

\section{Wolfgang Schadewaldts Übersetzungskonzept als leitende Maxime oder als Feigenblatt? Die Übersetzungen durch von Albrecht und Fink am Ende des 20. Jahrhunderts}

Das 19. Jahrhundert ist, wie eben gezeigt, die Blütezeit der übersetzenden Lehrer (und in geringerem Umfang noch der Geistlichen), die ihr Alltagsgeschäft durch Publikation - und gegebenenfalls repräsentative Ausstattung des Drucks - sublimieren konn$\operatorname{ten}^{350}$ und damit die von der Universitätsphilologie, aber auch Dichtern und Schriftstellern offen gelassene Leerstelle besetzten. ${ }^{351}$ Von diesem Anspruch zeugen auch die nicht nur in Schulprogrammen, sondern auch in Büchern und wissenschaftlichen Zeitschriften dokumentierten Interessen an Textkritik und Textkonstitution, wie sie generell die Philologie des 19. Jahrhunderts prägten. ${ }^{352}$

In erstaunlicher Diskrepanz zu diesen gelehrten Bemühungen steht die Tatsache, dass die gesamte erste Hälfte des 20. Jahrhunderts ohne eine Neuübersetzung der $\mathrm{Me}$ tamorphosen auskommen musste. Zwischen Bulle (1898) und (Rösch) 1952 gab es offenkundig nur Nachdrucke der vorliegenden Versionen, v. a. derjenigen von Voß und Suchier. Das demonstriert drastisch, wie sehr Ovid in der Wertschätzung selbst der Schulmänner gesunken war, die sich zwar im Unterrichtsgeschehen immer wieder mit den Metamorphosen auseinanderzusetzen hatten, aber sich aus einer eigenen Übersetzung keinen Zuwachs an Prestige erhofften.

349 Lubitz (2009), 196-207, bes. 201.

350 Vgl. auch Fritsch (1987) über Hermann Menge, der seine Erfahrungen als Schulmann (neben dem Repetitorium und den lexikalischen Arbeiten) auch in eine Horaz-Übersetzung in Prosa (besonders für Primaner gedacht) münden ließ.

351 Zum sich ankündigenden Ende dieser Symbiose an der Wende vom 19. zum 20. Jahrhundert siehe Baumbach (2002) sowie Cancik/Cancik-Lindemaier (2002).

352 Vgl. generell Schmidt (2002). 
Noch die von der Nachkriegszeit bis in die 80er Jahre des 20. Jahrhunderts am weitesten verbreiteten Übersetzungen (neben Thassilo von Scheffers ${ }^{353}$ Übersetzung), die Tusculum-Ausgabe ${ }^{354}$ von Erich Rösch ${ }^{355}$ (zuerst 1952 ${ }^{356}$ ) und die Artemis-Ausgabe von Hermann Breitenbach ${ }^{357}$ (zuerst 1958), ${ }^{358}$ die in zahlreichen Nachauflagen weite Verbreitung fanden, wählten problemlos den deutschen Hexameter und geben darüber nur mit knappen Worten Rechenschaft. ${ }^{359}$ Da diese beiden Übersetzungen keine prin-

353 Lebensdaten (siehe http://www.munzinger.de/document/00000004449) 1873-1951; wirkte seit seiner Promotion 1900 als freier Schriftsteller und Übersetzer antiker Autoren. T. von Scheffer übersetzt das Proömium folgendermaßen: »Neue Gestaltung, in die sich Körper verwandeln, zu künden, / Treibt es mein Herz. O Götter, ihr habt ja jene verwandelt. / Fördert meinen Entschluß. Vom ersten Anfang der Schöpfung / fort bis auf unsere Zeit seid stets meines Liedes Geleiter.«

354 Siehe auch die Angaben bei Johannes Saltzwedel, Tusculum - Bibliographie der zweisprachigen Ausgaben antiker Literatur (Onlinefassung: http://www.venturus.de/vframe.htm?vtusc.htm).

355 Erich Rösch, nach den Matrikeln der Unversität Rostock (http://matrikel.uni-rostock.de/id/ 200018714/) geb. 1900 in Heidelberg, studierte in Heidelberg und (im Sommersemester 1923) Rostock Germanistik und Philosophie. 1925 wurde er in Heidelberg mit einer » vergleichenden Märchenstudie « Der getreue Johannes (ersch. Helsingfors 1928) promoviert. Im Frühjahr 1945 (Rösch [1952, $\left.{ }^{3} 1964\right], 771$ ) begann er mit der Übersetzung der Metamorphosen (Philemon und Baucis); die Apoll-Daphne-Sage wurde vorab im Gymnasium 56 (1949), 97-99, gedruckt. Weitere biographische Angaben sind nicht zu ermitteln.

3561988 wurde für die Neuauflage zwar der Einleitungs- und Anmerkungsteil durch Niklas Holzberg neu bearbeitet, die Übersetzung aber blieb unangetastet. Die letzte Ausgabe (1996) scheint nach dem Katalog der Deutschen Nationalbibliothek die 14. Auflage zu sein (so auch Saltzwedel, vorletzte Anm.). 2004 wurde sie durch die Übersetzung von Gerhard Fink ersetzt. Letztmals wurde sie vollständig (einsprachig) in der dtv-Taschenbuchausgabe 1997 gedruckt, 2005 lag sie noch einmal einer Künstleredition zugrunde (Ela Woźniewska, Mythen und Zeichen, Berlin 2005).

357 Hermann Breitenbach (1883-1967) wurde 1908 in Basel mit einer Arbeit De genere quodam titulorum comoediae Atticae promoviert und wirkte seither als Lehrer an der Kantonsschule Solothurn in der Schweiz. Die Metamorphosen-Übersetzung ist also offenbar nach dem Eintritt in den Ruhestand entstanden. Breitenbach übersetzt das Proömium folgendermaßen: »Von den Gestalten zu künden, die einst sich verwandelt in neue/Körper, so treibt mich der Geist. Ihr Götter, da ihr sie gewandelt, / Fördert mein Werk und lasset mein Lied in dauerndem Flusse / Von dem Beginne der Welt bis auf meine Zeiten gelangen! $\ll$

358 Vgl. von Albrecht (2004), 48.

359 Vgl Mindt (2007a), 55-57; z. B. weist von Scheffer (1948), XVIIIf., nur darauf hin, dass er »einzelne besonders treffende Ausdrücke, ja hin und wieder einen vollen Vers « aus früheren Übersetzungen übernommen habe, ohne auch nur ein Wort über die metrische Gestaltung prinzipiell zu verlieren. Ausführlicher ist Rösch $\left(1952,{ }^{3} 1964\right), 772: »[\ldots]$ bin ich mir darüber klar, daß der antike Hexameter im Deutschen nicht nachgeahmt werden kann, sondern daß es sich um einen deutschen Vers handelt, der an die Stelle des antiken tritt «. Bezeichnend für die Schwierigkeiten ist die recht offenherzige Fortsetzung: $\gg \mathrm{Daß}$ ich oft die letzte Silbe eines Verses Auftakt zum nächsten werden lasse und dabei gelegentlich auch wage, Wörter auf zwei Verse zu verteilen, wird manchen Leser vielleicht zunächst befremden. Doch möchte ich auf dieses Mittel nicht verzichten, denn es ermöglicht oft, eine natürlichere Wortstellung zu wählen und eine tragfähige Hebung an den Anfang des Verses zu bringen. Daß dabei das sprachliche Einzeldasein des Verses aufgehoben wird, scheint mir kein Schaden, sondern ein Gewinn für den erzählerischen Fluß des Ganzen zu sein.« 
zipiellen Neuerungen gegenüber den bereits besprochenen bieten, ${ }^{360}$ sind sie hier genauso ausgeklammert wie die wohlfeile Auswahlausgabe von Plankl/Vretska im Reclam-Verlag (zuerst 1951, immer noch im Verlagsprogramm geführt ${ }^{361}$.

Man kommt also nicht umhin zu konstatieren, dass zwischen Voß und der Mitte des 20. Jahrhunderts keine in irgendeiner Weise als zielgerichtet benennbare übersetzerische Entwicklung feststellbar ist, zumal die einzige nicht-hexametrische Übersetzung, diejenige von Constantin Bulle, in jeder Hinsicht ein Randereignis blieb. Alle Übersetzer kämpfen mit der Verteilung des Gedankengangs auf das Metrum. Sie wählen eine oftmals künstlich archaisierende Sprache, die weder dem Stand der zeitgenössischen deutschen Literatursprache nahe kommt, noch die Tatsache wirklich berücksichtigt, dass Ovids Dichtersprache bei allem Traditionsbezug innovativ war und klassizistische Verkrustungen aufsprengen wollte. ${ }^{362}$ Insofern konstruieren diese Übersetzungen gewissermaßen einen ahistorisch konservativen Ovid, der einer nostalgischen Antikeverklärung zum Vehikel dienen kann und die zukunftsgerichteten, auch subversiven Potentiale ausblendet. Damit zeichnen die Übersetzungen unwillkürlich, aber unverkennbar, die als Abwehrkampf empfundene Haltung der schulischen wie universitären Klassischen Philologie seit dem 19. Jahrhundert nach.

Wolfgang Schadewaldt ist der einzige Vertreter der universitären Klassischen Philologie des 20. Jahrhunderts, der sich sowohl mit einem theoretischen Konzept als auch in viel beachteten Übersetzungen einen Namen verschafft hat, wobei er geschickt auch den Rundfunk zur Verbreitung nützte. Sein Homer (Odyssee: 1958; Ilias: 1975) löste aufs Ganze gesehen Voß' Übersetzung als den deutschen Homer ab. ${ }^{363}$ Seine dem $\gg$ dokumentarischen Übersetzen « zugrundeliegende Konzeption legte er an zahlreichen Stellen variiert nieder, so im Nachwort zur deutschen Fassung der Elektra des Sophokles: ${ }^{364}$

Erstens: im Übersetzen das wiederzugeben, was dasteht und so wie es dasteht, nämlich vollständig, ohne Verkürzungen, Hinzufügungen.

Zweitens: die originalen Vorstellungen, Begriffe wie Bilder, in ihrer griechischen Eigenart unverändert ohne moderne Übermalungen auch im deutschen Wortlaut zu bewahren.

Und drittens: die Folge dieser Vorstellungen, ihre »Syntax« - als Abfolge, wie die Dinge und Kräfte der Welt im Nacheinander dem Dichter vor die Augen kommen - bis zur Stellung des einzelnen Wortes in Satz und Vers, soweit irgend möglich, auch im Deutschen einzuhalten.

360 Vgl. z. B. Rösch zu met. 4,55-58: »Pyramus er, der Schönste der Jünglinge, Thisbe, vor allen / Mädchen die Herrlichste, sie, die der Osten nannte sein eigen, / wohnten sie Haus an Haus, wo Semiramis einst um die hohe / Stadt, wie erzählt wird, den Ring aus gebrannten Steinen geschlossen.«

361 Auch hieraus sei das Proömium zitiert: »EINGANG / Körper, in andre Gestalten verändert, will ich besingen; Götter, fördert mein Werk ( $i h r$ hab ja auch jene verwandelt), / Schirmend geleitet das Lied, das vom Anbeginne der Welt - / Verse an Verse gereiht - bis zu unseren Zeiten herabführt. «

362 Zahllose Belege für die »Modernität« von Ovids Dichtersprache finden sich bei Bömer (19692006).

363 Siehe ausführlich Mindt (2009), 277-297.

364 Siehe hierzu sowie zur Kritik und Weiterentwicklung von Schadewaldts Maximen den Beitrag von Poiss et al. (in diesem Band), bes. $\$ 2$. 
Schadewaldts Wirkung lässt sich nicht nur an der Verbreitung seiner eigenen Publikationen ablesen, sondern auch an der Tatsache, dass er selbst für die nicht von ihm übersetzten Autoren, namentlich auch für die lateinischen, den Prosawiedergaben den Weg öffnete und sich die Übersetzer explizit auf ihn berufen. ${ }^{365}$

\subsection{Michael von Albrecht (geb. 1933) 366}

Mit den 80er Jahren ändert sich das Bild, sowohl das Ovid-Bild in der Forschung und einer breiteren Öffentlichkeit ${ }^{367}$ - die $\gg$ Modernität $\ll{ }^{368}$ Ovids wird erkannt und offensiv ausgespielt - als auch das Erscheinungsbild der nunmehr auf den Markt drängenden Übersetzungen, in denen die Prosa den Vers ersetzt: ${ }^{369}$ Michael von Albrecht (1981) und Gerhard Fink (1989, basierend auf Rode) setzen die Metamorphosen in Prosa um; von Albrecht beruft sich dabei ausdrücklich auf Schadewaldt. ${ }^{370}$ Michael von Albrecht begann seine akademische Karriere in Tübingen, wo Wolfgang Schadewaldt zu dieser Zeit Inhaber eines Lehrstuhls für Klassische Philologie mit der ergänzenden Denomination $\gg$ Gräzistik und Fortleben der Antike $\ll^{371}$ war. Auch wenn das - soweit ich sehe - an keiner Stelle thematisiert ist, scheint diese Tübinger Prägung ein spätes Movens für von Albrechts Übersetzertätigkeit ab den 80er Jahren des 20. Jahrhunderts ${ }^{372}$ zu sein, unbeschadet der Tatsache, dass in die ersten zweieinhalb Jahrzehnte seiner Zeit als Heidelberger Lehrstuhlinhaber keine einschlägigen Publikationen fallen.

Das persönliche Erleben spricht auf jeden Fall unverkennbar aus dem Nachwort zur 1981 erstmals publizierten Metamorphosen-Übersetzung, dem Auftakt von Michael von Albrechts übersetzerischem Corpus:

W. Schadewaldts Prinzip des »dokumentarischen Übersetzens « hat für die Aneignung griechischer Texte in Deutschland Maßstäbe gesetzt, auch wenn sein Charisma schwer nachzuahmen ist. Auf das Übersetzen aus dem Lateinischen läßt sich seine Methode nicht restlos übertragen, weil das Lateinische dem Deutschen viel ferner steht als das Griechische.

365 Vgl. dazu Mindt (2009), 343-349.

366 Vgl. die Würdigung anlässlich der Verleihung des Johann-Heinrich-Voß-Preises für Übersetzung 2004 der Deutschen Akademie für Sprache und Dichtung durch Kalka (2004) (auch zu den übrigen Übersetzungen: Catull, Vergil, Ovids liebeselegische Dichtungen).

367 Vgl. Schmitzer (2010), 568-570.

368 Vgl. Ziolkowski(2005).

369 Der Topos von der Unübersetzbarkeit (vgl. S. 196f.) aus den Alten Sprachen findet sich aber immer noch, z. B. bei Reichert (2010), 17 (zu met. 1,522): »Lässt sich das, was Ovid gemacht hat, in irgendeine andere Sprache übersetzen? Übersetzen im üblichen Sinne lässt es sich gewiss nicht. «

370 von Albrecht (1981), 393-399.

371 Heck (1993), 398.

372 Die Belege sind ermittelbar unter http://d-nb.info/gnd/117756873 (ein früher Vorläufer ist die Übersetzung eines griechischen Texts, der Pythagoras-Vita des Iamblich, Zürich 1963). 
Eine wörtliche Übersetzung aus dem Griechischen kann naiv und ursprünglich, eine solche aus dem Lateinischen barbarisch und stillos klingen. ${ }^{373}$

Michael von Albrecht kehrt zur in der Goethezeit, bei Klopstock, Humboldt und anderen angesiedelten Vorstellung von einer engen Beziehung zwischen dem Griechischen und dem Deutschen zurück, wozu auch die Qualifizierung als »naiv und ursprünglich « und damit die Integration in den klassischen Originalitätsdiskurs gehört. ${ }^{374}$ Der Übersetzer nützt dieses alte Wahrnehmungsparadigma, um eine partielle Abkehr von der Autorität Schadewaldts zu rechtfertigen, dem er allerdings beim Postulat, die ursprüngliche Abfolge der Vorstellungen zu wahren, folgt (396). Allerdings erfordere das Deutsche wesentlich mehr Nebensätze, in die die lateinischen Partizipialkonstruktionen aufgelöst werden müssten, wie überhaupt die deutsche Syntax und Wortstellung restriktiveren Regeln unterliege als die lateinische. ${ }^{375}$ Vor allem beansprucht von Albrecht auf einem Gebiet Innovation: ${ }^{376}$

[Die Übersetzung] beachtet die künstlerische Verwendung der Erzähltempora und spiegelt so die Feinstruktur der ovidischen Erzählung wider. Ovid erzielt duch abwechselnden Gebrauch des historischen Perfekts und des historischen Präsens Reliefwirkungen [...]. Dies lässt sich im Deutschen durch den von den bisherigen Übersetzern gescheuten Wechsel von Vergangenheit und Gegenwart nachahmen [...]. Nicht nachbilden läßt sich im Deutschen [...] die aspekt- und strukturbedingte Abwechslung von Imperfekt und Perfekt, die im Lateinischen eine Scheidung von »Hintergrund « und »Vordergrund « ermöglicht.

In diesem Anspruch schlägt sich nicht zuletzt von Albrechts eigene Forscherbiographie nieder, worin er einen raren Fall in der Übersetzungsgeschichte Ovids darstellt: Seit seiner Dissertation hat sich von Albrecht gerade auch mit stilistischen Fragen der lateinischen Literatur und besonders der Dichtungen Ovids befasst. ${ }^{377}$ Diesen wissenschaftlichen Ertrag möchte er implizit auch für die Übersetzung fruchtbar machen, was schon an und für sich sehr wünschenswert ist, da das Gesamtbild eines Autors ja genuin wichtig für dessen Übersetzung ist, so dass in diesem Fall eine Koinzidenz möglich erscheint. Deshalb ist es an dieser Stelle nötig, noch einmal einen genaueren Blick auf die Gestaltung von Ovids Erzählung und die Forschungserträge zu werfen, eben da von Albrecht in diesen Diskurs eingebunden ist.

Die Probe aufs Exempel, der Blick auf das Proömium als erste Schlüsselstelle führt aber zu einer gewissen Ernüchterung:

Von Gestalten zu künden, die in neue Körper verwandelt wurden, treibt mich der Geist. Ihr Götter - habt ihr doch jene Verwandlungen bewirkt -, beflügelt mein Beginnen mit eurem

373 von Albrecht (1981), 397. Ebenfalls im Nachwort zur Übersetzung bezieht sich von Albrecht auch auf seinen Tübinger Lehrer Ernst Zinn und dessen (unpublizierte) Teilübersetzung der Metamorphosen in Prosa mit Illustrationen von Manfred Henniger (1969, als Autograph nachgewiesen im OPAC der Bayerischen Staatsbibliothek, nicht entleihbar).

374 Zur wissenschaftsgeschichtlichen Einordnung der Auffassung von der Nähe des Deutschen zum Griechischen siehe Kitzbichler (2009), 34.

375 Vgl. Kienpointner (2009), 359-385.

376 von Albrecht (1981), 396.

377 Z. B. von Albrecht (1963); von Albrecht (1968); von Albrecht (1970). 
göttlichen Atem und führt meine Dichtung ununterbrochen vom allerersten Ursprung der Welt bis zu meiner eigenen Zeit.

Entgegen seiner Ankündigung, die gedankliche Reihenfolge zu bewahren, setzt von Albrecht das deutsche Äquivalent zum hexameterschließenden formas an die Spitze. Die Begründung (»habt ihr doch $[\ldots] \ll ;$ nam vos mutastis [...]) steht vor der Nennung des Unternehmens (»Beginnen «; coeptis), das von Ovid im letzten Wort des Proömiums genannte carmen wird (als »meine Dichtung «) an eine unauffällige Stelle im letzten Satz vorgezogen. Man kann auch noch auf weniger auffällige Abweichungen verweisen, auf die Nichtberücksichtigung von de-ducere, auf die Ausweitung von adspirate in » beflügelt $[\ldots]$ mit göttlichem Atem «. Und anders als die zugrunde liegende Teubneriana von Anderson (1977) scheint von Albrecht undokumentiert statt illa das althergebrachte illas zu lesen. Die Übersetzung an sich ist durchaus transparent und sprachrichtig, aber bemerkenswert ist doch, wie folgenlos an dieser exponierten Stelle des Textes die ausdrücklichen Maximen des Übersetzers bleiben.

Dieser Befund gilt zumindest in abgeschwächter Form auch für den Beginn der Erzählung von Pyramus und Thisbe, wo die Prosa eigentlich höhere Flexibilität erlauben sollte.

Pyramus und Thisbe, er der schönste der jungen Männer, sie herrlicher als alle Mädchen im Orient, bewohnten benachbarte Häuser in der hochgebauten Stadt, die Semiramis mit Mauern aus Lehmziegeln umgeben haben soll. Nachbarschaft machte sie miteinander bekannt und erlaubte ihnen die ersten Schritte der Annäherung. Mit der Zeit wuchs die Liebe; sie hätten auch Hochzeit gefeiert, aber die Väter verboten es. Eines aber konnten sie nicht verbieten: Beide waren gleichermaßen in Liebe entbrannt, die ihnen den Verstand raubte. Keinen Mitwisser gibt es, sie sprechen duch Winke und Zeichen, und je mehr die Liebesglut versteckt ist, desto heftiger ist ihr Feuer.

Dass der Chiasmus in der alter-altera-Konstruktion nicht beibehalten ist, ist nicht zwingend, ebenso wenig die Auflösung des Relativsatzes. Problematischer noch ist die Angleichung der deutschen Übersetzung von contiguas und vicinia, die Ovids Signifikanz abschattet. Ebenso lässt »Hochzeit feiern « das gezielte taedae iure Ovids verblassen, worin die religiös-juristische Regelhaftigkeit der Hochzeitszeremonie enthalten ist. ${ }^{378}$ Dagegen vollzieht von Albrecht konsequent und seiner Ankündigung gemäß den Tempuswechsel gegen Ende der Passage, der nicht nur die Lebendigkeit der Erzählung erhöht, sondern auch auf die zeitlose Sentenz vorausweist. Allerdings fügt er ein wenig pedantisch »Liebesglut « ein und doppelt damit (in einem etwas schiefen Bild) die Feuermetaphorik. ${ }^{379}$ Der Übersetzer nützt längst nicht überall, wo er es könnte, die Möglichkeit zur Wahrung der gedanklichen Abfolge.

Das setzt sich auch in der emotionalen Passage der Erzählung fort:

378 Das erstaunt ein wenig, denn von Albrecht (1981), bes. 2336, beweist ja eigentlich Sensibilität für das Eindringen von solchen Anachronismen in Ovids mythologische Erzählung.

379 Siehe dazu Huber-Rebenich (1994), 134. - Ob ein gelehrter volksetymologischer Bezug zu $\pi u$ oder

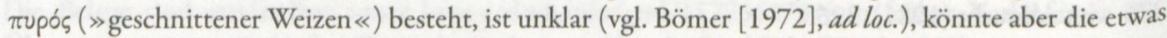
eigenwillige Feuermetaphorik noch weiter motivieren (vgl. Schmitzer [1992], 531). 
Später verließ Pyramus das Haus. Er sah im tiefen Staub ganz deutlich die Spuren des wilden Tieres. Da erbleichte er übers ganze Gesicht. Doch als er auch noch das blutbefleckte Kleidungsstück fand, sprach er: »Eine Nacht wird zwei Liebende vernichten. Thisbe hätte es wahrhaftig verdient, lange zu leben; doch meine Seele ist voller Schuld. Ich habe dich, Bejammernswerte, getötet, da ich dich bei Nacht in eine gefährliche Gegend kommen ließ und nicht als erster hierher kam. Zerfleischt meinen Leib und verzehrt mit wildem Biß meine fluchbeladenen Eingeweide, all ihr Löwen, die ihr unter diesem Felsen haust! Aber es zeugt von Ängstlichkeit, den Tod nur zu wünschen! « Er nimmt Thisbes Umhang, trägt ihn zum Schatten des Baumes, an dem sie sich verabredet hatten. Und nachdem er das vertraute Gewand mit Tränen benetzt und mit Küssen bedeckt hatte, sprach er: »Trinke du jetzt auch mein Blut! « Und das Schwert, mit dem er umgürtet war, stieß er sich in den Leib. Sogleich zog er es sterbend aus der heißen Wunde und lag rücklings am Boden. Da springt das Blut hoch empor, wie wenn lange Wasserstrahlen aus einem schadhaften Bleirohr durch einen feinen Riß zischend hervorschießen und stoßweise die Luft durchbrechen. Vom Mordblut besprengt, werden die Früchte des Maulbeerbaumes schwarz, und von Blut gerötet, färbt die Wurzel die am Baum hängenden Maulbeeren purpurn.

Der Duktus des Textes hat ein wenig Schwierigkeiten, Ovids Emotionalität nachvollziehbar zu machen. Die artistische Stellung von una duos [...] nox [...] amantes ist zwar schwer in akzeptablem Deutsch nachzuahmen, aber durch die Aufgabe der Schlussstellung von amantes beraubt sich der Übersetzer auch des Anschlusses e quibus und muss mit dem eingefügten Namen »Thisbe « neu einsetzen. Ebenso geht der Superlativ dignissima ${ }^{380}$ verloren. Ovids ego te nimmt durch die Zusammenrückung den Gegensatz von una duos wieder auf. Überhaupt wählt von Albrecht die sicheren, dafür unspektakulären Varianten (»es zeugt von Ängstlichkeit «), die auch zu einer gewissen Blässe des Ausdrucks führen, zu einer Art von »Normalisierung «. Das wird auch ganz besonders an dem Satz »Und das Schwert [...] « deutlich: Ovid schiebt die Nennung des fatalen Requisits bis zum syntaktisch letztmöglichen Zeitpunkt auf und erzielt damit einen gewissen Überraschungseffekt, denn von einem Schwert war vorher noch nicht die Rede: ${ }^{381}$ Der Dichter lässt das Schwert genauso überraschend in die Erzählung eintreten, wie es Pyramus überraschend zur Hand hat. ${ }^{382}$ Diese Reduktion der ovidischen Erzählamplituden umfasst auch die blasse Wiedergabe von nec mora (im Lateinischen zugleich ein Wortspiel mit moriens) als $\gg$ sogleich $\ll$, das die Signifikanz der gezielten substantivischen Ausdrucksweise des Originals mindert. Man könnte das noch ergänzen, doch ist der Tenor des Befundes klar: von Albrecht gibt ein klares Bild von Inhalt und Verlauf der Sage von Pyramus und Thisbe, ohne sich wirklich auf die teils kühne Sprach- und Gedankenwelt Ovids en detail einzulassen.

$\mathrm{Ob}$ das ein kontingentes Resultat oder durchgängige Machart ist, ist an der Pygmalion-Passage als letzter zu überprüfen:

380 Bömer (1972), ad loc., über die Verbindung zum epigraphischen und elegischen Motiv der mors immatura.

381 Vgl. Bömer (2000) über Ovids » unbekümmerten Umgang « mit solchen erzählerischen Details.

382 Schmitzer (1992), 531. - Tarrant (2004), ad loc.: »Versus mihi suspectus «; Tarrant liest im folgenden Vers im Unterschied zu den übrigen aktuellen Editionen (auch Barchiesi/Rosati [2007]) ut statt et und verändert damit auch die syntaktische Abteilung - womöglich mit Recht. 
Als er nach Hause kam, zog es ihn zu seinem Mädchenbild. Er warf sich auf das Lager und küßte sie. Da war ihm, als sei sie warm. Wieder legt er Mund an Mund und tastet mit der Hand nach der Brust. Er tastet noch, da wird das Elfenbein weich, verliert seine Starrheit, weicht zurück und gibt den Fingern nach, so wie Wachs vom Hymettus an der Sonne geschmeidig wird, sich unter dem Druck des Daumens zu tausenderlei Gestalten formen läßt und in der Hand des Bildners immer bildsamer wird. Pygmalion staunt. Er traut seiner Freude noch nicht und fürchtet, er täusche sich. Wieder und wieder prüft der Liebende mit der Hand sein Wunschbild. Fleisch und Blut ist's; mit dem Daumen prüft er, wie es in den Adern pocht. Da dankt der Held von Paphos der Venus mit Worten, die aus vollstem Herzen strömen, und preßt den Mund endlich auf wirkliche Lippen.

Das Mädchen hat den Kuß empfunden, sie ist errötet! Jetzt hebt sie scheu zu seinem Auge ihr Auge empor - und zugleich mit dem Himmel erblickt sie den Mann, der sie liebt. Der Ehe, die sie gestiftet, steht die Göttin bei. Schon haben sich die Hörner des Mondes neunmal zur vollen Scheibe gerundet, da gebiert sie Paphos, nach der die Insel benannt ist.

Für sich genommen bietet der Textausschnitt einen problemlosen Einblick in den Gang von Ovids Erzählung, die (in den Metamorphosen in dieser Richtung sehr seltene) Verwandlung des Bildwerks in menschliche Gestalt und menschliches Wesen. ${ }^{383}$ Bei genauerem Hinsehen ist aber auch hier Ovids sprachliches Vorgehen ohne Zwang in der Zielsprache aufgegeben, auch wenn es sich auf den ersten Blick nur um Marginalien handelt: incumbens ist weit weniger heftig als » warf sich auf «; manibus ist als Singular wiedergegeben; die passive Form temptatum, die die Blickrichtung auf das Objekt der Begierde lenkt, ist bei von Albrecht als aktive Handlung Pygmalions umgesetzt. Das Wortspiel fit utilis usu wird gänzlich aufgelöst (lumen lumina etwas später ist ebenfalls nicht umgesetzt), und ist damit von Ovids Intention abgerückt. Das hypotaktische Gefüge ab dum stupet wird in Parataxe transformiert. Im tum vero Paphius [...]-Satz ist das inhaltliche Verhältnis von Haupt- und Relativsatz umgekehrt. Diese Auflistung mag etwas pedantisch erscheinen, doch zeigt sich daran, dass die vom Übersetzer angekündigten Abweichungen von Schadewaldts Maximen nicht aus der sprachlichen, durch den lateinisch-deutsch Kontrast gegebenen Notwendigkeit, sondern offenbar anlasslos, eventuell aus dem Sprachempfinden des Übersetzers heraus geschehen sind. Damit erweist sich der programmatische, sich an die Autorität Schadewaldts anlehnende Anspruch als eher deklaratorisch denn substantiell - ein Befund, der ganz offenbar von genereller Geltung für die Übersetzung der antiken Literatur ist: Schadewaldt legitimiert die Wahl der Prosa, die weitergehenden Implikationen sind allenfalls akzidentiell umgesetzt.

383 Wohl eine Flüchtigkeit ist das »sie « am Beginn der Passage, das keinen syntaktischen Anschluss hat, sich in einer Constructio ad sensum auf »Mädchen « bezieht, wobei diese Verbindung offenbar über das Lateinische simulacrum puellae, nicht über das deutsche Kompositum hergestellt ist. 


\subsection{Gerhard Fink (1934-2013)}

Etwas anders stellt sich die Sache bei Gerhard Fink dar, ${ }^{384}$ der sich dem Übersetzungsthema zunächst aus praktischer Schulsicht und fachdidaktischer Perspektive genähert hatte, bevor er seine Adaption von Rodes Übersetzung publizierte. Mit der Wahl dieser Übersetzung als Grundlage - eine Auskunft über das Zustandekommen dieser Konstellation wird nicht gegeben - ist die Prosaform zwingend verbunden und bedarf deshalb nicht der Legitimation durch die Berufung auf Schadewaldt. Vielmehr vertritt er eine deutlich zielsprachenorientiertere Position, die die Lesbarkeit und Rezipierbarkeit durch den zeitgenössischen Leser in den Vordergrund stellt. ${ }^{385}$

Im Folgenden sei die bereits besprochene Übersetzung anmerkungsweise mit Finks Übersetzung verbunden, um im Vergleich die Weiterverarbeitung deutlicher werden zu lassen:

[Jeder Vers der Metamorphosen] wurde ohne Rücksicht auf die Vorgaben von Rodes neu übersetzt, dann mit dessen Übersetzung verglichen und unter Berücksichtigung der oben genannten Ziele - Verständlichkeit, Lesbarkeit, Wohlklang - neu formuliert. Dabei achteten wir in der Regel energischer als von Rode auf die lateinische Wortfolge, wenn sie für die Darstellung bedeutsam war, und auf die angewandten Stilmittel. ${ }^{386}$

Fink verschreibt sich damit einer Synthese aus Zielsprachenorientierung (in der Wortwahl) und Ausgangssprachenorientierung (bei der Wortstellung und damit der Gedankenabfolge), also einer partiellen Orientierung an Schadewaldt, ohne dass letzteres explizit gemacht würde. Und in der Tat setzt Fink diese Prinzipien konsequenter als von Albrecht um, so am Beginn der Erzählung von Pyramus und Thisbe: ${ }^{387}$

Pyramus und Thisbe, von den Jünglingen er der schönste und sie das reizendste unter den Mädchen des Morgenlandes, bewohnten aneinanderstoßende Häuser dort, wo nach der Sage Semiramis ihre hohe Stadt mit Ziegelmauern umgeben hat. Bekanntschaft und erste Stufen der Neigung erlaubte die Nähe; mit der Zeit wuchs die Liebe, und sie hätten sich durch die Bande der Ehe vereint, doch das verboten die Väter. Was sie nicht verbieten konnten,

384 Gerhard Fink (geb. 1934) wurde 1958 mit der Arbeit Pandora und Epimetheus. Mythologische Studien in Erlangen promoviert und wirkte danach als Gymnasiallehrer in Nürnberg. Neben schulpraktischen und fachdidaktischen Arbeiten publizierte er vor allem zum Antikebezug in Nürnberg (Götter in Nürnberg, Nürnberg 1994; Konrad Celtis, Norimberga, Nürnberg 2000 [einsprachige Übersetzung]) sowie (neben den Metamorphosen) Übersetzungen von Seneca (Die kleinen Dialoge, München; Epistulae morales ad Lucilium, 2007) Horaz (Satiren, 2000; Epistulae, 2003), Vergil (Aeneis, 2005) sowie Platon (Große Dialoge, 2001). Für sein Übersetzungskonzept grundlegend ist Fink (1992) (mit fachdidaktischer Ausrichtung). Vgl. auch Mindt (2009), $347 \mathrm{f}$.

385 Mindt (2009), $347 \mathrm{f}$.

386 Fink (1989), 421.

387 Rode: »Pyramus, der Jünglinge schönster, und Thisbe, die reizendste unter den Mädchen des Morgenlandes, bewohnten aneinander stoßende Häuser in der erhabenen Stadt, welche - der Sage nach - Semiramis mit Mauren von gebackenen Steinen umgeben hat. Die Nachbarschaft stiftet unter ihnen Bekanntschaft, und Freundschaft, die mit der Zeit Liebe wird. Gern hätten sie sich auch durch eheliche Bande verbunden; allein die Väter verbieten es. Doch können diese auch verbieten, daß nicht beider Herzen, von gleicher Liebe eingenommen, brennen? Sobald sie unbelauscht sind, sprechen sie durch Blicke und Zeichen mit einander; und je verborgener, desto heftiger lodert ihre Flamme.« 
war, daß beide, gleichermaßen entflammt, voneinander nicht ließen. Niemand weiß davon; sie sprechen durch Winke und Zeichen, und je verborgener es ist, desto heftiger lodert das Feuer.

In der Tat ist der Chiasmus alter altera sprachangemessen im Deutschen bewahrt. »Jünglinge « hat ebenso wie »Morgenland « einen leicht altertümlichen Klang; beides findet sich wie auch »reizendste unter den Mädchen « schon bei Rode, bewahrt auf diese Weise auch im Sprachgebrauch das märchenhafte Ambiente, das auch durch den orientalischen Erzählrahmen hergeführt wird. Generell wählt Fink einen weniger alltäglichen Ton im Deutschen als von Albrecht: »der Sage nach « statt »soll «, »Bande der Ehe « statt »Hochzeit gefeiert «. ${ }^{388}$ Dafür ist captis mentibus nicht im Sinne der Psychopathologie, ${ }^{389}$ sondern als Ausdruck der wechselseitigen Verfallenheit aufgefasst.

Wie von Albrecht wechselt Fink mit Ovid am Ende das Tempus und lenkt damit narrativ auf die sentenzhafte Schlusswendung des Abschnitts hin. ${ }^{390}$ Insgesamt ist Finks Adaption von Rodes Fassung der derzeit konsequenteste Nachvollzug der narrativen Abfolge der Metamorphosen in Prosa und tritt damit parallel zur hexametrischen Fassung von Voß.

\section{Das führt Fink bis an den Rand der deutschen Sprachüblichkeit:}

Später davongeeilt, erblickte im tiefen Sand die deutlichen Spuren des Raubtiers Pyramus, und sein ganzes Gesicht erblaßte. Als er aber noch das vom Blut gerötete Gewand fand, sprach er: »So soll eine Nacht zwei Liebende vernichten! Von uns hätte sie vor allem ein langes Leben verdient; schuldig bin ich allein, ich habe dich, Bedauernswerte, gemordet, der ich dich an so schreckensvolle Orte zur Nachtzeit kommen ließ und nicht zuerst da war.

388 Vgl. Fink (1989), 420: »Wir folgen also in diesem Punkt ganz unserem Vorbild von Rode und streben zugleich danach, daß die Prosa, in die wir den Ovid umsetzen, nicht zu prosaisch gerät.

$>$ Poetische Prosa < versprach von Rode seinen Lesern, und er hielt sein Versprechen:

$>$ Unter Wünschen des Heils, das ihr selbst gebricht, so du es ihr nicht gibst, grüßt dich ein liebendes Mädchen, der, ach! Schaam verbiethet, sich zu nennen!<

So beginnt bei von Rode die in ihren Bruder verliebte Byblis einen Brief (Met. IX $528 \mathrm{ff}$.).

Das ist sehr gewählt formuliert, hat aber doch ein wenig Patina angesetzt. Unsere für Leser des 20. Jahrhunderts bestimmte Übersetzung will diese Patina mitnichten völlig entfernen - sonst ginge ja eben der für das Epos kennzeichnende hohe Stil verloren -, sondern nur einen Mittelweg finden zwischen Verständlichkeit, Lesbarkeit und Wohlklang.

Bei uns schreibt Byblis folgendermaßen:

$>$ Heil, woran es ihr selbst gebricht, wenn du es nicht spendest, wünscht dir ein liebendes Mädchen. Scham, ach, Scham verbietet es ihr, sich zu nennen!<

Quam, nisi tu dederis, non est habitura salutem,

\section{hanc tibi mittit amans. Pudet, a! pudet edere nomen.}

Der Vergleich mit von Rode und dem Original zeigt, daß unsere Übersetzung von Rodes Wortwahl zu bewahren trachtet, dabei aber das etwas platte > gibst < mit > spendest < auf eine höhere Sprachebene hebt, durch Ersatz des altertümlichen $>$ so $<$ durch $>$ wenn $<$ und Abänderung des sperrigen $>$ Unter Wünschen des Heils< einige Härten glättet und zugleich die Wortwiederholung pudet, a! pudet nachbaut. «

389 Vgl. oben Anm. 127.

390 Rode wechselt ebenfalls ins Präsens, allerdings zu einem deutlich früheren Zeitpunkt der Erzählung, da er auch mit dem quod non potuere [...]-Abschnitt erheblich freier, nämlich mit Blick auf generelle Aussagen, umgeht. 
Zerreißt meinen Leib und verschlingt mein verruchtes Herz mit wütenden Bissen, all ihr Löwen, die ihr in dieser Felsenkluft haust! Doch es ist feige, den Tod nur zu wünschen! « Den Mantel Thisbes hebt er auf und nimmt ihn mit sich in den Schatten jenes Baumes, und als er dem vertrauten Gewand seine Tränen geweiht, seine Küsse gespendet hat, spricht er: »Trinke nun auch mein Blut in vollen Zügen! « Und er stieß sich das Schwert, womit er umgürtet war, tief in die Weichen. Gleich darauf zog er es sterbend aus der brennenden Wunde und lag rücklings am Boden. Das Blut spritzt hoch empor, nicht anders, als wenn ein brüchiges Bleirohr platzt und aus dem schmalen Spalt zischend das Wasser in langem Strahl herausschießt und im Bogen die Luft teilt. Die mordbespritzten Früchte des Baumes färben sich dunkel, und die Wurzeln, vom Blute feucht, lassen die Beeren am Aste sich röten. ${ }^{391}$

Die Endstellung des Subjekts im ersten Hauptsatz hat im deutschen Sprachgebrauch einen erheblichen Aufmerksamkeitseffekt, da das den üblichen Satzbauplänen nicht entspricht. ${ }^{392}$ Im folgenden reduziert Fink deutlich die das Emotionale betonende Fassung Rodes, die sich gegenüber Ovid etwa durch die Einfügung von Interjektionen wie »ha« und »ach « eher verselbständigt hat. Dennoch versucht auch Fink den lateinischen Text emotional aufzuwerten, etwa durch die Wiedergabe des doppelten dedit mit »geweiht « und »gespendet «. Einen typographischen Ausweg findet Fink für die Antithese una duos: Um bei »eine « (anstelle von »eine einzige« o. ä.) bleiben zu können und den lateinischen Ausdruck nicht im Deutschen auszuweiten, kursiviert er das Wort und setzt damit ein optisches, vom unbestimmten Artikel unterscheidendes Betonungszeichen. ${ }^{393}$ Wie bei von Albrecht wird auch hier die von Ovid dezidiert gewählte Stellung von ferrum allerdings normalisiert.

Die bisher gemachten Beobachtungen zeigen schon, dass Fink ein weniger auf das bloß Inhaltliche und Sprachübliche zielendes Konzept vertritt als von Albrecht, dass er vielmehr die Rode'sche Vorlage gerade hinsichtlich der Steigerung des Ausdrucks in reduzierter Form fortschreibt, ohne dass sich daraus allerdings ein völlig konsistentes übersetzerisches Konzept gewinnen ließe.

391 Rode: »Ha! Eine Nacht vertilgt zwei Liebende! Ach! Sie war des längsten Lebens würdig; aber ich allein bin schuldig. Ich Unglückseliger, ich habe dich ermordet; da an einem so schreckenvollen Ort in der Nacht ich Dich kommen hieß, und nicht vor dir da war. Mich, mich zerreißt, ihr Löwen, die ihre diesen Felsen bewohnt! Meine ruchlosen Glieder verzehrt mit wilden Bissen! Doch, nur ein Feiger wünscht den Tod. Mit den Worten hebt er Thisbens Gewand auf, und mit ihm begiebt er sich in den Schatten des verabredeten Baums. Hier netzt er mit Thränen, hier küßt er er das bekannte Kleid. Endlich spricht er: Itzt tränke auch mit meinem Blute Dich! und senkt das Eisen, womit er umgürtet war, sich tief in die Eingeweide, und sterbend reißt er es plötzlich wieder aus der dampfenden Wunde. Als er rückwärts da liegt am Boden, springt hoch das Blut empor; nicht anders, als wenn eine beschädigte Bleiröhre berstet, zischend aus der Oeffnung der dünne Wasserstrahl hervor spritzt, und spritzend die Lüfte zertheilt.

Die Früchte des Baumes, besprengt mit Blute, wandeln so fort ihre Farbe, und mit Blute benetzt färbt die Wurzel mit Purpurröthe die herniederhangenden Maulbeeren.«

392 Vgl. Kienpointner (2009), 264-290.

393 Auch im folgenden Satz wäre eine solche Auszeichnung (oder eine andere Wortstellung) sinnvoll gewesen, da der Rückbezug von »vor allem « auf »sie « weniger sprachüblich ist als der Vorverweis auf »ein langes Leben«, was erst entweder durch den Blick ins lateinische Original oder durch den Fortgang des Textes modifiziert und korrigiert wird. 


\section{Dieser Befund gilt auch für die Pygmalion-Erzählung:}

Kaum heimgekehrt, begibt sich Pygmalion wieder zu seinem geliebten Bild, legt sich neben ihm nieder und küßt es - da scheint es warm zu sein! Er küßt es noch einmal und legt ihm die Hand an die Brust - da wird unter seiner Hand das Elfenbein weich, verliert seine Härte, gibt den Fingern nach und nimmt Eindrücke an, gleich wie Wachs vom Hymettos in der Sonne erweicht, unter dem Druck des Daumens mancherlei Gestalt annimmt und beim Formen immer formbarer wird. Während der Liebende staunt, sich erst zaghaft freut und noch fürchtet, er könne sich täuschen, sucht er sich wieder und wieder mit den Händen zu überzeugen, daß sich sein Wunsch erfüllt hat - und das Bild leibt und lebt! Es pochen dem tastenden Daumen die Adern entgegen! Nun sucht der paphische Künstler seinen Dank an Venus in eine Fülle feierlicher Worte zu fassen und preßt seine Lippen endlich auf wirkliche Lippen; das Mädchen fühlt den Kuß, errötet, und während es ängstlich sein lichtes Auge zum Licht erhebt, sieht es zugleich mit dem Himmel seinen Geliebten. ${ }^{394}$

Auch hier bemüht sich Fink um die Beibehaltung des sprachlichen Duktus, auch hier korrigiert er textfernere Entscheidungen Rodes, aber auch hier gibt es wieder $\mathrm{Ab}$ weichungen, deren Motivation nicht leicht klar wird: » zu seinem geliebten Bild « statt Rodes »zum Bilde seiner Geliebten « (lat. simulacra suae [...] puellae), »küßt es noch einmal « (ähnlich auch Rode) für admovit os iterum, worin die körperliche Bewegung hin zum sich erstaunlich verändernden Bild, nicht die Tatsache des Kusses ausgedrückt ist, parallel zur ähnlich intendierten Bewegung der Hände. Mit $\gg$ beim Formen immer formbarer « reduziert Fink (im Unterschied zu Rode) die aufs Allgemeine zielende, sentenzhafte Aussage Ovids. Für corpus erat übernimmt Fink Rodes wortspielartige Version (corpus > »leibt «), heros gibt er allerdings ohne Gegenstück im Lateinischen mit $\gg$ Künstler « wieder. Deutlich spürbar (und über Rode hinausgehend) erkennt Fink das abschließende Wortspiel Ovids und öffnet mit »lichtem Auge « den deutschen Text für die beiden Bedeutungen von lumen.

\subsection{Fazit}

Das späte 20. Jahrhundert erlebte eine kaum zu erwartende Steigerung des Interesses an Ovid in einer breiteren kulturellen Öffentlichkeit. Sichtbar wurde das am phänomenalen Erfolg von Christoph Ransmayrs Roman Die letzte Welt (1988) - aber das ist

394 Rode: »Als er heimgekehrt, begiebt er sich wieder zum Bilde seiner Geliebten, drückt neben ihm das Lager und küßt es: Da schien es warm zu sein! Er küßt es noch einmal; fühlt mit der Hand auf die Brust, und unter seiner Hand erweichet das Elfenbein, verliert seine Härte, giebt nach und nimmt Eindrücke an; gleichwie Hymettisches Wachs an der Sonne weich wird, und dem Drucke des Daumens folgend, mancherlei Gestalten annimmt und durch den Gebrauch nützlich wird. Indem er staunt, der Liebende, schüchtern sich freuet, noch sich zu täuschen fürchtet und wieder und wieder sich mit der Hand von der Erfüllung seiner Wünsche zu überzeugen sucht: Leibt und lebt das Bild, es pochen dem fühlenden Daumen die Adern entgegen! Nun bricht entzückt der Paphische Held in Dankgebete an Venus aus, drückt auf den nunmehr wirklichen Mund seine Lippen, und das Mädchen fühlt den Kuß, erröthet, und indem sie schüchtern ihren Blick zum Lichte aufschlägt, sieht sie mit dem Himmel zugleich ihren Geliebten.« 
gewissermaßen nur die Spitze des Eisbergs. ${ }^{395}$ Ransmayrs Roman verheißt im Untertitel ein »ovidisches Glossar«, das dem Leser den Vergleich zwischen den Romanfiguren und den Figuren der Metamorphosen ermöglichen soll und ausdrücklich auf von Albrechts Übersetzung basiert. Die Taschenbuchausgabe der Letzten Welt erschien im Fischer Verlag, wo flankierend dann auch Finks Übersetzung in einer preiswerten Ausgabe publiziert wurde.

Das kann schlaglichtartig zeigen, wie sich am Ende des 20. und am Beginn des 21. Jahrhunderts diese zwei Übersetzungen auf dem Buchmarkt weitgehend durchgesetzt haben - beide existieren obendrein auch als Hörbücher (aber offenbar - Stand 2014 - nicht als E-Books) -, die jeweils das Prinzip der Wiedergabe in Prosa realisieren und sich damit in die von Wolfgang Schadewaldt gesetzten Paradigmenreihe einer zeitgemäßen Übersetzung antiker Texte einreihen. Die metrischen Übersetzungen sind aus den aktuellen Verlagsverzeichnissen (im Unterschied noch zur Situation in der Mitte des 20. Jahrhunderts) entweder verschwunden (so Rösch und Breitenbach ${ }^{396}$ ) oder sind Träger von preisgünstigen Reprints (da das Urheberrecht erloschen ist) oder Ausgaben mit speziellem Zielpublikum (so der Voß' Übersetzung beigegebene PicassoZyklus im Insel-Taschenbuch für an »schönen « Büchern Interessierte). ${ }^{397}$ Daneben ist als weiteres Phänomen in den letzten Jahren verstärkt die unausgesprochene Wirkung zu berücksichtigen, die durch die im Internet zugänglichen Übersetzungen (die auch durch Suchmaschinen wie Google besonders leicht gefunden werden) verbreitet wird. Dabei ist weniger an die großen Digitalisierungsprojekte gedacht (zusammengefasst etwa in Google Books oder dem von deutschen Bibliotheken betriebenen Zentralen Verzeichnis digitalisierter Drucke: www.zvdd.de; siehe unten), die aufgrund der Frakturschrift oft kaum oder nur schwer maschinenlesbar und damit auch nicht suchmaschinenfreundlich sind, sondern in HTML (also reine, nur mit Formatauszeichnungen angereicherte Textdateien) umgesetzte historische, gemeinfreie Übersetzungen. So ist etwa die erstmals 1858 erschienene, in überarbeiteten Nachauflagen und Nachdrucken verbreitete Übersetzung von Reinhart Suchier auf der gerade für Schulzwecke oft aufgesuchten Internetseite http://www.gottwein.de/Lat/ov/ovmet 01001.php als gemeinfrei (darin auch derjenigen von Voß vergleichbar) verwendet und hat von da ihren Weg in zahlreiche andere Seiten, auch Diskussionsforen und Blogs gefunden (und wird derzeit auch bei E-Books - etwa für Amazon Kindle - als kostengünstige Alternative genutzt). Wie sich solches Recycling in der weiteren Entwicklung der E-Book-Märkte positionieren wird, ist derzeit noch längst nicht abzusehen.

395 Vgl. Schmitzer (2010).

396 Die einsprachige Reclam-Ausgabe mit der Übersetzung Breitenbachs (letzte Ausgabe 1986) ist noch lieferbar, wird aber (auch in den Buchhandelsregalen) dominiert von der zweisprachigen Ausgabe Michael von Albrechts, die auch nur unwesentlich teurer ist (18,80€ statt 13,80€, Stand 2012).

397 Suchiers Übersetzung (1858) wurde (in der Bearbeitung von Liselot Huchhausen, zuerst 1968) 1992 im Aufbau-Verlag Berlin nochmals gedruckt und liegt etwa dem Internetprojekt Mutatas dicere formas - Ovidprojekt Berlin/Potsdam (2004/2006) (http://www.telemachos.hu-berlin.de/materialien/ovidprojekt/start/start.html) zugrunde. 
Ein noch weniger wirklich zu erfassendes Phänomen, das mit dem Internet aufgekommen ist, ist die Verbreitung von Übersetzungen entweder von Schülern oder für Schüler gedacht, die als unauffällige, also jeden literarischen Anschein vermeidende Hausaufgabenhilfe o. ä. Verbreitung finden und frühere gedruckte, oftmals anonym erschienene (»von einem Schulmanne «) Schülerhilfen weitgehend ersetzt haben. ${ }^{398}$ Diese Publikationen entziehen sich, wie gesagt, einer genaueren Würdigung, da sie äußerst flüchtig sind, sie seien deshalb hier als Paraphänomen wenigstens genannt, aber nicht weiter erörtert.

Wieder ans Licht befördert haben nicht zuletzt die Digitalisierungsprojekte verschiedener Träger eine nicht unbeträchtliche Zahl von fast vergessenen Übersetzungen der Metamorphosen vor allem des 18. Jahrhunderts, die aber in den Kontext der generellen Übersetzungsdiskussionen der Vorklassik gehören und damit das missing link zwischen den Versuchen der Frühen Neuzeit und der Goethezeit bilden. Auch diese Übersetzungen haben - allerdings von der Fachwelt beinahe unbemerkt - ein zweites Leben im Internet gewonnen.

Die in den »etablierten « Übersetzungen zu findende deklaratorische Orientierung an Schadewaldts Vorgaben, ${ }^{399}$ die Michael von Albrecht in seinem Nachwort sogar explizit macht, geht aber nicht einher mit einer durchgehenden Übernahme in die tatsächlichen deutschen Textfassungen. Vielmehr schlagen die Übersetzer auch da, wo eine Übernahme diese Prinzipien problemlos (auch was die deutschen Sprachüblichkeiten betrifft) möglich gewesen wäre, nicht selten eigene Wege ein. Damit erweisen sich die Rekurse auf Schadewaldt nicht selten lediglich als Legitimation für die Wahl der Prosa als sprachliches Medium der Übersetzung. Die Frage nach der dualen Sprachenspezifik, den Kontrasten und Gemeinsamkeiten von Ausgangs- und Zielsprache wird über den Wortschatz hinaus nur selten überhaupt andiskutiert (eine Ausnahme ist Fink [1989]), so dass auch die nicht nur poetisch, sondern vor allem auch inhaltlich bedingten Abweichungen von üblicher Syntax, Satzreihenfolge etc. im lateinischen Original nur sehr selten zu Konsequenzen für die syntaktische Form der deutschen Wiedergabe führen, dass also unausgelotet bleibt, inwieweit gewagte lateinische Fassungen ebenso gewagt im Deutschen wiedergegeben werden können.

398 Aktuell erhältlich ist noch die Metamorphosen-Fassung der Reihe Königs Übersetzungen des BangeVerlags (übersetzt von Iris Rogge) mit dem Untertitel »Wortgetreue Übersetzung « und der Verlagsankündigung: »Deutsche Übersetzungen zu lateinischen Texten drücken sich häufig so gewählt aus, dass man den Originaltext dahinter kaum mehr erkennt. Für den Schulunterricht suchen Schüler deshalb wortgetreue Übersetzungen. Der Band Ovid, Metamorphosen bietet Schülern und Lehrern die wortgetreue deutsche Übersetzung aller 15 Bücher dieses Klassikers im handlichen Format zusammengefasst. (https://www.bange-shop.de/metamorphosen-3).

399 Vgl. Mindt (2009), 343-349. Eine Beispiel ist zuletzt Holzberg (2012), 95 f., der explizit Schadewaldt nennt, aber von der Beibehaltung der Wortstellung in der Vorlage (nicht der Reihenfolge der Vorstellungen) spricht. 
Hinzu kommt, dass (noch immer) keine wirkliche Diskussion über die Leistungen von und Erwartungen an Übersetzungen in Gang gekommen ist. ${ }^{400}$ Die Theoriediskussion ist weitgehend eingeschlafen, der Anschluss an Textlinguistik und Übersetzungstheorie ist nicht vollzogen worden, trotz mancher Ansätze in früheren Jahrzehnten. Eine öffentliche Debatte hat nur die Ilias-Übersetzung von Raoul Schrott ${ }^{401}$ (und in geringerem Umfang Christoph Martin) 402 $^{2}$ ausgelöst, also - wie schon in den letzten mehr als zwei Jahrhunderten - die Übersetzungen griechischer Texte. Während Ovids Metamorphosen ein wahrlich neuartiges dichterisches Unterfangen war, angekündigt schon mit den ersten beiden Worten des Proömiums in nova, das auch keinen tatsächlichen Nachfolger fand, sind die Metamorphosen-Übersetzungen aufs Ganze gesehen viel weniger wagemutig, sondern ziehen sich auf die Vermittlung des stofflichen Gehalts zurück. Eine ästhetische Aneignung der Metamorphosen und eine Integration in den poetischen Diskurs der eigenen Zeit, wie sie schon Albrecht von Halberstadt versucht hatte, steht nicht mehr auf der Agenda der MetamorphosenÜbersetzungen. ${ }^{403}$

\title{
Literaturverzeichnis ${ }^{404}$
}

\author{
Editionen (chronologisch)
}

Metamorphoseon Libri XV, ed. Io. Georgius Walchius, Leipzig 1714.

Opera que extant, 5 vols., Londini 1745.

Opera omnia: Metamorphoseon libri XV e recensione N. Heinsii, Lipsiae 1758.

Metamorphoseon libri XV oder Bücher der Verwandelungen. Mit teutschen Anmerkungen, Nürnberg 1759.

Metamorphoses, ed. Gottlieb Ermann Gierig, Lipsiae 1804-1807.

Metamorphoseon libri XV mit kritischen und erläuternden Anmerkungen von E. C. Chr. Bach, Hannover 1831-1836.

400 Vgl. für diesen Befund die Dokumente in Kitzbichler/Lubitz/Mindt (2009a). Es steht zu hoffen, dass der Beitrag von Poiss et al. (in diesem Band) neue Impulse auch außerhalb des Sonderforschungsbereichs »Transformationen der Antike « bewirkt.

401 Schrott (2009); vgl. die höchst umfangreiche, aber monomanische Rezension von Dräger (2009).

402 Vgl. Janka (2010).

403 Es wäre allenfalls auf Christoph Ransmayrs Neumontage der Metamorphosen und die dem Roman vorausgehenden quasi-übersetzerischen Vorarbeiten zu verweisen, vgl. Schmitzer (2001a).

404 Vgl. auch (für Ausgaben und Nachdrucke seit 1979) den Unesco-Index translationum (http://www. unesco.org/xtrans/). Die Bibliographie enthält auch Texte und Übersetzungen, die ich nicht einsehen konnte (mit non vidi gekennzeichnet), die aber wenigstens genannt werden sollen, um spätere Recherchen zu erleichtern, wenn etwa die Digitalisierungen historischer Bestände noch weiter voranschreiten. 
Metamorphoseon libri $X V$. recensuit, varias scripturas omnium codicum adhoc collatorum et vetustissimarum editionum apposuit, commentariis instruxit, praefatus est et indicem addidit Vitus Loers, Leipzig 1843.

Metamorphosen libri XV, rec. Hugo Magnus, Berlin 1914.

Metamorphoses, ed. W. S. Anderson, Stuttgart/Leipzig ${ }^{5} 1993$ (1. Auflage: 1977; 9. Aufl., München et al. 2001 [im Abschnitt 5.1 verwendet]).

Metamorphoses, rec. R. J. Tarrant, Oxford 2004.

\section{Kommentare (chronologisch)}

Regio, Raffaele, In metamorphosin enarrationes I (libri I-IV) [1493], a cura di Matteo Benedetti, Firenze 2008.

Bersuire, Pierre, Metamorphosis Ovidiana moraliter [...] explanata. Introductory Notes by Stephen Orgel, Paris 1509, (Reprint) New York/London 1979.

Spreng, Johann, Metamorphoses Ovidii, Argumentis quidem soluta oratione; Enarrationibus autem \& allegoriis Elegiaco versu accuratissime expositae summaque; diligentia ac studio illustratae per M. Joh. Sprengium Augustan., Augsburg 1563 (Onlinefassung: http://www.mdz-nbn-resolving.de/urn/resolver.pl?urn=urn:nbn: de:bvb:12-bsb11088660-5).

Sabinus, Georg, Fabularum poeticarum P. Ovidii metamorphosi descriptarum interpretatio ethica physica \& historica Autore G. S., [Heidelberg] 1606.

Gonet, Jean-Baptiste, Clypeus theologiae thomisticae, Bd. 2, 3. Aufl., Berlin/Bordeaux 1669.

de Boyer d'Argens, Jean Baptiste, Réflexions historiques et critiques sur le goût et sur les ouvrages des principaux auteurs anciens et modernes, Berlin 1743.

Bömer, Franz, P. Ovidius Naso, Metamorphosen. Kommentar von F. B., Bd. 1-8,1, Heidelberg 1969-2006.

Barchiesi, Alessandro/Rosati, Gianpero (Hgg.), Ovidio, Metamorfosi Volume I, libri III. A cura di A. B. e G. R., traduzione di Ludovica Koch, Milano 2004.

Barchiesi, Alessandro/Rosati, Gianpiero, Ovidio, Metamorfosi Volume II, libri III-IV. A cura di A. B. e G. R., traduzione di Ludovica Koch, Milano 2007.

Rosati, Gianpiero, Ovidio, Metamorfosi Volume III, libri V-VI. A cura di G.R., traduzione di Gioachino Chiarini, Milano 2009.

Kenney, Edward J., Ovidio, Metamorfosi. Volume IV, libri VII-IX. A cura di E. J. K., traduzione di Gioachino Chiarini, Milano 2011.

Reed, Joseph D., Ovidio, Metamorfosi. Volume V, libri X-XII. A cura di J.D.R., traduzione di Gioachino Chiarini, Milano 2013.

\section{Übersetzungen (chronologisch)}

Capellanus, Andreas/Hartlieb, Johannes, Das buoch Ovidy von der liebe zu erwerben. auch die liebe ze verschmehen, Augsburg 1482. (Rössig 1997, Nr. 19). 
de Bonsignori, Giovanni, Ovidio Metamorphoseos vulgare, mit Kommentar und Nachwort aus dem Lateinischen übersetzt von G. de B., Venedig 1497 (Onlinefassung: http://nbn-resolving.de/urn/resolver.pl?urn=urn:nbn:de:bvb:12-bsb00049624-0).

Halberstadt, M. Albrechten von, P. Ovidij Nasonis, des aller sinnreichsten Poeten Metamorphosis, das ist von der wunderbarlicher Verenderung der Gestalten der Menschen, Thier, und andere Creaturen etc. Jederman lüstlich, besonder aber allen Malern, Bildthauwern, und dergleichen allen künstnern nützlich, von wegen der ertigen Invention und Tichtung. Etwan durch den Wolgelerten M. Al. v. H. inn Reime weiß verteutscht. Jetz erstlich gebessert und mit Figuren der Fabeln gezirt durch Georg Wickram zu Colmar etc. EPIMYTHIUM. Das ist, Der lüstigen Fabeln des obgemelts buchs Auslegung, jederman kurzweilig, vornemlich aber allen Liebhabern der Edeln Poesie stadtlich zu lesen Gerhardi Lorichii Hadamarii (Mainz 1545 [ $\left.{ }^{2} 1551\right]$ ). (Rössig 1997, Nr. 166).

Posthius, Johannes, P. G. Tetrasticha in Ovidii Metam. lib. XV. quibus accesserunt Vergilij Solis figurae elegantiss. \& iam primum in lucem editae. Schöne Figuren auss dem fürtrefflichen Poeten Ouidio, allen Malern, Goldtschmiden, und Bildthauwern, zu nutz unnd gutem mit fleiss gerissen durch Vergilium Solis, unnd mit Teutschen Reimen kürtzlich erkläret, dergleichen vormals im Truck nie außgegangen, Durch Joh. Posthium von GermerßSheim Frankfurt a.M.1563 (Onlinefassung: http://nbnresolving.de/urn:nbn:de:0128-1-20392).

Spreng, M. Johann, P. Ovidii Nasonis deß Sinnreichen und hochverstendigen Poeten Metamorphoses oder Verwandlung mit schönen Figuren gezieret auch kurtzen Argumenten und außlegungen erkläret und in Teutsche Reymen gebracht Durch M. Johan Spreng von Augspurg, Frankfurt 1564. (Rössig 1997, Nr. 206).

Dall'Anguillara, Giovanni Andrea, Le Metamorfosi di Ovidio. Ridotte da Gio. A. dall'A. in ottava rima, con l'annotationi die Gioseppe Horologgi, et con gli argomenti di Francesco Turchi, 2. Aufl., Venedig 1587.

Metzger, Ambrosius, Metamorphosis Ovidij in Meisterthöne gebracht, hg. v. Hartmut Kugler, Berlin 1981.

de Benserade, Isaac, Metamorphoses D'Ovide En Rondeaux. In Zwey bundert und sechs und zwanzig zweyreimichten nemlich acht-und fünf-bündigen Rund-Gedichten Oder Rondeaux, Nürnberg 1689 (Onlinefassung: http://resolver.sub.uni-goettingen.de/purl?PPN740800779).

Baur, Johann Wilhelm, Ovidii Metamorphosis oder Verwandelungs-Bücher; Bellissimum Ovidii Theatrum seu: pulcherrimae P. Ovidii Nasonis poetae admodum ingeniosi (qui, teste Hieronymo Wolfio, tanquam Mosis discipulus, de mundi creatione cecinit) historiae; bundert und fünfzig neüe Kunstreiche Kupffer-Bildungen aus des zwar Heidnischen, aber Sinnreichen Poeten Ovidij Fünfzehn Büchern von seltzamer verwandelung der gestalten...mit teutschen Reimen öffentlich herausgegeben Durch den Kunstberühmten Joh. W. Baur inventirt und Durch Abraham Aubry in Kuppfer gestochen, Nürnberg 1703.

Schmidt, Johann Georg, P. Ovidii Nasonis XV. Bücher der Verwandlungen In das Teutsche übersetzt Dergestalt Daß die in denselben vorkommende Gemüths=Reden der Götter Göttinnen Helden ec Meistens in Reimen Die übrigen Erzeblungen aber in 
ungebundener Rede vorgetragen werden ... von Joh. G. S., Straßburg 1712. (Rössig 1997, Nr. 496).

Sedlezki, J. B., Ovids Verwandlungen aus dem Lateinischen übersetzt von J. B. S., Augsburg/Leipzig 1763.

Lindner, Johann Gottlieb, Lebrreicher Zeitvertreib in Ovidianischen Verwandlungen, Leipzig 1764 (Onlinefassung: http://www.mdz-nbn-resolving.de/urn/resolver. pl?urn=urn:nbn:de:bvb:12-bsb10242251-0).

Safft, Johann Samuel, Ovids Verwandlungen ins Deutsche übersetzt und mit Anmerkungen hg. v. Joh. S. S., Berlin 1766.

Haymann, Christoph Johann Gottfried, Versuch einer poetischen Uebersetzung eines Theils der zwey ersten Buecher Ovids von den Verwandlungen, gewagt und mit Anmerk. versehen von Chr. Joh. G. H., der Annen-Schule zu Dresden Rectorn ..., Dresden 1772. (Non vidi).

Bürger, Gottfried August, Dido, Ein episches Gedicht, aus Virgils Äneis gezogen (1777), in: Bürger's sämmtliche Werke, hg. v. August Wilhelm Bohtz, Göttingen 1835 (Onlinefassung: https://books.google.de/books/download/B\%C3\%BCrgers_ s\%C3\%A4mmtliche_Werke_hrsg_von_Augu.pdf).

Bremer, Johann Christoph, Verwandlungen aus dem Ovid, Leipzig 1781 (Onlinefassung: http://resolver.staatsbibliothek-berlin.de/SBB000032DA00000000). (Rössig 1997, Nr. 1067).

${ }^{* * *}$, Ferdinand, Ovids Verwandlungen, Fünfzehn Bücher, Frey übersetzt von $F .{ }^{* * *}$, o. O. 1786. (Rössig 1997, Nr. 1155)

Schlüter, Johann Georg Karl, Ovids Verwandlungen, metrisch übersetzt von Joh. G. K. Schlüter, Leipzig 1786.

Krome, F. W., Verwandlungen, metrisch übersetzt, Dresden 1789. (Non vidi: Rössig 1997, Nr. 1232; offenbar nur vorhanden in der Bibliothek des Kaiser-KarlsGymnasium Aachen, lt. KVK).

Voß, Johann Heinrich, Publii Virgilii Maronis Georgicon libri quattuor, Publius Virgilius Maro Landbau, vier Gesänge, übersetzt und erklärt von Joh. H. V., Eutin/Hamburg 1789.

Starcke, Gotthelf Wilhelm Christoph, Gedanken über die Übersetzung griechischer Dichter, nebst einzelnen Gedichten des Ovid, Mimnermus, Theognis, Pindar, Bacchylides und Simonides, (Schulprogramm) Bernburg 1790.

Schiller, Friedrich, Dido, Freie Uebersetzung des vierten Buches der Aeneide (1791), in: Supplemente zu Schillers Werken, aus seinem Nachlaß im Einverständnis und unter Mitwirkung der Familie Schillers, Erste Abtheilung: Nachlese und Variantensammlung, hg. v. Karl Hoffmeister, Stuttgart/Tübingen 1840 (Onlinefassung: https:// books.google.de/books/download/Supplemente_zu_Schillers_Werken_Aus_sein.pdf).

Holzbirn, Amalgund, Verwandelte ovidische Verwandlungen, Ad modum Blumauerii, Mit Anmerkungen, Erstes Buch, Stuttgart 1790, Zweytes und drittes Buch 1791.

Holzbirn, Amalgundus, Des weiland woblbestellt römischen Hofpoeten Publius Ovidius Naso Metamorphos, das ist, Verwandlungen, mit aecht französischer Freyheit übersetzt, und dabey von allen Obscönitaeten sorgsam laxirt und purgirt durch $A$. $H$., dermabligen Rector des Gymnasii zu Novazembla, Erstes Buch, Hamburg 1792 
(Onlinefassung: http://www.mdz-nbn-resolving.de/urn/resolver.pl?urn=urn:nbn: de:bvb:12-bsb10111520-0).

Schlüter, J. G. Carl, P. Ovids Naso's Kunst zu lieben. Ein Gedicht in drey Gesängen, metrisch übersetzt von J. G. C. S., Leipzig 1793.

Heynemann, [Simon], Des P. Ovidius Naso Verwandlungen, übersetzt von [S.] H., Frankfurt a. M. 1797.

Voß, Johann Heinrich, Verwandlungen nach Publius Ovidius Naso von Joh. H. V., 2 Bde., Berlin 1798. (Rössig 1997, Nr. 1907)

Rösch, Franz Nikolaus, Versuch einer metrischen Übersetzung der Stelle aus Ovids Verwandungen L. XV. v. 746-870 Nebst kritischer Beleuchtung der vorzüglichsten abweichenden Lesearten, (Schulprogramm) Würzburg 1816.

Hindenberg, Karl Wilhelm, Eine metrische Übersetzung der 2. Elegie des 1. Buches der Klagen des Ovidius, nebst einem Vorwort, (Schulprogramm) Heiligenstadt 1826.

Pfitz, Heinrich Christian, Die Klaglieder des Publius Ovidius Naso. Übersetzt und erläutert von H. Chr. P., München 1826.

Schreiber, Gottfried Adolf, Versuch einer metrischen Übersetzung des 2. Buches von Ovids Klageliedern, (Schulprogramm) Mühlhausen/Thüringen 1828.

Helm, Johann Martin, Drei Elegien des Publius Ovidius Naso in metrischer deutscher Übersetzung mit dem Urtexte, (Schulprogramm) Mannheim 1829.

Krieger, Johann Peter, Die Trennung, Drittes Lied aus dem ersten Buche der Klagegesänge des P. Ovidius Naso. Metrische Übersetzung, mit Bemerkungen, vorzüglich über die Feststellung des mit abgedruckten Grundtextes, (Schulprogramm) Zweibrücken 1829.

Pfitz, Heinrich Christian, Publius Ovidius Naso's Werke, Verwandlungen, übersetzt von H. Chr. P., Bdch. 1-5, Stuttgart 1833.

Blumauer, Aloys, Aloys Blumauer's gesammelte Werke. Einzig vollständige und rechtmässige, mit den Gesetzen des Deutschen Bundes conforme, neueste Gesammtausg., Stuttgart 1840.

Borscht, Joseph, Das zweite Buch der Metamorphosen des Publius Ovidius Naso metrisch übersetzt, (Schulprogramm) Speyer 1850.

Suchier, Reinhart, Kritisches zu Ovid nebst Proben einer Übersetzung des Werkes von R. S., (Schulprogramm) Hanau 1853.

Lindemann, Heinrich, P. Nasonis Opera, Ovids Werke. Berichtigt, übersetzt und erklärt von H. L., Leipzig 1853-1867. (Erster Theil: Die Verwandlungen Buch 1-5 1853; Zweiter Theil: Die Verwandlungen Buch 6-10 1854; Dritter Theil: Die Verwandlungen Buch 11-15 1856; Vierter Theil: Liebesergüsse 1859; Fünfter Theil: Die Liebeskunst; Die Heilmittel der Liebe; Die Schönheitsmittel 1861; Sechster Theil: Die Heroiden 1867). (Nicht bei Rössig 1997).

Klussmann, Ernst, Proben eine Übersetzung des Ovidschen Festkalenders, (Schulprogramm) Rudolstadt 1855.

Schönke, K. A., Die Sagenwelt der Alten. Für die Jugend bearbeitet von K. A. S., Berlin 1856. (In den darauffolgenden Auflagen veröffentlicht unter dem Titel: K. A. Schönke, Die Sagenwelt der Alten. Ein Lesebuch aus Ovid für die Jugend, 3. Aufl., durchgesehen von Dr. H. Clodius, Direktor, Berlin 1908.) 
Fertig, Michael, Proben einer Übersetzung von Ovid's Metamorphosen, (Schulprogramm) Landshut 1857.

Fertig, Michael, Drei der schönsten Stellen aus den Metamorphosen Ovid's, (Schulprogramm) Landshut 1861.

Suchier, Reinhart, Ovids Metamorphosen, übersetzt und erläutert von R. S., 3 Bde., 2. Aufl., Stuttgart 1868 (Onlinefassung: http://www.mdz-nbn-resolving.de/urn/ resolver.pl?urn=urn:nbn:de:bvb:12-bsb10702378-7/ sowie http://www.mdz-nbnresolving.de/urn/resolver.pl?urn=urn:nbn:de:bvb:12-bsb10702379-8). (1. Aufl. 1858; Rössig 1997, Nr. 2839).

Reinlein, Pius, Der Niobe-Mythus nach Ovid übersetzt und erklärt, (Schulprogramm) Augusburg 1871.

Meichelt, Heinrich, Probe einer Ovid-Übersetzung, (Schulprogramm) Offenburg 1882.

Thiele, Karl, Übersetzungen aus Ovid in achtzeiligen jambischen Strophen mit Anmerkungen, (Schulprogramm) Sondershausen 1882.

Thiele, Karl, Übersetzungen aus Ovid in Stanzen mit Anmerkungen, (Schulprogramm) Sondershausen 1887.

Koch, Alwin, Des Publius Ovidius Naso Briefe der Heroiden. 1-9. metrisch übersetzt, (Schulprogramm) Frankenthal 1888.

Zwirnmann, Robert, Ovids Verwandlungen, übersetzt von R. Z., Gotha 1895. (non vidi, nicht bei Rössig 1997).

Hamelbeck, Wilhelm, Ovids Verwandlungen in deutsche Hexameter übertragen von W. H., Mülheim a. Rhein 1896-1897. (Non vidi; nicht bei Rössig 1997).

Bulle, Constantin, Ovids Verwandlungen, in Stanzen übersetzt von C. B., Bremen 1898. (Nicht bei Rössig 1997).

Altendorf, Otto, Proben aus einer Ovidübersetzung, (Schulprogramm) Gießen 1903.

John, Oskar, Proben aus Ovids Ars amandi und Amores, in Stanzen übersetzt, (Schulprogramm) Königshütte 1904.

Stählin, Otto, Des Clemens von Alexandreia ausgewählte Schriften, aus dem Griechischen übersetzt von O. S., 2 Bde., München 1934.

von Scheffer, Thassilo, Ovid, Metamorphosen, verdeutscht von T. v. S., Wiesbaden 1948. (Rössig 1997, Nr. 7918).

Kindt, Karl, Märchen und Mythen Ovids, Berlin 1949.

Rösch, Erich, Ovid, Metamorphosen, übersetzt von E. R., München 1952. (Nicht bei Rössig 1997).

Breitenbach, Hermann, Ovid, Metamorphosen, Epos in 15 Büchern, übersetzt und hg. v. H. B., mit einer Einleitung von L. P. Wilkinson, Zürich/Stuttgart 1958. (Rössig 1997, Nr. 9543).

Rode, August, Apulejus, Der goldene Esel, übertr. von A. R., hg. v. Horst Rüdiger, Zürich 1960.

von Albrecht, Michael, Ovid, Metamorphosen, in deutsche Prosa übertragen von M. v. A., München 1981. (Rössig 1997, Nr. 14213).

von Rode, August, Ovid, Metamorphosen. Das Buch der Mythen und Verwandlungen. nach der ersten deutschen Prosaübersetzung durch A. v. R. neu übersetzt und hg. v. Gerhard Fink, Zürich/München 1989. (Rössig 1997, Nr. 16224). 
von Rode, August, Ovid, Metamorphosen. Das Buch der Mythen und Verwandlungen, nach der ersten deutschen Prosaübersetzung durch A. v. R. neu übersetzt und herausgegeben von Gerhard Fink, Düsseldorf/Zürich 2001.

Kindt, Karl, Märchen und Mythen Ovids, Berlin 1949.

Rode, August, Apulejus, Der goldene Esel, übertr. von A. R., hg. v. Horst Rüdiger, Zürich 1960.

Holzberg, Niklas, Liebesgedichte der Antike, hg. v. Ulla Hahn, Auswabl, Übersetzung und Nachwort von N. H. Stuttgart 2012.

von Albrecht, Michael, Ovid, Metamorphosen, lateinisch-deutsch, übersetzt von M. v. A., Ditzingen 2010.

\section{Andere Quellenschriften (chronologisch)}

Opitz, Martin, Prosodia Germanica, Oder Buch von der Deutschen Poeterey: Jn welchen alle ibre Eigenschafft und Zugehör gründlich erzählet, und mit Exempeln ausgeführet wird, Breslau 1624 (zitiert nach der Ausgabe 1690).

Buchner, August, August Buchners kurzer Weg-Weiser zur Deutschen Tichtkunst, aus ezzlichen Exemplarien ergänzet, mit einem Register vermehret und auff vielfältiges Ansuchen der Studierenden izo erstmalig hervorgegeben durch M. Georg Götzen, Jena 1663.

Gonet, Jean-Baptiste, Clypeus theologiae Thomisticae, Paris 1669.

von Birken, Sigmund, Teutsche Redebind-und Dicht-Kunst, oder Kurze Anweisung zur Teutschen Poesy mit Geistlichen Exempeln: Samt dem Schauspiel Psyche und Einem Hirten-Gedichte, Nürnberg 1679.

de Boyer d'Argens, Jean-Baptiste, Réflexions historiques et critiques sur le goût et sur les ouvrages des principaux auteurs anciens et modernes, Berlin 1743.

von Goethe, Johann Wolfgang, Sämtliche Werke nach Epochen seines Schaffens, hg. v. K. Richter, München 1985-1998 (MA).

Norden, Eduard, P. Vergilius Maro: Aeneis Buch VI, Leipzig 1927.

Winckelmann, Johann Joachim, Geschichte der Kunst des Alterthums, hg. v. Heinrich Meyer u. Johann Schulze, 4 Bde., Dresden 1809-1815 (= Winckelmanns Werke, Bd. 3-6).

Scheller, Immanuel Johann Gerhard/Lünnemann, Heinrich Georg, Lateinisch-deutsches und deutsch-lateinisches Handlexicon vornehmlich für Schulen, 4 . Aufl., Leipzig 1807.

\section{Sekundärliteratur}

von Albrecht, Michael, Die Parenthese in Ovids Metamorphosen und ihre dichterische Funktion, Hildesheim 1963 (= Diss., Tübingen 1959). 
von Albrecht, Michael, »Zur Funktion der Tempora in Ovids elegischer Erzählung «, in: Ovid, hg. v. Michael von Albrecht/Ernst Zinn, Darmstadt 1968 (= Wege der Forschung, 92), 451-467.

von Albrecht, Michael, $\gg \mathrm{Zu}$ Vergils Erzähltechnik. Beobachtungen zum Tempusgebrauch in der Aeneis «, in: Glotta 48 (1970), 219-229.

von Albrecht, Michael, $\gg$ Mythos und römische Realität in Ovids >Metamorphosen $<\ll$, in: $A N R W$ II.31.4 (1981) 2328-2342.

von Albrecht, Michael, »Chancen und Grenzen des Übersetzens. Dankrede«, in: Jabrbuch der Deutschen Akademie für Sprache und Dichtung, Göttingen 2004, 4550.

Anemüller, Bernhard, »Lindner, Johann Gottlieb «, in: $A D B 18$ (1883), 705 f. (Onlinefassung: http://www.deutsche-biographie.de/sfz51630.html).

Auhagen, Ulrike, »Vergilischer als Vergil? Zu Schillers Nachdichtung des vierten Buches der Aeneis «, in: Würzburger Jabrbücher N. F. 34 (2010), 209-230.

Aurnhammer, Achim/Martin, Dieter (Hgg.), Mythos Pygmalion. Texte von Ovid bis John Updike, Leipzig 2003.

Bachleitner, Norbert, »Der Übersetzungsbetrieb des 18. und 19. Jahrhunderts in soziologischer Sicht «, in: Harbsmeier/Kitzbichler/Lubitz/Mindt (2008), 103-117.

Baillot, Anne/Fantino, Enrica/Kitzbichler, Josefine (Hgg.), Voß’ Übersetzungssprache. Voraussetzungen, Kontexte, Folgen, Berlin 2014.

Baro, Christine, »Wenn Göttergatten Jungfrauen bezirzen. Erotik und ihre Folgen in der moralisierenden Mythenrezeption bei Hans Sachs«, in: Simpliciana, Schriften der Grimmelshausen-Gesellschaft 31 (2009), 377-397.

Bartsch, Karl, Albrecht von Halberstadt und Ovid im Mittelalter, Quedlinburg/Leipzig 1861.

Bartsch, Tatjana/Becker, Marcus/Bredekamp, Horst/Schreiter, Charlotte (Hgg.), Das Originale der Kopie. Kopien als Produkte und Medien der Transformation von Anti$k e$, Berlin 2010 (= Transformationen der Antike, 17).

Bartoněk, Antonín, A Comparative Graeco-Latin Sentence Syntax within the European Context, München 2010 (= Lincom Studies in Indo-European Linguistics, 37).

Baumbach, Manuel, »Lehrer oder Gelehrter? Der Schulmann in der Altertumswissenschaft des 19. und frühen 20. Jahrhunderts «, in: Most (2002), 115-141.

Behmenburg, Lena, »dieweil ir swester was sein weib. Zur Bedrohung der familiären Ordnung in Georg Wickrams Philomela«, in: Müller/Mecklenburg (2007), 135146.

Behmenburg, Lena, Philomela. Metamorphosen eines Mythos in der deutschen und französischen Literatur des Mittelalters, Berlin 2009.

Benz, Richard, Wandel des Bildes der Antike in Deutschland. Ein geistesgeschichtlicher Überblick, München 1948.

Binder, Hermann, »Schiller und Virgil «, in: Deutsche Vierteljabrsschrift für Literaturwissenschaft und Geistesgeschichte 24 (1950), 101-128.

Boeckh, August, Encyklopädie und Methodologie der philologischen Wissenschaften, Leipzig ${ }^{2} 1886$. 
Böhme, Hartmut/Rapp, Christof/Rösler, Wolfgang (Hgg.), Übersetzung und Transformation, Berlin 2007 (= Transformationen der Antike, 1).

Böhme, Hartmut et al., Transformation. Ein Konzept zur Erforschung kulturellen Wandels, München 2011.

Bömer, Franz, »Der Erzähler Ovid«, in: Gymnasium 107 (2000), 1-23.

Botley, Paul, »Fifteenth-Century Translators on Their Art: Leonardo Bruni and Giannozzo Manet «, in: Böhme/Rapp/Rösler (2007), 61-78.

Bräuer, Rolf, »Ovids >Metamorphosen < in der Übertragung Albrechts von Halberstadt «, in: Geschichte der deutschen Literatur von den Anfängen bis zur Gegenwart (2. Band: Mitte des 12. bis Mitte des 13. Jahrhunderts), hg. v. Kollektiv für Literaturgeschichte Volk und Wissen unter der Leitung von Rolf Bräuer, Berlin 1990, 159-166.

Brüggemann, Theodor, »Antike Mythologie als Bildungsgut im 17. und 18. Jahrhundert in Büchern für die Jugend «, in: Mythen, Märchen und moderne Zeiten. Beiträge zur Kinder- und Jugendliteratur, hg. v. Clemens Alfred Baumgärtner/Alfred E. Maier, Würzburg 1987, 11-31.

Brüggemann, Theodor, »Zur Rezeption antiker Mythologie in der Kinder- und Jugendliteratur der Goethezeit«, in: Imprimatur. Ein Jahrbuch für Bücherfreunde, NF 12 (1987), 93-116.

Bucchi, Gabriele, Meraviglioso diletto. La traduzione poetica del Cinquecento e le Metamorfosi d'Ovidio di Giovanni Andrea dell' Anguillara, Pisa 2011.

Bursian, Conrad, »Jacob, Friedrich «, in: ADB 13 (1881), 556-558.

Bursian, Conrad, Geschichte der classischen Philologie in Deutschland von den Anfängen bis zur Gegenwart, 2 Bde., München/Leipzig 1883.

Butters, Friedrich, Ueber die Bipontiner und die Editiones Bipontinae, (Schulprogramm) Zweibrücken 1877.

Cancik, Hubert/Cancik-Lindemaier, Hildegard, »>Das Gymnasium in der Knechtschaft des Staates $<$. Zu Entstehung, Situation und Thema von Friedrich Nietzsches $>$ Wir Philologen « , in: Most (2002), 97-113.

Cappelletti, Francesca, »L'utilizzazione allegorica dei miti tratti dalle Metamorfosi di Ovidio nella pittura e nell'emblematica fra ' 500 e ' $600 \ll$, in: Horn/Walter (1997), 229-252.

Carlsohn, Erich, »Die Bibliothek von Hans Sachs «, in: Börsenblatt für den deutschen Buchhandel, Frankfurter Ausgabe 16 (1960), 747-748.

Couturier-Heinrich, Clémence, »Autorität und Konkurrenz. Zur Reaktion von Goethe und Schiller auf Vossens Hexameterlehre und -praxis«, in: Baillot/Fantino/ Kitzbichler (2014), 71-92.

Dettmer, Herrmann, Zur Charakteristik von Schillers Umdichtungen des Vergil, (Schulprogramm) Hildesheim 1899.

Devine, A.M./Stephens, Laurence D., Latin Word Order. Structures, Meaning and Information, Oxford 2006.

Dönike, Martin, Pathos, Ausdruck und Bewegung. Zur Ästhetik des Weimarer Klassizimus 1796-1806, Berlin/New York 2005. 
Dräger, Paul, »Rez. Homer, Ilias. Übertragen von Raoul Schrott. Kommentiert von Peter Mauritsch, München 2008 «, in: Göttingische Gelehrte Anzeigen 261 (2009), 1-27 (Onlinefassung: http://www.uni-tuebingen.de/troia/deu/Rezension-SchrottHomer.pdf).

»Dz.«, »Rez. zu Ovids Verwandlungen metrisch übersezt von Iohann Georg Carl Schlüter «, in: Allgemeinen Deutschen Bibliothek, Bd. 73 (1787), 558-561.

Eckstein, Friedrich August, Nomenclator philologorum, Leipzig 1871.

Elflein, Werner, Verssprache. Zum Problem der Abhängigkeit von Vers und Sprache am Beispiel deutschsprachiger Versubersetzungen von Vergils Aeneis, Diss. Göttingen 1972.

Elit, Stefan, Die beste aller möglichen Sprachen der Poesie. Klopstocks wettstreitende Übersetzungen lateinischer und griechischer Literatur, St. Augustin 2002 (= Die Antike und ihr Weiterleben, 3).

Engelmann, Wilhelm/Enslin, Theodor Christian Friedrich, Bibliotheca auctorum classicorum, 7. Aufl., Leipzig/Paris 1847.

Evers, Daniela, Die schönsten Sagen des Klassischen Altertums. Zur Bedeutung und Funktion der Bearbeitung antiker mythologischer Erzäblungen in der Kinder-und Jugendliteratur des 19. Jabrhunderts, Mörlenbach 2001.

Ewers, Hans-Heino, Literatur für Kinder und Jugendliche. Eine Einführung in grundlegende Aspekte des Handlungs- und Symbolsystems Kinder- und Jugendliteratur. Mit eine Auswahlbibliographie Kinder- und Jugendliteraturwissenschaft, München 2000.

Ewers, Hans-Heino, Erfahrung schrieb's und reicht's der Jugend. Geschichte der deutschen Kinder- und Jugendliteratur vom 18. bis zum 20. Jahrhundert, Frankfurt a. M. 2010.

Faems, An/Minet-Mahy, Virginie/Van Coolput-Storms, Colette (Hgg.), Les translations d'Ovide au Moyen Age, Louvain-La-Neuve 2011.

Fantino, Enrica, »Je näher ihm, desto vortrefflicher «. Eine Studie über die Genese Voß'scher Übersetzungssprache und -konzeption von den Anfägen bis zur HomerÜbersetzung, Diss., Leipzig 2014 (ungedruckt).

Feldherr, Andrew, »Reconciling Niobe«, in: Hermathena 177/178 (2004/2005), 125-146.

Feldherr, Andrew, Playing Gods. Ovid's Metamorphoses and the Politics of Fiction, Princeton 2010.

Fielitz, Sonja, Wit, Passion and Tenderness. Ovids Metamorphosen im Wandel der Diskurse in England zwischen 1660 und 1800, Frankfurt u. a. 2000.

Fink, Gerhard, » >... Da rauschte Phoebus' Leier <. Grenzen und Möglichkeiten angemessenen Übersetzens antiker Dichter «, in: AU 35/1 (1992) 34-47.

Fisher, Elizabeth A., Planudes' Greek translation of Ovid's Metamorphoses, New York/London 1990.

Fodor, Nóra, Die griechischen Übersetzungen lateinischer Autoren durch Maximos Planudes, Diss. Heidelberg 2004 (Onlinefassung: http://www.ub.uni-heidelberg.de/ $\operatorname{archiv/8700).~}$ 
Fondermann, Philipp, Kino im Kopf. Zur Visualisierung des Mythos in den »Metamorphosen « Ovids, Göttingen 2008.

Freedman, Luba/Huber-Rebenich, Gerlinde (Hgg.), Wege zum Mythos, Berlin 2001.

Fritsch, Andreas, »Bemerkungen zum Verhältnis von Philologie und Schule bei Ulrich von Wilamowitz-Moellendorff «, in: Latein und Griechisch in Berlin 26 (1982), 69.

Fritsch, Andreas, »Hermann Menge als Pädagoge «, in: $A U 30 / 3$ (1987) 25-40.

Frölich, Andrea, Herrschaftsstrukturen und Herrschaftslegitimation in der Literatur. Der Thüringer Landgrafenhof unter Hermann I (1170-1217), Diss. Frankfurt a. M. 2007 (Onlinefassung: http://publikationen.ub.uni-frankfurt.de/volltexte/2007/ $5049 /$ pdf/FroelichAndrea.pdf).

Fuhrmann, Manfred, Der europäische Bildungskanon des bürgerlichen Zeitalters, 2. Aufl., Frankfurt 1999.

Gatti, Pierluigi, »Da impudicitiae praedicato a princeps della narrazione. Ovidio fra Medievo e Rinascimento «, in: Undique mutabant atque undique mutabantur. Beiträge zur augusteischen Literatur und ibren Transformationen, hg. v. Pierluigi Gatti/Nina Mindt, Göttingen (2011) (=Vertumnus, 8), 147-170.

Gatti, Pierluigi, Ovid in Antike und Mittelalter. Geschchte der philologsichen Rezeption, Stuttgart 2014 (= Hermes Einzelschriften, 106).

Geominy, Wilfried, Die Florentiner Niobiden, Bonn 1984.

Giesecke, Michael, Der Buchdruck in der Frühen Neuzeit. Eine historische Fallstudie über die Durchsetzung neuer Informations- und Kommunikationstechnologien, Frankfurt a. M. 1991.

Grimm, Jacob und Wilhelm, Deutsches Wörterbuch, 16 Bde., Leipzig 1854-1961 (Onlinefassung: http://dwb.uni-trier.de/de/).

Guthmüller, Bodo, »Lateinische und volkssprachliche Kommentare zu Ovids >Metamorphosen ««, in: Der Kommentar in der Renaissance, hg. v. August Buck/Otto Herding, Boppard 1975, 119-139.

Guthmüller, Bodo, »Formen des Mythenverständnisses um $1500 \ll$, in: Horn/Walter (1997), 37-61.

Hannemann, Britta, Weltliteratur für Bürgertöchter. Die Übersetzerin Sophie MereauBrentano, Göttingen 2005.

Harbsmeier, Martin/Kitzbichler, Josefine/Lubitz, Katja/Mindt, Nina (Hgg.), Übersetzung antiker Literatur. Funktionen und Konzeptionen im 19. und 20. Jahrbundert, Berlin 2008 (= Transformationen der Antike, 7).

Harper, Anthony John, Studien zum deutschen weltlichen Kunstlied des 17. ud 18. Jahrbunderts, Amsterdam 1992.

Heck, Eberhard, »Ernst Zinn«, in: Eikasmos 4 (1993) 393-401.

Heinzmann, Julia-Maria, Die Bubllieder des Hans Sachs. Form, Gehalt, Funktion und sozialhistorischer Ort, Wiesbaden 2001.

Hexter Ralph, »Ovid in translation in Medieval Europe «, in: Translation, Traduction, Übersetzung, Bd. 2, hg. v. Harald Kittel et al., Berlin 2007, 1311-1328.

Hofmann, Heinz, »Ovids >Metamorphosen< in der Forschung der letzten 30 Jahre (1950-1979)«, in: ANRW II.31.4 (1981), 2161-2273. 
Holzberg, Niklas, Hans-Sachs-Bibliographie 1977-2013 [2013] (Onlinefassung: http://www.niklasholzberg.com/Homepage/Bibliographien_files/BiblHansSachs .docx).

Horn, Hans-Jürgen/Walter, Hermann (Hgg.), Die Rezeption der Metamorphosen des Ovid in der Neuzeit: Der antike Mythos in Text und Bild, Berlin 1995.

Horn, Hans-Jürgen/Walter, Hermann (Hgg.), Die Allegorese des antiken Mythos, Wiesbaden 1997 (= Wolfenbütteler Forschungen, 75).

Horn, Hans-Jürgen, »Die Tetrasticha des Johannes Posthius zu Ovids Metamorphosen und ihre Stellung in der Überlieferungsgeschichte «, in: Horn/Walter (1995), 214-224.

Horn, Hans-Jürgen, »Eine neue Verwandlung der $>$ Verwandlungen $<\ll$, in: Freedman/ Huber-Rebenich (2001), 183-191.

Horn, Hans-Jürgen, »Eine neue Verwandlung der >Verwandlungen $<\ll$, in: Wege zum Mythos, hg. v. Luba Freedman /Gerlinde Huber-Rebenich, Berlin 2001, 183-191.

Hosäus, Wilhelm, »Rode, August von «, in: ADB 29 (1889), $2 \mathrm{f}$.

Huber, Christoph, »Albrecht von Halberstadt «, in: Killy (2008), 81.

Huber-Rebenich, Gerlinde, »Beobachtungen zur Feuermetaphorik im sermo amatorius in Ovids Metamorphosen «, in: RhM 137 (1994), 127-140.

Huber-Rebenich, Gerlinde, »Die Macht der Tradition. Metamorphosen-Illustrationen im späten 16. und frühen 17. Jahrhundert «, in: Freedman/Huber-Rebenich (2001), 141-161.

Huber-Rebenich, Gerlinde, »Ovids Phaëthon in der textbegleitenden Druckgraphik des 15. und 16. Jahrhunderts «, in: Phaëthon. Ein Mythos in Antike und Moderne, hg. v. Karl-Joachim Hölkeskamp/Stefan Rebenich, Wiesbaden 2009, 69-91.

Hurrelmann, Bettina, Klassiker der Kinder-und Jugendlektüre, Frankfurt a. M. 1995.

Hurrelmann, Bettina, »Kinder- und Jugendliteratur in der literarischen Sozialisation «, in: Taschenbuch der Kinder- und Jugendliteratur, hg. v. Günter Lange, Bd. 2, Hohengehren 2000, 901-920.

James, Paula, The Legacy of Ovid's Pygmalion Myth on Screen. In pursuit of the perfect woman, New York 2011.

Janka, Markus, »Neue Rhapsoden braucht das Land. Christoph Martin und Raoul Schrott auf der Suche nach einem deutschen Homer der Postmoderne «, in: Text+Kritik-Sonderband VIII/10 »Homer und die deutsche Literatur «, hg.v. Heinz-Ludwig Arnold/Hermann Korte, München 2010, 242-261.

Janka, Markus/Stierstorfer, Michael, »Von Arkadien über New York ins Labyrinth des Minotaurus. Mythologische Orte in Ovids Metamorphosen und aktueller Kinderund Jugendliteratur «, in: Gymnasium 122 (2015), 1-46.

Jarislowski, Johanna, Schillers Übertragungen aus Vergil im Rahmen der deutschen Aeneis-Übersetzungen des 18. Jahrbunderts, Jena 1928.

Kalka, Joachim, »Nüchternheit und Strenge aus Liebe zum Text. Laudatio auf Michael von Albrecht «, in: Jabrbuch der Deutschen Akademie für Sprache und Dichtung, Göttingen 2004, 41-44.

Kallendorf, Craig, The other Virgil: >Pessimistic < readings of the Aeneid in early modern culture, Oxford 2007. 
Karrer, Klaus, Johannes Posthius (1537-1597). Verzeichnis der Briefe und Werke mit Regesten und Posthius-Biographie, Wiesbaden 1993.

Kienpointner, Manfred, Latein - Deutsch kontrastiv. Vom Phonem zum Text, Tübingen 2009 (= Deutsch im Kontrast, 23).

Kipf, Stefan, »Homer im Klassenzimmer. Odyssee-Rezeption in der modernen Kinder- und Jugendliteratur «, in: Antike Kultur und Geschichte, Band 4. Die Antike außerhalb des Hörsaals, hg. v. Kai Brodersen, Münster 2003, 76-96.

Kipf, Stefan, »Der Schulmann als vir doctissimus - Preußische Schulprogramme im Spannungsfeld von Wissenschaft und Öffentlichkeit«, in: Zeitschrift für Germanistik 23 (2013), 259-275.

Kitzbichler, Josefine, »Nach dem Wort, nach dem Sinn. Duale Übersetzungstypologien «, in: Böhme/Rapp/Rösler (2007), 31-46.

Kitzbichler, Josefine, »Für wen übersetzen? Beobachtungen in Übersetzungsvorreden «, in: Harbsmeier/Kitzbichler/Lubitz/Mindt (2008), 61-79.

Kitzbichler, Josefine/Lubitz, Katja/Mindt, Nina (Hgg.), Dokumente zur Theorie der Übersetzung antiker Literatur in Deutschland seit 1800, Berlin/New York 2009a.

Kitzbichler, Josefine/Lubitz, Katja/Mindt, Nina, Theorie der Übersetzung antiker Literatur in Deutschland seit 1800, 2009b.

Kitzbichler, Josefine, »Von 1800 bis zur Mitte des 19. Jahrhunderts «, in: Theorie der Übersetzung antiker Literatur in Deutschland seit 1800, hg. v. Josefine Kitzbichler/Katja Lubitz/Nina Mindt, Berlin/New York (2009b), 13-111.

Kitzbichler, Josefine, »>Minder philologisch als künstlerisch<. Johann Gustav Droysens Aristophanes-Übersetzung «, in: Philosophie und Politik - Historie und Philologie, hg. v. Stefan Rebenich/Hans-Ulrich Wiemer, Frankfurt a. M. (2012), 63-92.

Kitzbichler, Josefine, Der Wettstreit um Homer im 18. Jahrhundert. Dokumentation, Ms. 2012a.

Kitzbichler, Josefine, Homer-Übersetzungen zwischen 1871 und 1918. Fallstudien. mit einer Bibliographie deutscher Übersetzungen der Homerischen Epen von den Anfängen bis zur Gegenwart, Ms. 2012b.

$\mathrm{Kleßmann}$, Eckart, Vergil und seine deutschen Übersetzer, Stuttgart 2009 (= Akademie der Wissenschaften und der Literatur, Klasse der Literatur, Abhandlungen 2009/2).

von Klöden, Karl Friedrich/Schmidt, Valentin Heinrich, Die ältere Geschichte des Köllnischen Gymnasiums, bis zu seiner Vereinigung mit dem Berlinischen Gymnasium [zum grauen Kloster], nebst einigen Worten über dessen jetzige Bestimmung, Berlin 1825 (Onlinefassung: http://www.mdz-nbn-resolving.de/urn/resolver.pl?urn= urn: nbn:de:bvb:12-bsb10736808-1).

Klopstock, Friedrich Gottlieb, Grammatische Gespräche, Altona 1794.

Korten, Lars, »Metrik als Tonkunst. Zur Zeitmessung der deutschen Sprache von Johann Heinrich Voß«, in: Baillot/Fantino/Kitzbichler (2014), 33-49.

Kössler, Franz, Personenlexikon von Lehrern des 19. Jahrbunderts, (Vorabdruck) 2007

(Onlinefassung: http://geb.uni-giessen.de/geb/volltexte/2008/6106/). 
Kugler, Hartmut, Handwerk und Meistergesang. Ambrosius Metzgers MetamorphosenDichtung und die Nürnberger Singschule im frühen 17. Jahrhundert, Göttingen 1977.

Kuhlmann, Peter/Schneider, Helmuth (Hgg.), Geschichte der Altertumswissenschaften. Biographisches Lexikon, Stuttgart/Weimar 2012 (= Der Neue Pauly, Suppl. 6).

Kühlmann, Wilhelm/ Aurnhammer, Achim (Hgg.), Killy Literaturlexikon: Autoren und Werke des deutschsprachigen Kulturraumes, Berlin ${ }^{2} 2008$.

Laage, Karl Ernst, »Zur Problematik einer Prosaübertragung der Aeneis (Vergil, Aeneis I 1-296)《, in: Gymnasium 68 (1961), 97-112.

Laird, Andrew, »Vergil: Aeneis «, in: Der Neue Pauly Suppl. 7: Die Rezeption der antiken Literatur. Kulturhistorisches Werklexikon (2010), 1108-1138.

Landfester, Manfred, »Ovidius Naso, Publius (Ovid)«, in: Der Neue Pauly, Suppl. 2: Geschichte der antiken Texte. Autoren- und Werklexikon (2007), 430f.

Lateiner, Donald, »Mimetic Syntax. Metaphor from Word Order, especially in Ovid «, in: $A J P h 111$ (1990), 204-237.

Laufhütte, Hartmut, »Programmatik und Funktionen der allegorischen Verwendung antiker Mythenmotive bei Sigmund von Birken (1616-1681)«, in: Horn/Walter (1997), 287-310.

Leonhardt, Jürgen, Latein. Geschichte einer Weltsprache, München 2009.

Lindemann, Heinrich, Materialien zu Aufgaben Lateinischer Verse, von den ersten Anfängen in Herstellung umgestellter Verse bis zur höchsten Vollkommenheit in Fertigung selbstständiger Dichtungen zum Schul und Selbstunterrichte, Leipzig 1830 (Erster Theil) (Onlinefassung: http://www.mdz-nbn-resolving.de/urn/resolver. pl?urn=urn:nbn:de:bvb:12-bsb10586753-0).

Lübben August, »Neues Bruchstück von Albrecht von Halberstadt «, in: Germania 10 (1865), 237-245.

Lubitz, Katja, »Von der Mitte des 19. Jahrhunderts bis $1927 \ll$, in: Theorie der Übersetzung antiker Literatur in Deutschland seit 1800, hg. v. Josefine Kitzbichler/Katja Lubitz/Nina Mindt, Berlin/New York 2009b, 113-235.

Lyne, Raphael, »Ovid in English Translation «, in: The Cambridge Companion to Ovid, hg. v. Philip Hardie, Cambridge 2002, 249-263.

Maltby, Robert, A Lexicon of Ancient Etymologies, Leeds 1991.

Meusel, Johann, Georg/Hamberger, Georg Christoph, Das gelehrte Teutschland oder Lexikon der jetzt lebenden teutschen Schriftsteller, angefangen von G. Chr. Hamberger, fortgesetzt von Joh. G. Meusel. Fünfte, durchaus vermehrte Ausgabe, Siebenter Band, Lemgo 1798.

Meusel, Johann Georg, Lexikon der vom Jahr 1750 bis 1800 verstorbenen teutschen Schriftsteller, Bd. 12: Leipzig 1812, Bd. 13, Leipzig 1813.

Mindt, Nina, $\gg$ Begegnungen mit $>$ der Antike $<$. Zum Umgang mit Rezeptionsformen «, in: Gymnasium 114 (2007), 461-474.

Mindt, Nina, »Die optimale Transformation (der Antike). Ein Überblicksversuch über die Übersetzungsdiskussion in der Gegenwart «, in: Böhme/Rapp/Rösler (2007a), $47-60$. 
Mindt, Nina, »Von 1927 bis zur Gegenwart «, in: Theorie der Übersetzung antiker Literatur in Deutschland seit 1800, hg. v. Josefine Kitzbichler/Katja Lubitz/Nina Mindt, Berlin/New York (2009b), 237-353.

Möckel, Sebastian, »Zwischen Muster und Anverwandlung. Übersetzungen des antiken Liebesromans in der Frühen Neuzeit«, in: Böhme/Rapp/Rösler (2007), 137155.

Moisan, Jean-Claude, »Aneau, traducteur d'Ovide: la consolidation du récit «, in: Bulletin de l'Association d'étude sur l'bumanisme, la réforme et la renaissance, $\mathrm{N}^{\circ} 35$, 1992, 5-15 (Onlinefassung: http://www.persee.fr/web/revues/home/prescript/ article/rhren_0181-6799_1992_num_35_1_1858).

Moog-Grünewald, Maria, »Benserades Metamorphoses en rondeaux. Eine emblematische Bearbeitung der ovidischen Verwandlungsgeschichten «, in: Horn/Walter (1995), 225-238.

Most, Glenn (Hg.), Disciplining classics = Altertumswissenschaft als Beruf, Göttingen 2002 (= Aporemata, 6).

Müller, Adelheid, Sehnsucht nach Wissen. Friederike Brun, Elisa von der Recke und die Altertumskunde um 1800, Berlin 2012.

Müller, Jan-Dirk, Übersetzung in der Frühen Neuzeit. Zwischen Perfektionsideal und einzelsprachlicher Differenzierung, in: Böhme/Rapp/Rösler (2007), 81-104.

Müller, Maria E./Mecklenburg, Michael (Hgg.), Vergessene Texte - verstellte Blicke. Neue Perspektiven der Wickram-Forschung, Frankfurt 2007.

Müller, Ulrich, »Vergils Aeneis in den Übersetzungen von Friedrich Schiller und Rudolf Alexander Schröder. Ein Vergleich«, in: Jahrbuch der Deutschen Schillergesellschaft 14 (1970), 347-365.

Muncker, Franz, »Voß, Johann Heinrich «, in: ADB 40 (1896), 334-349

Niedermeier, Michael, »Von der Schrift in die Landschaft. Die Isis-Initiation des Apuleius in der Mystischen Partie des Wörlitzer Gartens«, in: Böhme/Rapp/Rösler (2007), 267-308.

Neuhöffer, Rudolf, Schiller als Übersetzer des Vergil, (Schulprogramm) Warendorf 1893.

Oakley-Brown, Liz, Ovid and the Cultural Politics of Translation in Early Modern England, Aldershot/Burlington 2006.

Paul, Manfred, Der Englische Garten zu Wörlitz, Berlin ${ }^{2} 1994$.

Paulsen, Friedrich, Geschichte des gelehrten Unterrichts aus den deutschen Schulen und Universitäten vom Ausgang des Mittelalters bis zur Gegenwart. Mit besonderer Rücksicht auf den klassischen Unterricht, Leipzig 1885.

Paulsen, Friedrich, Geschichte des gelehrten Unterrichts auf den deutschen Schulen und Universitäten vom Ausgang des Mittelalters bis zur Gegenwart, mit besonderer Rücksicht auf den klassischen Unterricht, 2. umgearb. und sehr erw. Aufl., Leipzig 1896.

Pefgen, Elisabeth, »Mythen und Literatur. Theoretische Erläuterung einer produktiven Beziehung «, in: Das Literatursystem der Gegenwart und die Gegenwart der Schule, hg. v. Michael Kämper-van den Boogart, Hohengehren 1997, 148-165. 
Peters, Ursula, »Fürstenhof und höfische Dichtung. Der Hof Hermanns von Thüringen als literarisches Zentrum «, in: Von der Sozialgeschichte zur Kulturwissenschaft, hg. v. Ursula Peters, Tübingen 2004, 37-58.

Petzold, Leander, »Traditionelle Formen der Volksdichtung und ihre Bedeutung für die Lektüre von Kindern und Jugendlichen «, in: Volksüberlieferung und Jugendliteratur, hg. v. Alfred Clemens Baumgärtner, Würzburg 1983, 15-36.

Petzold, Leander, »Märchen, Mythen und Sagen«, in: Taschenbuch der Kinder- und Jugendliteratur, hg. v. Günther Lange, Hohengehren 2000.

Pfeiffer, Ingo, »August Rode als Übersetzer antiker Literaturen «, in: Mitteilungen des Vereins für Anbaltische Landeskunde, 10 (2002), 123-133.

Pfeiffer, Rudolf, Die Meistersingerschule in Augsburg und der Homerübersetzer Johannes Spreng, München 1919 (= Schwäbische Geschichtsquellen und Forschungen, 2).

Pleticha, Heinrich, »Antike Mythen und Sagen in der deutschen Jugendliteratur - ein Überblick «, in: Mythen, Märchen und moderne Zeiten. Beiträge zur Kinder-und Jugendliteratur, hg. v. Alfred Clemens Baumgärtner/Alfred E. Maier, Würzburg 1987, 33-42.

Rebenich, Stefan, »Theodor Mommsen, die deutschen Professoren und die Revolution von $1848 \ll$, in: Theodor Mommsen. Wissenschaft und Politik im 19. Jahrhundert, hg. v. Alexander Demandt/Axel Goltz/Heinrich Schlange-Schöningen, Berlin/ New York 2005, 13-35.

Reeve, Michael, »Heinsius' Manuscripts of Ovid «, in: RhM 117 (1974), 133-166.

Reichert, Klaus, Zwischen den Zeilen. Über das Un-Angemessene der Übersetzung, Göttingen 2010.

Reinhardt, Udo, Ovids Metamorphosen in der modernen Kunst. Eine visuelle Ergänzung für die Schullektüre, Bamberg 2001.

Renger, Almut-Barbara, »Frankreich in wissenschaftgeschichtlicher Perspektive: Ausgrenzung und Einbindung der Klassischen Philolpogie in Institutionen des Gran Siècle «, in: Most (2002), 1-38.

Rode, August, »Beschreibung des Fürstlichen Anhalt-Dessauischen Landhauses und englischen Gartens zu Wörlitz (1798) «, in: Der Englische Garten (1994), 9-139.

Roethe, Gustav, »Spreng, Johannes «, in: ADB 35 (1893), 288-291.

Rosenfeld, Hellmut, »Albrecht von Halberstadt «, in: NDB 1 (1953), 177-179.

Rössig, Wolfgang, Literaturen der Welt in deutscher Übersetzung. Eine chronologische Bibliographie, Stuttgart 1997.

Rücker, Brigitte, Die Bearbeitung von Ovids Metamorphosen durch Albrecht von Halberstadt und Jörg Wickram und ibre Kommentierung durch Gerhard Lorichius. Göppingen 1997 (= Göppinger Arbeiten zur Germanistik, 641).

Runge, Otto, Die Metamorphosen-Verdeutschung Albrechts von Halberstadt, Berlin 1908.

Rupprich, Hans/de Boor, Helmut/Newald, Richard, Die deutsche Literatur vom späten Mittelalter bis zum Barock, Zweiter Teil, München 1973.

Rutenfranz, Maria, Götter, Helden, Menschen. Rezeption und Adaption antiker Mythologie in der deutschen Kinder- und Jugendliteratur, Frankfurt a. M. 2004. 
Scheible, Heinz/Ebneth, Bernhard, »Sabinus, Georg«, in: Neue Deutsche Biographie 22 (2005), $320 \mathrm{f}$.

Schmidt, Erich, »Wickram, Jörg«,in: Allgemeine Deutsche Biographie 42 (1897), 328336.

Schmidt, Friedrich August/Voight, Bernhard Friedrich, Neuer Nekrolog der Deutschen, 12. Jg. (1834), Erster Theil, Weimar 1836.

Schmidt, Joachim, Volksdichtung und Kinderlektüre in der ersten Hälfte des 19. Jahrbunderts, Berlin 1977, 130-138.

Schmidt, Peter Lebrecht, »Philologie, II. Latinistik «, in: Der Neue Pauly 15/2 (2002), 278-327.

Schmidt, Peter Lebrecht, »Uz und Horaz «, in: Dichter und Bürger in der Provinz. Johann Peter Uz und die Aufklärung in Ansbach, hg. v. Ernst Rohmer/Theodor Verweyen, Tübingen 1998, 77-98.

Schmitt, Stefanie, »Humanistisches bei Georg Wickram? Zur Problematik deutschsprachiger humanistischer Literatur «, in: Humanismus in der deutschen Literatur des Mittelalters und der Frühen Neuzeit, hg. v. Nicola McLelland/Hans-Jochen Schiewer/Stefanie Schmitt, Tübingen 2008, 137-154.

Schmitt-von Mühlenfels, Franz, Pyramus und Thisbe. Rezeptionstypen eines Ovidischen Stoffes in Literatur, Kunst und Musik, Heidelberg 1972.

Schmitzer, Ulrich, »Bruegel, Coecke und Ovid - ein Nachtrag«, in: Zeitschrift für Kunstgeschichte 52 (1989), $423 \mathrm{ff}$.

Schmitzer, Ulrich, »Meeresstille und Wasserrohrbruch. Über Herkunft, Funktion und Nachwirkung der Gleichnisse in Ovids Erzählung von Pyramus und Thisbe (met. 4,55-166) «, in: Gymnasium 99 (1992), 519-545.

Schmitzer, Ulrich, Ovid, Hildesheim/New York 2001 (2011).

Schmitzer, Ulrich, »Tomi, das Kaff, Echo die Hure - Ovid und Christoph Ransmayrs $>$ Die letzte Welt<«, in: Mythen in nachmythischer Zeit. Die Antike in der deutschsprachigen Literatur der Gegenwart, hg. v. Bernd Seidensticker/Martin Vöhler, Berlin 2001a, 276-297.

Schmitzer, Ulrich, »Transformierte Transformation. Eine Fallstudie zu Erzähltechnik und Rezeption der Metamorphosen Ovids anhand der Actaeon-Sage «, in: Gymnasium 118 (2008), 23-46.

Schmitzer, Ulrich, »Ovid«, in: Der Neue Pauly, Suppl. 7, Die Rezeption der antiken Literatur (2010), 557-575.

Schmitzer, Ulrich, »Jakob Baldes Batrachomyomachie«, in: Paideia 66 (2011), 491 508.

Schönberger, Otto, »Mythos und Mythologie auf der Unterstufe des Gymnasiums «, in: Erbe, das nicht veraltet. Dialog Schule und Wissenschaft 11, hg. v. Peter Neukam (1979), 177-207.

Schreurs, Anna, »Ein selbgewachsner Maler illustriert die Malerbibel. Wickrams Holzschnitt zu Ovids >Metamorphosen<«, in: Müller/Mecklenburg (2007), 169-184.

Schrott, Raoul, »Sieben Prämissen einer neuen Übersetzung der Ilias $(2006) \ll$, in: Kitzbichler/Lubitz/Mindt (2009a), 499-505.

Schweiger, Franz Ludwig Anton, Handbuch der classischen Bibliographie, Leipzig 1834. 
Schwindt, Jürgen Paul, »Dido, Klopstock und Charlotte Buff - Vergilreminiszenz(en) in Goethes > Werther<? «, in: Antike \& Abendland 42 (1996), 103-118.

Schwindt, Jürgen Paul, $\gg$ Werther und die $>$ Dichter der Vorzeit< - Catull-Reminiszenzen in Goethes Frühwerk «, in: Gymnasium 104 (1997), 293-300.

Sieber, Andrea, $\gg$ Transgressionen des Begehrens in Wickrams >Metamorphosen<Bearbeitung «, in: Müller/Mecklenburg (2007), 147-168.

Siemann, Wolfram, $\gg$ Deutschlands Ruhe, Sicherheit und Ordnung «: Die Anfänge der politischen Polizei 1806-1866, Berlin/New York 1985.

Spevak, Olga, Constituent Order in Classical Latin Prose, Amsterdam, Philadelphia 2010 (= Studies in Language Companion Series, 117).

Stackmann, Karl, $\gg$ Die Auslegungen des Gerhard Lorichius zur $>$ Metamorphosen $<-$ Nachdichtung Jörg Wickrams«, in: Zeitschrift für Deutsche Philologie 86/Sonderheft (1967), 120-160.

Stackmann, Karl, Mittelalterliche Texte als Aufgabe. Kleine Schriften I, Göttingen 1997, 26-50.

Stoichita, Victor I., Der Pygmalion-Effekt. Trugbilder von Ovid bis Hitchcock, München 2011.

Stroh, Wilfried, Ovid im Urteil der Nachwelt. Eine Testimoniensammlung, Darmstadt 1969.

Thimann, Michael, Lügenhafte Bilder. Ovids favole und das Historienbild in der italienischen Renaissance, Göttingen 2002.

Thimann, Michael, Jean Jacques Boissard, Ovids Metamorphosen 1556. Die Bilderhandschrift 79 C 7 aus dem Berliner Kupferstichkabinett, Berlin 2005.

Thimann, Michael, Gedächtnis und Bild-Kunst. Die Ordnung des Künstlerwissens in Joachim von Sandrarts Teutscher Akademie, Freiburg 2007.

Veith, Franz Anton, Bibliotheca Augustana, Alphabetum XI, Augsburg 1795.

Warburg, Aby, Sandro Botticellis »Geburt der Venus « und $\gg$ Frühling «, Diss. Straßburg 1893.

Weller, Emil, Die maskirte Literatur der älteren und neueren Sprachen. I Index pseudonymorum, Leipzig 1856.

Weller, Emil, Index pseudonymorum Wörterbuch der Pseudonymen oder Verzeichniss aller Autoren, die sich falscher Namen bedienten, Leipzig 1856.

Weller, Emil, Die falschen und fingierten Druckorte, Repertorium der seit der Erfindung des Buchdrucks unter falscher Firma erschienenen deutschen, lateinischen und französischen Schriften, Bd. 1, 2. Aufl., Leipzig 1864.

Wheeler, Stephen M., A Discourse of Wonders. Audience and Performance in Ovid's Metamorphoses, Philadelphia 1999.

von Wilamowitz-Moellendorff, Ulrich, Philologie und Schulreform, Göttingen 1892.

von Wilamowitz-Moellendorff, Ulrich, »Was ist übersetzen «, in: Reden und Vorträge, Bd. 1, Berlin ${ }^{4} 1925$ (= Kitzbichler/Lubitz/Mindt 2009a, 326-349).

von Wilamowitz-Moellendorff, Ulrich, Erinnerungen 1848-1914, Leipzig 1928.

Wilke, Ulrich/Suerbaum, Werner (Hgg.), Der »Nürnberger Vergil« von 1688. Georg Christoph Eimmarts »Aeneis«-Illustrationen nach Zeichnungen von Georg Jacob Lang, Neukirchen 2013. 
Wilpert von, Gero (Hg.), Sachwörterbuch der Literatur, 7.verb. und erw. Aufl., Stuttgart 1989.

Ziolkowski, Theodore, Ovid and the Moderns, Ithaca/New York 2005.

Abstract: »Des Ovids Verwandlungen verteutscht. « Translations of the Metamorphoses since the Middle Ages and the Early Modern Period

The Metamorphoses of Publius Ovidius Naso (43 BC-AD 17/18) is among the earliest non-Christian texts from antiquity to be translated into German. Beginning with Albrecht of Halberstadt (around 1200), they can be studied across more than 800 years of translation history. In doing so, it is possible to compare how differently the Middle Ages, Humanism, the Baroque period, and the Enlightenment dealt with the same textual corpus; how, and to what extent, the classicizing model of translation, developed through Greek texts, could be adapted to Latin texts; what the consequences were of reducing the Metamorphoses' reception to elementary school readingmaterial in the 19th and 20th centuries; and, finally, what the effects have been of the cultural rediscovery of Ovid in the past few decades. This will be worked out diachronically in passages from the prooemium, the story of Pyramus and Thisbe, and the Pygmalion story. 